\title{
WestVirginiaUniversity
}

THE RESEARCH REPOSITORY @ WVU

Graduate Theses, Dissertations, and Problem Reports

2006

\section{Curve number dependence on basic hydrologic variables governing runoff}

Samuel J. Lamont

West Virginia University

Follow this and additional works at: https://researchrepository.wvu.edu/etd

\section{Recommended Citation}

Lamont, Samuel J., "Curve number dependence on basic hydrologic variables governing runoff" (2006). Graduate Theses, Dissertations, and Problem Reports. 2414.

https://researchrepository.wvu.edu/etd/2414

This Dissertation is protected by copyright and/or related rights. It has been brought to you by the The Research Repository @ WVU with permission from the rights-holder(s). You are free to use this Dissertation in any way that is permitted by the copyright and related rights legislation that applies to your use. For other uses you must obtain permission from the rights-holder(s) directly, unless additional rights are indicated by a Creative Commons license in the record and/ or on the work itself. This Dissertation has been accepted for inclusion in WVU Graduate Theses, Dissertations, and Problem Reports collection by an authorized administrator of The Research Repository @ WVU.

For more information, please contact researchrepository@mail.wvu.edu. 


\title{
Curve Number Dependence on Basic Hydrologic Variables Governing Runoff
}

\author{
Samuel J. Lamont \\ Dissertation submitted to the \\ College of Engineering and Mineral Resources \\ at West Virginia University \\ in partial fulfillment of the requirements \\ for the degree of
}

Doctor of Philosophy

in Civil and Environmental Engineering

Robert N. Eli, Ph.D., Chair Jerald J. Fletcher, Ph.D. Donald D. Gray, Ph.D. Lianshin Lin, Ph.D. Thomas A. Galya, Ph.D.

Department of Civil and Environmental Engineering Morgantown, West Virginia
2006

Keywords: Curve Number, HSPF, Watershed Modeling, CHIA 


\begin{abstract}
Curve Number Dependence on Basic Hydrologic Variables Governing Runoff
\end{abstract}

Samuel J. Lamont

The suitability of applying the NRCS Curve Number (CN) to continuous runoff prediction is examined by studying the dependence of the $\mathrm{CN}$ on several hydrologic variables. The continuous watershed model Hydrologic Simulation Program-FORTRAN (HSPF) is employed as a theoretical watershed in two numerical procedures designed to investigate the influence of soil type, soil depth, storm depth, storm distribution, and initial abstraction ratio value $(\lambda)$ on the $\mathrm{CN}$. This study stems from a concurrent project involving the design of a computer modeling system to support the Cumulative Hydrologic Impact Assessments (CHIA) of over 230 watersheds throughout WV. A link between the CN and HSPF soil moisture parameters is proposed for continuous runoff simulation in surface mine affected watersheds in West Virginia. A soil physics model and numerical procedure have been developed to back calculate CN's at Antecedent Runoff Condition (ARC) II from synthetic rainfall input and simulated direct runoff. A second method of $\mathrm{CN}$ determination is also described to provide a reference to the calculated $\mathrm{CN}$ values. Each HSPF parameter set, determined through calibration and by the soil physics model, is treated as a unique hypothetical watershed. It was found that the calculated CN's are highly dependent on all of the computational variables, therefore the use of the $\mathrm{CN}$ in continuous modeling based on antecedent soil moisture or rainfall alone does not appear to be appropriate. Differences between $\lambda=0.05$ and $\lambda=0.2$ are seen predominantly in the lower storm depth calculations. It is suggested that a different symbol be used to distinguish classic CN's from continuous CN's. 


\section{Table of Contents}

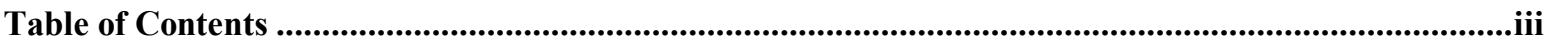

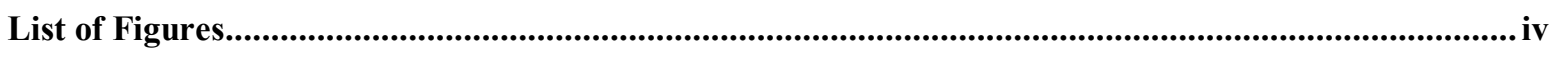

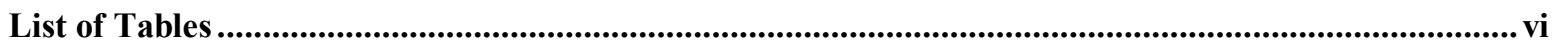

Acknowledgments............................................................................................................................................. vii

Dedication........................................................................................................................................................ viii

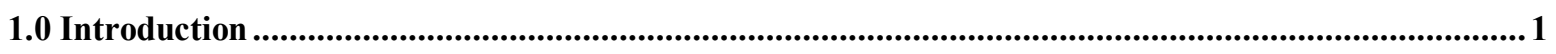

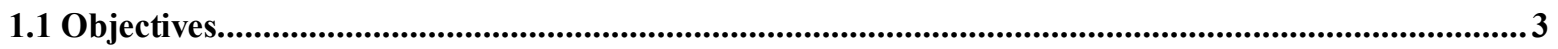

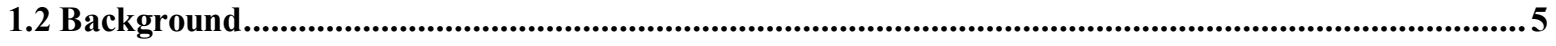

1.3 Curve Number Method Summary...................................................................................................6

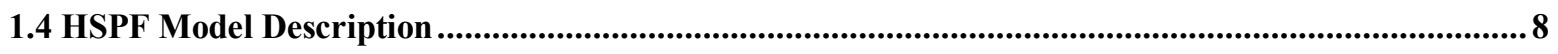

1.5 Baseline HSPF Calibration Summary .................................................................................................. 9

1.6 Soil Physics Model .......................................................................................................................................12

1.6.1 Relating HSPF Parameters to NRCS CN using a Soil Water Physics Model ....................................... 12

1.6.2 Computation of Equivalent HSPF Parameters for NRCS Curve Numbers.......................................... 15

2.0 Methodology .......................................................................................................................................................... 20

2.1 Curve Number Computation Using Cyclic Storm Input ..........................................................................20

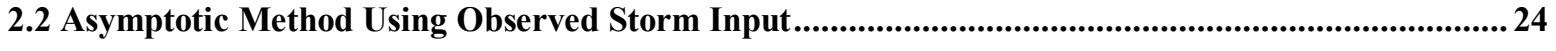

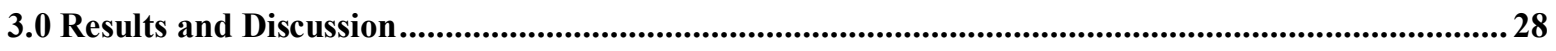

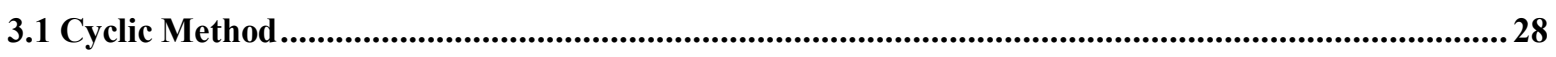

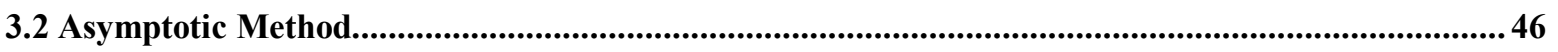

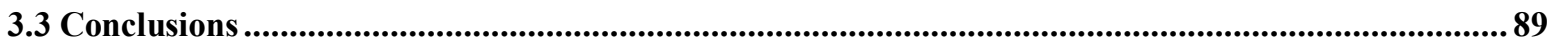

4.0 Summary and Conclusions .................................................................................................................. 91

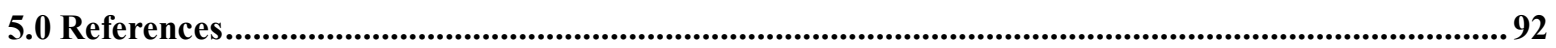

Appendix A. HSPF Calibration, Verification, and Parameter Optimization Study ................................... 1

Appendix B. Final Calibration User's Control Input File (UCI)................................................................ 32

Appendix C. Cyclic and Asymptotic Methods User's Control Input File (UCI).........................................54 


\section{List of Figures}

Figure 1. Flow Schematic and Storage Components within the HSPF PERLND Module...................................9

Figure 2. West Virginia CHIA Trend Stations and Calibration Watersheds.....................................................10

Figure 3. West Virginia CHIA Trend Stations and Verification Watersheds......................................................11

Figure 4. Soil Microstructure and Soil Water Variables (Soil Physics Model) ..................................................... 12

Figure 5. Soil Moisture Content as a Function of Soil Depth (Soil Physics Model).............................................. 13

Figure 6. INFILT as a Function of Green-Ampt Infiltration Capacity and Soil Hydraulic Conductivity........ 20

Figure 7. Synthetic Storm Distributions, Hourly Time Increment, 1 mm Accumulated Depth.......................... 22

Figure 8. Sample Cyclic HSPF Input (Type II Rainfall and PET) and Output (DRO)......................................23

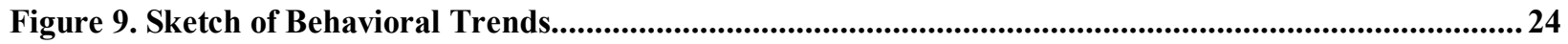

Figure 10. Location of Rainfall Gages Used in the Asymptotic Method...............................................................26

Figure 11. Storm Distribution Relative Frequency Histograms for each Gage.................................................. 27

Figure 12. Cyclic Method, CN vs. Storm Depth, Clay Loam, $\lambda=0.2$, Uniform Storm Distribution ...............29

Figure 13. Cyclic Method, $C N$ vs. Storm Depth, Clay Loam, $\lambda=0.2$, Full Triangular Storm Distribution ... 30

Figure 14. Cyclic Method, CN vs. Storm Depth, Clay Loam, $\lambda=0.2$, Type II Storm Distribution .................. 31

Figure 15. Cyclic Method, CN vs. Storm Depth, Clay Loam, $\lambda=0.2$, WDM Triangular Storm Distribution 32

Figure 16. Cyclic Method, CN vs. Storm Depth, Silt Loam, $\lambda=0.2$, Uniform Storm Distribtution ................. 33

Figure 17. Cyclic Method, CN vs. Storm Depth, Silt Loam, $\lambda=0.2$, Full Triangular Storm Distribution ......34

Figure 18. Cyclic Method, CN vs. Storm Depth, Silt Loam, $\lambda=0.2$, Type II Storm Distribution ..................... 35

Figure 19. Cyclic Method, CN vs. Storm Depth, Silt Loam, $\lambda=0.2$, WDM Triangular Storm Distribution .36

Figure 20. Cyclic Method, CN vs. Storm Depth, Clay Loam, $\lambda=0.05$, Uniform Storm Distribution.............. 37

Figure 21 . Cyclic Method, CN vs. Storm Depth, Clay Loam, $\lambda=0.05$, Full Triangular Storm Distribution 38

Figure 22. Cyclic Method, CN vs. Storm Depth, Clay Loam, $\lambda=0.05$, Type II Storm Distribution ................39

Figure 23. Cyclic Method, CN vs. Storm Depth, Clay Loam, $\lambda=0.05$, WDM Triangular Storm Distribution

Figure 24. Cyclic Method, $C N$ vs. Storm Depth, Silt Loam, $\lambda=0.05$, Uniform Storm Distribution................. 41

Figure 25. Cyclic Method, CN vs. Storm Depth, Silt Loam, $\lambda=0.05$, Full Triangular Storm Distribution ... 42

Figure 26. Cyclic Method, CN vs. Storm Depth, Silt Loam, $\lambda=0.05$, Type II Storm Distribution

Figure 27. Cyclic Method, CN vs. Storm Depth, Silt Loam, $\lambda=0.05$, WDM Triangular Storm Distribution 44

Figure 28. Cyclic Method Mean Infiltration vs. Soil Depth, Clay Loam .........................................................45

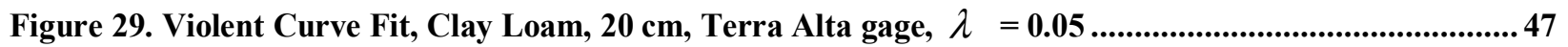

Figure 30. Asymptotic Method, CN Fit Curves vs. Storm Depth, Clay Loam, $\lambda=0.2$, Terra Alta ................ 49

Figure 31. Asymptotic Method, CN Fit Curves vs. Storm Depth, Clay Loam, $\lambda=0.2$, Beckley.......................50 
Figure 32. Asymptotic Method, CN Fit Curves vs. Storm Depth, Clay Loam, $\lambda=0.2$, Elkins ........................51

Figure 33. Asymptotic Method, CN Fit Curves vs. Storm Depth, Clay Loam, $\lambda=0.2$, Dunlow ......................52

Figure 34. Asymptotic Method, CN Fit Curves vs. Storm Depth, Silt Loam, $\lambda=0.2$, Terra Alta ...................53

Figure 35. Asymptotic Method, CN Fit Curves vs. Storm Depth, Silt Loam, $\lambda=0.2$, Beckley .........................54

Figure 36. Asymptotic Method, CN Fit Curves vs. Storm Depth, Silt Loam $\lambda=0.2$, Elkins ...........................55

Figure 37. Asymptotic Method, CN Fit Curves vs. Storm Depth, Silt Loam, $\lambda=0.2$, Dunlow ........................56

Figure 38. Asymptotic Method, CN Fit Curves vs. Storm Depth, Clay Loam, $\lambda=0.05$, Terra Alta .............. 57

Figure 39. Asymptotic Method, CN Fit Curves vs. Storm Depth, Clay Loam, $\lambda=0.05$, Beckley .....................58

Figure 40. Asymptotic Method, CN Fit Curves vs. Storm Depth, Clay Loam, $\lambda=0.05$, Elkins ......................59

Figure 41. Asymptotic Method, CN Fit Curves vs. Storm Depth, Clay Loam, $\lambda=0.05$, Dunlow .................... 60

Figure 42. Asymptotic Method, CN Fit Curves vs. Storm Depth, Silt Loam, $\lambda=0.05$, Terra Alta ................ 61

Figure 43. Asymptotic Method, CN Fit Curves vs. Storm Depth, Silt Loam, $\lambda=0.05$, Beckley ...................... 62

Figure 44. Asymptotic Method, CN Fit Curves vs. Storm Depth, Silt Loam, $\lambda=0.05$, Elkins .......................63

Figure 45. Asymptotic Method, CN Fit Curves vs. Storm Depth, Silt Loam, $\lambda=0.05$, Dunlow ...................... 64

Figure 46. Asymptotic Method, CN vs. Storm Depth, Terra Alta, $10 \mathrm{~cm}$ Soil Depth............................................68

Figure 47. Asymptotic Method, CN vs. Storm Depth, Terra Alta, 15 cm Soil Depth.......................................69

Figure 48. Asymptotic Method, CN vs. Storm Depth, Terra Alta, 20 cm Soil Depth.........................................70

Figure 49. Asymptotic Method, CN vs. Storm Depth, Terra Alta, $25 \mathrm{~cm}$ Soil Depth........................................... 71

Figure 50. Asymptotic Method, CN vs. Storm Depth, Terra Alta, $30 \mathrm{~cm}$ Soil Depth........................................... 72

Figure 51. Asymptotic Method, CN vs. Storm Depth, Terra Alta, 35 cm Soil Depth........................................... 73

Figure 52. Asymptotic Method, CN vs. Storm Depth, Terra Alta, $40 \mathrm{~cm}$ Soil Depth........................................... 74

Figure 53. Asymptotic Method, CN vs. Storm Depth, Terra Alta, 45 cm Soil Depth.......................................... 75

Figure 54. Asymptotic Method, CN vs. Storm Depth, Terra Alta, 50 cm Soil Depth........................................... 76

Figure 55. Asymptotic Method, CN vs. Storm Depth, Terra Alta, 60 cm Soil Depth........................................... 77

Figure 56. Asymptotic Method, CN vs. Storm Depth, Terra Alta, 70 cm Soil Depth........................................... 78

Figure 57. Asymptotic Method, CN vs. Storm Depth, Terra Alta, 80 cm Soil Depth............................................ 79

Figure 58. Asymptotic Method, CN vs. Storm Depth, Terra Alta, 90 cm Soil Depth...........................................80

Figure 59. Asymptotic Method, CN vs. Storm Depth, Terra Alta, $100 \mathrm{~cm}$ Soil Depth.........................................81

Figure 60. Asymptotic Method, CN vs. Storm Depth, Terra Alta, 120 cm Soil Depth......................................... 82

Figure 61. Asymptotic Method, CN vs. Storm Depth, Terra Alta, 140 cm Soil Depth.......................................... 83

Figure 62. Asymptotic Method, CN vs. Storm Depth, Terra Alta, 160 cm Soil Depth......................................... 84

Figure 63. Asymptotic Method, CN vs. Storm Depth, Terra Alta, $180 \mathrm{~cm}$ Soil Depth........................................85

Figure 64. Asymptotic Method, CN vs. Storm Depth, Terra Alta, 200 cm Soil Depth....................................... 86

Figure 65. Asymptotic Method Mean Infiltration vs. Soil Depth, Clay Loam...................................................... 88

Figure 66. Antecedent LZS , Clay Loam, 200 cm Soil Depth, Terra Alta......................................................89 


\section{List of Tables}

Table 1. Soil Texture Class Hydraulic Properties................................................................................................. 19

Table 2. INFILT versus Hydrologic Soil Group (BASINS Technical Note 6, U.S. EPA, 2001)..........................20

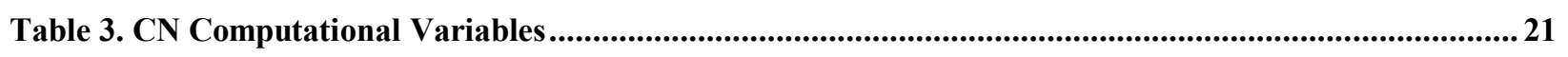

Table 4. Asymptotic Method Curve Fits, $\lambda=0.2$ ('s' = standard, Eqn. 15; 'v' = violent, Eqn. 16).................. 65

Table 5. Asymptotic Method Curve Fits, $\lambda=0.05$ ('s' = standard, Eqn. 15; 'v' = violent, Eqn. 16).................66

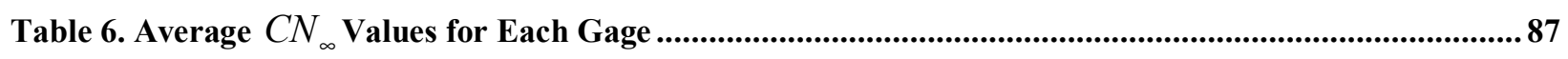




\section{Acknowledgments}

First I would like to thank the West Virginia Department of Environmental Protection and the U.S. Office of Surface Mining for their roles in supporting this research. I would also like to thank Aqua Terra Consultants, Jim Sams of the USGS, Pittsburgh, PA and Kate Flynn of the USGS, Reston, VA for their technical guidance and expertise. I am also grateful to my former colleague Elena Hoeg for her collaboration and contributions to this research.

Secondly, I would like to thank my advisor, Dr. Robert N. Eli, for his generosity, optimism, humor, and friendship. I have learned much more than what is simply written on these pages thanks to his guidance and support. I would also like thank Dr. Jerald J. Fletcher for providing me with the opportunity to undertake this research and for including me as part of the NRAC team. I would like to thank the rest of my committee members, Dr. Thomas A. Galya, Dr. Donald D. Gray, and Dr. Lianshin Lin for their time and contributions. I must also thank Linda Cox whose knowledge and clarity makes it that much easier for all of us.

Finally, I would like to thank my family. My parents, Dave and Priscilla have given me infinite and unconditional love and support throughout every stage of my life, and have taught me more than they will ever know. My sisters, Sally, Susan, and Meg may not realize how much I still look up to them. And last but not least, my brother-in-law Peter has become a true mentor and brother to me over the years. Thank you all. 
Dedication

To Mom and Dad 


\subsection{Introduction}

The most common problem encountered in hydrologic modeling is the lack of descriptive watershed data availability necessary to select the appropriate values of the model's controlling parameters. The popularity of the NRCS (Natural Resource Conservation Service) Curve Number (CN) method is based on its simplicity and embodiment of much of a given watershed's hydrologic characteristics in a single parameter. Specifically, a single parameter value embodies the ability of the surface and subsurface of the watershed to retard and capture a portion of the precipitation input, thus separating the gross precipitation into that portion that remains in the watershed, and is ultimately lost to evapotranspiration and groundwater recharge, from that portion that passes through the watershed outlet as direct runoff. As dictated by assumptions inherent in the original development of the Curve Number method, the application of the method as a model of a given watershed's separation of precipitation into losses and direct runoff requires that a single storm event be selected (of 24 hours duration, or less). Therefore, the Curve Number method is commonly termed an "event-based model", as opposed to a "continuous model". A continuous model differs from the event-based model in its ability to produce a continuous record of outflow predictions over a longer period of time, which may include many separate precipitation events occurring sequentially.

Since its original development, the Curve Number method has been modified and adapted for application in many continuous models by making additional assumptions with respect to the applicability of the basic concept to a continuously variable precipitation input. The original concept did not explicitly include time as a variable, and only predicted the total storm runoff volume. Although the basic definition of the Curve Number has not been changed, the method is now often used in continuous models in a much different context than originally intended. The typical application assumes that the Curve Number is a random variable that is some continuous function of the moisture content of the soil, in addition to the soil characteristics and hydrologic condition (average ability to infiltrate). The separation of losses from runoff is then computed continuously over time as a function of the changing $\mathrm{CN}$ value. This type of extended application to continuous models has provoked many questions about the validity of the assumptions required, some of which have been discussed in the literature. 
The cumulative hydrologic impact assessment (CHIA) of mining on watersheds is driven by regulatory requirements that require monitoring stream water discharges and water quality parameters, and also requires a scientifically acceptable method for the prediction of mining impacts on these parameters in the future. These requirements can be addressed by application of a suitable hydrologic and water quality model. The HSPF model (Hydrologic Simulation Program Fortran, Bicknell et al. 2001) has been selected to provide these predictive estimates of mining impacts on stream water quantity/quality in the state of West Virginia. Each mine site is unique, and by definition is characterized by dramatically altered hydrologic conditions due to the extensive land disturbances. Typical changes feature altered topography, removal of vegetation and native soil structures, and highly modified drainage features that typically include drainage and sedimentation ditches, and runoff and sedimentation control detention basins. The hydrologic design of these latter structures uses the Curve Number (CN) method as an acceptable hydrologic model for the design of runoff and sediment control structures. Therefore, the CN value is generally available for any current or planned mine site, and has some legal standing due to its inclusion in various state and federal permits that are required prior to development of a new mine site. It is not the purpose of this study to address the adequacy, or lack thereof, of the Curve Number method in the design of the drainage structures, but rather to address its suitability for use in HSPF in the context of conducting the CHIA analysis.

Since the HSPF model is a complex, nonlinear, continuous model, it has many parameters that must be determined through a suitably designed calibration study on those watersheds to which it is to be applied. The application of HSPF generally involves the subdivision of the total watershed area into sub-basins, each of which can be modeled independently with regard to its rainfall inputs and corresponding outflows. If a potential mine site is to be contained within the larger watershed, it is represented as one of the many subbasins, normally requiring that the corresponding HSPF parameters be determined through a suitable calibration procedure. The application of HSPF to hypothetical mine site sub-basin would seem to present insurmountable problems, given that calibration is not possible, and given the fact that there are no pre-existing data available to guide parameter selection. However, an intriguing possibility presents itself if one can accept that a validated Curve Number (CN) value is available. If the Curve Number can be related to those HSPF parameters that control the separation of losses from direct runoff, then perhaps the calibration requirement can be side- 
stepped. This latter possibility can only be justified if the $\mathrm{CN}$ value is accepted as being correct, and that the method itself is accepted as appropriate for the given application. Additionally, those remaining parameters that control the other components of the watershed hydrology model must be selected via other means. In this study, it is assumed that the mine site $\mathrm{CN}$ value has already been validated, and that those parameters not directly related to the separation of precipitation into losses and direct runoff can be adapted from the general calibration for the whole watershed containing the mine site location(s).

The focus of this study is to investigate the possibility of use of a pre-existing mine site Curve Number (a single CN value) to select a set of surrogate HSPF parameters that govern the equivalent separation of precipitation input into losses and direct runoff. Since there is no direct method of relating a given $\mathrm{CN}$ value to the appropriate set of surrogate HSPF parameters, an inverse computational method is to be developed to back-calculate Curve Numbers from a set of HSPF parameters that have been derived from an intermediary soil physics model. The soil physics model serves as a sort of translator between the HSPF parameters and the Curve Number. However, this translation can not be perfect since it is not possible to equate multiple HSPF parameters to a single fixed value Curve Number. The central question to be investigated is whether or not the translation is adequate to permit the HSPF model to behave similarly to the $\mathrm{CN}$ method. The implications of the answer to this question reach beyond this application, to shed light on the adequacy of the use of the Curve Number in continuous hydrologic models, and further, to address a long lived controversy regarding the adequacy of the Curve Number method in general.

\subsection{Objectives}

As discussed above, the complexity of continuous watershed models, such as HSPF, requires the determination of a relatively large set of parameter values in order to fit the model to the hydrological characteristics of the watershed being modeled. The purpose of this research is to investigate the feasibility of using a predetermined NRCS Curve Number as guidance in the selection of those HSPF parameter values that are principal in governing the separation of precipitation into losses and direct runoff. Since multiple HSPF parameters must be related to a single $\mathrm{CN}$ value, it is apparent that HSPF cannot produce an exact reproduction of the separation

of losses and direct runoff, under all possible hydrologic conditions, as would be produced by the 
Curve Number method. This anticipated inability to produce an equivalent single valued Curve Number, across the range of variation of all input hydrologic variables, requires that a carefully designed investigation be completed to quantitatively measure the performance of HSPF in reproducing Curve Number behavior. In practice, this latter investigation will involve the completion of numerical experiments involving HSPF modeling runs that produce outputs from selected inputs, from which an equivalent $\mathrm{CN}$ value is calculated. Since a single valued relationship between $\mathrm{CN}$ values and HSPF parameters is not anticipated, there is a possibility that a limited number of functional relationships can be developed that allow the translation between the two to be practical. Before this investigation can proceed to measure this level of practicality, the procedures and algorithms that define the HSPF parameter subset, from which a corresponding $\mathrm{CN}$ value is computed, must be designed and developed. These research tasks will ultimately lead to several objectives being accomplished in this study:

1. Development of a translation methodology (using a suitable soil physics model) that establishes a relationship between a subset of HSPF parameters and soil characteristics that can be in turn related to $\mathrm{CN}$ values.

2. Completion of suitably designed numerical experiments to determine the relationship between a given subset of HSPF parameters and the Curve Number.

3. Evaluation of the practicalities of adoption of the Curve Number as a model parameter simplification technique in HSPF, and by extension, to other complex continuous watershed models.

4. Conclusions and recommendations regarding the overall applicability of the Curve Number method in HSPF applications to mined watersheds, and in watershed modeling in general. 


\subsection{Background}

This research stems from an effort to build a computer modeling system for the prediction of the cumulative hydrologic impact assessment (CHIA) of surface coal mining on water quality and quantity in 235 Trend Station Watersheds (TSW's) in West Virginia. These TSW's were selected by the West Virginia Department of Environmental Protection (WVDEP) and are defined by water quality sampling points at their outlets. The project involves members of the Division of Resource Management and the Department of Civil and Environmental Engineering at West Virginia University, the U.S. Office of Surface Mining, and the WVDEP (Fletcher et al., 2004). The continuous watershed model HSPF was combined with the GISbased Watershed Characterization and Modeling System (WCMS), which was developed by the Natural Resource Analysis Center (NRAC) at WVU (Strager, 2005). The CHIA modeling analysis consists of two scenarios, (1) the existing or baseline conditions and (2) the proposed surface mine site conditions.

To establish baseline conditions, a joint calibration procedure was followed using five watersheds throughout West Virginia. This resulted in one HSPF parameter set for the entire Trend Station region. Four separate watersheds were used to verify the parameter set. To model the proposed mine sites, a relationship between the Curve Number $(\mathrm{CN})$ and several HSPF parameters was proposed based on a soil physics model, facilitating the use of CN's within HSPF. This relationship was developed due to the lack of runoff data needed for the calibration of HSPF to surface mine sites and because mine site CN's are available to the users of the CHIA modeling system. A numerical experiment was designed to back-calculate theoretical CN's as a function of three HSPF parameter values for a range of soil types, soil depths, storm depths, 24hour synthetic storm distributions, and initial abstraction ratios. A second numerical experiment was designed based on the work of Hawkins (1993) to calculate CN's over the same range of watershed variables using historical precipitation records and HSPF-simulated direct runoff. In both numerical procedures, HSPF is treated as a theoretical watershed and is used to generate runoff from rainfall input. 


\subsection{Curve Number Method Summary}

The Curve Number method for estimating direct runoff from storm rainfall was developed in 1954 by the USDA Soil Conservation Service (now known as the Natural Resources Conservation Service, NRCS). It is described in the NRCS National Engineering Handbook Section 4-Hydrology (NEH-4), Chapter 4, Storm Runoff Data (NRCS, 1993). Storm runoff depth is calculated by the expression

$$
\begin{aligned}
& Q=\frac{\left(P-I_{a}\right)^{2}}{\left(P-I_{a}+S\right)} \text { for } P>I_{a} \\
& Q=0 \quad \text { for } P \leq I_{a}
\end{aligned}
$$

where $Q$ and $P$ are storm runoff and rainfall depths, respectively $(\mathrm{mm}), I_{a}$ is the initial abstraction, and $S$ is the potential maximum retention when $P=I_{a}$. The storage index $S$ is then transformed to the more intuitive Curve Number by the equation

$$
C N=25.4\left(\frac{1000}{10+S}\right)
$$

where $S$ is in millimeters. The Curve Number, which is dimensionless, ranges between 0 and 100 and is an index of hydrologic soil group, soil condition, land cover, and antecedent conditions. Historically, the relationship between $I_{a}$ and $S$ was fixed at $I_{a}=0.2 S$ where the quantity $I_{a} / S$ is defined as the initial abstraction ratio $(\lambda)$. Three initial watershed conditions were described by the Antecedent Moisture Condition (AMC) based on the previous five-day rainfall amount. AMC I applied to dry conditions, AMC III applied to wet conditions, and AMC II applied to the average moisture condition. It has since been recognized, however, that prior rainfall explains only part of the variation of the $\mathrm{CN}$. Therefore the terminology has been changed to Antecedent Runoff Condition (ARC) (Woodward et al., 2002).

Because of its simplicity, predictability, and reliance on only one parameter, the Curve Number method has become well established in hydrologic practice with numerous applications throughout the world (Ponce and Hawkins, 1996). Typically the method is applied in one of three modes. The first and most common mode is as a frequency transform between rainfall and runoff, where a storm event of a given return period is used to predict the direct runoff corresponding to the same return period. A second mode of application is to determine infiltration rates over short time intervals for the development of flood hydrographs through use 
of unit hydrographs. The third mode of application is to determine direct runoff from individual storm events imbedded in a continuous time series record. This mode is used in continuous simulation models which attempt to account for the $\mathrm{CN}$ variability between storm events by tracking antecedent moisture conditions through measures of previous rainfall and/or soil moisture (Hjelmfelt, et al., 2001).

Many criticisms have arisen concerning the application of the $\mathrm{CN}$ method since its inception. Ponce and Hawkins (1996) list several disadvantages to the method including, (1) it provides little guidance on how to vary antecedent conditions, (2) it was developed with regional data mostly from the Midwest U.S., (3) it is best suited for agricultural sites, (4) there is no accounting for spatial variability, and (5) the initial abstraction ratio is traditionally fixed at 0.2. Equation 1 can be manipulated algebraically and differentiated, provided an equation for the infiltration rate, $\frac{d F}{d t}$ (Hjelmfelt, 1980).

$$
\frac{d F}{d t}=\frac{S^{2}}{\left(P-I_{a}\right)+S^{2}} \frac{d P}{d t}
$$

The use of the method in this form has been criticized because of the dependence of the infiltration rate on rainfall intensity.

The method's use in continuous models has also been criticized (Van Mullem, et al., 2002). Hjelmfelt et al. (2001) state that the application of the $\mathrm{CN}$ method in continuous models may be completely different from the classic $\mathrm{CN}$ application and that more research is needed in this area. Van Mullem (1992) examined four infiltrometer studies throughout the US and found no significant relationship between soil moisture and the CN. Woodward and Plummer (2000) state that the five-day antecedent rainfall depth is not the best measure of antecedent runoff conditions and therefore it is not included in the latest version of the NEH-4 manual (NRCS, 1993).

Despite such criticisms, many variations of the CN method have been applied to continuous models. Mishra and Singh (2004) review four continuous CN models (Williams and LaSeur (1976), Hawkins (1978), Pandit and Gopalakrishnan (1996), and Mishra et al. (1998)) and propose a new variation that includes computations for the soil moisture budget, evapotranspiration (ET), surface flow routing, and baseflow contributions. Other continuous $\mathrm{CN}$ models include GLEAMS (Leonard, 1987), EPIC (Williams, 1987), SWAT (Arnold, 1995), 
QUALHYMO (Rowney, 1992) and AnnAGNPS (Bingner and Theurer, 2001). Typically these models calculate daily ARC II CN values by defining ARC I to be the soil wilting point and ARC III to be the soil field capacity. A review of many of these and other watershed models can be found in Bora and Bera (2003).

Finally, the value of the initial abstraction ratio $(\lambda)$ has also been debated. Hawkins and others (2002) studied several hundred plots of rainfall-runoff data using event analysis and model fitting to determine $\lambda$. They found that using $\lambda=0.05$ better fit the data and is more appropriate for runoff calculations. The effect of using $\lambda=0.05$ appeared mainly at low storm depths or lower $\mathrm{CN}$ values.

\subsection{HSPF Model Description}

HSPF is a comprehensive, continuous model designed to simulate surface and subsurface water quantity and quality processes occurring in a watershed. Its origins can be traced to the Stanford Watershed Model which was developed in the 1970's. Today, HSPF is supported by the EPA (2000). It has over twenty parameters defined in its User's Control Input (UCI) file (Bicknell 2001), many of which must be determined through calibration. Surface and subsurface flow drains from pervious land use/cover categories, (PERLND's), which are assigned unique sets of model parameters, into the appropriate stream segments (RCHRES's). Figure 1 is a schematic of the PERLND module describing its various storages and parameters. 


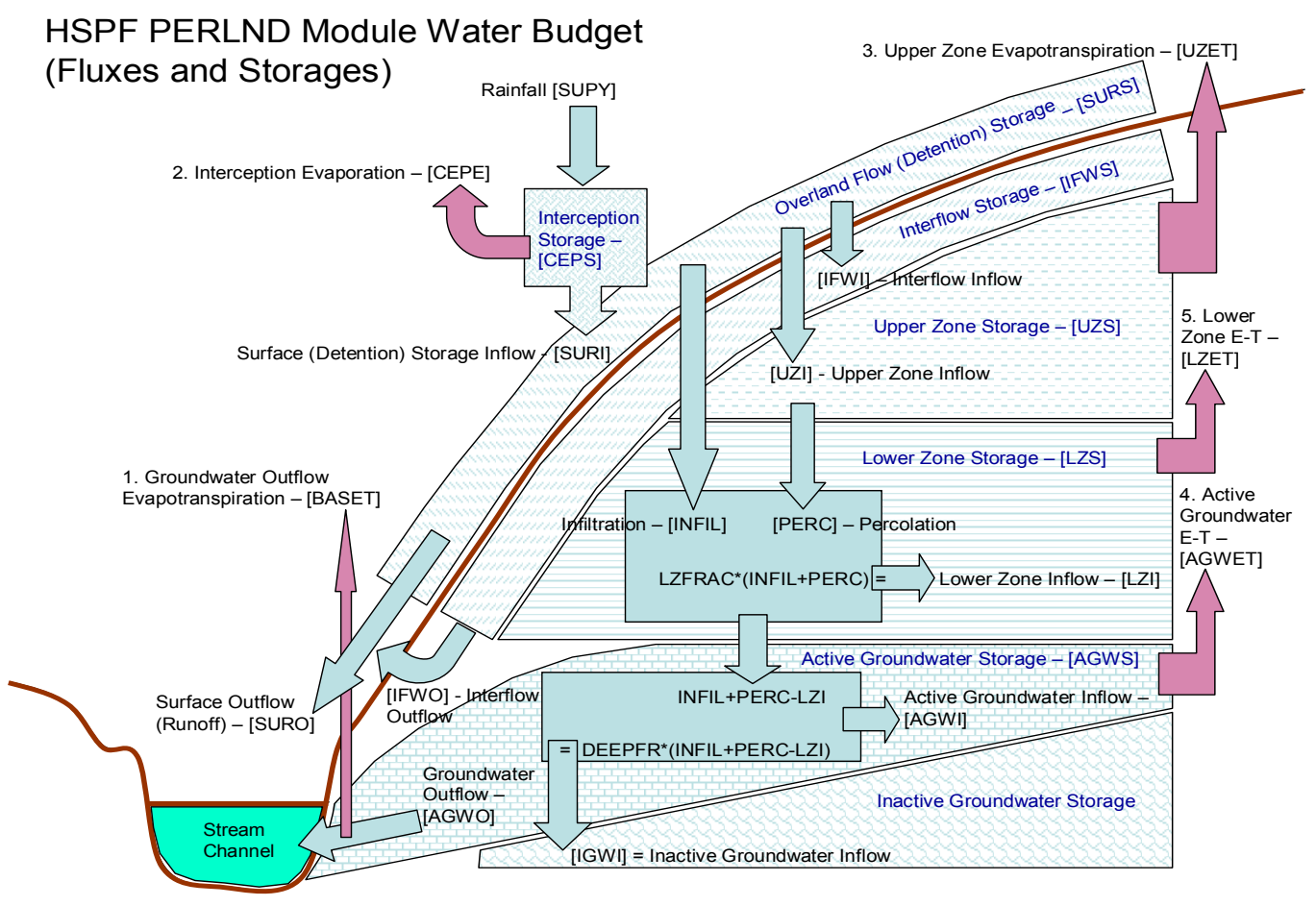

Figure 1. Flow Schematic and Storage Components within the HSPF PERLND Module

The minimum model inputs are precipitation and potential evapotranspiration (PET) time series while each of the computed storages and fluxes can be output in time series format. HSPF has been applied to a large number of watershed studies in a wide variety of locations. Forty-five studies using the model in the United States have been summarized in a user-friendly software package called HSPFParm (Donigian et al., 1999). Sams and Witt (1995) calibrated HSPF to two surface mined watersheds in Fayette County, PA, providing local relevance to this study.

\subsection{Baseline HSPF Calibration Summary}

The WVDEP Trend Station Watershed water quality sampling points rarely coincided with USGS stream gaging stations required for model calibration. This fact, along with the obvious impracticality of individually calibrating to 235 watersheds, led to the adoption of a joint-calibration strategy following the work of Donigian (2002) and Dinacola (1990, 2001). Five calibration watersheds scattered throughout the state were selected with the intent of finding one parameter set for all of the trend station watersheds (Figure 2). Five additional verification watersheds were used to test the validity of transferring the resulting parameters (Figure 3 ). The Big Sandy watershed was used for both calibration and verification by using different simulation 
time periods. This resulted in one parameter set for each of the nine land use categories for the entire trend station region. The land use categories (Forest, Pasture/Grassland, Urban/Developed, Existing Mine Land, Barren Land, Shrubland, Row Crop Agriculture, Surface Water, and Wetland) were based on 1993 GAP data (Strager and Yuill, 2002).

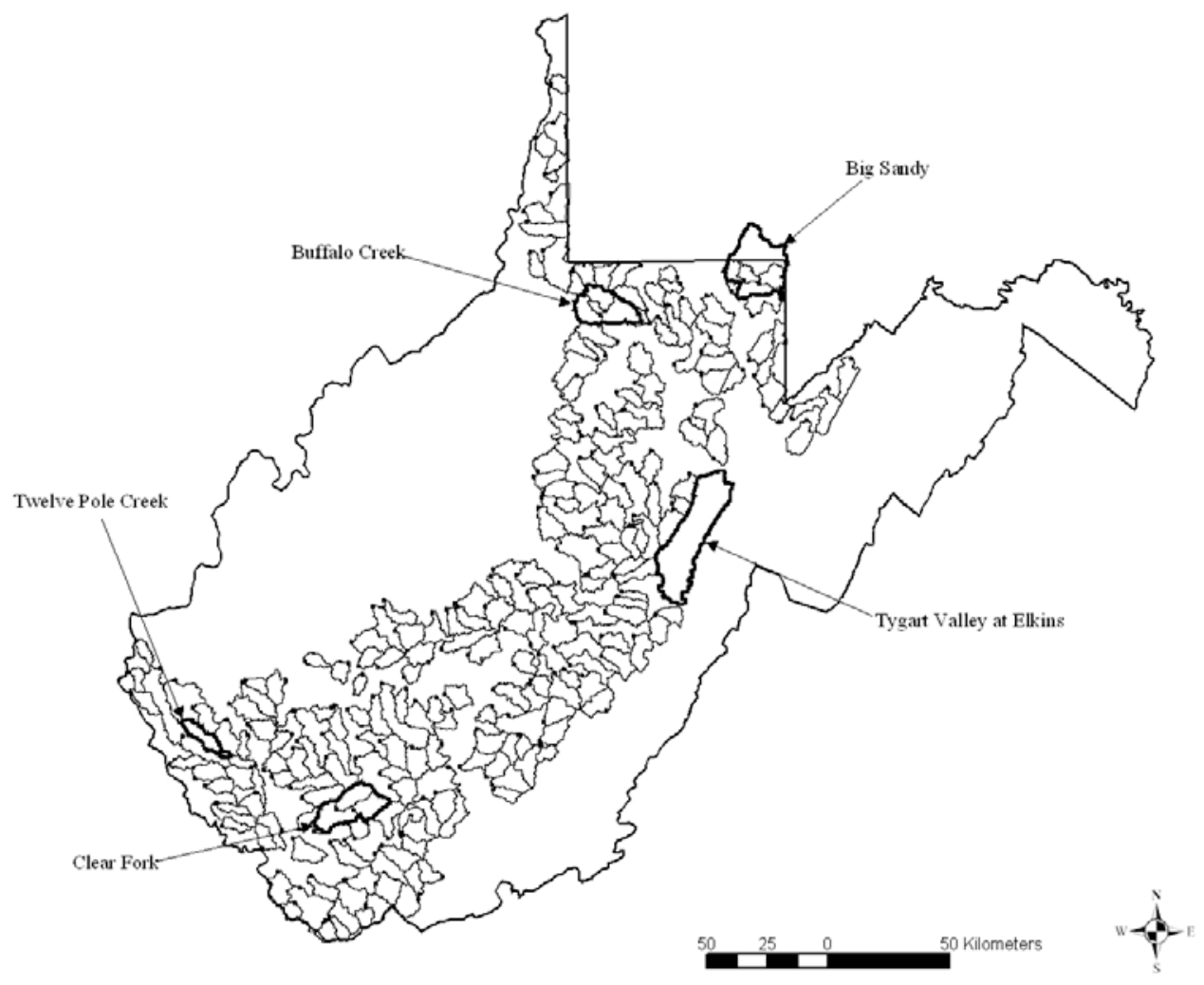

Figure 2. West Virginia CHIA Trend Stations and Calibration Watersheds. 


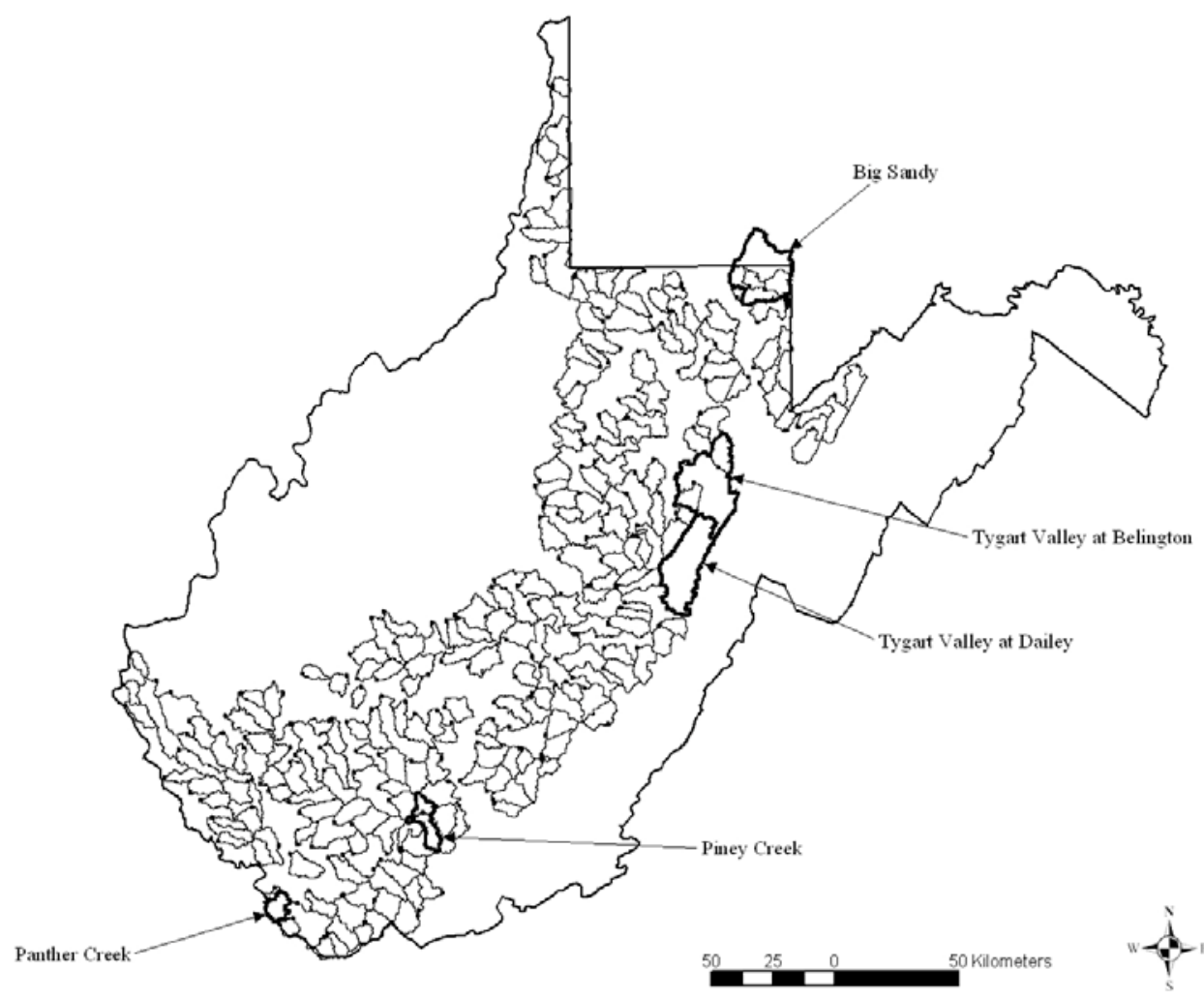

Figure 3. West Virginia CHIA Trend Stations and Verification Watersheds

The joint-calibration procedure involved two approaches. The first used the USGS semiautomated software HSPEXP (1994) which provides statistical and graphical error measures as well as parameter adjustment advice. A second calibration study was conducted using the independent parameter optimization package, PEST (Doherty, 2002). The final parameter set was selected through comparison of seven performance evaluating indices including the Coefficient of Determination $\left(r^{2}\right)$, the Coefficient of Efficiency $(E)$, and the Root Mean Square Error (RMSE). The simulated mean error is less than $12 \%$ for calibration watersheds and less than $15 \%$ for four of the verification watersheds. An unpublished technical report describing the calibration procedure in detail is included as Appendix A. Several agencies and individuals contributed to this report including the West Virginia Department of Environmental Protection, the U.S. Office of Surface Mining, Kate Flynn of the USGS, Reston, VA, Jim Sams of the USGS, Pittsburgh, PA, Dr. Robert Eli of the Department of Civil and Environmental Engineering at West Virginia University, and Elena Hoeg of the Natural Resource Analysis Center at WVU. The UCI file containing the final calibration parameter set is included as Appendix B. 


\subsection{Soil Physics Model}

\subsubsection{Relating HSPF Parameters to NRCS CN using a Soil Water Physics Model}

An analytical link was established between HSPF soil moisture parameters and physical soil attributes by adopting a soil water physics model based on the Green-Ampt (Green and Ampt, 1911) and the Brooks-Corey (Brooks and Corey, 1964) equations. The soil model is described in terms of the soil pore size distribution index $\left(\lambda_{p s}\right)$, soil porosity $(\eta)$, soil water suction head $(\psi)$, and soil moisture content $(\theta)$ shown in Figure 4.

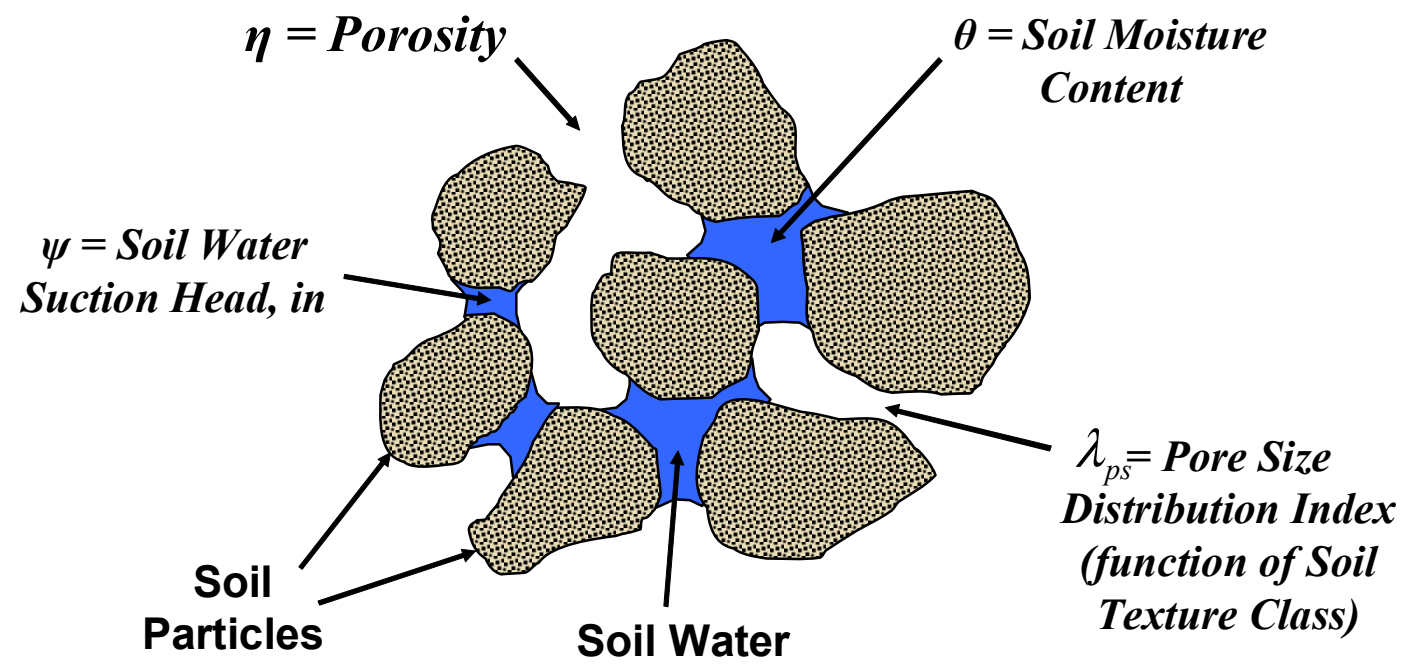

Figure 4. Soil Microstructure and Soil Water Variables (Soil Physics Model)

Brooks and Corey (1964) developed an empirical relationship between soil water suction head $\psi$ (cm of water) and effective saturation $s_{e}$, as a function of soil texture. The Brooks-Corey equation is

$$
s_{e}=\left[\frac{\psi_{b}}{\psi}\right]^{\lambda_{p s}}
$$


where $\psi_{b}$ is the soil water suction head at which air first enters the soil (called the bubbling pressure) and $\lambda_{p s}$ is pore size distribution index (a function of soil texture). The effective saturation is defined by

$$
s_{e}=\frac{\theta-\theta_{r}}{\eta-\theta_{r}}
$$

where $\theta$ is the moisture content of the soil $\left(\mathrm{cm}^{3} / \mathrm{cm}^{3}\right), \theta_{r}$ is the residual moisture content of the soil (equivalent to the wilting point), and $\eta$ is the soil porosity (see Figure 5 below).

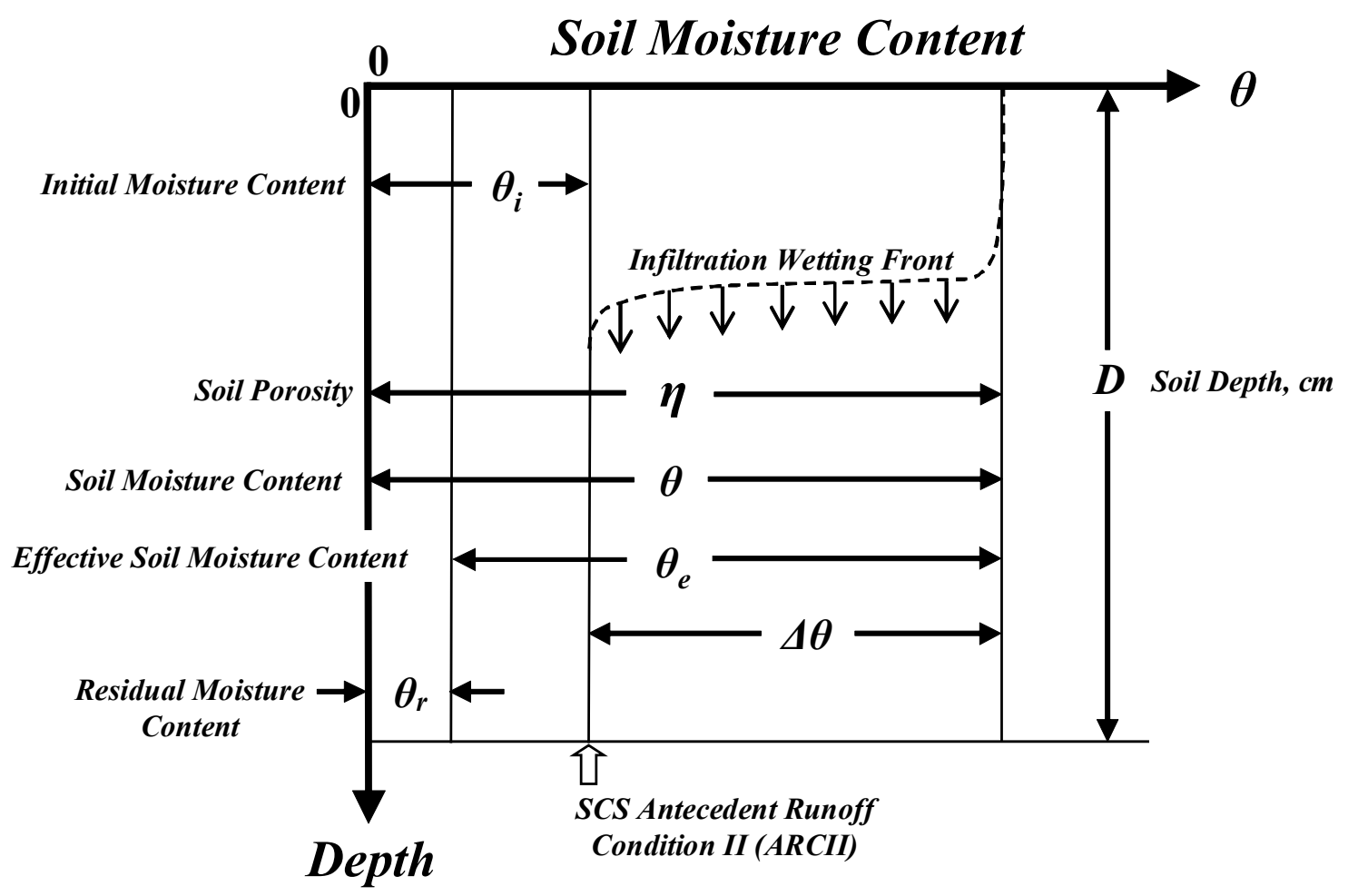

Figure 5. Soil Moisture Content as a Function of Soil Depth (Soil Physics Model)

Referring to Figure 5, the idealized soil water physics model assumes that the soil has homogeneous characteristics over the soil depth $D$. Neither the HSPF PERLND nor the CN method assumes that the soil has an explicit depth. In the soil water physics model, depth is required in order to compute soil water storage depth; and therefore, the soil depth is considered 
to be the "equivalent soil depth" that produces the desired storage capacity of the soil. It should be noted that the maximum possible soil moisture content is equal to the porosity $\eta$. The actual maximum soil moisture content will be slightly less than the porosity since a small amount of trapped air will remain in the soil when is fully saturated. In the development that follows, the moisture content at saturation will be assumed to be equal to the porosity since the simplification introduces a negligible error. The effective moisture content, $\theta_{e}$, is the amount of moisture that can be removed by gravity drainage and plant transpiration, assuming that the soil is initially saturated. The NRCS antecedent runoff condition (ARC I, ARC II, ARC III, or an intermediate value) is determined by initial moisture content, $\theta_{i}$, present in the soil prior to a storm event. To simplify the model description, the moisture content is assumed to be constant over the soil depth at any given point in time.

Brakensiek, Engleman, and Rawls (1981) used the Brooks-Corey equation (4) to develop a method to determine parameters for the Green-Ampt infiltration equation (1911). The GreenAmpt equation is

$$
f(t)=K\left[\frac{\psi \Delta \theta}{F(t)}+1\right]
$$

where $f(t)$ is the infiltration capacity at time $t, K$ is the unsaturated hydraulic conductivity, $\psi$ is the wetting front capillary pressure head, $\Delta \theta$ is the change in soil moisture content across the wetting front (Figure 5), and $F(t)$ is the accumulated infiltration at time $t$. Rawls, Brakensiek, and Miller (1983) used this same method to analyze approximately 5000 soil horizons across the United States to determine average values of the Green-Ampt parameters for different soil texture classifications. Table 1 lists 11 soil texture classifications used in this latter study, ranging from Sand (coarse particles) to Clay (very fine particles). Combining equations 5 and 6 , and solving for $\theta$ yields

$$
\theta=\theta_{r}+\left(\eta-\theta_{r}\right)\left[\frac{\psi_{b}}{\psi}\right]^{\lambda_{p s}}
$$

which relates soil moisture content $\theta$ to soil water suction head $\psi$ for a particular soil texture classification (for constant values of $\eta, \theta_{r}, \psi_{\mathrm{b}}$, and $\lambda_{p s}$ ). Equation 7 permits computation of the initial moisture content of the soil, $\theta_{\mathrm{i}}$, for any desired antecedent runoff condition (ARC) prior to a given storm event. 


\subsubsection{Computation of Equivalent HSPF Parameters for NRCS Curve Numbers}

Examination of the HSPF PERLND module algorithms identifies six of the 20 parameters that have principal influence on the infiltration and soil moisture storage processes and the shape of the direct runoff hydrograph:

$U Z S N=$ Upper zone nominal soil moisture storage $(\mathrm{mm})$.

$L Z S N=$ Lower zone nominal soil moisture storage $(\mathrm{mm})$.

$I N F I L T=$ Index to the mean infiltration rate $(\mathrm{mm} / \mathrm{hr})$.

INFEXP =Infiltration exponent parameter.

$I N T F W=$ Interflow inflow parameter.

$I R C=$ Interflow recession parameter (1/day).

The first four parameters predominate in the control of the infiltration and soil moisture storage processes, and the last two parameters predominate in the control of the shape of the direct runoff hydrograph. The HSPF model has two soil water storage variables, the upper zone storage $U Z S(\mathrm{~mm})$ and the lower zone storage $L Z S(\mathrm{~mm})$ (see Figure 1). The corresponding nominal storage capacities, UZSN and LZSN $(\mathrm{mm})$ are user adjustable model fitting parameters that are a function of "precipitation patterns and soil characteristics", according to BASINS Technical Note 6 (2000). The application of these nominal storage capacities in HSPF algorithms (Bicknell, et al, 2001) implies the following relationship between the nominal storages and the effective maximum storage capacities:

$$
\begin{aligned}
& U Z S_{\max }=3.0(U Z S N) \\
& L Z S_{\max }=2.5(L Z S N)
\end{aligned}
$$

In view of the PERLND model component design, as shown in Figure 1, there is no defined soil depth and the combined values of $U Z S$ and $L Z S$ are the total of all storage in the subsurface between the soil surface and the ground water table (neglecting the short term interflow storage). The description of the function of the upper zone storage $U Z S$, as stated in Hydrocomp (1969) (original source of the PERLND algorithm), is to provide for "depression storage and storage in highly permeable surface soils". It is further stated that "the upper zone storage prevents overland flow from a portion of the watershed depending on the value of the ratio $U Z S / U Z S N$, but since the nominal capacity $U Z S N$ is small, the upper zone retention percentage decreases rapidly with early increments of (rainfall) accretion". Inflow to the upper zone is governed by the storage ratio $U Z S / U Z S N$ alone and is not considered to be part of the 
infiltration process (Bicknell, et al, 2001). In view of these latter interpretations, the equivalent soil depth $D$ is assumed to be defined by the maximum effective storage capacity of the lower zone storage, $L Z S_{\max }$ :

$$
D=\frac{L Z S_{\max }}{\eta-\theta_{r}}
$$

As already noted above, $\eta$ is the soil porosity and $\theta_{r}$ is the residual moisture content. Combining equations 8 and 9 produces:

$$
L Z S N=\frac{\left(\eta-\theta_{r}\right) D}{2.5}
$$

Donigian and Davis (1978) presented guidelines on the ratio of the nominal capacities of the two storages, UZSN/LZSN. They recommended that the nominal storage capacity of the upper zone $U Z S N$ be from 0.06 to 0.14 of that for the lower zone LZSN. Therefore, an average ratio of 0.10 was selected:

$$
\frac{U Z S N}{L Z S N}=0.1
$$

Combining equations 10 and 11 , and solving for $U Z S N$, yields:

$$
U Z S N=\frac{\left(\eta-\theta_{r}\right) D}{25}
$$

The antecedent soil water depth of the lower zone storage, $L Z S_{i}$, corresponding to the NRCS type II antecedent runoff condition (ARC II) (SCS, 1986) can be computed for the effective soil depth $D$ if the corresponding soil moisture content $\theta_{i}$ is known:

$$
L Z S_{i}=\left(\theta_{i}-\theta_{r}\right) D
$$

Rawls and Brakensiek (1986) conducted studies comparing the runoff volume predictions of the Green-Ampt infiltration model to the $\mathrm{CN}$ model. They concluded that $\psi=340 \mathrm{~cm}$ was equivalent to the NRCS antecedent runoff condition II (ARC II). Using this value in equation 7 for each soil texture class results in the initial soil moisture content value $\theta_{i}$, which in turn can be used to compute the antecedent soil water depth using equation 13. Table 1 lists values of $\theta_{r}, \eta$, $\lambda_{p s}, \psi_{b}$, and $\theta_{i}$, for each soil texture class.

The remaining parameters required to establish the HSPF and CN relationship for the design storm direct runoff volume are the infiltration parameter INFILT $(\mathrm{mm} / \mathrm{hr})$ and the 
infiltration exponent parameter INFEXP. The HSPF infiltration capacity $I B A R(\mathrm{~mm} / \mathrm{hr})$ is computed by (Bicknell, et al, 2001)

$$
I B A R=\left[\frac{I N F I L T}{\left(\frac{L Z S}{L Z S N}\right)^{I N F E X P}}\right] I N F F A C
$$

where INFFAC is the frozen ground adjustment factor (set to 1 for unfrozen ground) and INFEXP is set equal to 2, consistent with typical applications of HSPF (U.S. EPA, 2000), and as recommended by Hydrocomp (1969). The values of INFILT for each of the soil texture classes listed in Table 2 are consistent with those values of INFILT recommended by BASINS Technical Note 6 (U.S. EPA, 2000) for NRCS Hydrologic Soil Groups A, B, C, and D, as listed in Table 2. The soil texture classes in Table 1 were first classified by hydrologic soil group using the soils data published by Nearing, et al., (1996). They compared NRCS Curve Numbers and hydrologic soil group classification to Green-Ampt hydraulic conductivities for a large number of soils covering a complete range of soil texture classes; therefore, it was possible to assign the proper hydrologic soil group to the soil texture classes in Table 1, according to soil texture class description and Green-Ampt hydraulic conductivity. After the appropriate hydrologic soil group 
classifications were determined, values of INFILT from Table 2 were assigned to each soil texture class so that the values varied smoothly from Sand to Clay, and so that the boundaries between hydrologic soil group classifications reflected the limits on the range of INFILT values listed in Table 1. In practice, this was accomplished by plotting estimated values of INFILT versus Green-Ampt infiltration capacity (at $\mathrm{F}(\mathrm{t})=1 \mathrm{~cm}$ ), and then adjusting the INFILT values by trial until a smooth curve fit was achieved (see Figure 6). The remaining less critical HSPF parameters were fixed at the values determined by the calibration process (Appendix A) and with guidance from Sams and Witt (1995) for the surface mine land cover condition. Therefore, each soil texture class (Table 1) represents a surface mine site land cover condition with a unique infiltration capacity. 


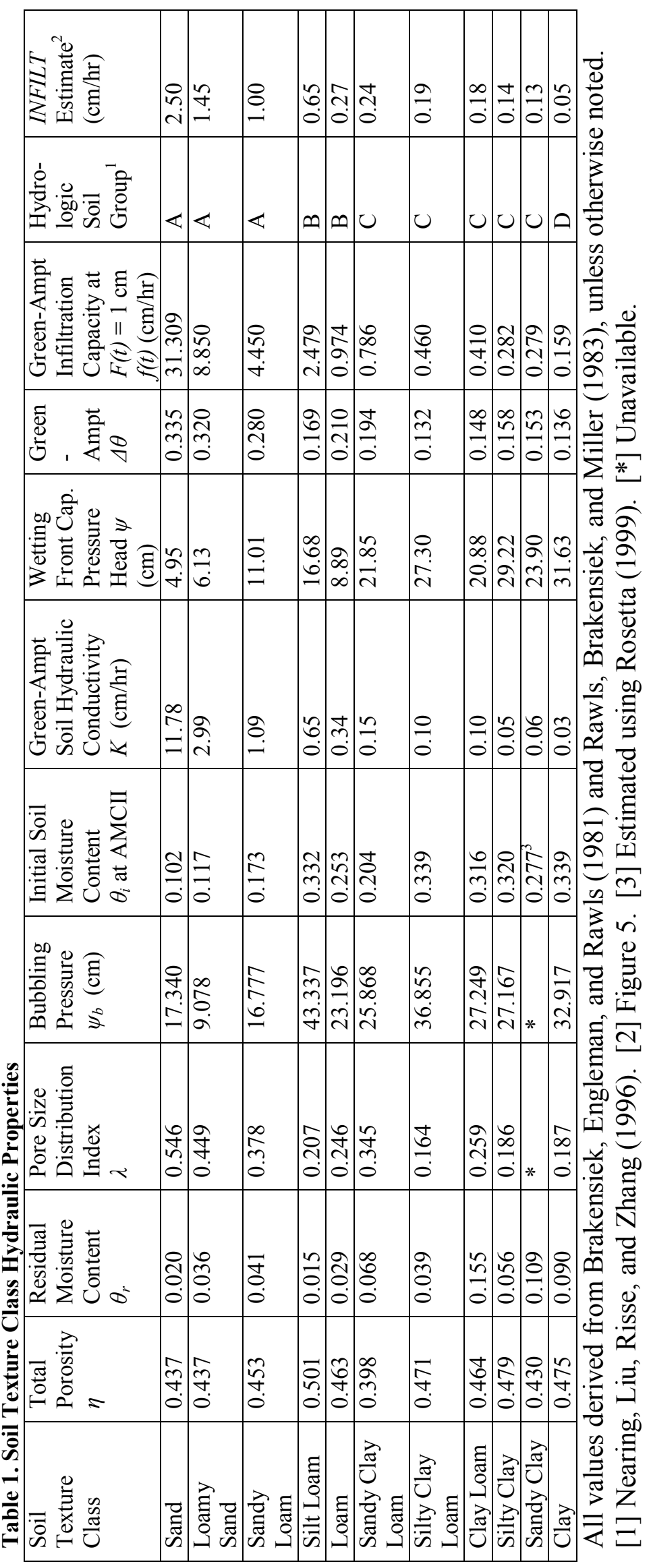


Table 2. INFILT versus Hydrologic Soil Group (BASINS Technical Note 6, U.S. EPA, 2001)

\begin{tabular}{|l|l|l|}
\hline $\begin{array}{l}\text { SCS } \\
\text { Hydrologic } \\
\text { Soil Group }\end{array}$ & $\begin{array}{l}\text { Estimate } \\
(\mathrm{mm} / \mathrm{hr})\end{array}$ & \\
\hline A & $25.4-63.5$ & Low \\
\hline B & $6.35-25.4$ & Moderate \\
\hline C & $3.175-6.35$ & Moderate to High \\
\hline D & $0.635-3.175$ & High \\
\hline
\end{tabular}

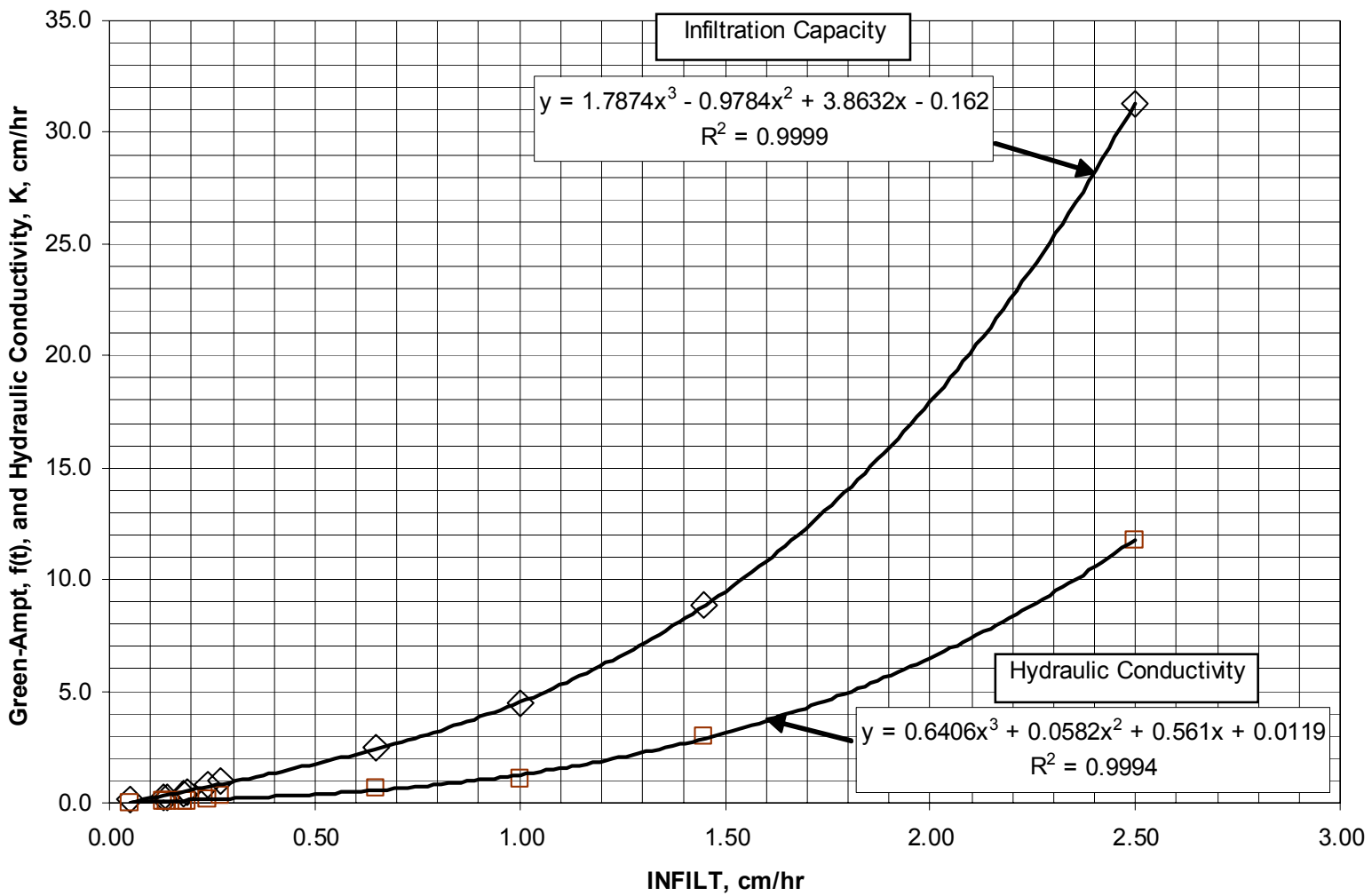

Figure 6. INFILT as a Function of Green-Ampt Infiltration Capacity and Soil Hydraulic Conductivity

\subsection{Methodology}

\subsection{Curve Number Computation Using Cyclic Storm Input}

Curve Numbers were determined numerically through an iterative process using HSPF with synthetic rainfall and potential evapotranspiration input in hourly increments 
for the range of variables shown in Table 3. The HSPF parameters (LZSN, UZSN, and INFILT) and the simulated soil moisture content corresponding to ARC II ( $\left.L Z S_{i}\right)$ were calculated for each equivalent soil depth using equations 10, 11, and 13 and Table 1. Therefore, each soil depth corresponds to a theoretical watershed with unique hydrologic characteristics. The remaining HSPF parameter values were determined through the joint calibration procedure and were fixed throughout this study (Appendix B). The input rainfall time series consisted of repetitive, regularly-spaced twenty-four hour storm events of constant distribution and depth (a cyclic storm input). Four synthetic storm distributions were used to examine their possible affect on the calculated Curve Numbers (Figure 7). It should be noted that the WDM (Watershed Data Management) Triangular distribution is used for the disaggregation of rainfall records in the EPA's software for managing meteorological time series data, WDMUtil (Hummel et al., 2001).

Table 3. CN Computational Variables

\begin{tabular}{|c|c|c|c|c|}
\hline Soil Type & Soil Depth (cm) & Storm Depth $(\mathrm{mm})$ & Storm Distribution & $\lambda$ \\
\hline Sand & 10 & 10 & \multirow{4}{*}{$\begin{array}{c}\text { NRCS Type II } \\
\text { Uniform } \\
\text { Full Triangular } \\
\text { WDM Triangular }\end{array}$} & 0.2 \\
\hline Loamy Sand & 15 & 20 & & 0.05 \\
\hline Sandy Loam & 20 & 30 & & \\
\hline Silt Loam & 25 & 40 & & \\
\hline Loam & 30 & 50 & & \\
\hline Sandy Clay Loam & 35 & 60 & & \\
\hline Silty Clay Loam & 40 & 70 & & \\
\hline Clay Loam & 45 & 90 & & \\
\hline Silty Clay & 50 & 110 & & \\
\hline Sandy Clay & 60 & 130 & & \\
\hline Clay & 70 & 150 & & \\
\hline & 80 & & & \\
\hline & 90 & & & \\
\hline & 100 & & & \\
\hline & 120 & & & \\
\hline & 140 & & & \\
\hline & 160 & & & \\
\hline & 180 & & & \\
\hline & 200 & & & \\
\hline
\end{tabular}



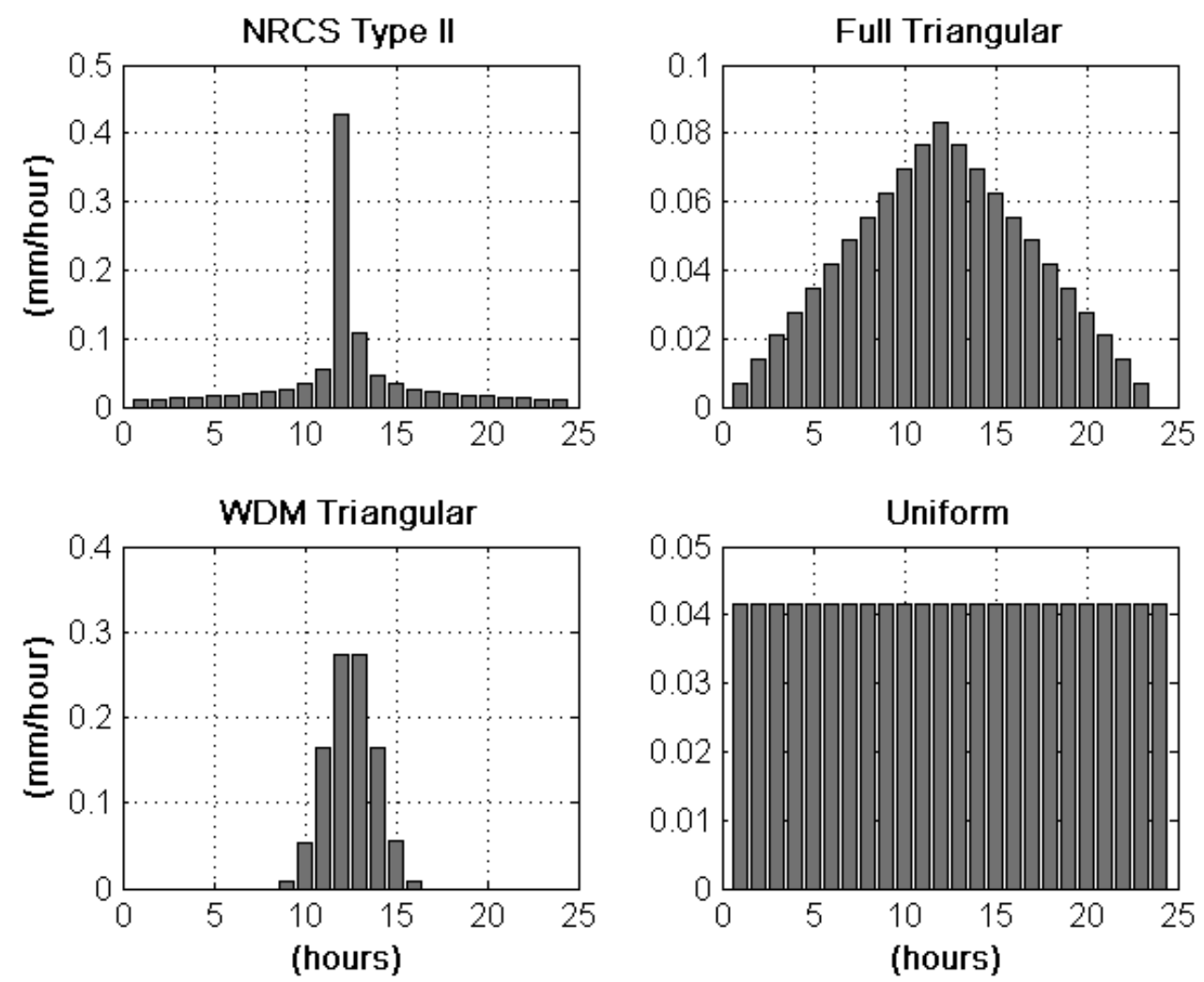

Figure 7. Synthetic Storm Distributions, Hourly Time Increment, 1 mm Accumulated Depth

The potential evapotranspiration (PET) time series consisted of a uniform rate maintained at a fixed value for all simulations consistent with a typical dry day rate $(\mathrm{mm} / \mathrm{hr}$ ) observed during the growing season (Figure 8). The PET was set to zero during the storm event. No diurnal fluctuation was used since the only purpose of the PET was to draw the soil moisture level down to the ARC II condition prior to the next cyclic storm event, and it was desirable not to introduce any unnecessary fluctuations into the simulation. Each simulation run was conducted over a sufficient number of storm cycles to ensure that cyclic equilibrium was reached in all of the HSPF PERLND output time series variables. Samples of the cyclic HSPF input and output are shown in Figure 8. 

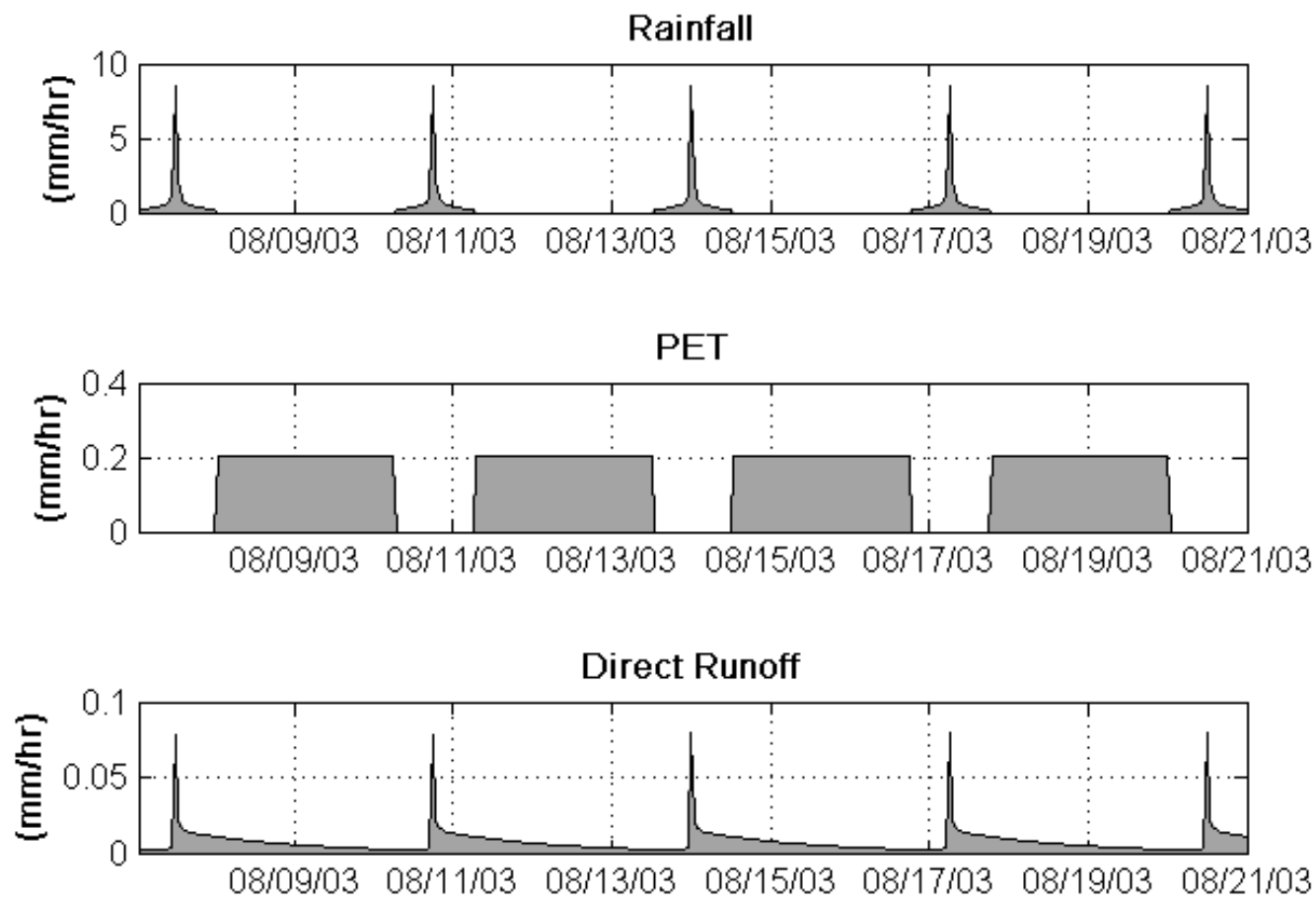

Figure 8. Sample Cyclic HSPF Input (Type II Rainfall and PET) and Output (DRO)

The time between storm events was varied by trial until the lower zone storage, $L Z S$, matched the initial ARC II condition computed using equation 13. The CN was then computed using equations 1-3 with the known value of $P$ (corresponding to a specific storm distribution) and the numerically determined value of $Q$ (the sum of SURO and IFWO HSPF output components between storm events). A check was included to ensure the rainfall depth satisfied the condition of equation 1. This procedure was performed over the ranges of each variable listed in Table 3 for the Silt Loam and Clay Loam soil types. These soil types were selected because of their relatively high and low infiltration rates, respectively (Table 2). Additionally, the computation time required to include all eleven soil types was considered prohibitive for this study. Each soil texture class requires 836 individual HSPF simulations in order to complete all combinations of the variables listed in Table 3. This excludes the Asymptotic Method (presented later) as well as post-processing requirements. 


\subsection{Asymptotic Method Using Observed Storm Input}

A second method of determining $\mathrm{CN}$ values from time series rainfall-runoff data was introduced to provide a reference to the values calculated in the synthetic cyclic storm procedure based on the soil physics model. This method follows Hawkins' (1993) asymptotic method of determining $\mathrm{CN}$ values from data for individual watersheds which has become widely recognized (VanMullem, et al., 2002; Hjelmfelt, 2001). It is based on the idea that the $\mathrm{CN}$ method is best suited to frequency transform applications. Each storm and its corresponding runoff events are extracted from a single time series record. These data pairs are then sorted individually by depth from high to low and are re-paired, ensuring that each rainfall-runoff pair are of equal return periods, even though they may not coincide in time. When the CN's are calculated from these ordered pairs and are plotted on the $y$-axis against storm depth on the x-axis, three trends often emerge. The first is known as complacent behavior where the $\mathrm{CN}$ decreases steadily with storm depth without approaching a constant value (Figure 9). CN's cannot safely be determined from data which exhibit this pattern because no constant value is approached. This trend has been found to indicate a partial source area situation (Hawkins, 1979; Pankey and Hawkins, 1981).

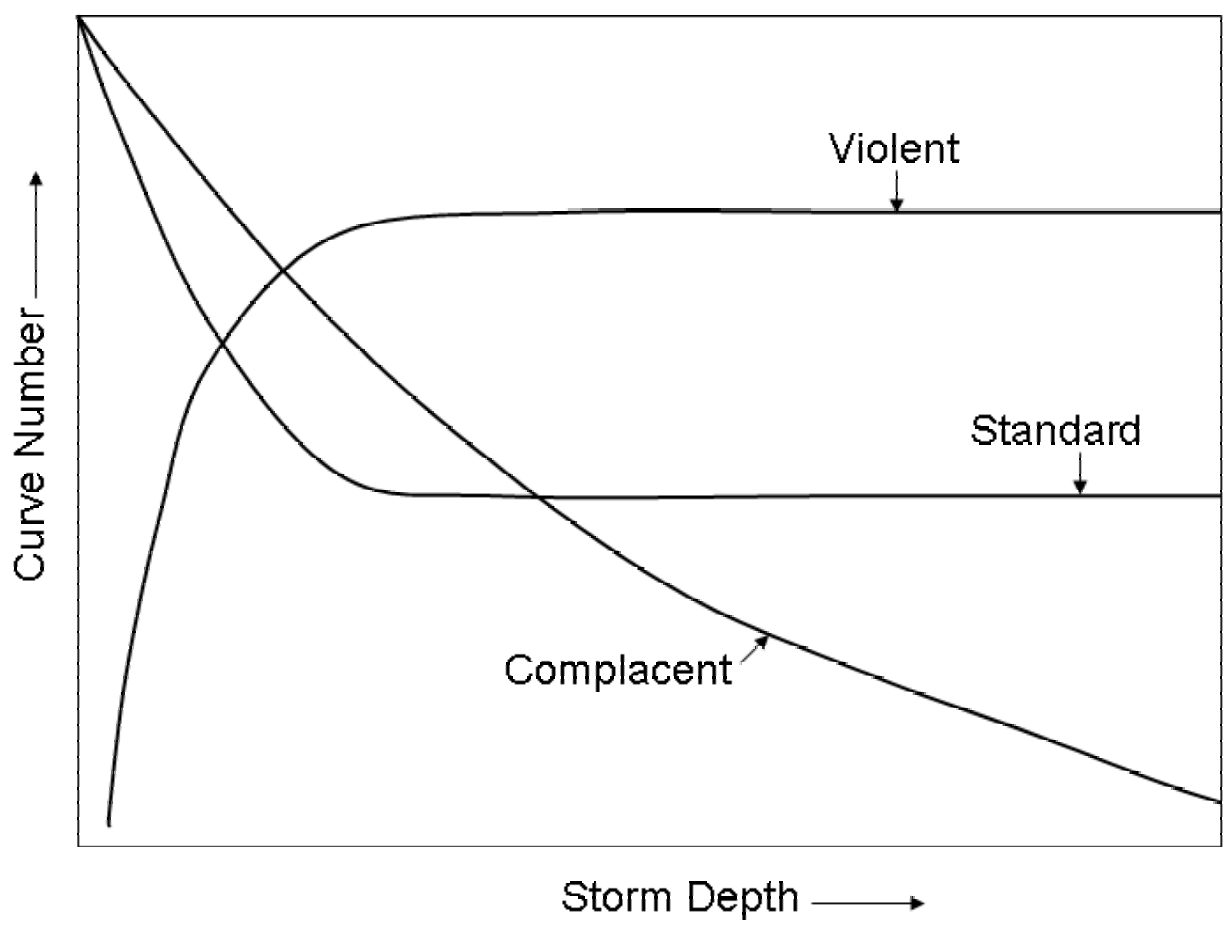

Figure 9. Sketch of Behavioral Trends 
The second trend is referred to as standard behavior, where the $\mathrm{CN}$ values decrease with increasing storm depth and approach a constant value (Figure 9). Hawkins found this to be the most common scenario, and hypothesized that runoff generation may include a variety of processes such as overland flow and interflow. He found that equation 15 can be used to fit the Standard behavior CN-P data sets, where $k$ is a fitting constant and $C N_{\infty}$ is the value that is approached as $\mathrm{P}$ increases. The value of $C N_{\infty}$ is used as the Curve Number identified with an individual watershed (Hawkins, 1993).

$$
C N(P)=C N_{\infty}+\left(100-C N_{\infty}\right) \exp (-k P)
$$

The third variation is known as violent behavior where the CN's rise suddenly with rainfall and then asymptotically approach a constant value. Violent behavior could indicate a threshold phenomenon at some critical rainfall depth. Hawkins also found that violent behavior was often accompanied by complacent behavior at lower rainfall depths. In this latter case, equation 16 (Hawkins, 1993) has been found to represent the CN-P data sets, ignoring any complacent behavior.

$$
C N(P)=C N_{\infty}[1-\exp (-k P)]
$$

It should be noted that Figure 9 is only a sketch showing the characteristic curve shapes of the three behavior types. It does not necessarily indicate relative positioning.

Hawkins' asymptotic method of CN determination was adopted for this study using simulated direct runoff from HSPF and long (a minimum of 20 years) historical precipitation records as model input. The precipitation records were gathered from four National Climatic Data Center (NCDC) stations scattered throughout the coal mining region in WV (Figure 10). 


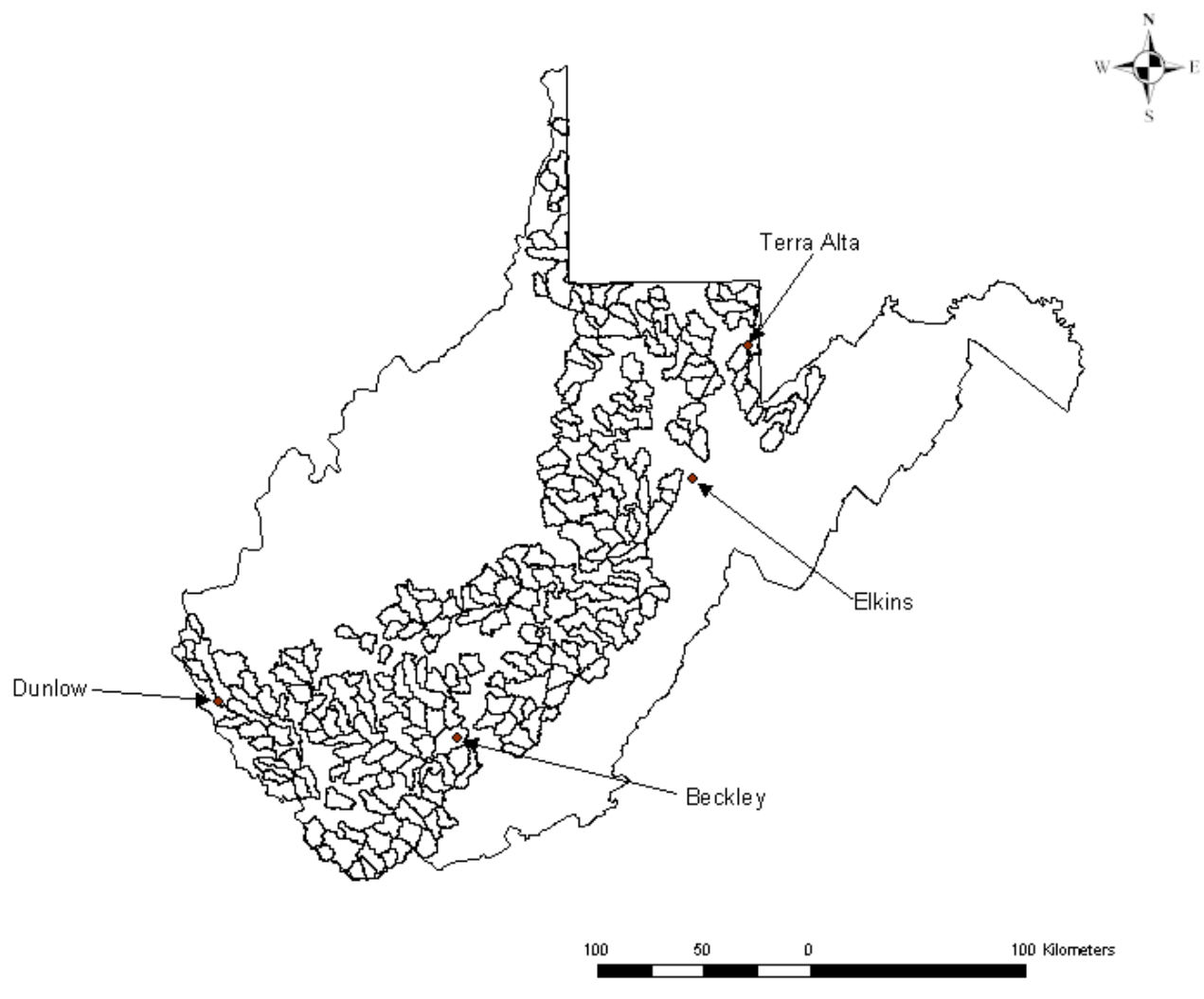

Figure 10. Location of Rainfall Gages Used in the Asymptotic Method

PET was calculated from daily minimum and maximum temperature records at the same gages and latitude using the Hamon method in the EPA's WDMUtil software package (Hummel et al., 2001).

An algorithm was written that automatically selected the input rainfall and simulated hourly runoff events based on the following criteria. A storm event must fall within a twenty-four hour window with zero total rainfall during the previous and subsequent 24 hour periods. Additionally, the total storm depth must be greater than a designated minimum depth; in this case $13 \mathrm{~mm}$ (about 0.5 inches). The condition specified by equation 1 was also enforced here. The storm event search was limited to the beginning of May to the end of September to exclude snowfall. The corresponding simulated direct runoff for each event was accumulated between the first hour of the selected storm event to either the hour at which the runoff has receded to the same value that existed before the storm, or alternately to the hour immediately preceding the next storm event. 
The number of storms selected for the Terra Alta, Elkins, Beckley, and Dunlow gages, using the above algorithm, was 163, 137, 133, and 45, respectively. The length of the selection period for the Terra Alta, Elkins, and Beckley gages was 25 years, while Dunlow was 20 years. The distributions of the selected storms at each gage were summarized using a relative frequency histogram. Each hourly accumulation within each storm was normalized using the total depth for that storm. These normalized hourly values were then averaged over the total number of storms and plotted on the same axes, providing a combined measure of storm distribution by relative depth that occurs in each hour of the storm for all selected storms at each gage, as shown in Figure 11. Since most of the selected storm events were of relatively short duration, the distributions in Figure 11 are heavily weighted in the first few hours of the 24 hour storm window.
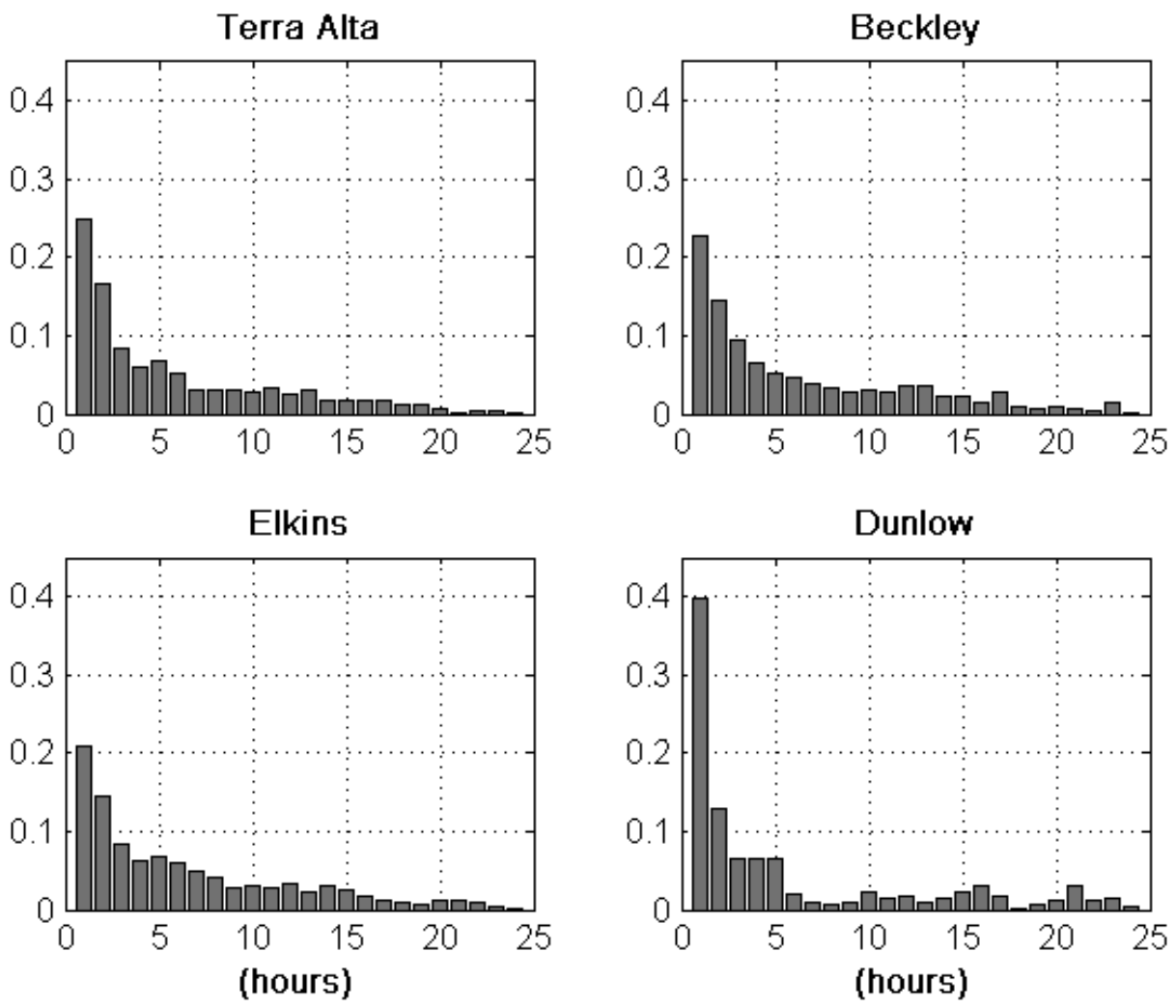

Figure 11. Storm Distribution Relative Frequency Histograms for each Gage 


\subsection{Results and Discussion}

\subsection{Cyclic Method}

Figures 12-27 are plots of the computed CN's vs. Storm Depth for Clay Loam and Silt Loam soils, using initial abstraction ratio $(\lambda)$ values of 0.05 and 0.2 over the full range of soil and storm depths for each storm distribution (see Table 3). Figures 12-15 are plots of the Clay Loam soil with $\lambda=0.2$. Figures 16-19 are plots of the Silt Loam soil with $\lambda=0.2$. Figures $20-23$ are plots of the Clay Loam soil with $\lambda=0.05$, and Figures 24-27 are plots of the Silt Loam soil with $\lambda=0.05$.

By examining Figures 12-27, it is apparent that the $\mathrm{CN}$ is a function of soil type, soil depth, storm depth, and storm distribution. In all cases, the Clay Loam soil results in higher $\mathrm{CN}$ values than the Silt Loam, due to the lower infiltration capacity of the Clay Loam as governed by the INFILT parameter (Table 2). For each soil type and storm distribution, $\mathrm{CN}$ values generally decrease with increasing soil depth. This can be explained by the increase in the upper and lower zone soil moisture storage parameters (UZSN and LZSN) with the increase in soil depth (Equations 10 and 12). For each soil depth, the CN's also vary with storm depth, typically describing violent behavior where the CN's increase abruptly and approach a constant value as storm depth increases. As Hawkins (1993) noted, the violent behavior is often preceded by complacent behavior at lower storm depths as shown in Figures 12-14, 18, 20-22, and 24-26. Additionally, the violent behavior is more prevalent at lesser soil depths and trends toward standard behavior as soil depth increases (Figures 12-14, 18, and 20-27).

The $\mathrm{CN}$ values are also dependent on the storm distributions. The curves of the CN's vs. storm depth for the Uniform and Full Triangular distributions describe a smoother shape than those from the Type II and WDM Triangular distributions. This may be explained by observing that the Type II and WDM Triangular distributions deliver the majority of the total storm depth in a period of time that is less than two hours (Figure 7). Conversely, the Uniform and Full Triangular distributions allocate rainfall more uniformly throughout the twenty-four hour period, resulting in lower hourly intensities. 


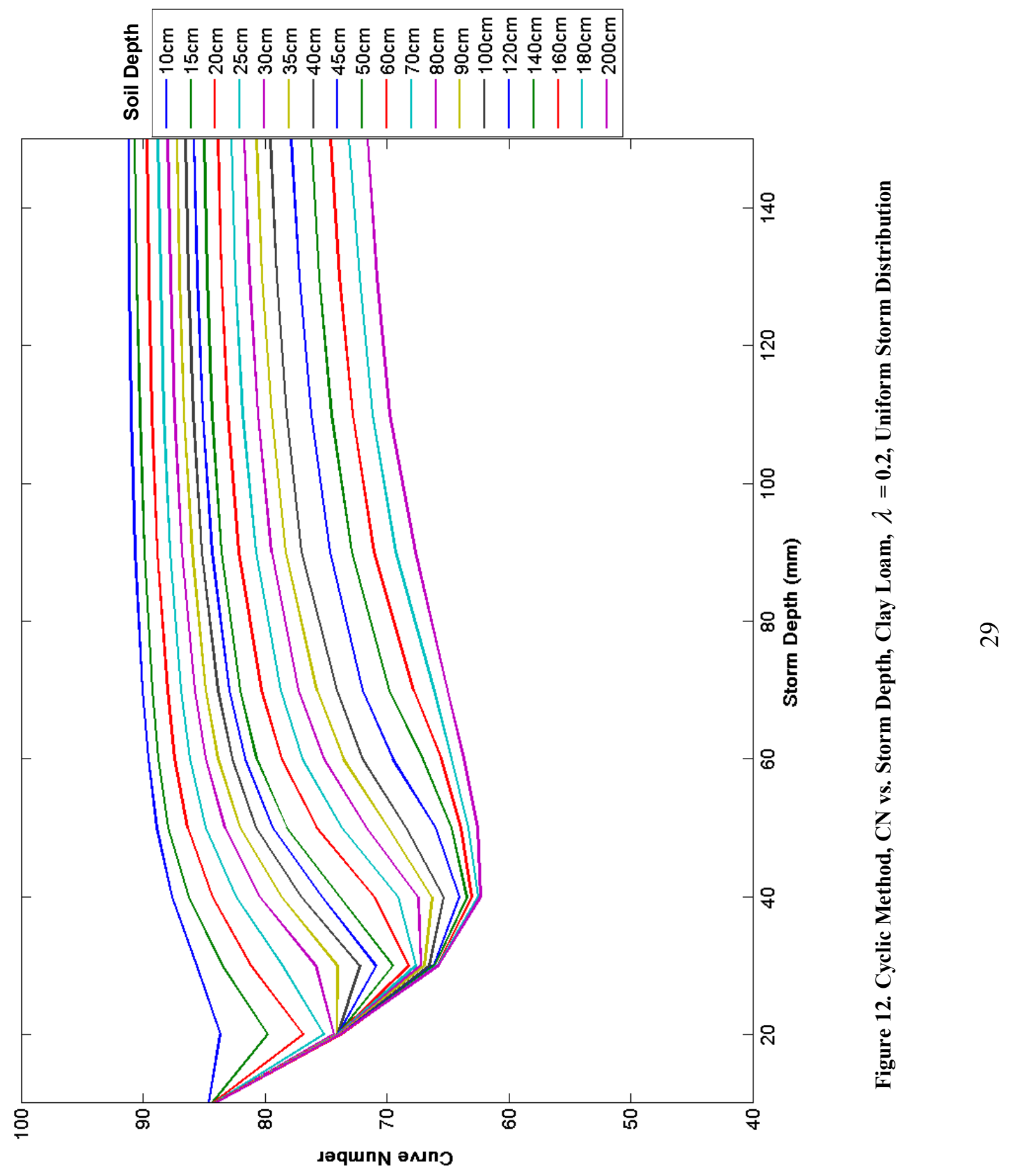




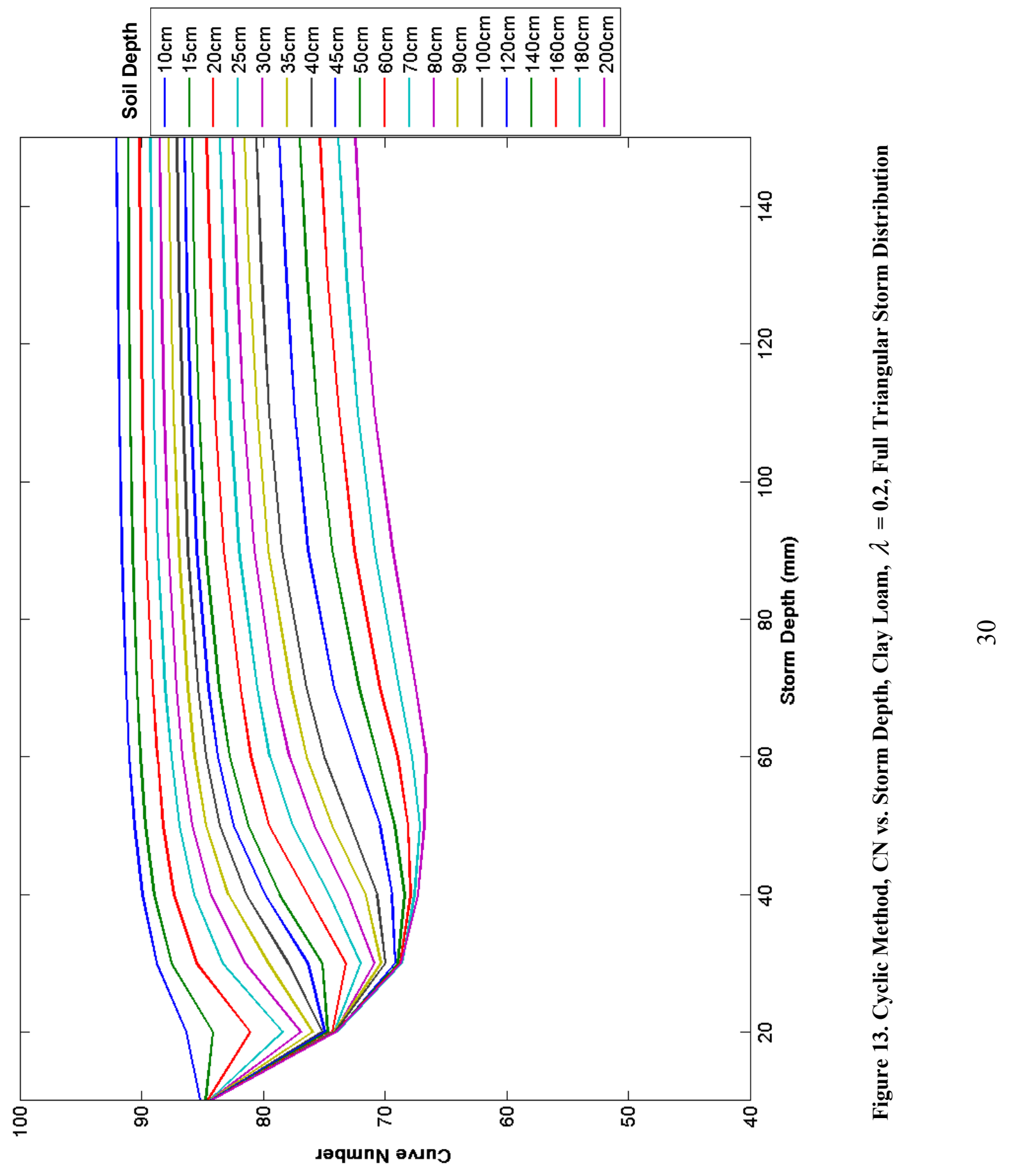




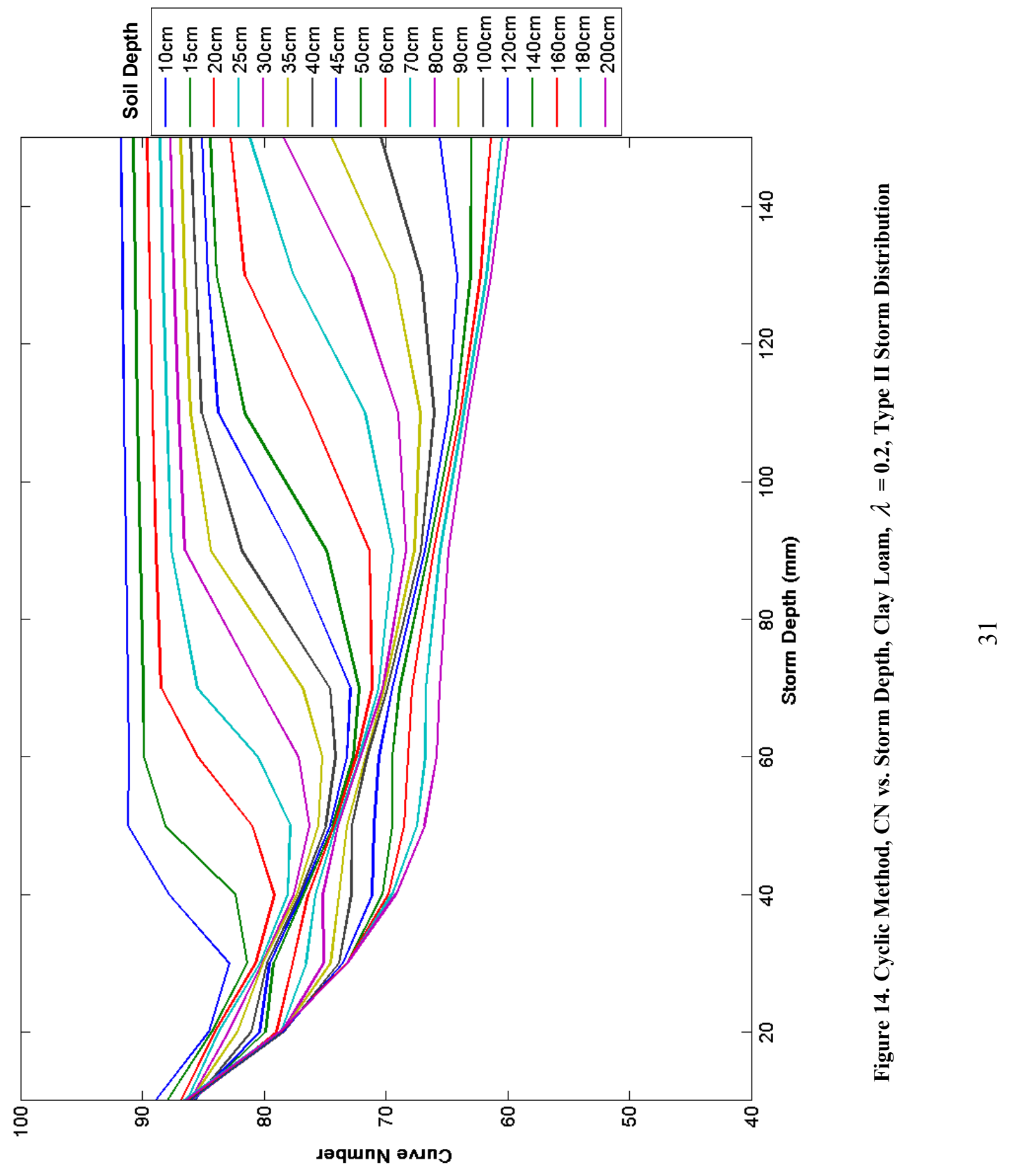




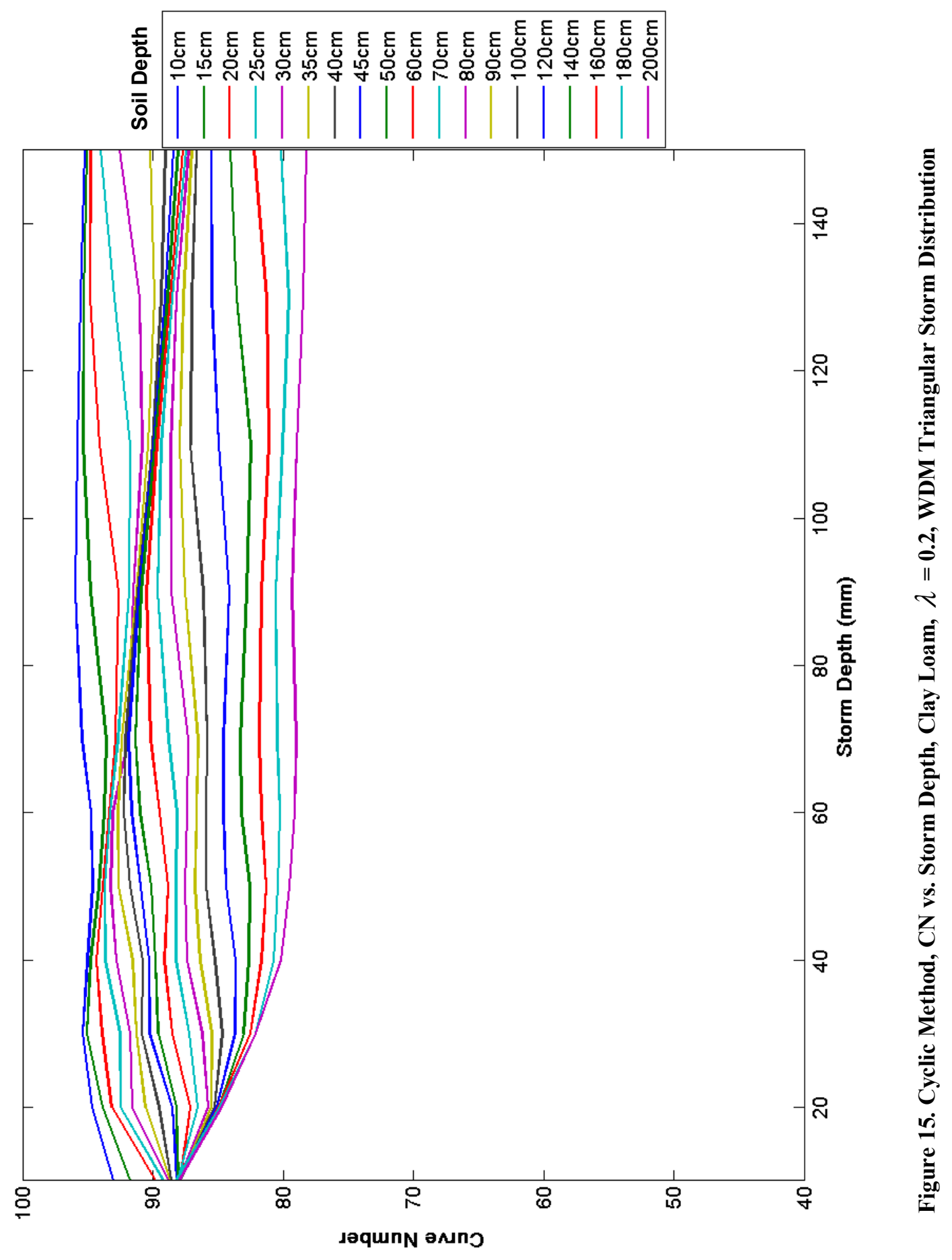




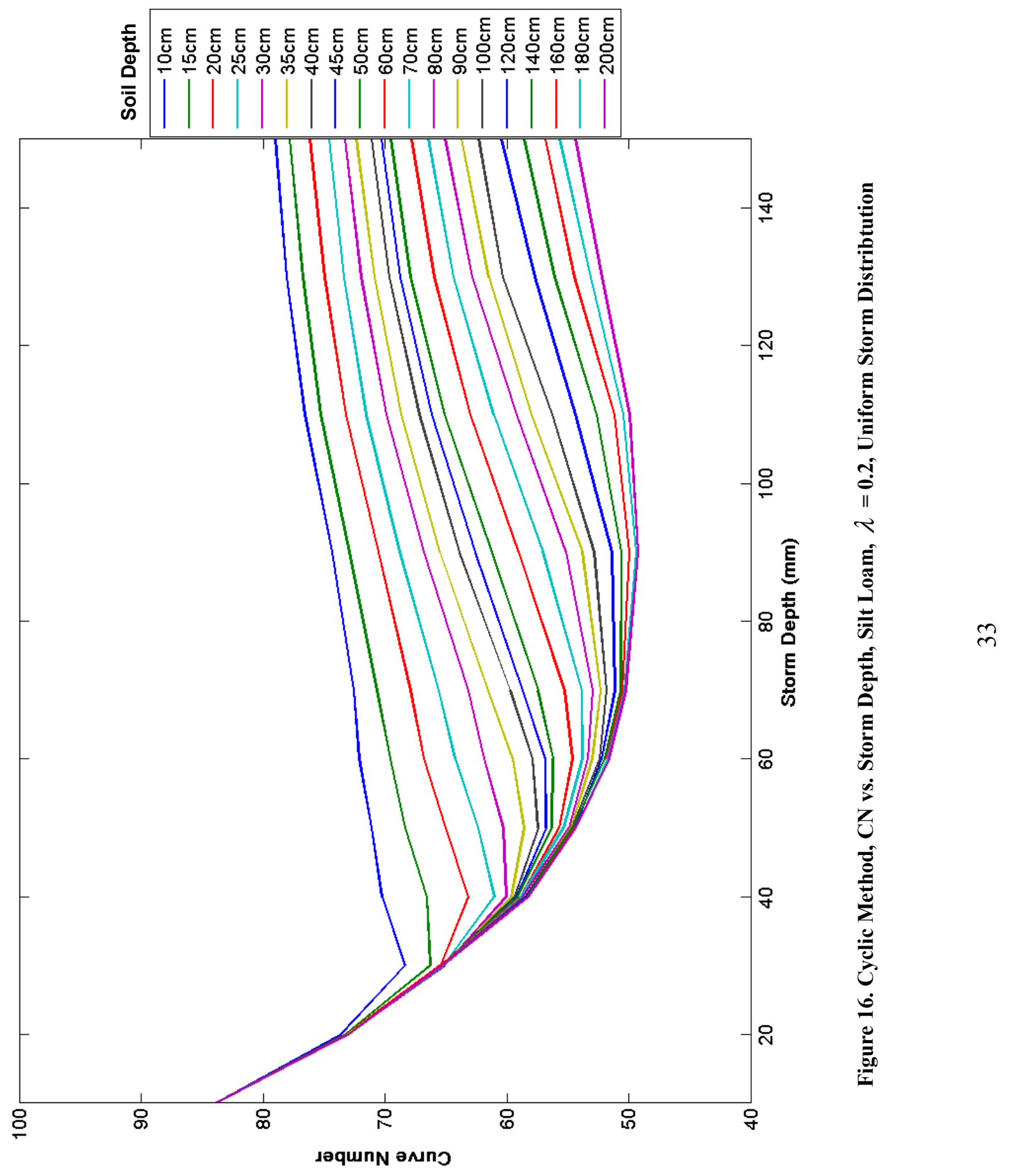




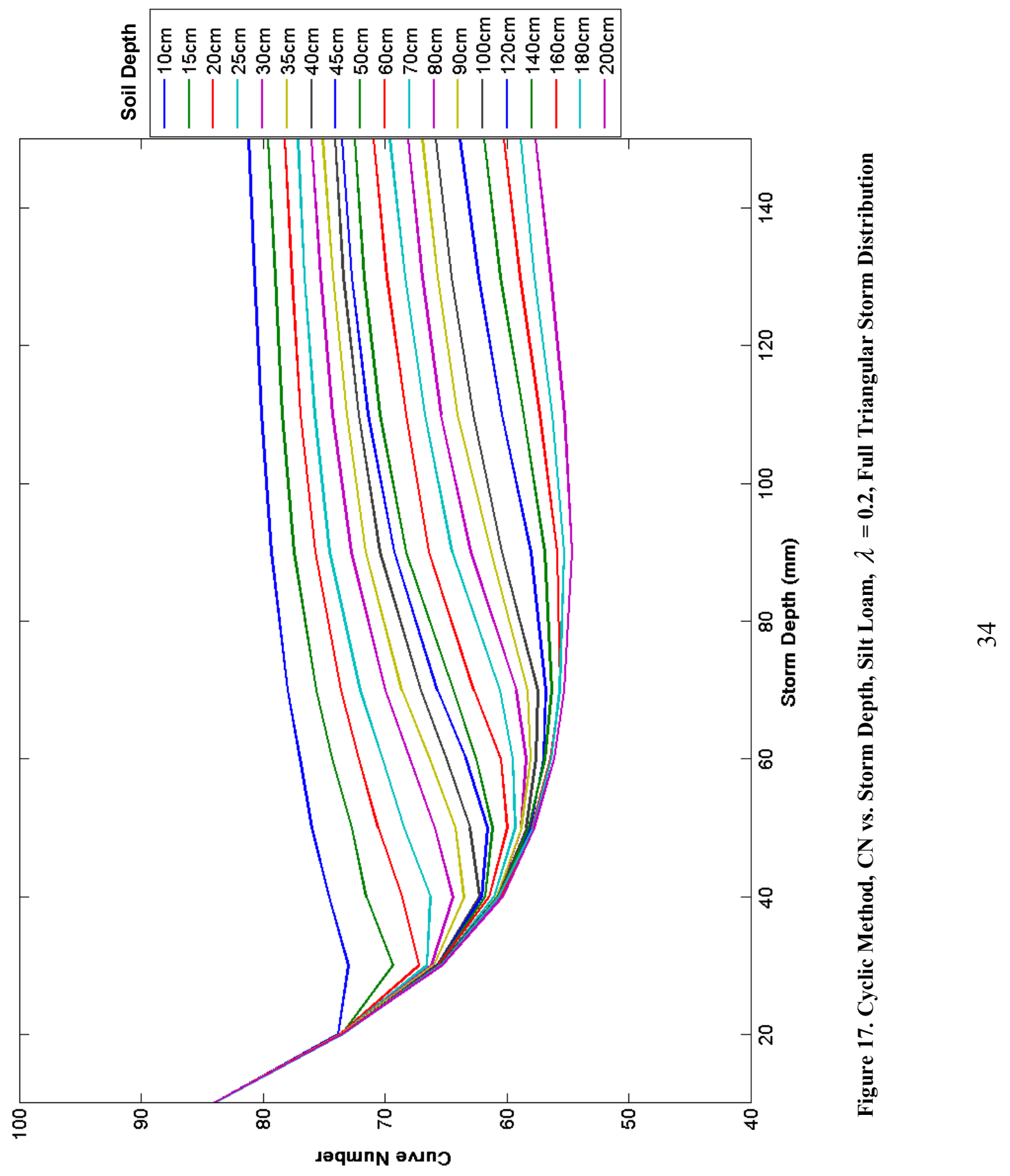




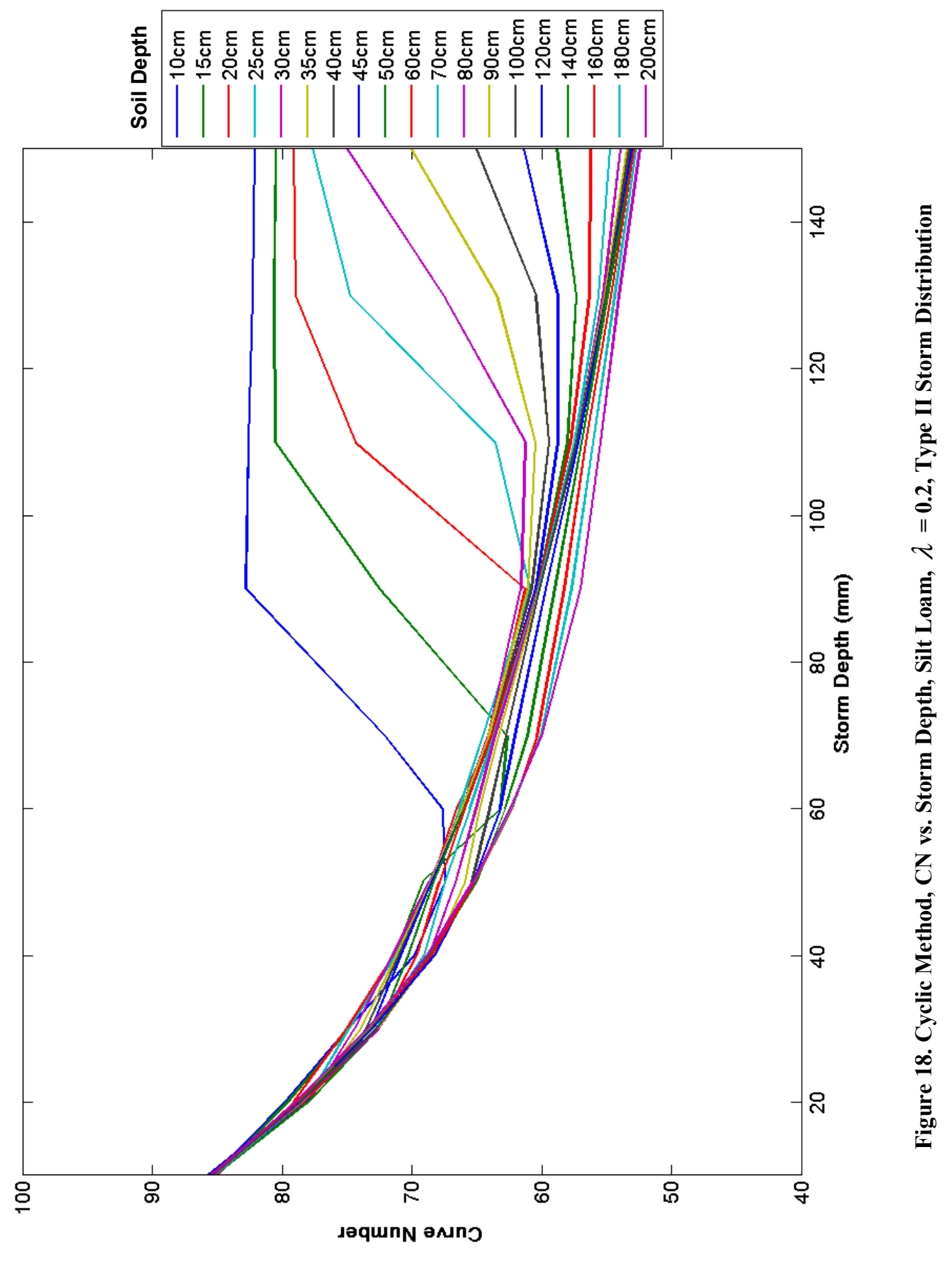




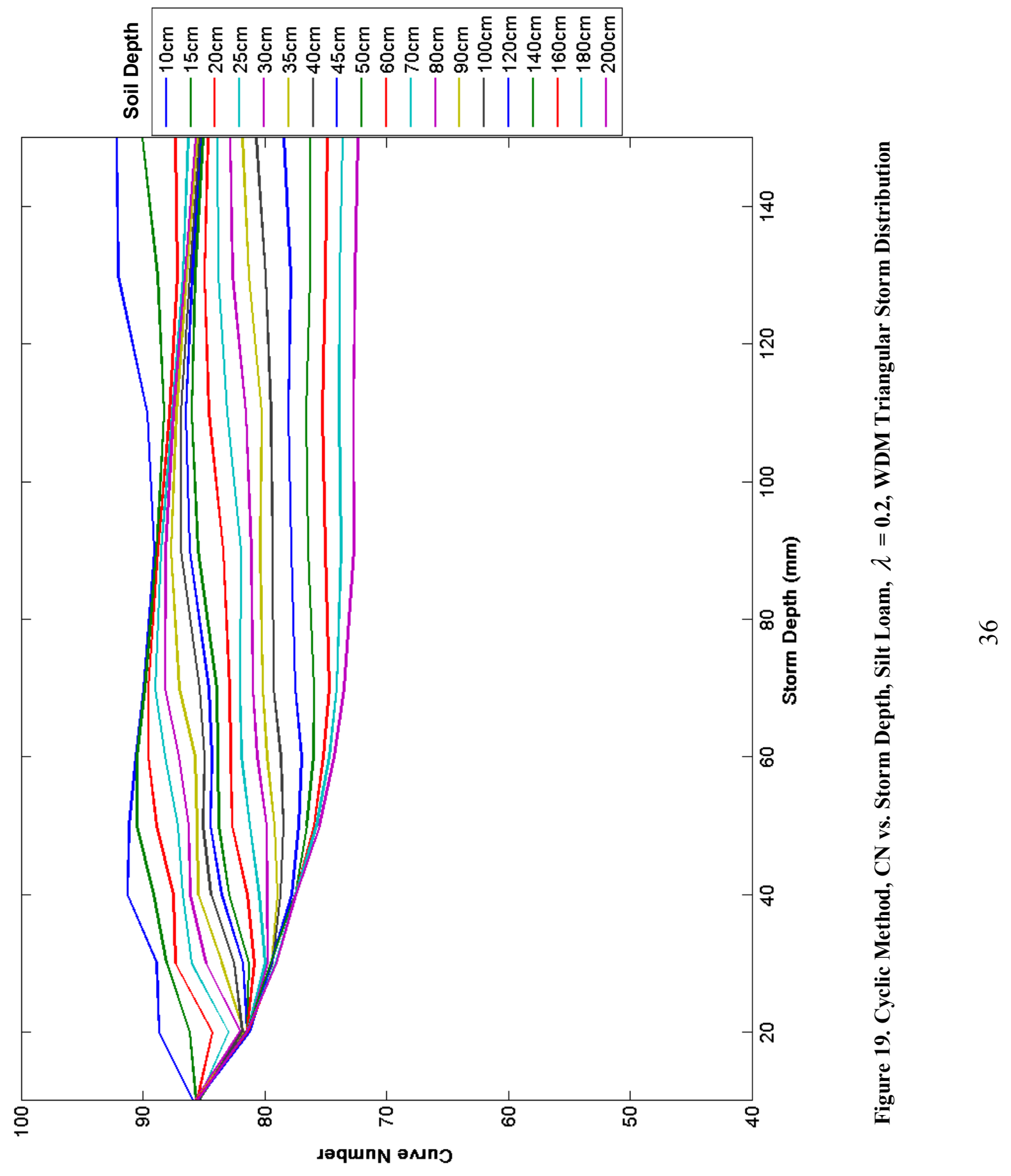




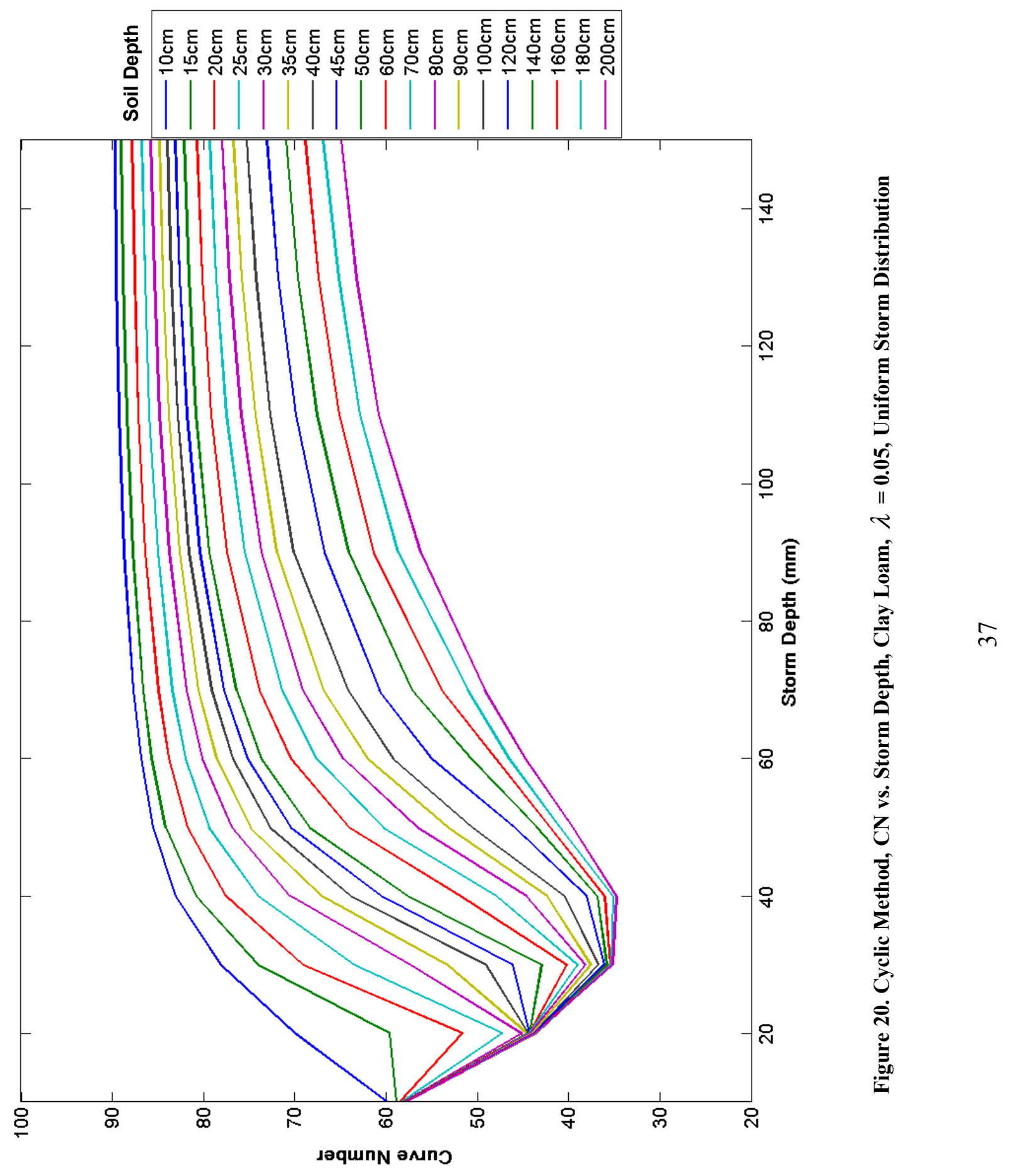




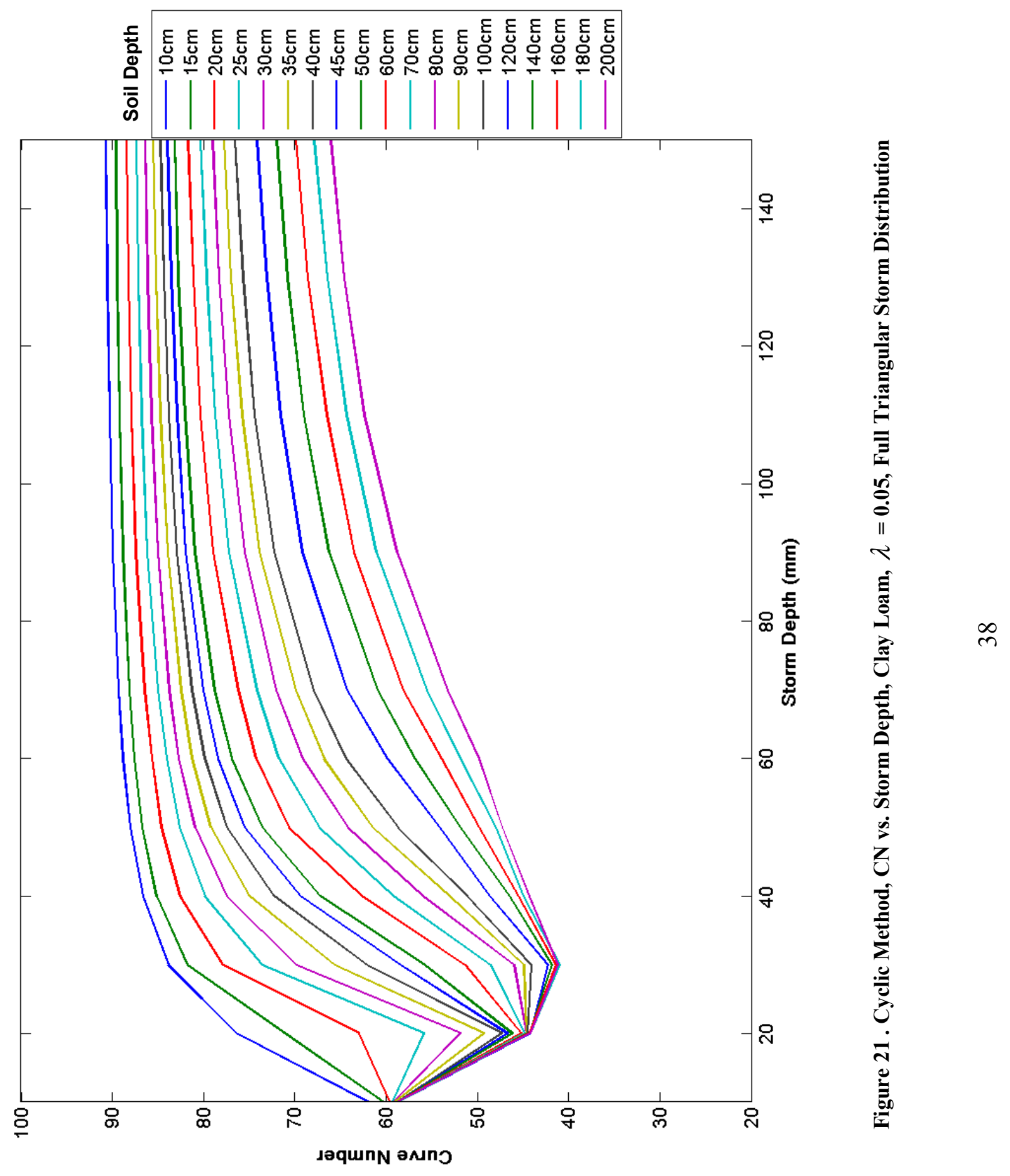




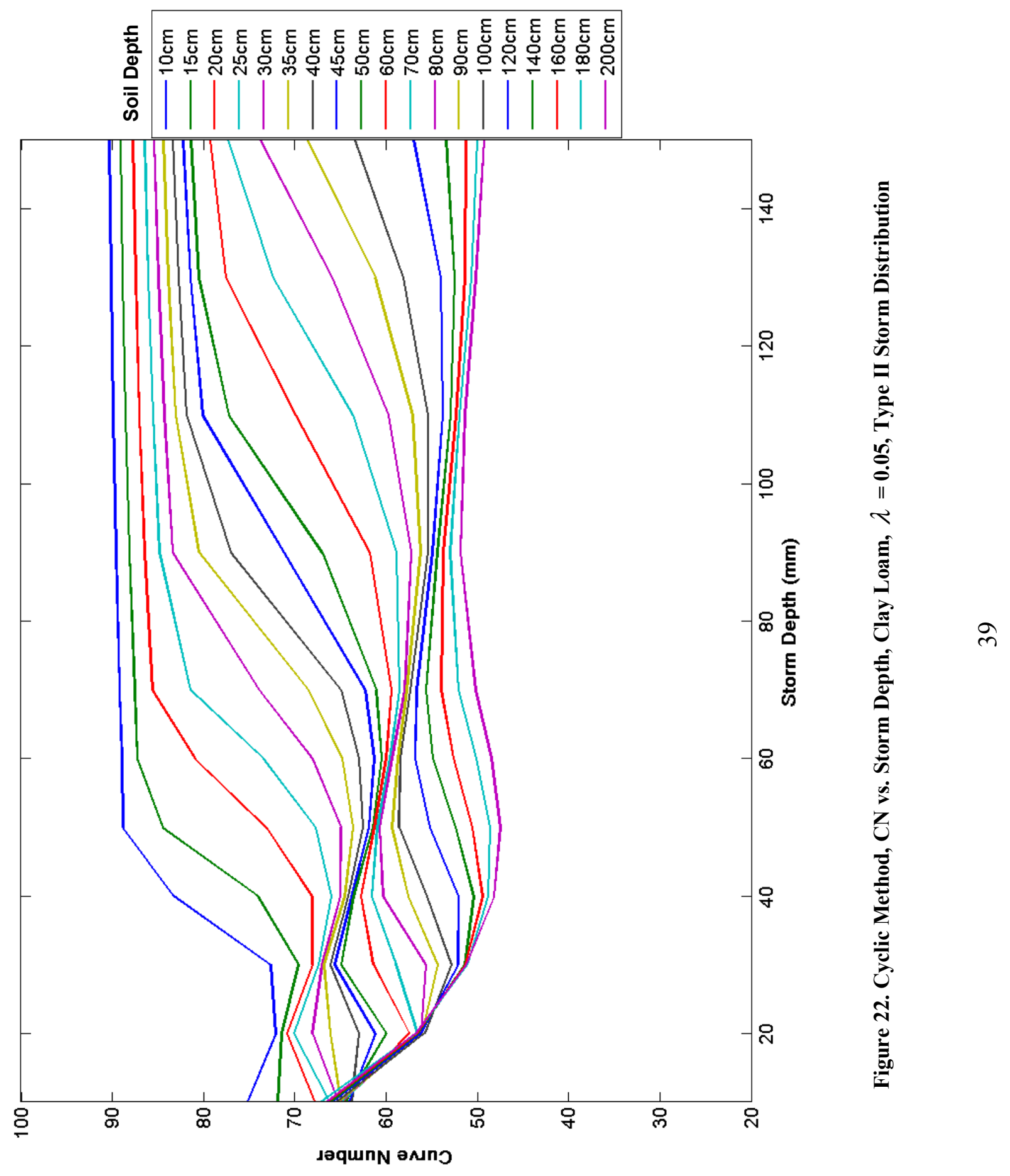




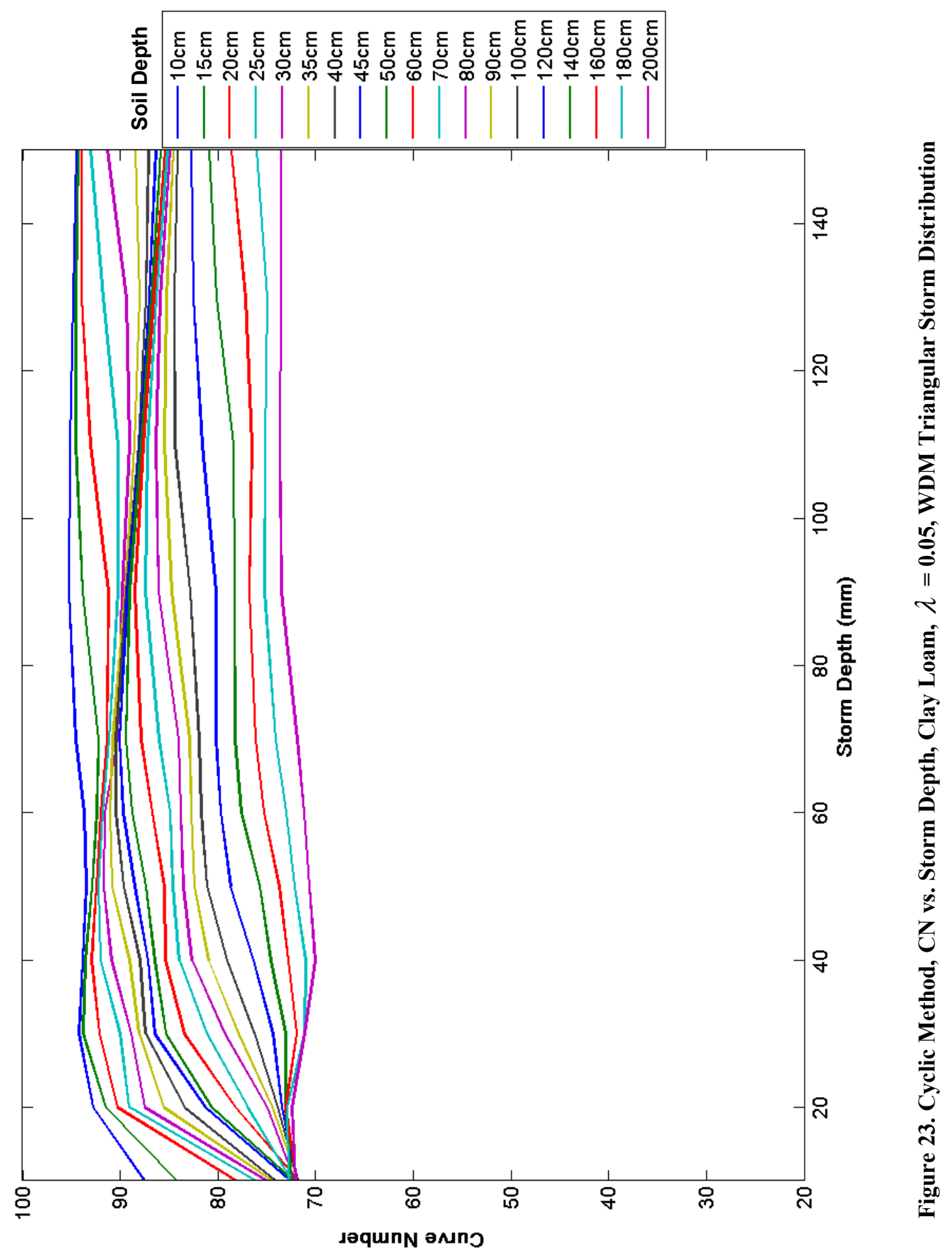




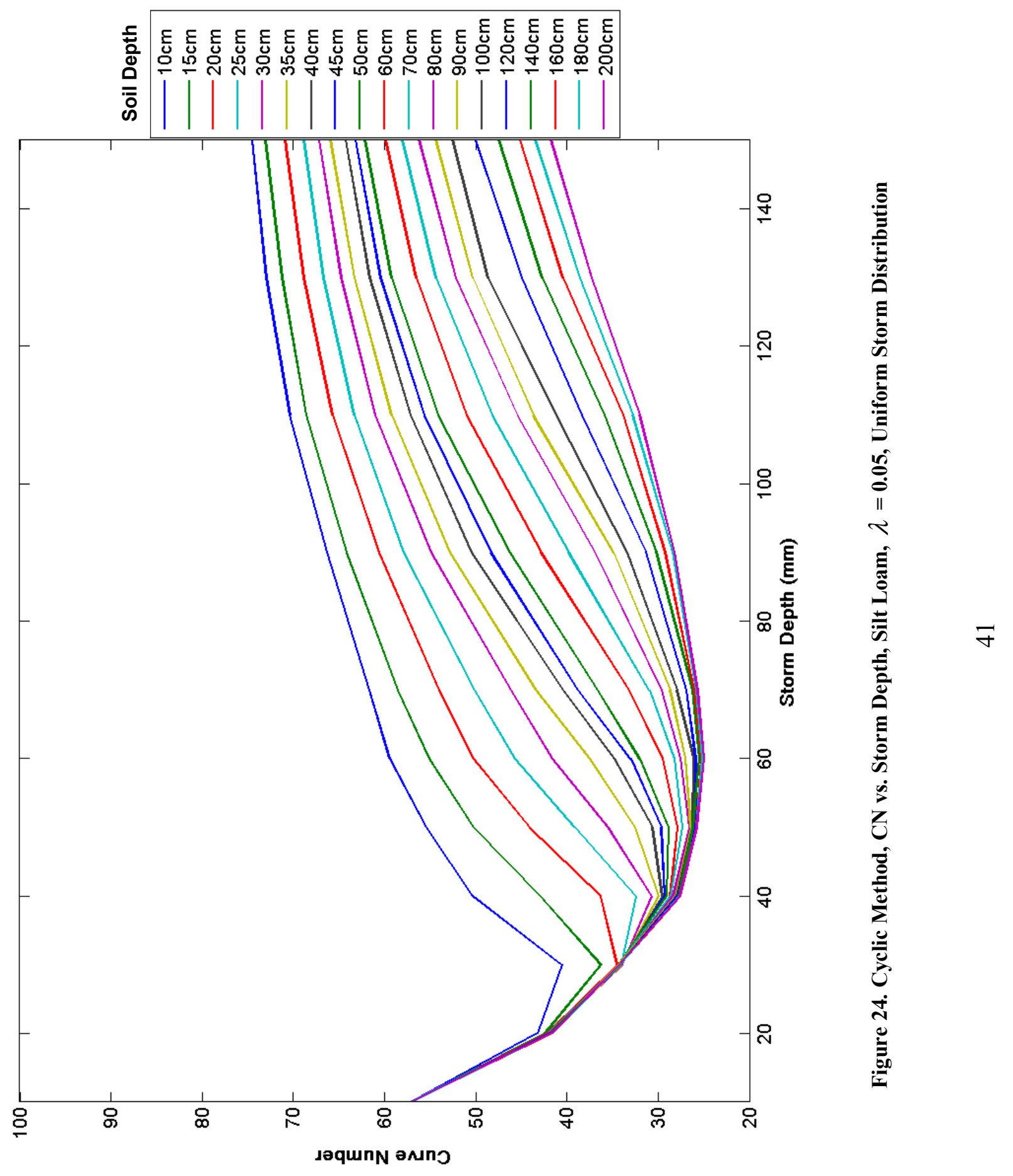




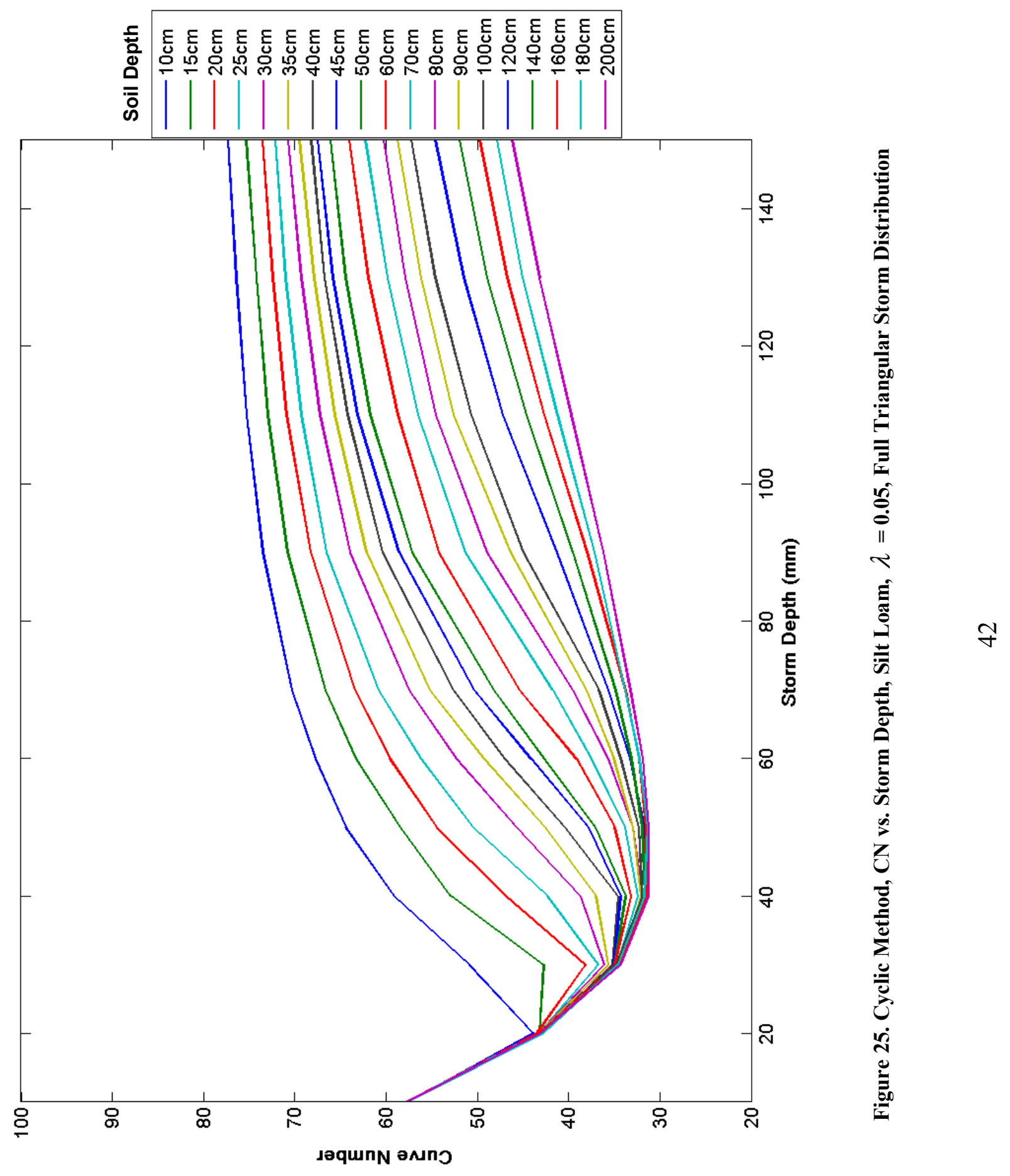




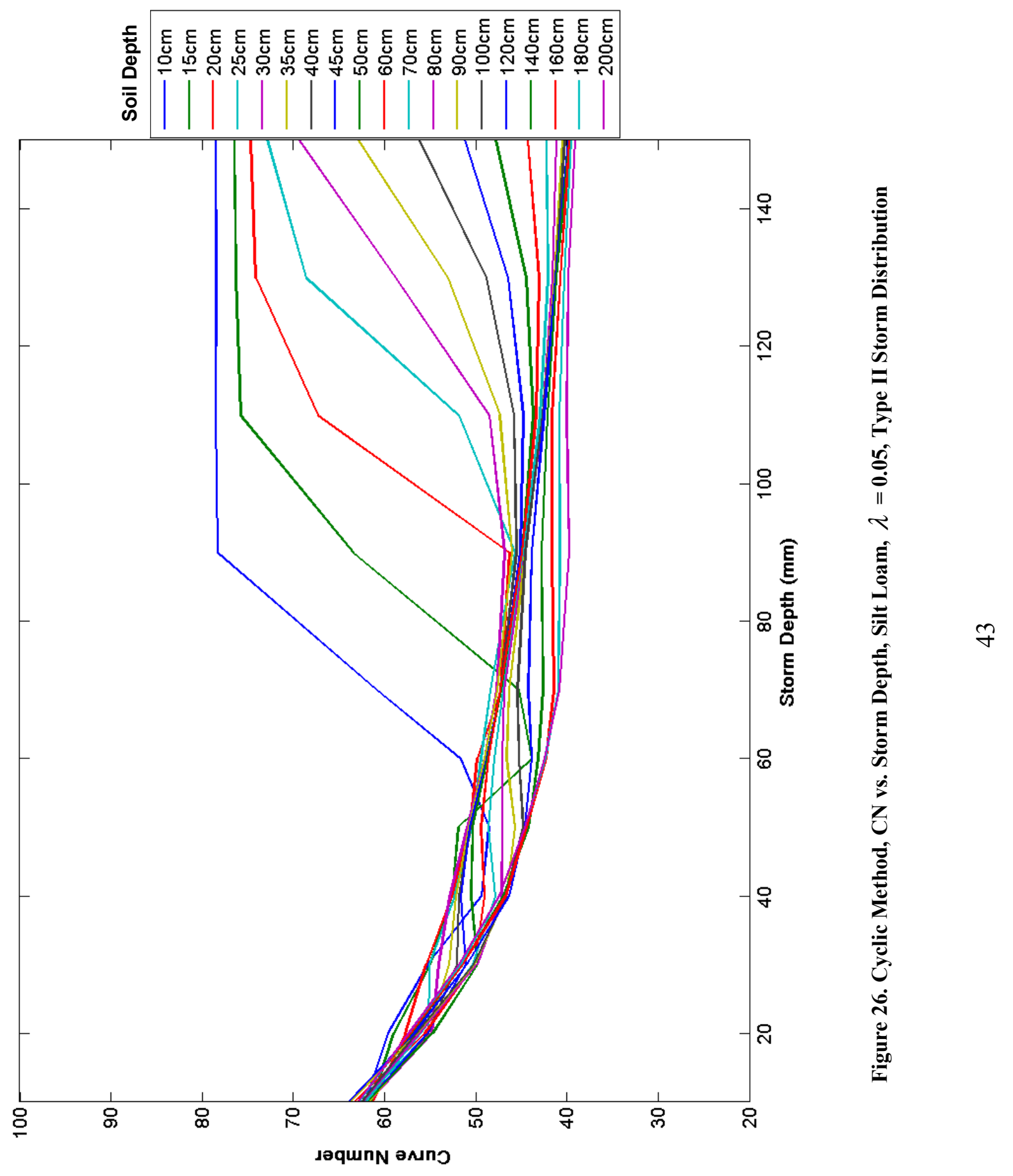




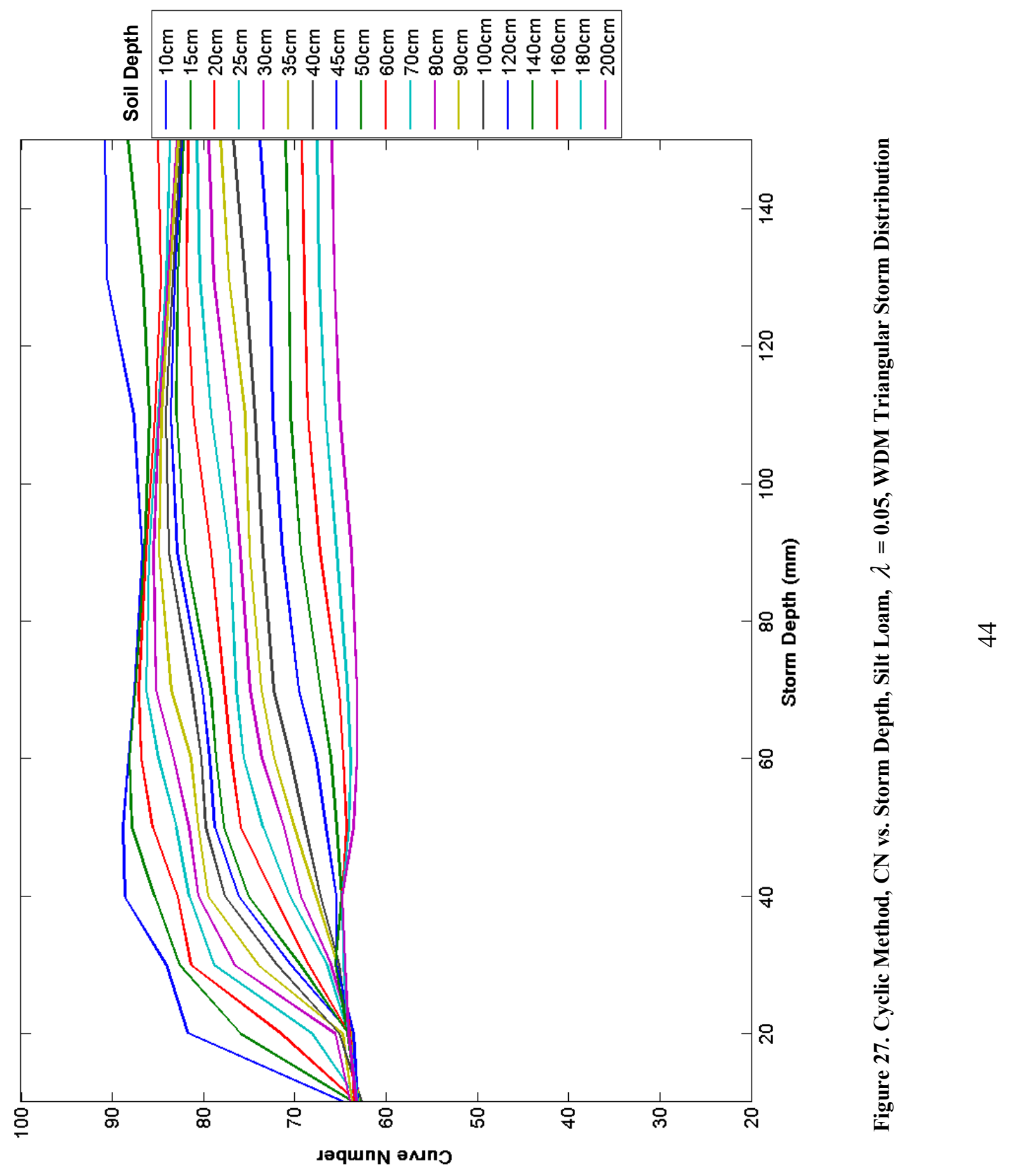


The WDM Triangular distribution results in the highest overall $\mathrm{CN}$ values, as shown in Figures 15, 19, 23, and 27. This can be explained by the fact that the total twenty-four hour rainfall depth in this distribution falls within an eight hour period, therefore providing less opportunity for infiltration. To illustrate this effect, the HSPF infiltration component was accumulated from the beginning of the storm event to the beginning of the next storm event and averaged over the range of storm depths for each soil depth. The results for each storm distribution for the Clay Loam soil are shown in Figure 28. The WDM Triangular distribution results in the least amount of infiltration, therefore producing the highest $\mathrm{CN}$ values.
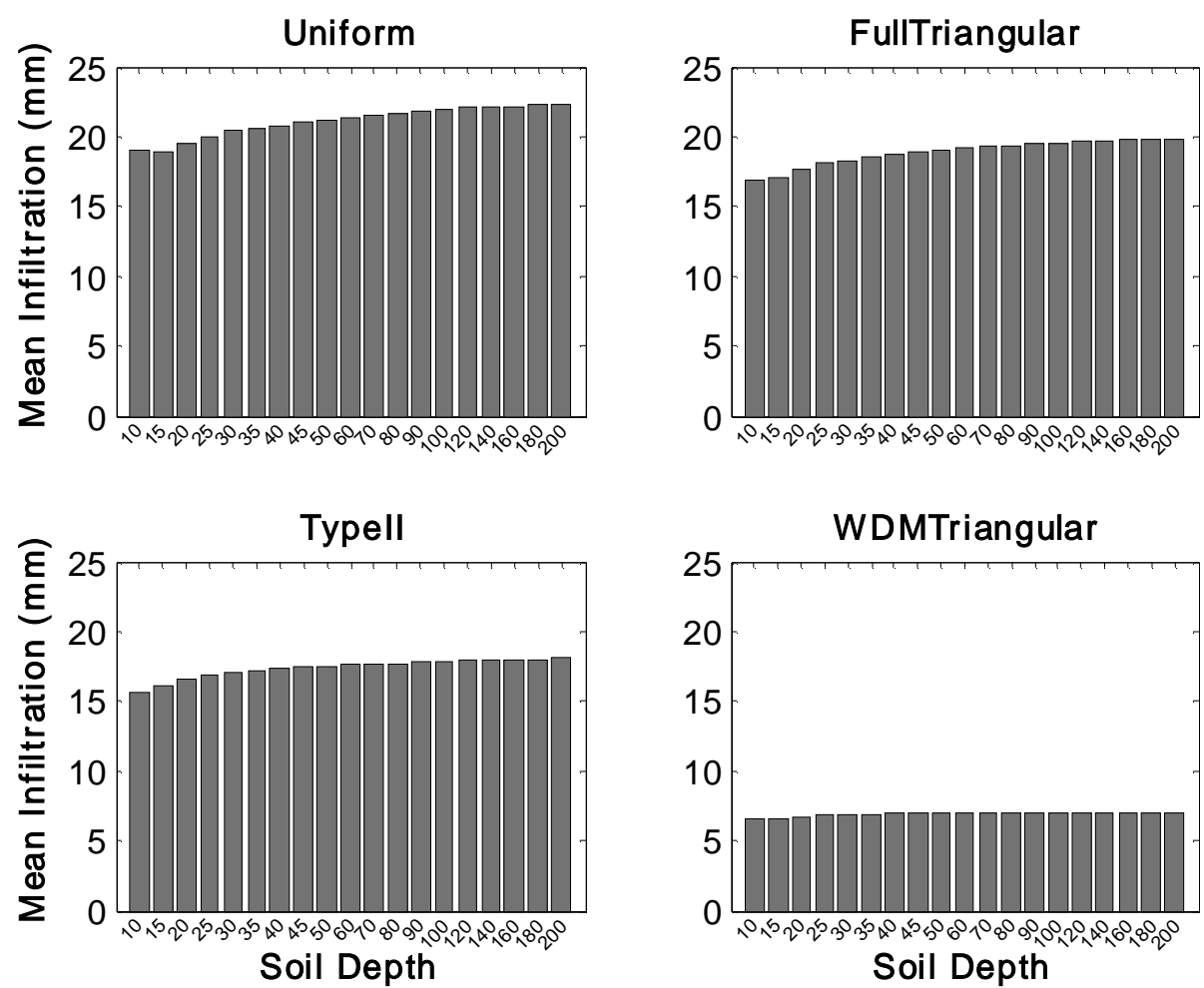

Figure 28. Cyclic Method Mean Infiltration vs. Soil Depth, Clay Loam

Finally, by comparing Figures 12-19 to Figures 20-27, it is apparent that the initial abstraction ratio $(\lambda)$ value of 0.05 versus 0.2 reduces the CN's calculated at low storm depths. This makes sense physically; since the storm and runoff depths are the same for each soil depth, and less initial abstraction (corresponding to a lower $\lambda$ value) results in a greater loss to the soil, producing a lower $\mathrm{CN}$ value. As the storm depth 
increases, the initial abstraction becomes a smaller percentage of the rainfall and its effect on the $\mathrm{CN}$ diminishes.

The results of the Cyclic Method indicate that the storm distributions consisting of high intensity hourly events (Type II and WDM Triangular) produce more irregular variation of the $\mathrm{CN}$ with storm depth (for example, see Figures 12-15). The curves of the lesser soil depths tend to describe a violent behavior, trending toward standard behavior as soil depth increases (Figures 12-25). Finally, the WDM Triangular distribution resulted in the lowest infiltration depth and therefore the highest $\mathrm{CN}$ values (Figures 15, 19, 23, 27, and 28). These findings can be compared to those of the Asymptotic Method that follows.

\subsection{Asymptotic Method}

The Asymptotic Method was applied to the same range of soil types and soil depths as the Cyclic method. The CN's calculated from the ranked rainfall-runoff pairs were plotted against rainfall for each soil depth. The equation that resulted in the highest $\mathrm{R}$-squared value (violent, equation 15 , or standard, equation 16) was fit to the data by minimizing the least-squared error using a Matlab (Mathworks, Inc.) optimization function (Lagarias, 1998). Figure 29 is an example fit of the equation for violent behavior for Clay Loam at a $20 \mathrm{~cm}$ soil depth with a simulation using data from the Terra Alta gage. 


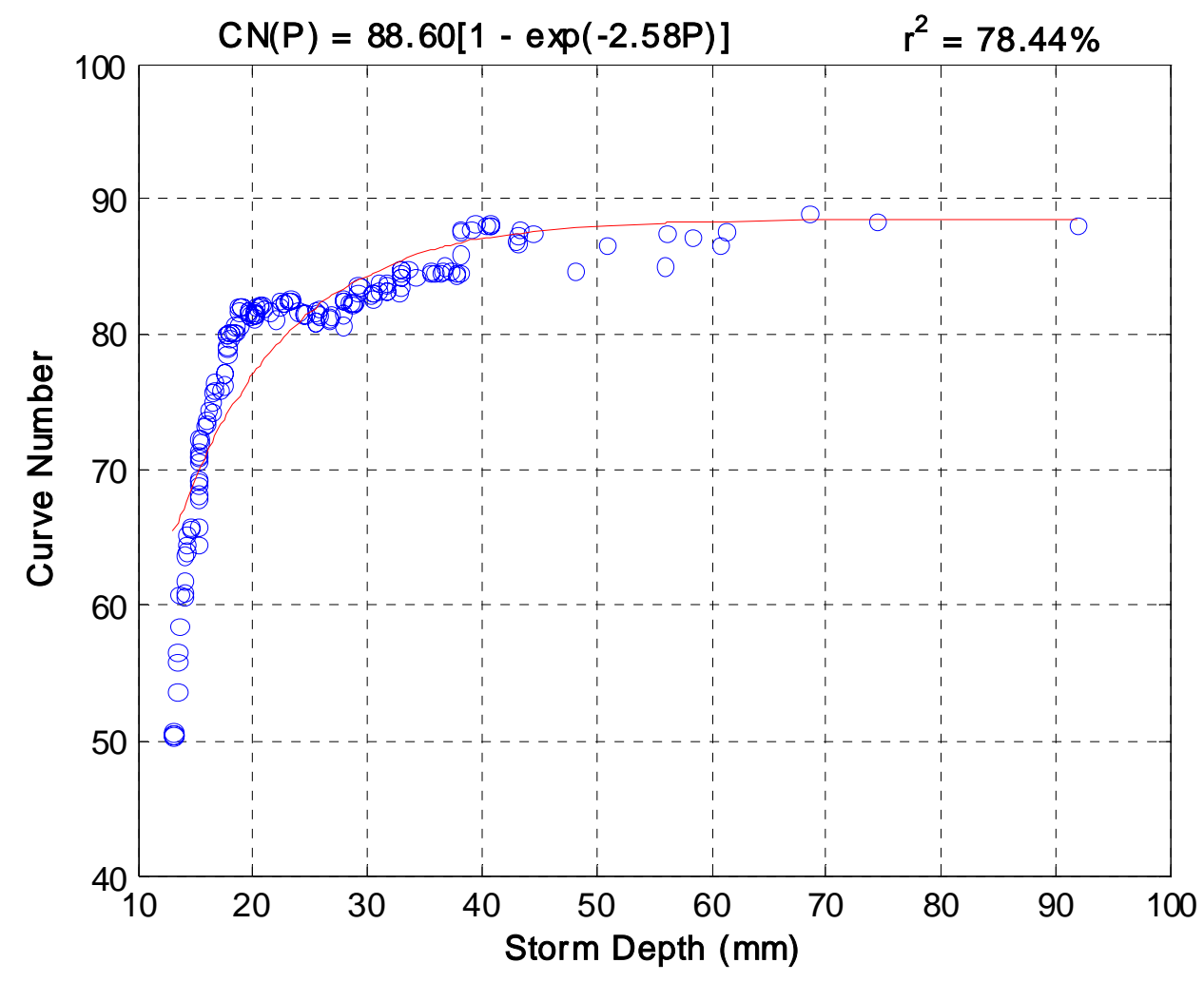

Figure 29. Violent Curve Fit, Clay Loam, $20 \mathrm{~cm}$, Terra Alta gage, $\lambda=0.05$

In this case the abrupt rise in $\mathrm{CN}$, characteristic of the so-called violent behavior is obvious and equation 17 fits the data reasonably well $\left(R^{2}=78.44 \%\right)$.

$$
C N(P)=88.60[1-\exp (-2.58 P)]
$$

This process was repeated for each soil depth and gaging station and the resulting curves were plotted on the same axes. Certain soil depths appeared to exhibit complacent behavior at low storm depths followed by violent behavior. In these instances the complacent behavior was ignored and only the violent points were used to fit Equation 16. Figures 30 to 45 show the results for the Clay Loam and Silt Loam soils with initial abstraction ratio values of 0.05 and 0.2 . Figures 30-33 are plots of the Clay Loam soil with $\lambda=0.2$. Figures 34-37 are plots of the Silt Loam soil with $\lambda=0.2$. Figures 38-41 are plots of the Clay Loam soil with $\lambda=0.05$, and Figures $42-45$ are plots of the Silt Loam soil with $\lambda=0.05$.

The fits with $R^{2}$ values less than $50 \%$ are shown as dotted lines. Tables 4 and 5 show the corresponding $C N_{\infty}$ values, fitting constants, and $R^{2}$ values for each curve fit. 
The type of fit is indicated with the letters 's' or 'v' (Equations 15 or 16, respectively), and the entries with $R^{2}$ values less than 50\% are shown in red. 


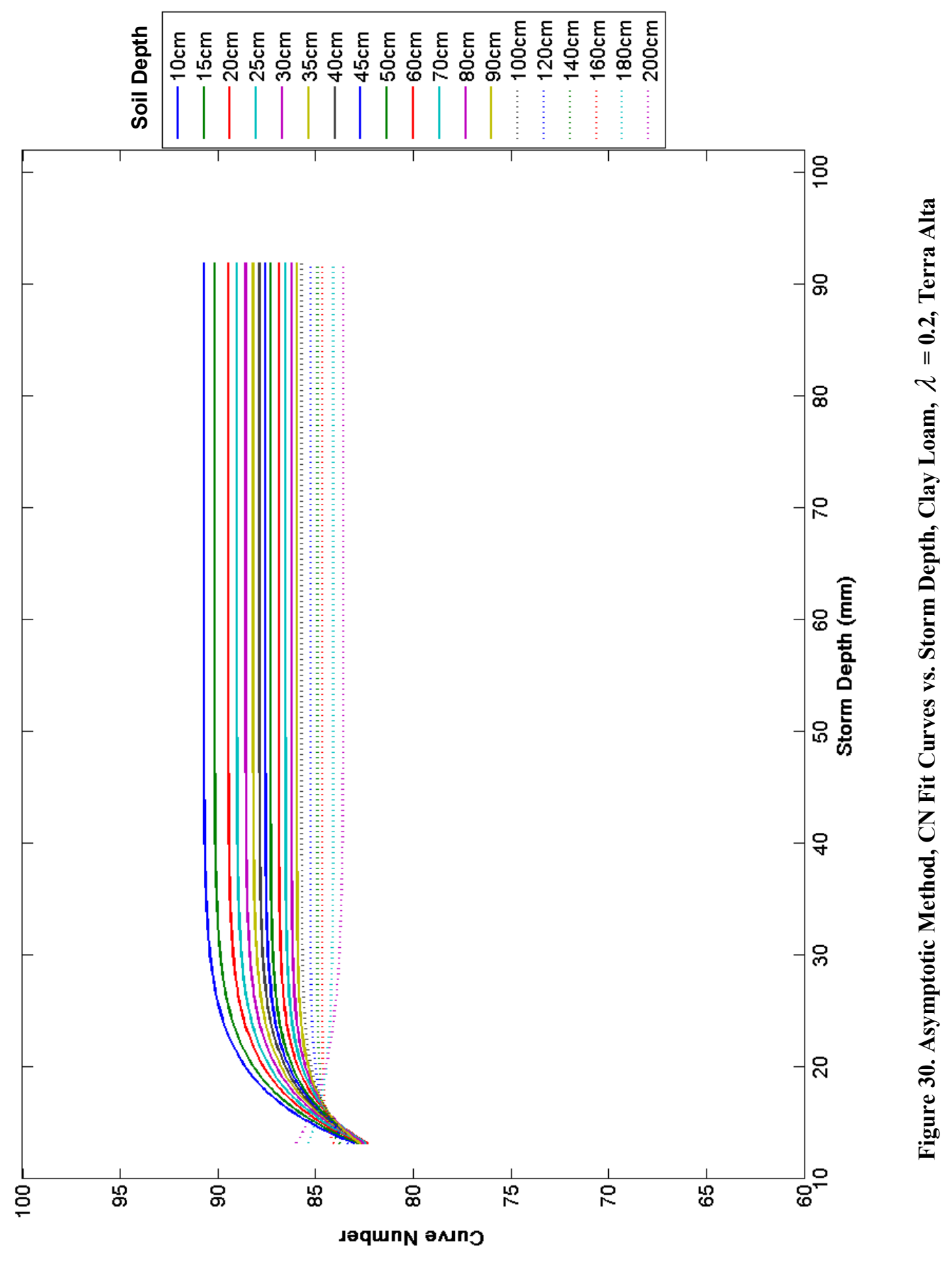




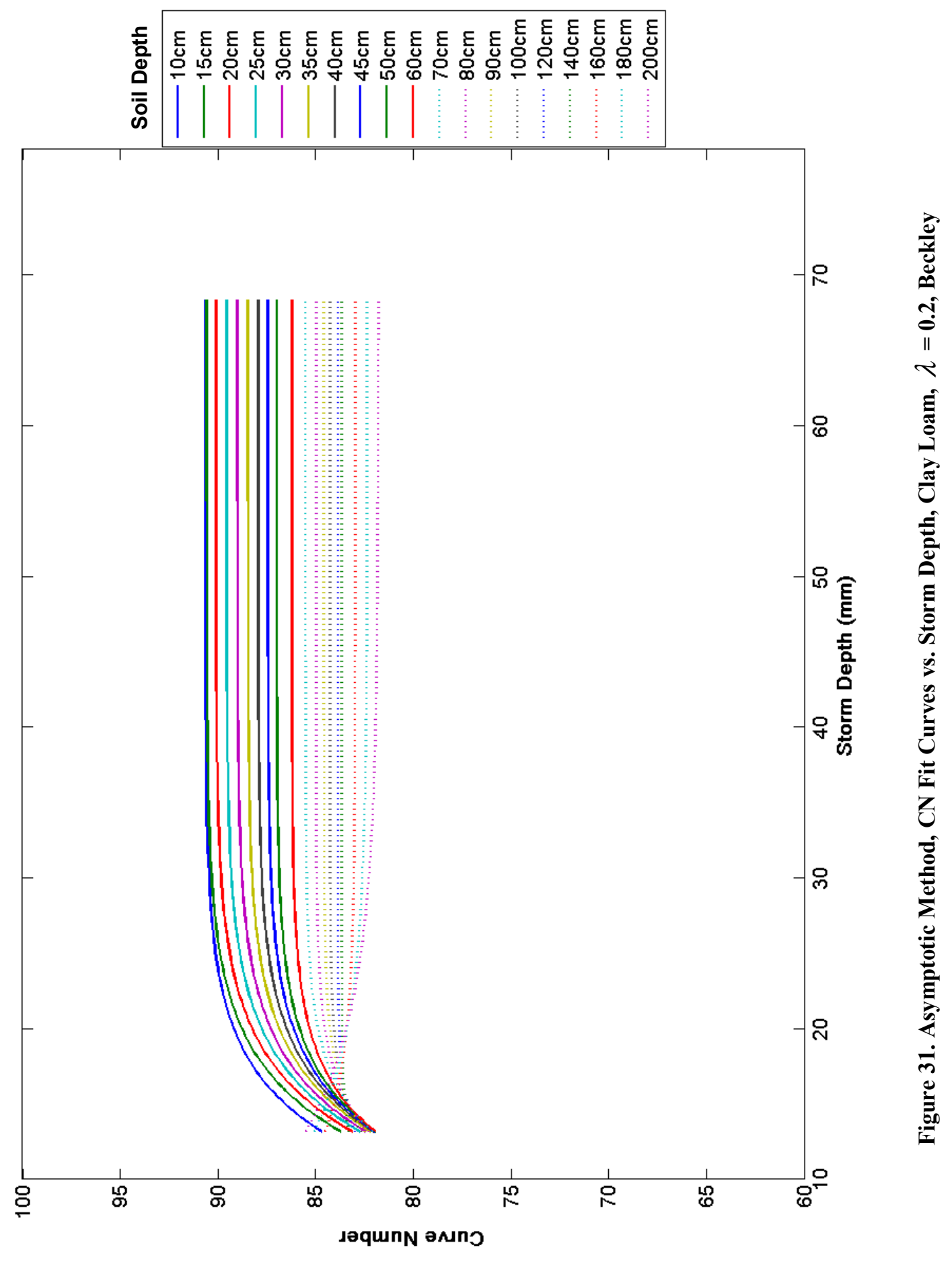




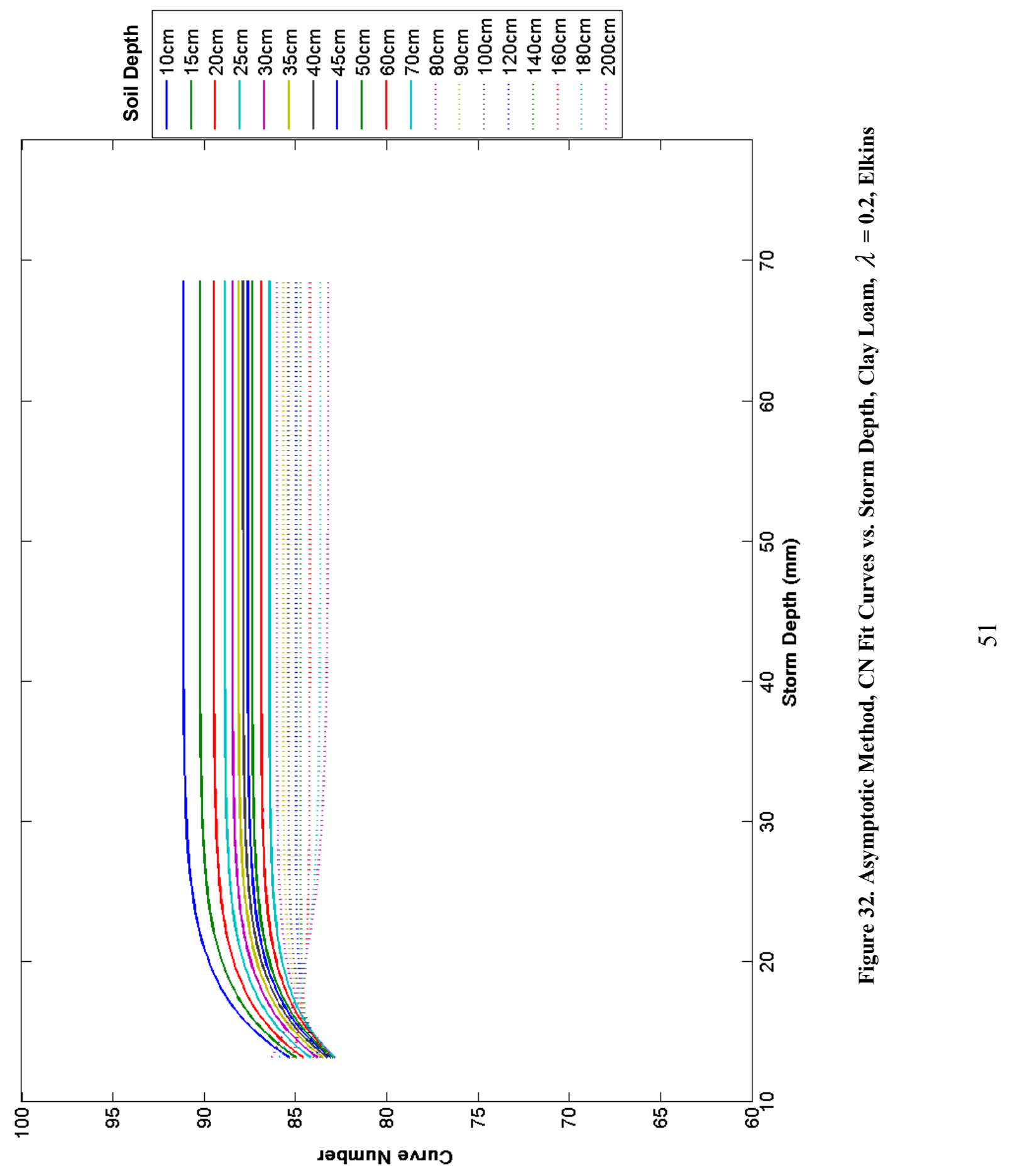




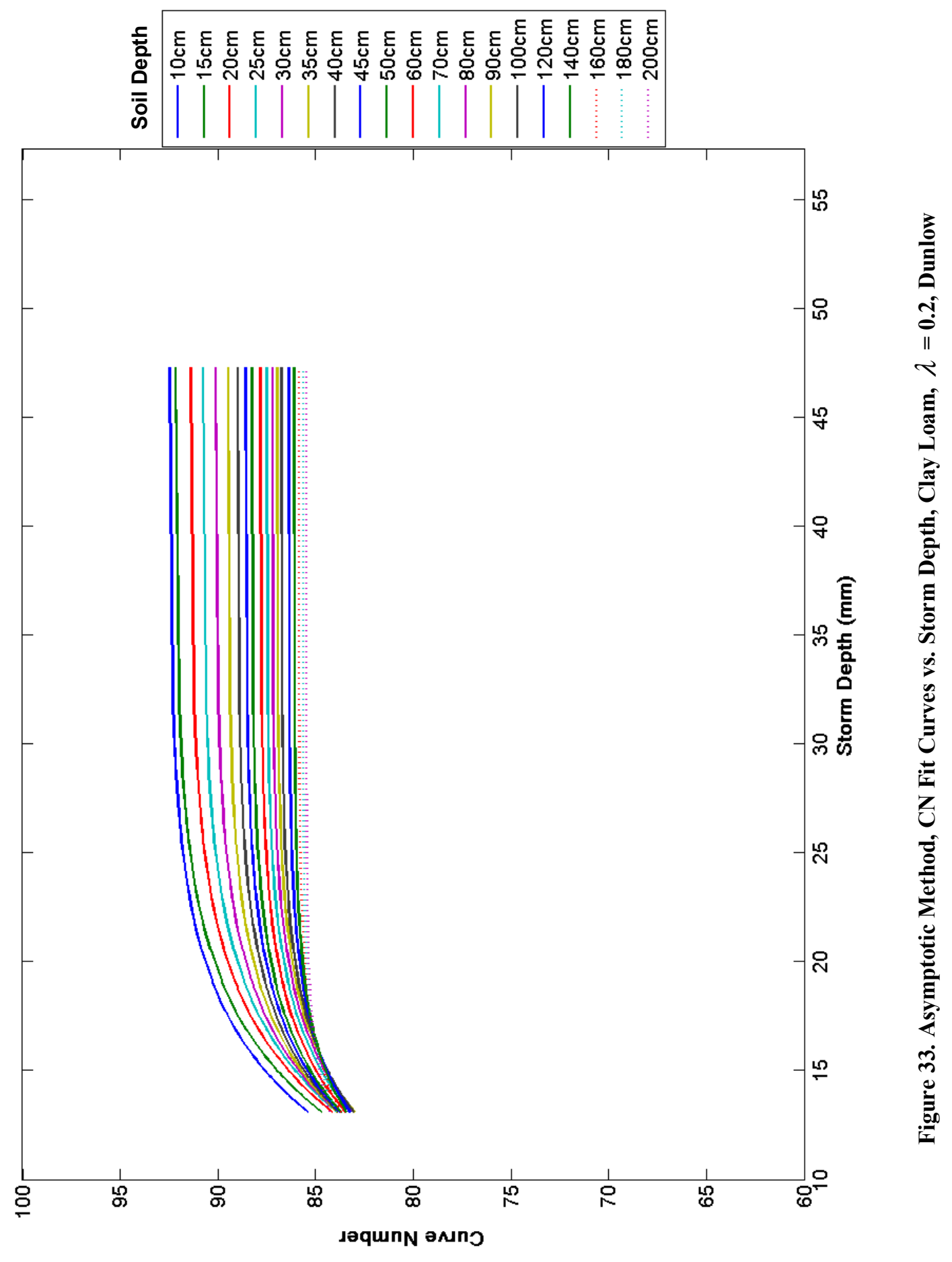




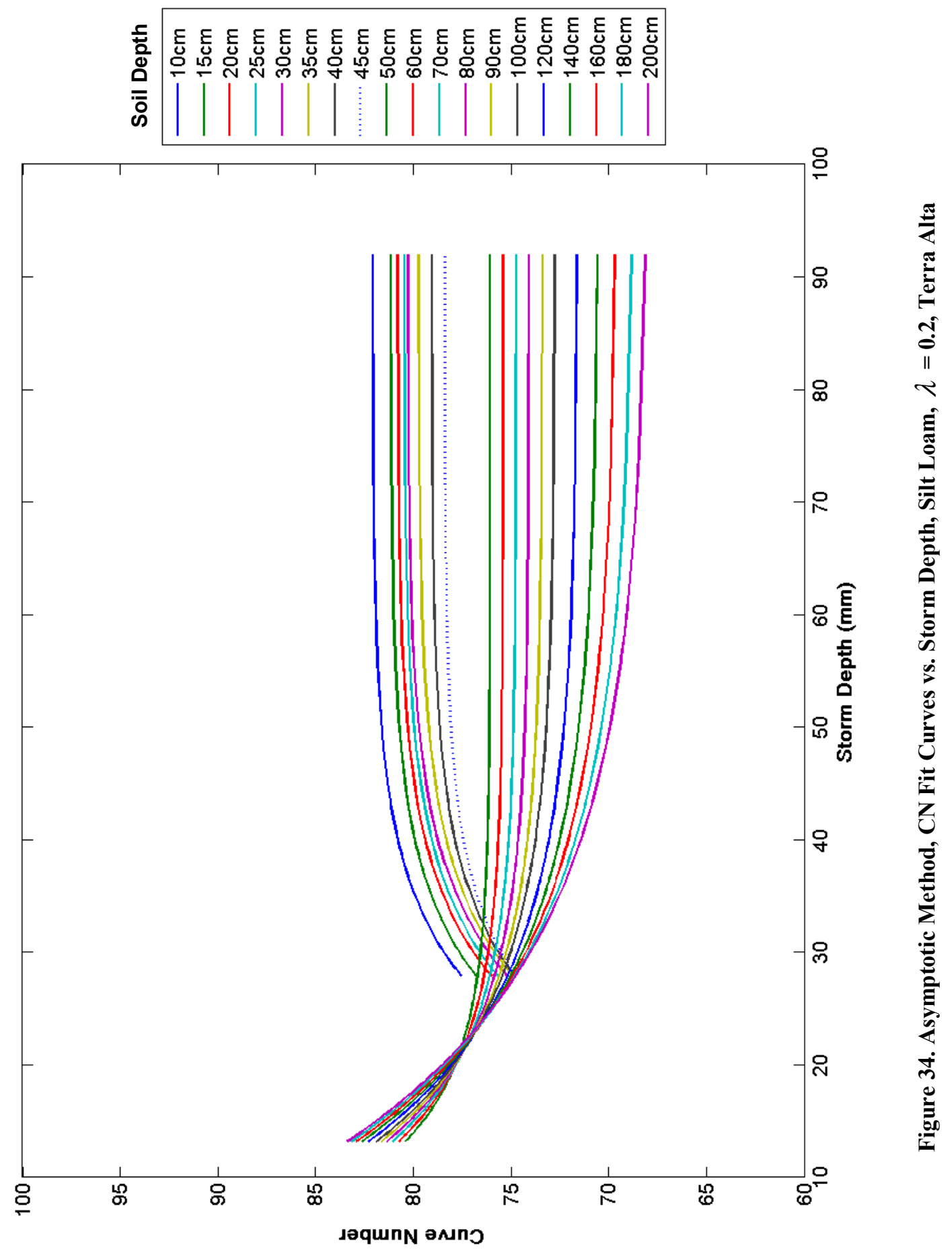




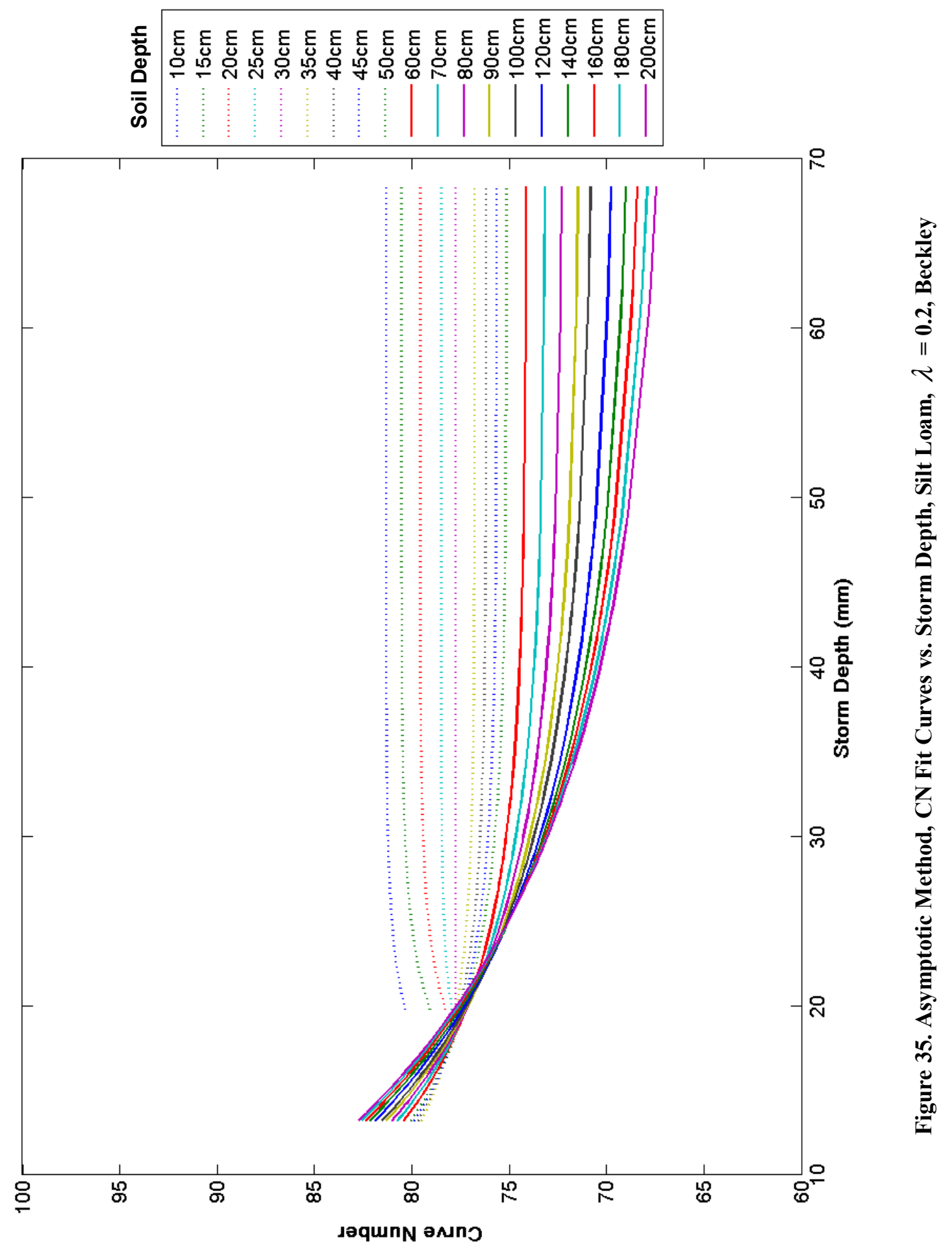




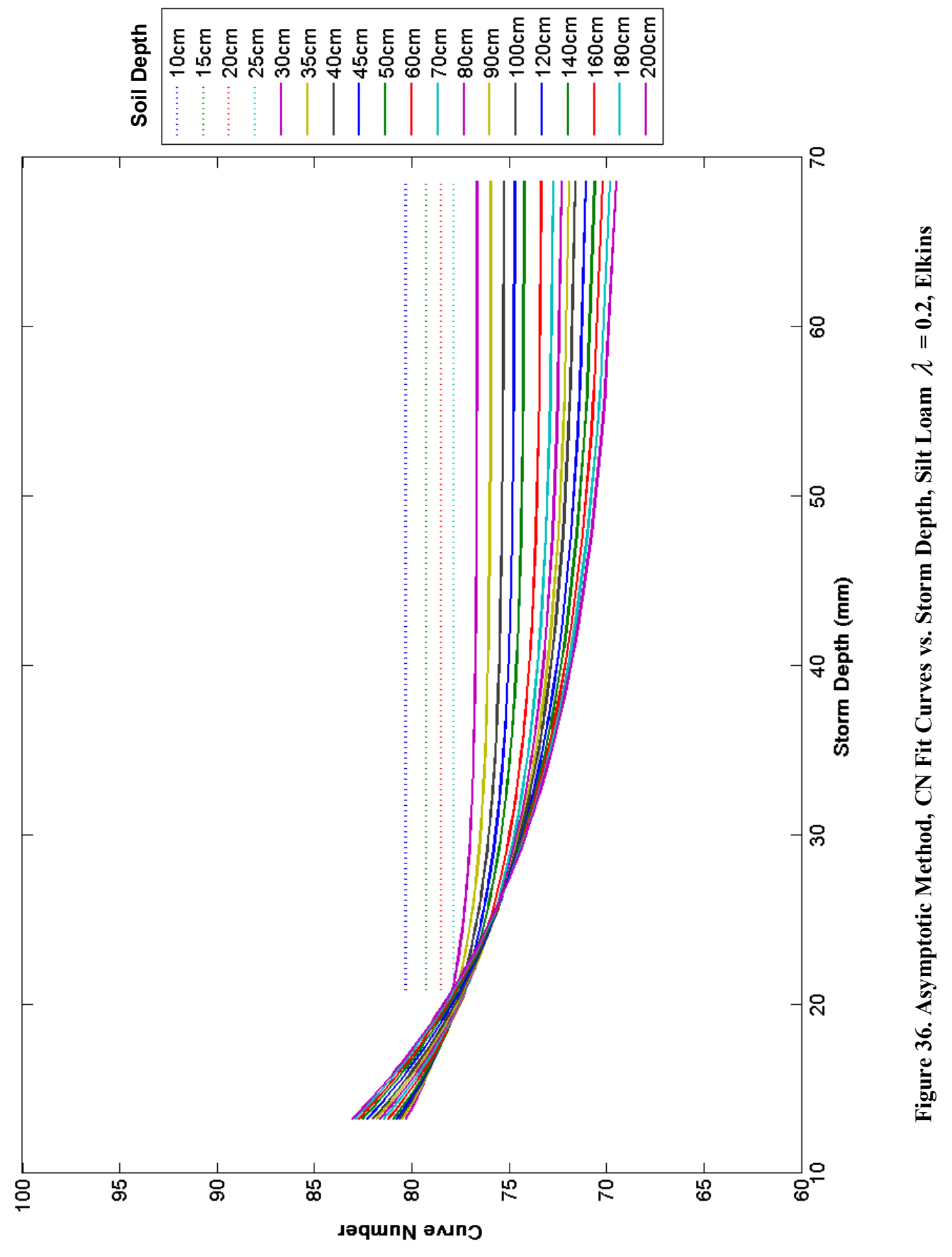




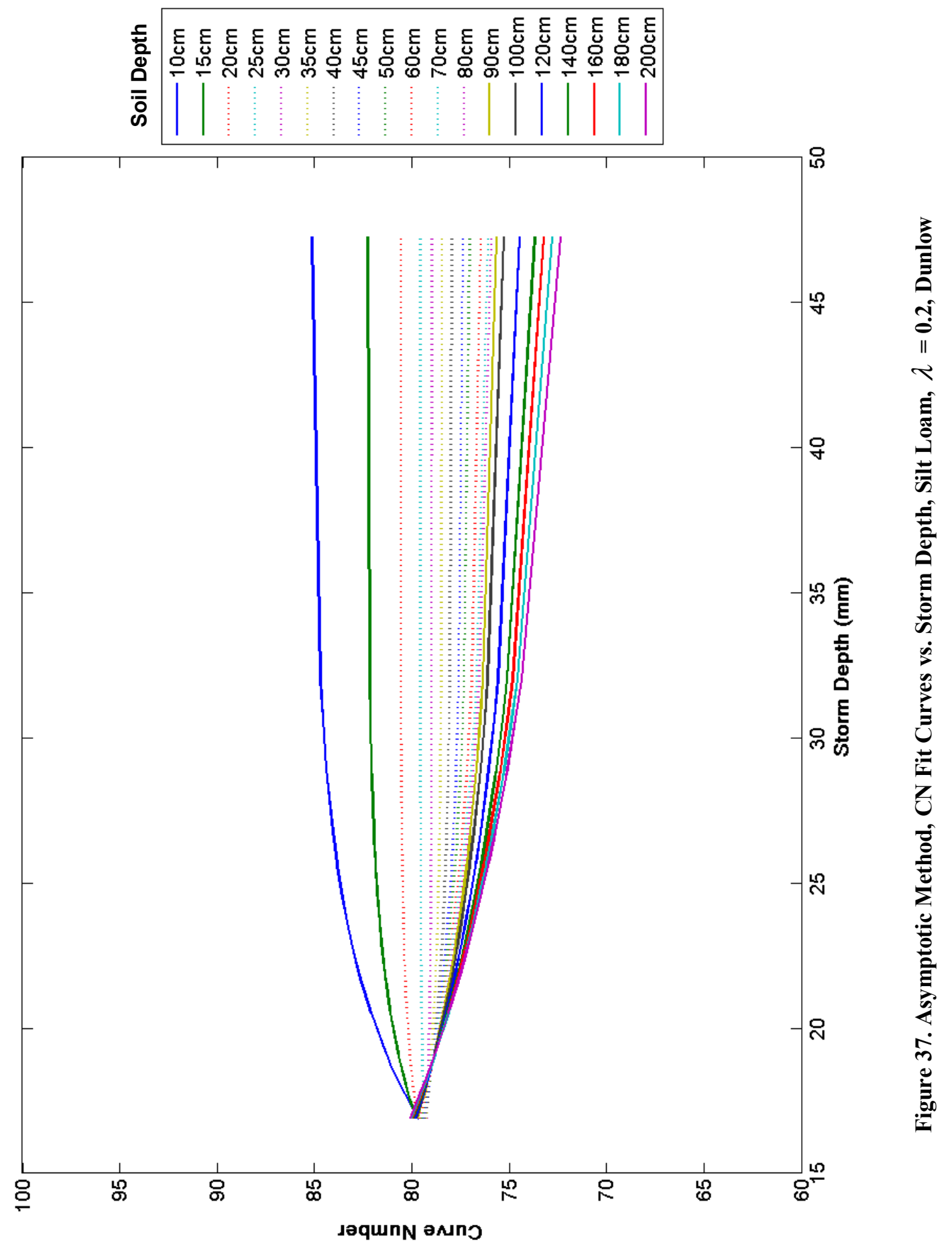




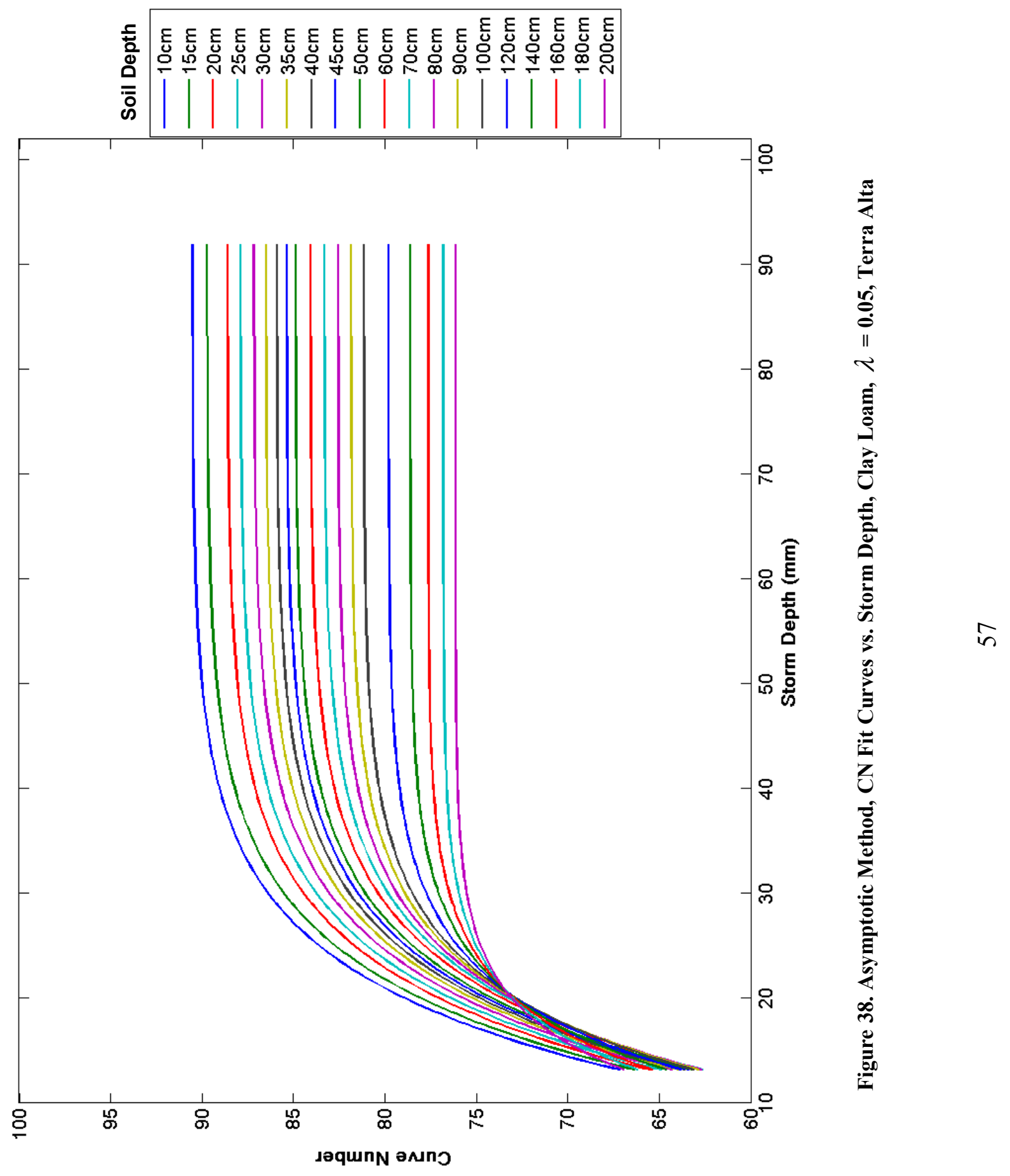




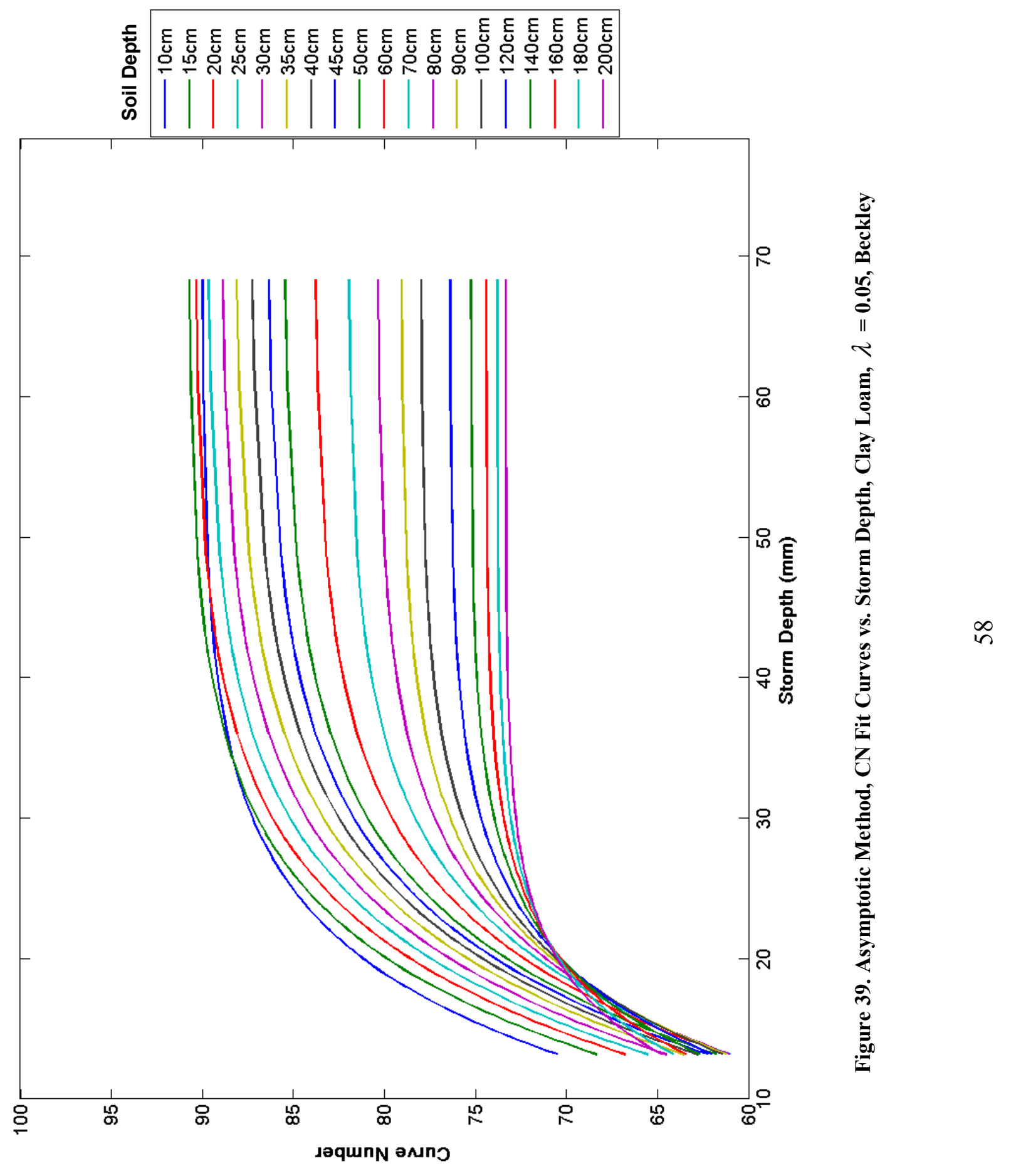




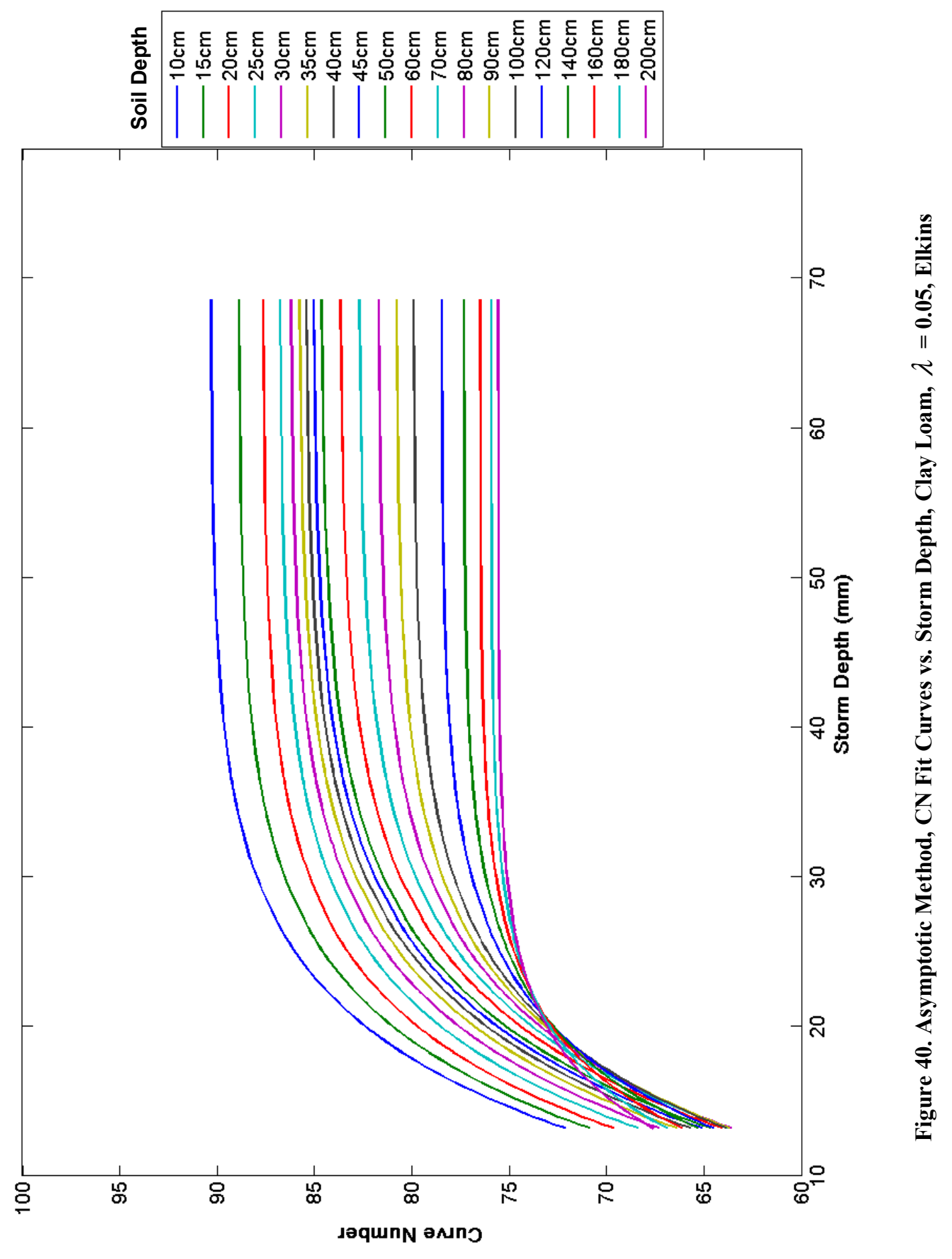




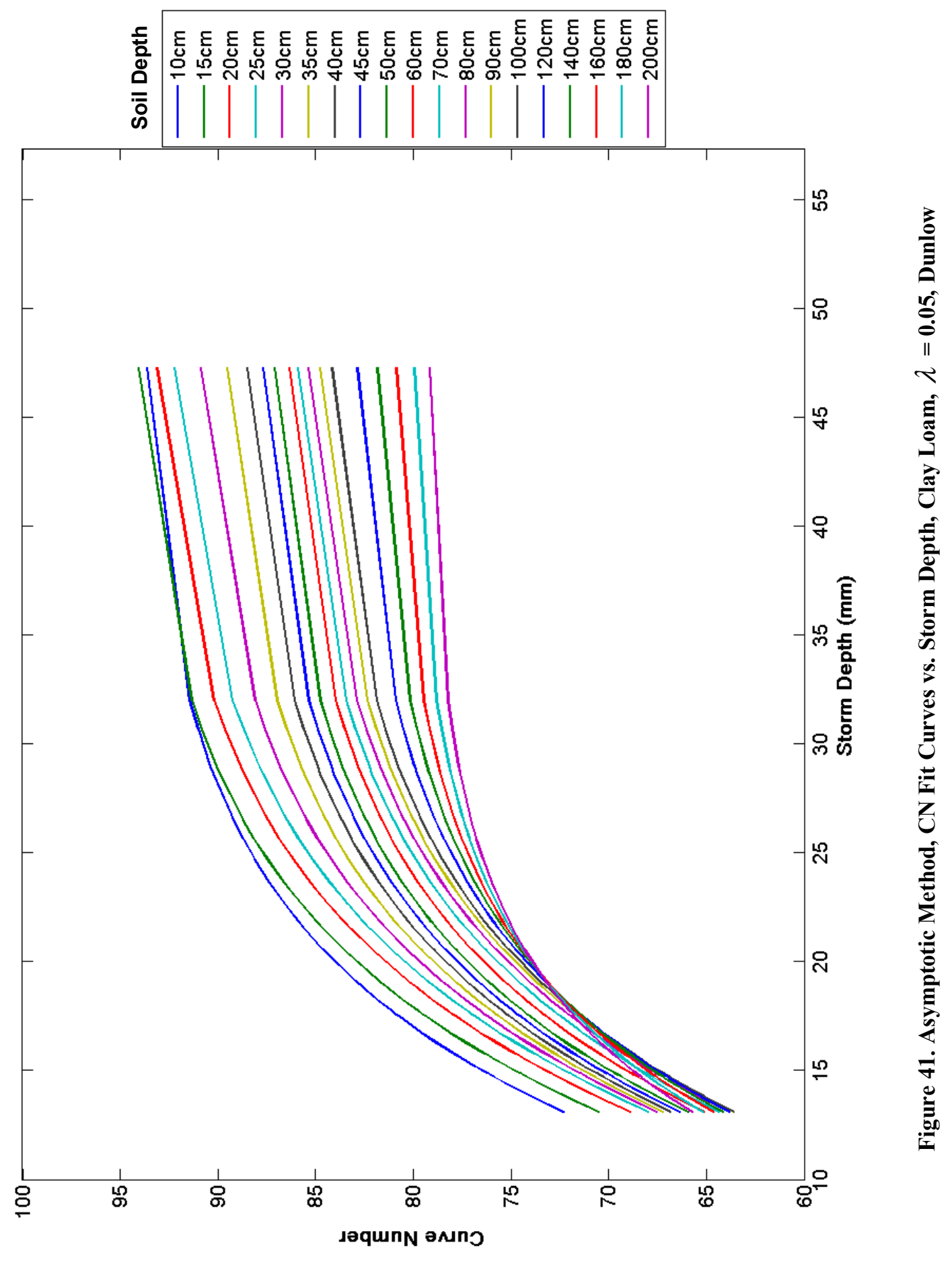




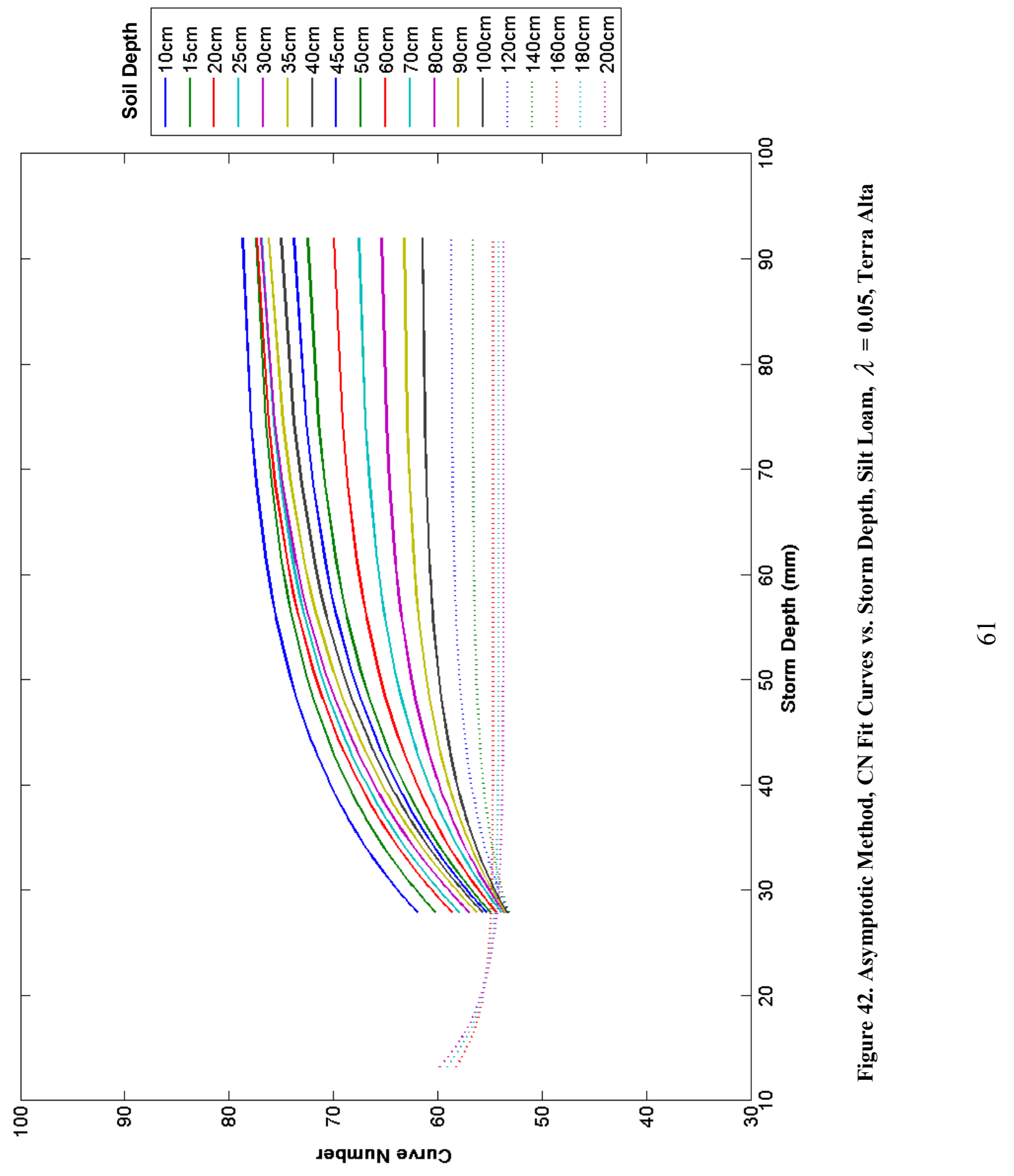




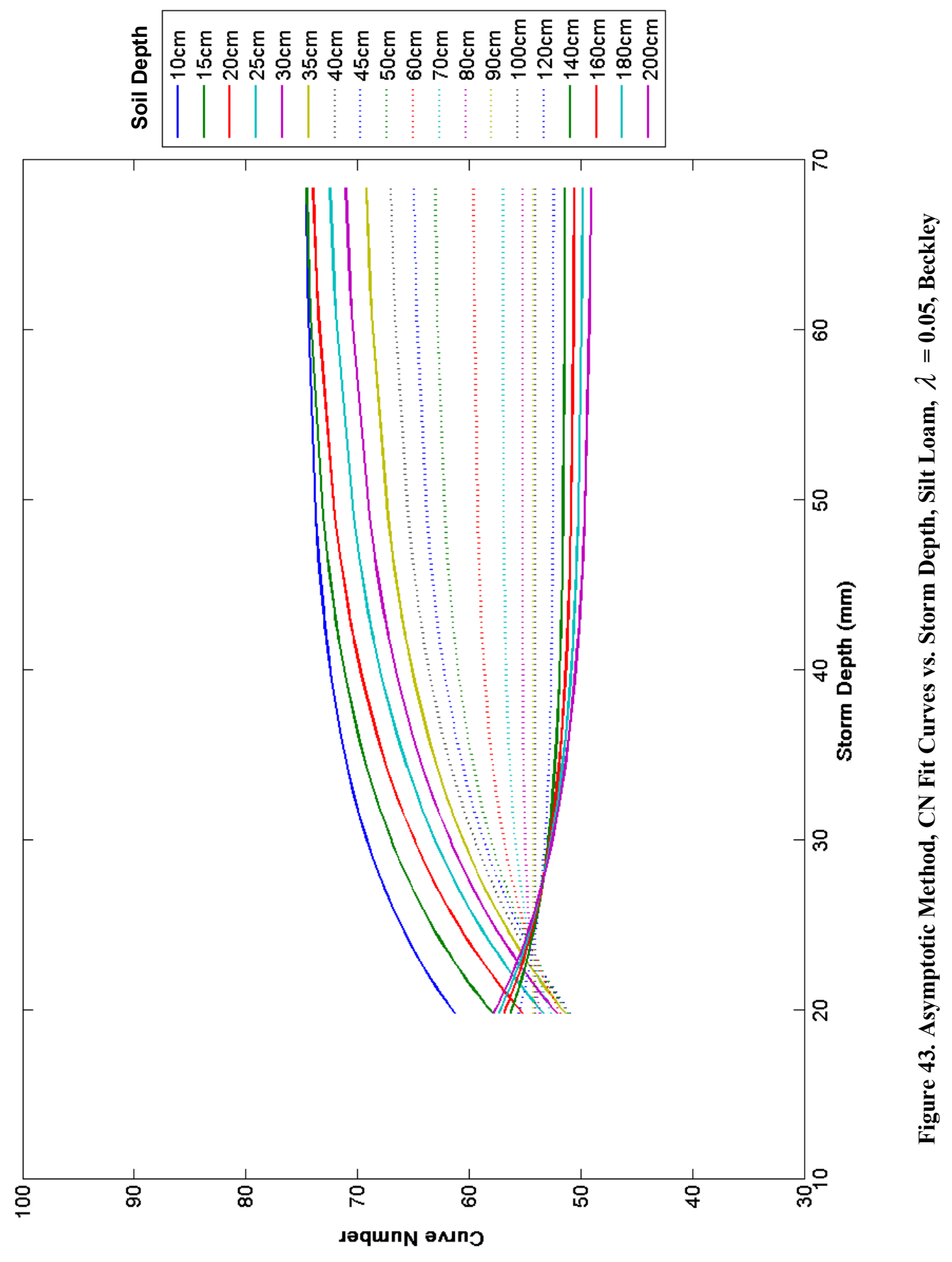




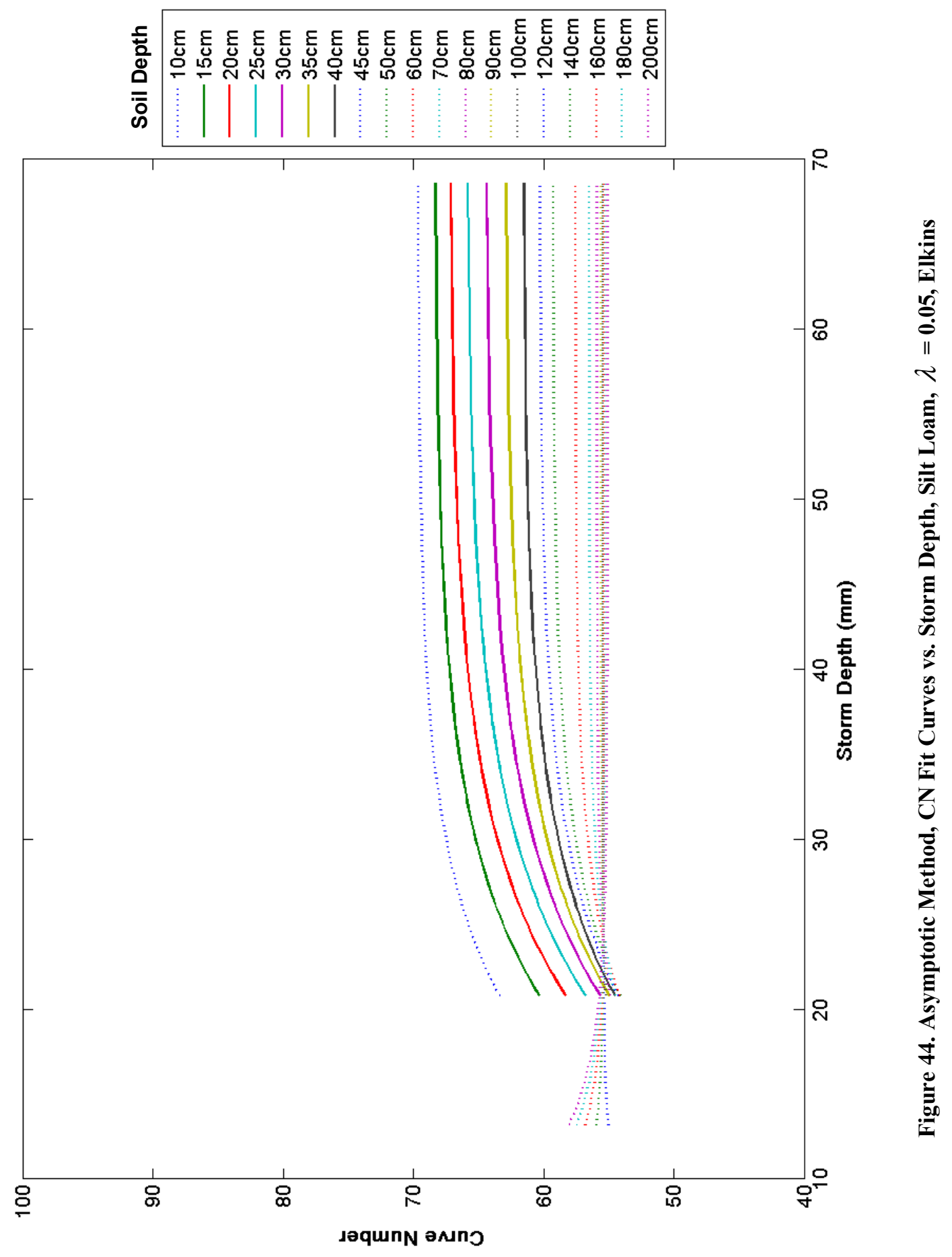




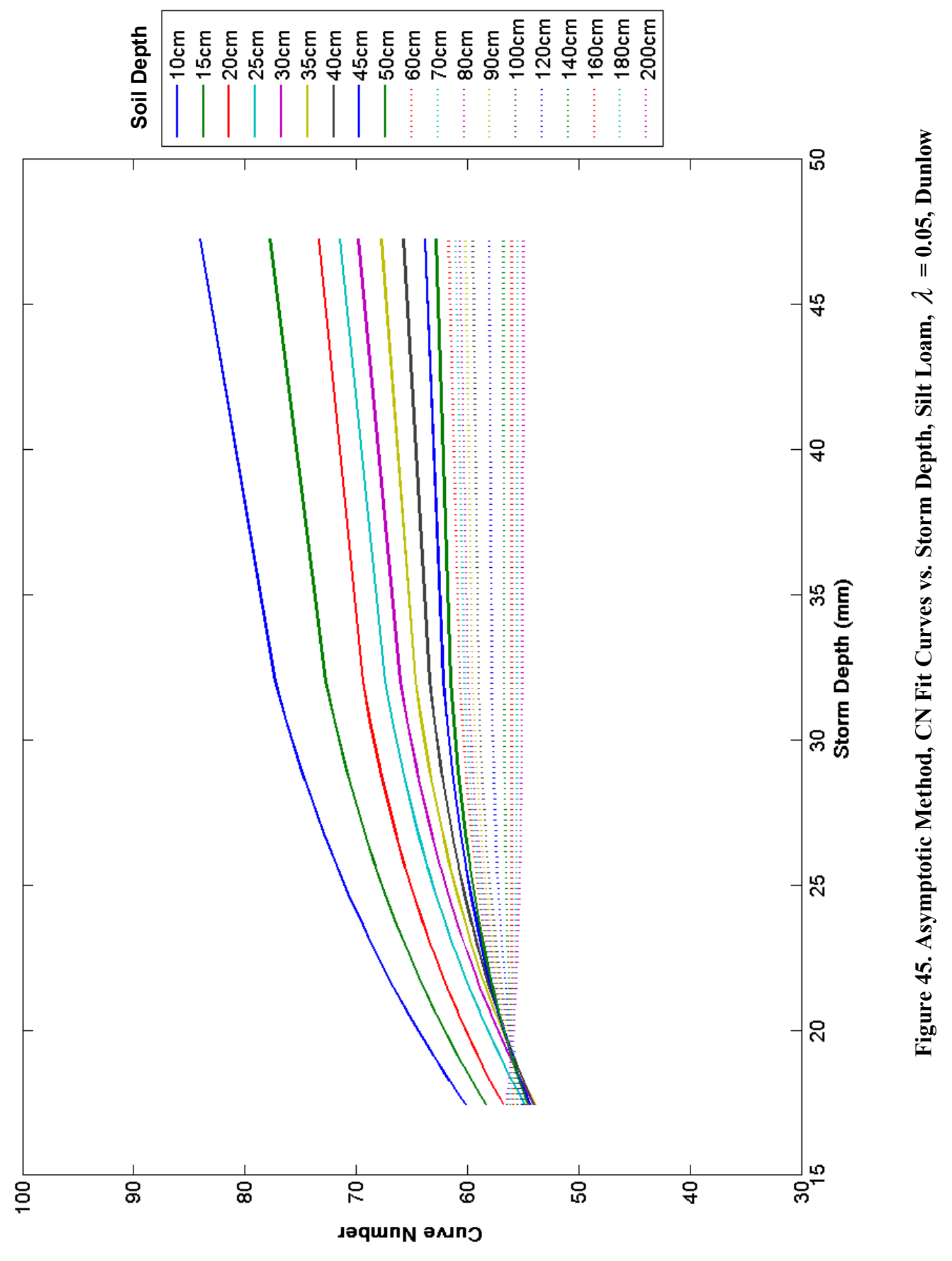


Table 4. Asymptotic Method Curve Fits, $\lambda=0.2$ ('s' = standard, Eqn. 15; 'v' = violent, Eqn. 16)

\begin{tabular}{|c|c|c|c|c|c|c|c|c|c|c|c|c|}
\hline \multirow[b]{3}{*}{ Soil Depth (cm) } & \multicolumn{6}{|c|}{ Terra Alta (163 storms) } & \multicolumn{6}{|c|}{ Beckley (133 storms) } \\
\hline & \multicolumn{3}{|c|}{ Clay Loam } & \multicolumn{3}{|c|}{ Silt Loam } & \multicolumn{3}{|c|}{ Clay Loam } & \multicolumn{3}{|c|}{ Silt Loam } \\
\hline & $C N_{\infty}$ & $k$ & $R^{2}$ & $C N_{\infty}$ & $k$ & $R^{2}$ & $C N_{\infty}$ & $k$ & $R^{2}$ & $C N_{\infty}$ & $k$ & $R^{2}$ \\
\hline 10 & 90.71 & 4.75 & $0.82 \mathrm{v}$ & 82.04 & 2.65 & $0.71 \mathrm{v}$ & 90.63 & 5.24 & $0.71 \mathrm{v}$ & 81.32 & 5.66 & $0.03 \mathrm{v}$ \\
\hline 15 & 90.17 & 4.82 & $0.82 v$ & 81.13 & 2.66 & $0.57 \mathrm{v}$ & 90.56 & 4.97 & $0.82 \mathrm{v}$ & 80.52 & 5.14 & $0.05 \mathrm{v}$ \\
\hline 20 & 89.46 & 4.94 & $0.81 \mathrm{v}$ & 80.76 & 2.58 & $0.55 \mathrm{v}$ & 90.09 & 4.92 & $0.87 \mathrm{v}$ & 79.57 & 5.28 & $0.03 \mathrm{v}$ \\
\hline 25 & 89.02 & 5.02 & $0.80 \mathrm{v}$ & 80.44 & 2.57 & $0.57 \mathrm{v}$ & 89.55 & 4.95 & $0.89 \mid \mathrm{v}$ & 78.49 & 6.35 & $0.00 \mathrm{v}$ \\
\hline 30 & 88.57 & 5.12 & $0.78 \mathrm{v}$ & 80.26 & 2.52 & $0.61 \mathrm{v}$ & 88.99 & 5.01 & $0.88 \mathrm{v}$ & 77.73 & 44.86 & $0.00 \mathrm{v}$ \\
\hline 35 & 88.18 & \begin{tabular}{|l|l|}
5.22 \\
\end{tabular} & $0.75 \mathrm{v}$ & 79.69 & 2.57 & $0.63 \mathrm{v}$ & 88.45 & 5.09 & $0.84 \mathrm{v}$ & 76.77 & 4.13 & $0.22 \mathrm{~s}$ \\
\hline 40 & 87.86 & 5.32 & $0.72 \mathrm{v}$ & 79.01 & 2.68 & $0.58 \mathrm{v}$ & 87.93 & 5.20 & $0.79 \mathrm{v}$ & 76.18 & 3.69 & $0.31 \mathrm{~s}$ \\
\hline 45 & 87.56 & 5.42 & $0.67 v$ & 78.33 & 2.83 & $0.48 \mathrm{v}$ & 87.43 & 5.33 & $0.75 \mathrm{v}$ & 75.63 & 3.37 & $0.40 \mathrm{~s}$ \\
\hline 50 & 87.30 & 5.52 & $0.63 v$ & 76.06 & 3.29 & $0.63 \mathrm{~s}$ & 86.97 & 5.47 & $0.69 \mathrm{v}$ & 75.11 & 3.12 & $0.49 \mathrm{~s}$ \\
\hline 60 & 86.87 & 5.68 & $0.59 v$ & 75.40 & 2.94 & $0.74 \mathrm{~s}$ & 86.20 & 5.78 & $0.58 \mathrm{v}$ & 74.10 & 2.72 & $0.66 \mathrm{~s}$ \\
\hline 70 & 86.53 & 5.85 & $0.57 v$ & 74.73 & 2.67 & $0.81 \mathrm{~s}$ & 85.51 & 6.19 & $0.43 \mathrm{v}$ & 3.12 & 2.43 & $81 \mathrm{~s}$ \\
\hline 80 & 86.22 & 6.07 & $0.56 \mathrm{v}$ & 74.08 & 2.45 & $0.87 \mathrm{~s}$ & 84.96 & 6.64 & $0.28 \mathrm{v}$ & 72.22 & 2.21 & $0.89 \mathrm{~s}$ \\
\hline 90 & 85.95 & 6.31 & $0.54 \mathrm{v}$ & 73.38 & 2.26 & $0.90 \mathrm{~s}$ & 84.56 & 7.12 & $0.18 \mathrm{v}$ & 1.33 & 2.03 & $92 \mathrm{~s}$ \\
\hline 100 & 85.70 & 6.58 & $0.48 \mathrm{~V}$ & 72.75 & 2.11 & $0.91 \mathrm{~s}$ & 84.25 & 7.64 & $0.10 \mathrm{v}$ & 70.64 & 1.91 & $.93 \mathrm{~s}$ \\
\hline 120 & 85.26 & 7.30 & $0.31 \mathrm{v}$ & 58 & 1.88 & $0.93 \mathrm{~s}$ & 83.86 & 8.83 & $03 \mathrm{v}$ & .48 & .73 & $92 s$ \\
\hline 140 & 84.91 & 8.29 & $0.13 \mathrm{v}$ & 70.51 & 1.71 & $0.94 \mathrm{~s}$ & 83.65 & 10.59 & $.01 \mathrm{~V}$ & 8.60 & 1.62 & $.91 \mathrm{~s}$ \\
\hline 160 & 84.66 & 9.65 & $0.04 \mathrm{~V}$ & 69.57 & 1.59 & $0.95 \mathrm{~s}$ & 82.96 & 4.65 & $0.04 \mathrm{~s}$ & 67.90 & 1.53 & $.90 \mathrm{~s}$ \\
\hline 180 & 84.09 & 4.81 & $0.05 \mathrm{~s}$ & 68.68 & 1.49 & $0.96 \mathrm{~s}$ & 82.35 & 3.60 & $0.13 \mathrm{~s}$ & 67.27 & 1.47 & $0.90 \mathrm{~s}$ \\
\hline 200 & 83.57 & 3.68 & $0.18 \mathrm{~s}$ & 90 & 1.41 & $0.96 \mathrm{~s}$ & 81.77 & 3.05 & $0.24 \mathrm{~s}$ & & 41 & $89 \mathrm{~s}$ \\
\hline & \multicolumn{6}{|c|}{ Elkins (137 storms) } & \multicolumn{6}{|c|}{ Dunlow (45 storms) } \\
\hline & \multicolumn{3}{|c|}{ Clay Loam } & \multicolumn{3}{|c|}{ Silt Loam } & \multicolumn{3}{|c|}{ Clay Loam } & \multicolumn{3}{|c|}{ Silt Loam } \\
\hline & $C N_{\infty}$ & $k$ & $R^{2}$ & $J_{\infty}$ & $k$ & $R^{2}$ & $C N_{\infty}$ & $k$ & $R^{2}$ & $C N_{\infty}$ & $k$ & $R^{2}$ \\
\hline 10 & 91.14 & 5.29 & $0.58 \mathrm{v}$ & 80.30 & 12.65 & $0.00 \mathrm{v}$ & 92.47 & 4.97 & $0.67 \mathrm{v}$ & 85.15 & 4.11 & $0.58 \mathrm{v}$ \\
\hline 15 & 90.23 & 5.46 & $0.61 \mathrm{v}$ & 79.25 & 12.70 & $0.00 \mathrm{v}$ & 92.18 & 4.86 & $0.79 \mathrm{v}$ & 82.27 & 5.24 & $0.50 \mathrm{v}$ \\
\hline 20 & 89.47 & 5.59 & $0.60 v$ & 78.49 & 14.66 & $0.00 \mathrm{v}$ & 91.39 & 4.91 & $0.80 \mathrm{v}$ & 80.56 & 6.84 & $0.06 \mathrm{v}$ \\
\hline 25 & 88.87 & 5.65 & $0.61 \mathrm{v}$ & 77.86 & 20.27 & $0.00 \mathrm{v}$ & 90.77 & 4.99 & $.83 \mathrm{v}$ & 79.55 & 8.89 & $0.00 \mathrm{v}$ \\
\hline 30 & 88.45 & 5.67 & $0.62 v$ & 76.64 & 3.57 & $0.55 \mathrm{~s}$ & 90.10 & 5.17 & $0.84 \mathrm{v}$ & 78.97 & 6.55 & $0.01 \mathrm{~s}$ \\
\hline 35 & 88.12 & 5.67 & $0.61 \mathrm{v}$ & \begin{tabular}{|l|}
75.92 \\
\end{tabular} & 3.21 & $0.68 \mathrm{~s}$ & 89.47 & 5.37 & $0.82 \mathrm{v}$ & \begin{tabular}{|l|}
78.44 \\
\end{tabular} & 4.89 & $0.06 \mathrm{~s}$ \\
\hline 40 & 87.86 & 5.67 & $0.61 \mathrm{v}$ & 75.27 & 2.94 & $0.75 \mathrm{~s}$ & 88.98 & 5.52 & $0.80 \mathrm{v}$ & 77.92 & 4.16 & $0.22 \mathrm{~s}$ \\
\hline 45 & 87.60 & 5.69 & $0.61 \mathrm{v}$ & 74.69 & 2.74 & $0.78 \mathrm{~s}$ & 88.57 & 5.64 & $0.79 \mathrm{v}$ & 77.33 & 3.58 & $0.39 \mathrm{~s}$ \\
\hline 50 & 87.36 & 5.73 & $0.59 \mathrm{v}$ & 74.18 & 2.58 & $0.83 \mathrm{~s}$ & 88.25 & 5.73 & \begin{tabular}{l|l}
$0.78 \mathrm{v}$ \\
\end{tabular} & 76.96 & 3.33 & $0.38 \mathrm{~s}$ \\
\hline 60 & 86.87 & 5.89 & $0.56 \mathrm{v}$ & 73.29 & 2.34 & $0.88 \mathrm{~s}$ & 87.81 & 5.81 & $0.76 \mathrm{v}$ & 76.37 & 2.99 & $0.30 \mathrm{~s}$ \\
\hline 70 & 86.42 & 6.11 & $0.53 \mathrm{v}$ & 72.66 & 2.19 & $0.91 \mathrm{~s}$ & 87.50 & 5.83 & \begin{tabular}{l|l}
0.82 & $v$
\end{tabular} & 75.94 & 2.78 & $0.26 \mathrm{~s}$ \\
\hline 80 & 86.01 & 6.39 & $0.48 \mathrm{v}$ & 72.20 & 2.08 & $0.93 \mathrm{~s}$ & 87.21 & 5.89 & $0.83 \mathrm{v}$ & 75.76 & 2.74 & $0.35 \mathrm{~s}$ \\
\hline 90 & 85.67 & 6.71 & $0.39 \mathrm{v}$ & 71.80 & 1.99 & $0.93 \mathrm{~s}$ & 86.96 & 5.98 & $0.84 \mathrm{v}$ & 75.45 & 2.64 & $0.50 \mathrm{~s}$ \\
\hline 100 & 85.38 & 7.09 & $0.30 \mathrm{v}$ & 71.44 & 1.91 & $0.92 \mathrm{~s}$ & 86.75 & 6.10 & $0.83 \mathrm{v}$ & 75.04 & 2.51 & $0.69 \mathrm{~s}$ \\
\hline 120 & 84.96 & 8.01 & $0.14 \mathrm{v}$ & 70.82 & 1.80 & $0.91 \mathrm{~s}$ & \begin{tabular}{|l|}
86.36 \\
\end{tabular} & \begin{tabular}{l|l}
6.42 \\
\end{tabular} & $0.71 \mathrm{v}$ & 74.09 & 2.27 & $0.89 \mathrm{~s}$ \\
\hline 140 & 84.71 & 9.23 & $0.04 \mathrm{v}$ & 70.30 & 1.71 & $0.92 \mathrm{~s}$ & 86.08 & 6.75 & $0.53 \mathrm{v}$ & 73.10 & 2.06 & $0.95 \mathrm{~s}$ \\
\hline 160 & 84.21 & 5.42 & $0.01 \mathrm{~s}$ & 69.82 & 1.63 & $0.91 \mathrm{~s}$ & 85.84 & 7.15 & $0.33 \mathrm{~V}$ & 72.48 & 1.96 & $0.95 \mathrm{~s}$ \\
\hline 180 & 83.62 & 3.83 & $0.10 \mathrm{~s}$ & 69.36 & 1.57 & $0.91 \mathrm{~s}$ & 85.64 & 7.65 & $0.18 \mathrm{v}$ & 71.90 & 1.87 & $0.97 \mathrm{~s}$ \\
\hline 200 & 83.19 & 3.26 & $0.19 \mathrm{~s}$ & 68.99 & 1.52 & $0.90 \mathrm{~s}$ & 85.46 & 8.28 & $0.10 \mathrm{~V}$ & 71.32 & 1.78 & $0.98 \mathrm{~s}$ \\
\hline
\end{tabular}


Table 5. Asymptotic Method Curve Fits, $\lambda=0.05$ ('s' = standard, Eqn. 15; 'v' = violent, Eqn. 16)

\begin{tabular}{|c|c|c|c|c|c|c|c|c|c|c|c|c|}
\hline \multirow[b]{3}{*}{ Soil Depth (cm) } & \multicolumn{6}{|c|}{ Terra Alta (163 storms) } & \multicolumn{6}{|c|}{ Beckley (133 storms) } \\
\hline & \multicolumn{3}{|c|}{ Clay Loam } & \multicolumn{3}{|c|}{ Silt Loam } & \multicolumn{3}{|c|}{ Clay Loam } & \multicolumn{3}{|c|}{ Silt Loam } \\
\hline & $C N_{\infty}$ & $k$ & $R^{2}$ & $C N_{\infty}$ & $k$ & $R^{2}$ & $C N_{\infty}$ & $k$ & $R^{2}$ & $C N_{\infty}$ & $k$ & $R^{2}$ \\
\hline 10 & 90.53 & 2.60 & $0.75 \mathrm{v}$ & 79.26 & 1.38 & $0.85 \mathrm{v}$ & 90.02 & 2.94 & $0.68 \mathrm{v}$ & 74.79 & 2.19 & $0.56 \mathrm{v}$ \\
\hline 15 & 89.73 & 2.58 & $0.77 \mathrm{v}$ & 78.08 & 1.34 & $0.79 \mathrm{v}$ & 90.77 & 2.69 & $0.78 \mathrm{v}$ & 74.98 & 1.89 & $0.67 \mathrm{v}$ \\
\hline 20 & 88.60 & 2.58 & $0.78 \mathrm{v}$ & 78.18 & 1.26 & $0.79 \mathrm{v}$ & 90.42 & 2.58 & $0.83 \mathrm{v}$ & 74.69 & 1.72 & $0.68 \mathrm{v}$ \\
\hline 25 & 87.90 & 2.58 & $0.80 \mathrm{v}$ & 77.83 & 1.24 & $0.78 \mathrm{v}$ & 89.75 & 2.52 & $0.86 \mathrm{v}$ & 73.24 & 1.67 & $0.63 v$ \\
\hline 30 & 87.17 & 2.57 & $0.82 \mathrm{v}$ & 78.05 & 1.19 & $0.80 \mathrm{v}$ & 88.99 & 2.48 & $0.88 \mathrm{v}$ & 71.84 & 1.66 & $0.59 \mathrm{v}$ \\
\hline 35 & 86.51 & 2.58 & $0.82 v$ & 77.27 & 1.18 & $0.83 \mathrm{v}$ & 88.22 & 2.45 & $0.90 \mathrm{v}$ & 69.88 & 1.70 & $0.55 \mathrm{v}$ \\
\hline 40 & $\begin{array}{l}85.92 \\
\end{array}$ & 2.59 & $0.82 \mathrm{v}$ & 75.98 & 1.20 & $0.85 \mathrm{v}$ & 87.37 & 2.44 & $0.90 \mathrm{v}$ & 67.51 & 1.81 & $0.48 \mathrm{~V}$ \\
\hline 45 & \begin{tabular}{|l|}
85.37 \\
\end{tabular} & 2.61 & $0.82 \mathrm{v}$ & 74.57 & 1.23 & $0.85 \mathrm{v}$ & 86.46 & 2.45 & $0.91 \mathrm{v}$ & 65.30 & 1.94 & $0.42 \mathrm{v}$ \\
\hline 50 & 84.88 & 2.62 & $0.81 \mathrm{v}$ & 73.16 & 1.27 & $0.84 \mathrm{v}$ & 85.55 & 2.46 & $0.90 \mathrm{v}$ & 3.23 & 2.12 & $0.35 \mathrm{v}$ \\
\hline 60 & 84.07 & 2.64 & $0.82 \mathrm{v}$ & 70.37 & 1.35 & \begin{tabular}{|l|}
$0.77 \mathrm{v}$ \\
\end{tabular} & 83.85 & 2.52 & $0.90 \mathrm{v}$ & 9.62 & 2.61 & $0.22 \mathrm{v}$ \\
\hline 70 & 83.32 & 2.68 & $0.83 \mathrm{v}$ & 67.77 & 1.45 & $0.70 \mathrm{v}$ & .01 & 2.62 & $0.88 \mathrm{v}$ & .97 & 3.32 & $0.12 \mathrm{v}$ \\
\hline 80 & 82.56 & 2.74 & $0.84 \mathrm{v}$ & 65.50 & 1.56 & $0.68 \mathrm{v}$ & 80.38 & 2.74 & $0.85 \mathrm{v}$ & 55.22 & 4.54 & $0.03 \mathrm{v}$ \\
\hline 90 & 81.84 & 2.81 & $0.85 \mathrm{v}$ & 63.25 & 1.70 & $0.61 \mathrm{v}$ & 79.09 & 2.86 & $0.82 \mathrm{v}$ & 1.24 & 46.87 & $0.00 \mathrm{v}$ \\
\hline 100 & 81.15 & 2.89 & $0.85 \mathrm{v}$ & 61.45 & 1.85 & $0.52 \mathrm{v}$ & 77.99 & 2.98 & $0.79 \mathrm{v}$ & 54.04 & 48.30 & $0.00 \mathrm{~V}$ \\
\hline 120 & $\begin{array}{l}79.79 \\
\end{array}$ & 3.09 & $0.84 \mathrm{v}$ & 58.69 & 2.16 & $0.39 \mathrm{v}$ & 76.40 & 3.21 & $0.75 \mathrm{v}$ & 52.43 & 3.50 & $0.38 \mathrm{~s}$ \\
\hline 140 & 78.60 & 3.32 & $0.81 \mathrm{v}$ & 56.58 & 2.57 & $0.24 \mathrm{v}$ & 75.24 & 3.45 & $0.71 \mathrm{v}$ & .40 & 2.95 & $.50 \mathrm{~s}$ \\
\hline 160 & $\begin{array}{l}77.62 \\
\end{array}$ & 3.55 & $0.77 \mathrm{v}$ & 54.68 & 4.89 & $0.23 \mathrm{~s}$ & 74.40 & 3.68 & $0.67 \mathrm{v}$ & 50.54 & 2.64 & $0.58 \mathrm{~s}$ \\
\hline 180 & 76.80 & 3.80 & $0.72 \mathrm{v}$ & 54.14 & 4.28 & $0.39 \mathrm{~s}$ & 73.78 & 3.91 & $0.64 \mathrm{v}$ & 9.74 & 2.42 & $.59 \mathrm{~s}$ \\
\hline 200 & 76.13 & 4.06 & $0.66 \mathrm{v}$ & 53.69 & 3.90 & $0.48 \mathrm{~s}$ & 73.32 & 4.13 & $0.61 / \mathrm{v}$ & 48.96 & 2.26 & $.61 \mathrm{~s}$ \\
\hline & \multicolumn{6}{|c|}{ Elkins (137 storms) } & \multicolumn{6}{|c|}{ Dunlow (45 storms) } \\
\hline & \multicolumn{3}{|c|}{ Clay Loam } & \multicolumn{3}{|c|}{ Silt Loam } & \multicolumn{3}{|c|}{ Clay Loam } & \multicolumn{3}{|c|}{ Silt Loam } \\
\hline m) & $C N_{\infty}$ & $k$ & $R^{2}$ & $C N_{\infty}$ & $k$ & $R^{2}$ & $C N_{\infty}$ & $k$ & $R^{2}$ & $C N_{\infty}$ & $k$ & $R^{2}$ \\
\hline 10 & 90.33 & 3.08 & $0.61 \mathrm{v}$ & 69.63 & 2.94 & $0.44 \mathrm{v}$ & 94.09 & 2.83 & $0.65 \mathrm{v}$ & 60 & 1.69 & $87 \mathrm{~V}$ \\
\hline 15 & 88.88 & 3.07 & $0.65 \mathrm{v}$ & 68.33 & 2.61 & $0.54 \mathrm{v}$ & 94.74 & 2.64 & $0.75 \mathrm{v}$ & .88 & 1.91 & $.95 \mathrm{v}$ \\
\hline 20 & 87.65 & 3.04 & $0.68 \mathrm{v}$ & 67.18 & 2.46 & $0.64 \mathrm{v}$ & 93.92 & 2.56 & $0.80 \mathrm{v}$ & 74.92 & 2.07 & $0.85 \mathrm{v}$ \\
\hline 25 & 86.78 & 2.98 & $0.72 \mathrm{v}$ & 65.90 & 2.41 & $0.63 \mathrm{v}$ & 93.04 & 2.54 & $0.84 \mathrm{v}$ & 73.00 & 2.03 & $0.74 \mathrm{v}$ \\
\hline 30 & 86.22 & 2.92 & $0.75 \mathrm{v}$ & 64.44 & 2.42 & $0.60 \mathrm{v}$ & 91.62 & 2.58 & $0.86 \mathrm{v}$ & 70.96 & 2.10 & $0.72 \mathrm{v}$ \\
\hline 35 & 85.79 & 2.86 & $0.77 \mathrm{v}$ & 62.93 & 2.52 & $0.57 \mathrm{v}$ & 90.18 & 2.65 & $0.85 \mathrm{v}$ & 68.32 & 2.29 & $0.63 \mathrm{v}$ \\
\hline 40 & 85.45 & 2.81 & $0.79 \mathrm{v}$ & 61.54 & 2.65 & $0.51 \mathrm{v}$ & 89.08 & 2.68 & $0.86 \mathrm{v}$ & 6.02 & 2.51 & $0.62 \mathrm{v}$ \\
\hline 45 & 85.07 & 2.79 & $0.79 \mathrm{v}$ & 60.30 & 2.81 & $0.41 \mathrm{v}$ & 88.27 & 2.70 & $0.87 \mathrm{v}$ & 63.93 & 2.79 & $0.57 \mathrm{v}$ \\
\hline 50 & 84.66 & 2.77 & $0.80 \mathrm{v}$ & 59.28 & 2.97 & $0.37 \mathrm{v}$ & 87.65 & 2.70 & $0.88 \mathrm{v}$ & 63.00 & 2.94 & $0.51 \mathrm{v}$ \\
\hline 60 & 83.69 & 2.79 & $0.81 \mathrm{v}$ & 57.56 & 3.45 & $0.25 \mathrm{v}$ & 86.94 & 2.68 & $0.89 \mathrm{v}$ & 61.85 & 3.15 & $0.36 \mathrm{v}$ \\
\hline 70 & 82.72 & 2.83 & $0.82 \mathrm{v}$ & 56.48 & 4.08 & $0.14 \mathrm{v}$ & 86.55 & 2.63 & $0.91 \mathrm{v}$ & 61.27 & 3.27 & $0.27 \mathrm{~V}$ \\
\hline 80 & 81.73 & 2.90 & $0.82 \mathrm{v}$ & 55.88 & 4.92 & $0.05 \mathrm{v}$ & 86.01 & 2.63 & $0.92 \mathrm{v}$ & 60.89 & 3.33 & $0.32 \mathrm{v}$ \\
\hline 90 & 80.79 & 2.98 & $0.81 \mathrm{v}$ & 55.56 & 5.90 & $0.02 \mathrm{v}$ & 85.40 & 2.64 & $0.92 \mathrm{v}$ & 60.31 & 3.47 & $0.38 \mathrm{~V}$ \\
\hline 100 & 79.92 & 3.09 & $0.80 \mathrm{v}$ & 55.43 & 6.83 & $0.01 \mathrm{v}$ & 84.73 & 2.69 & $0.92 \mathrm{v}$ & 59.57 & 3.68 & $0.46 \mathrm{~V}$ \\
\hline 120 & 78.46 & 3.32 & $0.77 \mathrm{v}$ & 55.37 & 9.65 & $0.01 \mathrm{~s}$ & 83.30 & 2.81 & $0.91 \mathrm{v}$ & 58.04 & 4.34 & $0.44 \mathrm{~V}$ \\
\hline 140 & 77.33 & 3.58 & $0.71 \mathrm{v}$ & 55.41 & 8.50 & $0.00 \mathrm{~s}$ & 82.16 & 2.94 & $0.89 \mathrm{v}$ & 56.71 & 5.64 & $0.15 \mathrm{v}$ \\
\hline 160 & 76.48 & 3.84 & $0.64 \mathrm{v}$ & 55.32 & 6.59 & $0.04 \mathrm{~s}$ & 81.11 & 3.08 & $0.85 \mathrm{v}$ & 55.97 & 9.78 & $0.00 \mathrm{v}$ \\
\hline 180 & 75.91 & 4.10 & $0.58 \mathrm{v}$ & 55.20 & 5.75 & $0.09 \mathrm{~s}$ & 80.13 & 3.25 & $0.80 \mathrm{v}$ & 55.45 & 5.82 & $0.09 \mathrm{~s}$ \\
\hline 200 & 75.55 & 4.33 & $0.52 \mathrm{v}$ & 55.09 & 5.25 & $0.13 \mathrm{~s}$ & 79.27 & 3.42 & $0.76 \mathrm{v}$ & 54.92 & 4.83 & 0.28 \\
\hline
\end{tabular}


The results of the Asymptotic Method, included as Figures 30-45 and Tables 4-5, also indicate a dependence of the $\mathrm{CN}$ on soil type, soil depth, storm depth, and storm distribution. As in the Cyclic Method, the $\mathrm{CN}$ values are higher for the Clay Loam soil than the Silt Loam soil. The CN's also generally decrease with increasing soil depth. The majority of the curve fits are classified as violent, with the exception of the Silt Loam soil where $\lambda=0.2$. The least accurate curve fits ( $R^{2}$ values in red, see Tables $\left.4-5\right)$ typically arise in the transition zones between violent and standard behavior.

The violent behavior tends to be most prevalent at lesser soil depths, transitioning toward standard or complacent behavior at greater soil depths. This trend was also seen in the Cyclic Method (Figures 12-27). Complacent behavior was often found to precede violent behavior at low storm depths. Following the work of Hawkins (1993), the complacent data points that plotted below a selected threshold rainfall depth were ignored in these cases. Figure 34 is an example (Terra Alta gage, Silt Loam, $\lambda=$ 0.2 ) where the complacent data points below a storm depth of $28 \mathrm{~mm}$ were ignored for the 10-45 cm soil depths. Figures 46-64 are the individual curve fits comprising Figure 34. It should be noted that in some cases a standard fit (Equation 15) resulted in a high $R^{2}$ value although the data may possibly be more accurately characterized as complacent. This occurred most often in the greater soil depths. An example is shown in Figure 64.

The scatter of the data points in Figures 46-64 demonstrates the considerable variation of the $\mathrm{CN}$ with storm depth, which can be compared to that of the Type II and WDM Triangular storm distributions of the Cyclic Method (Figures 18 and 19). This scatter appeared in the plots of the individual curve fits from all gages. It may be explained by noting that according to Figure 11, the storms recorded at the Terra Alta, Beckley, Elkins, and Dunlow gages consist of relatively high intensity hourly rainfall intervals comparable to the Type II and WDM Triangular storm distributions. 


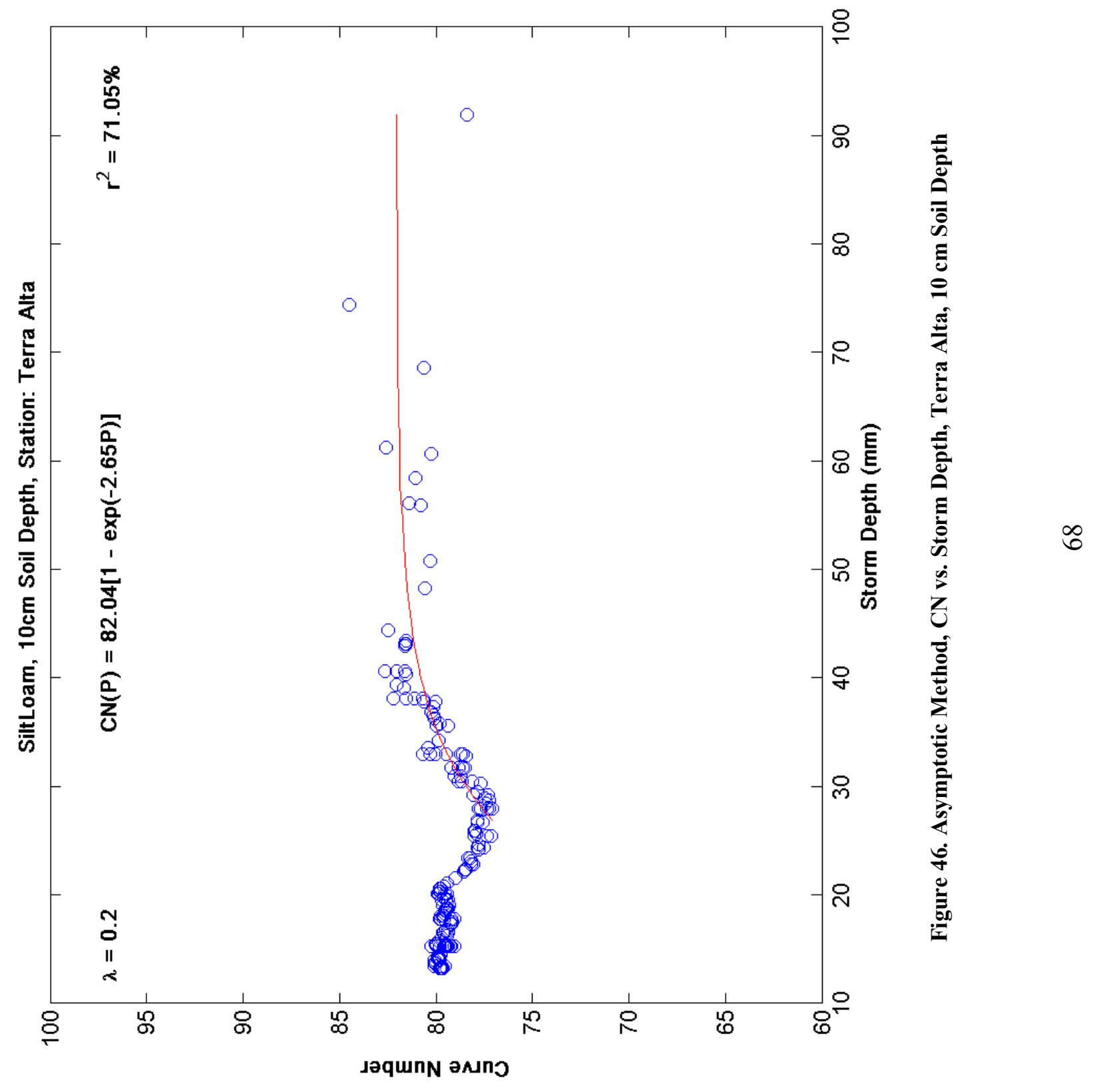




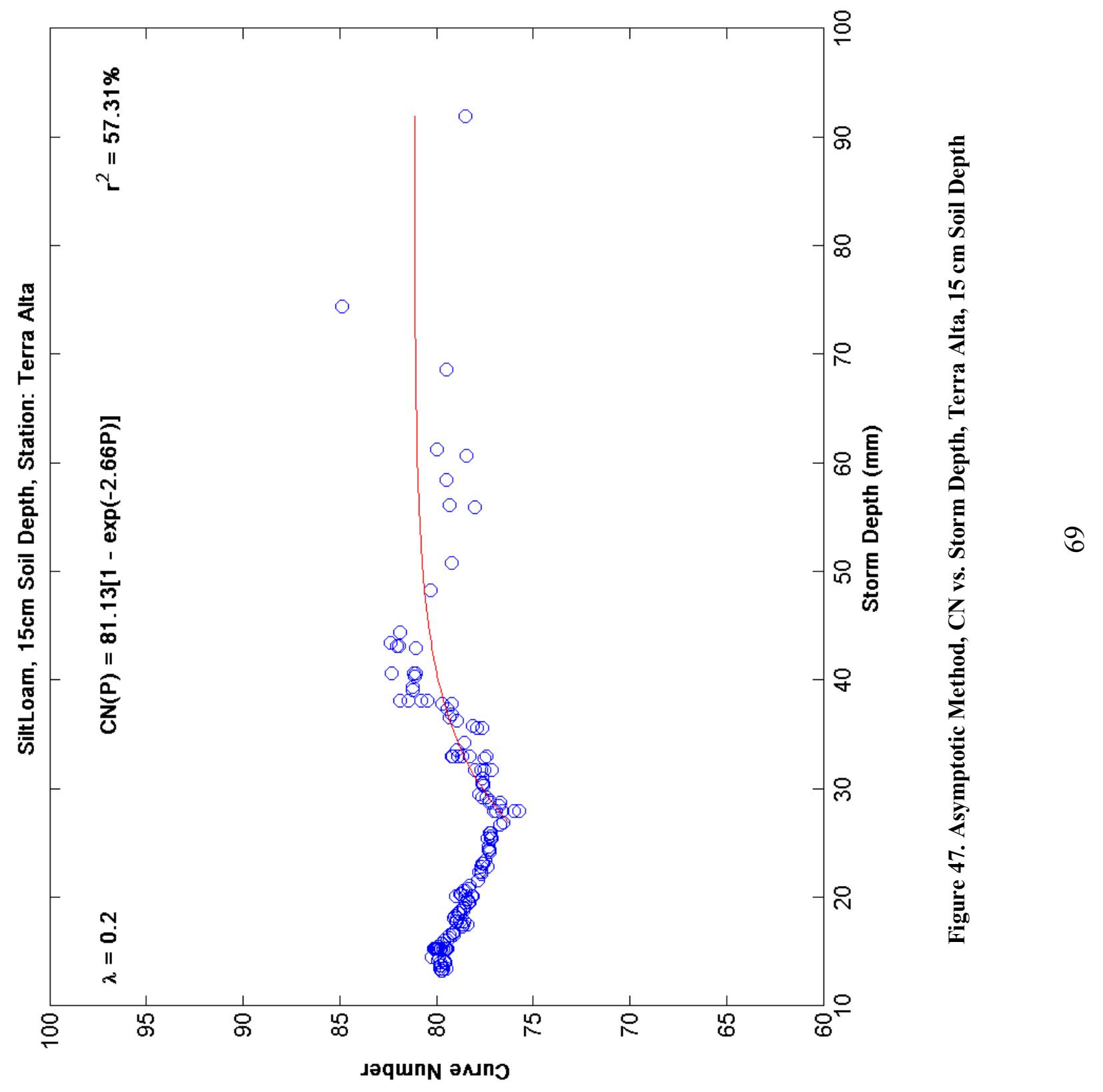




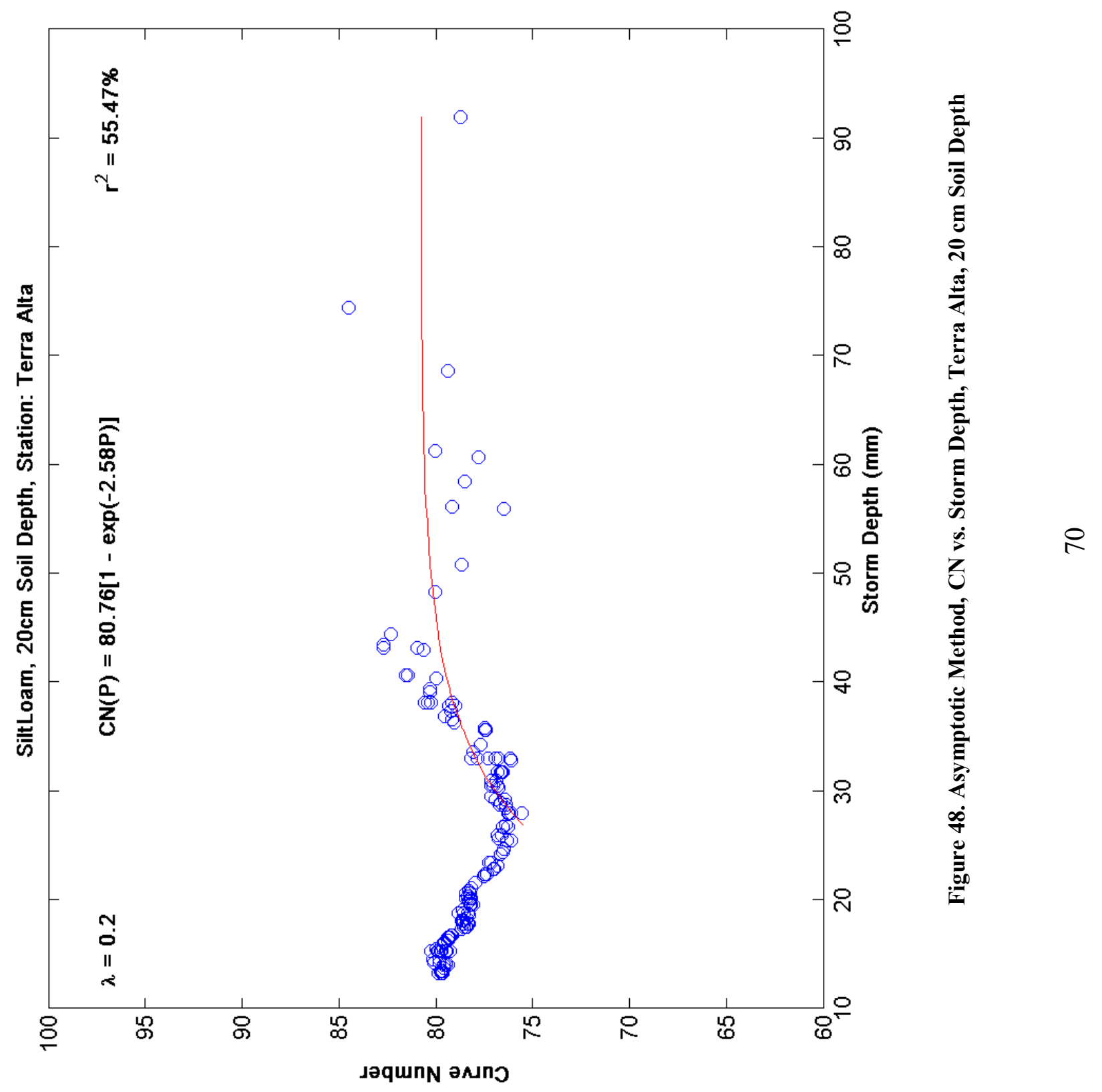




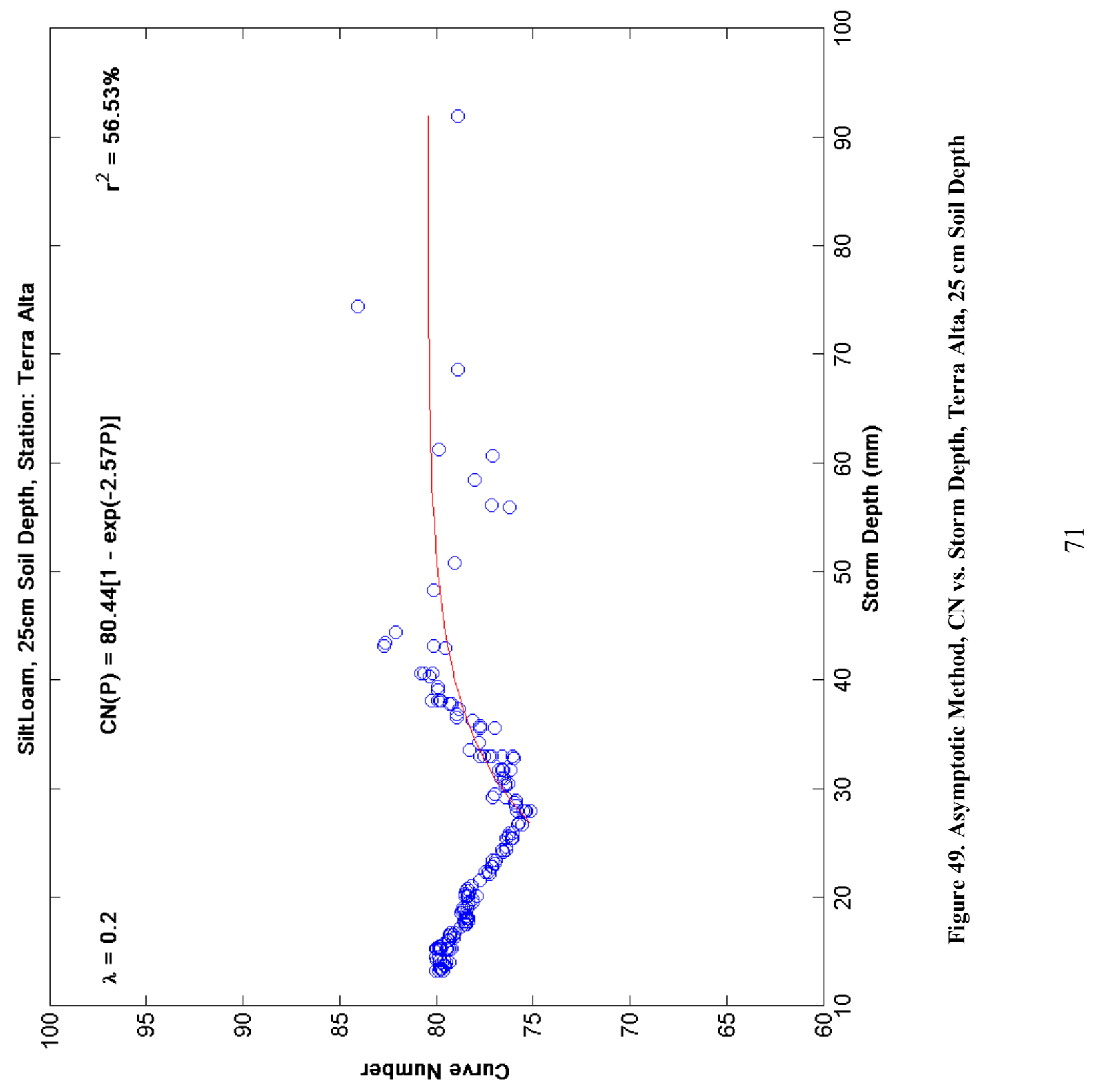




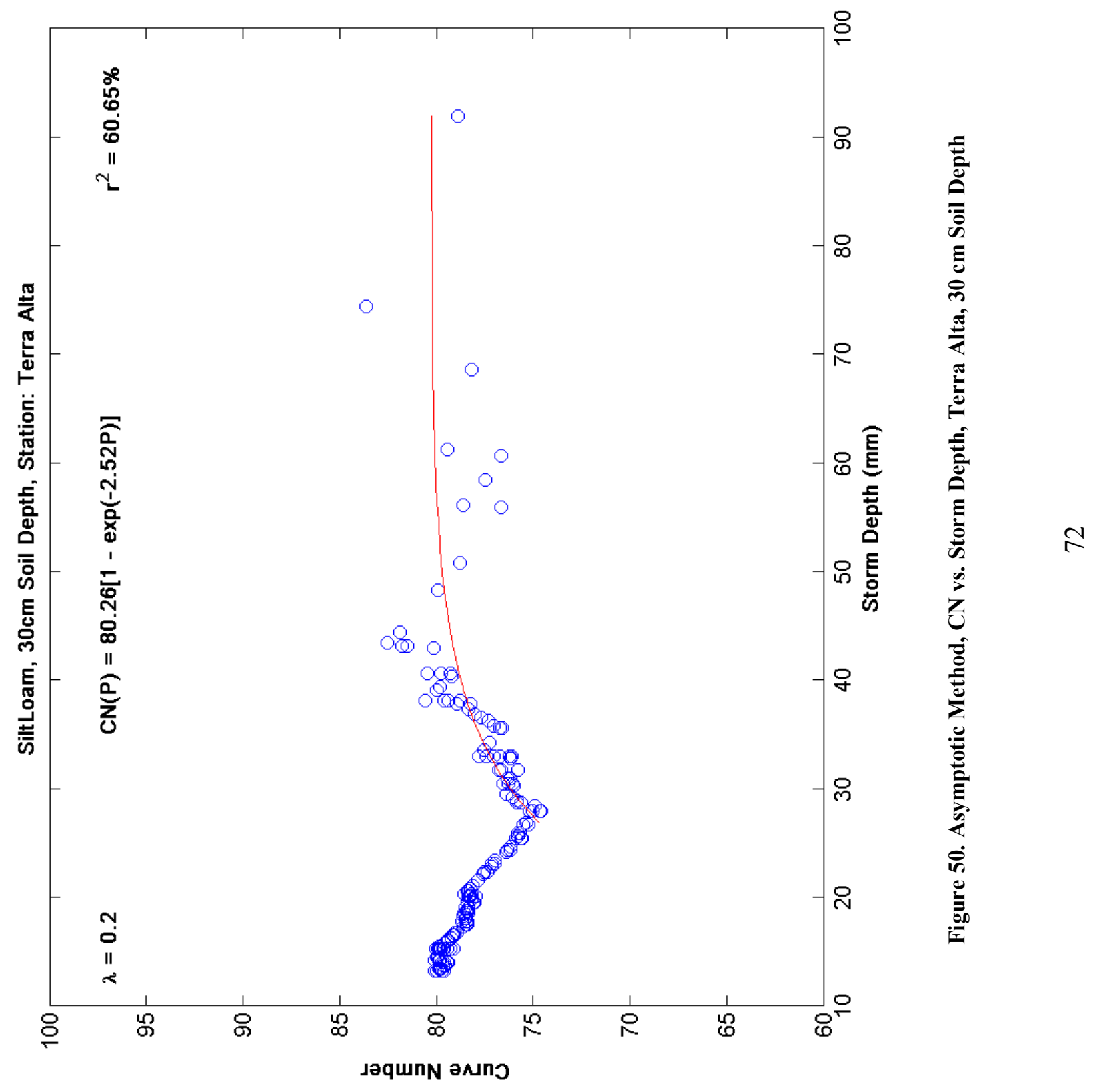




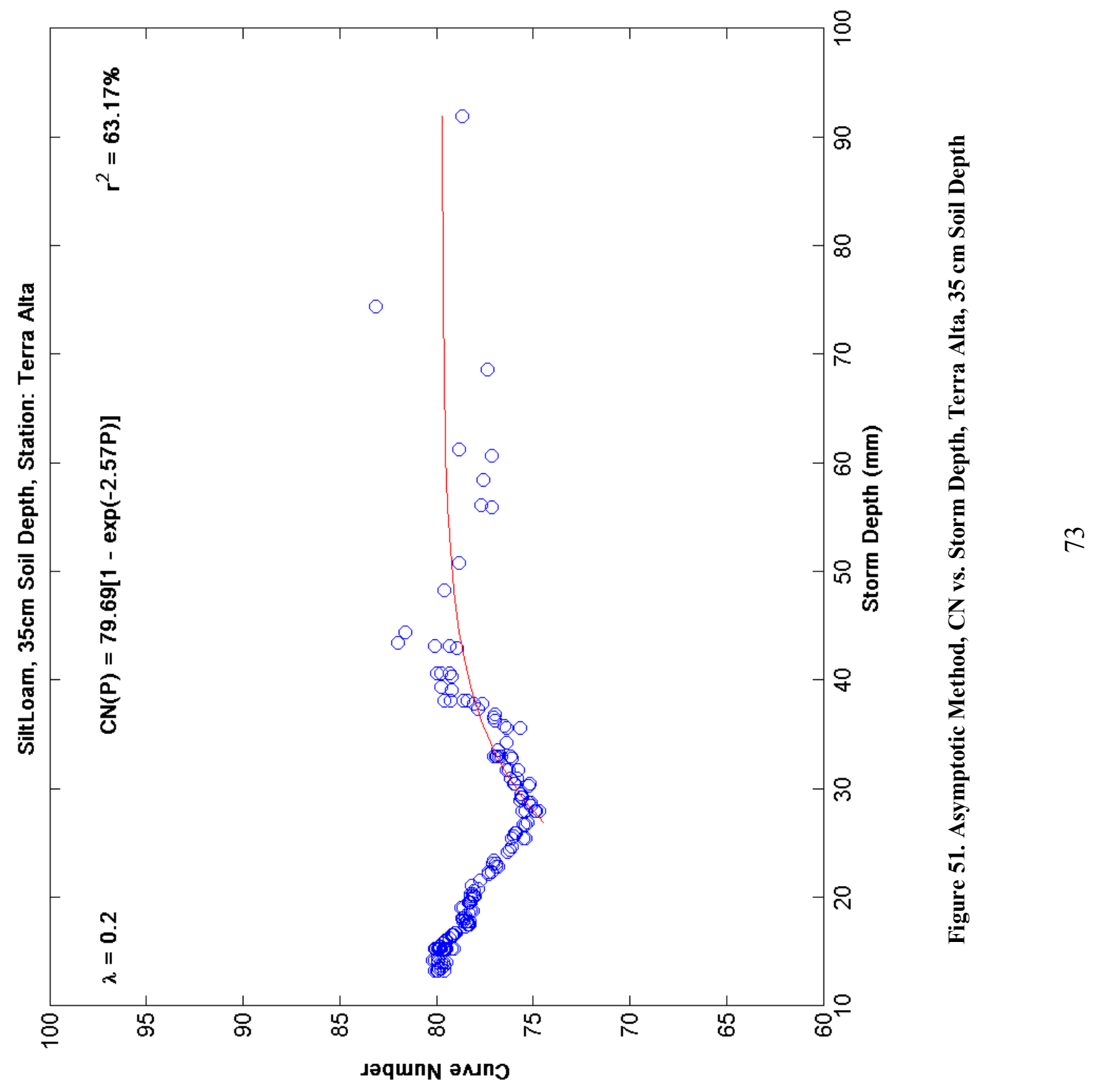




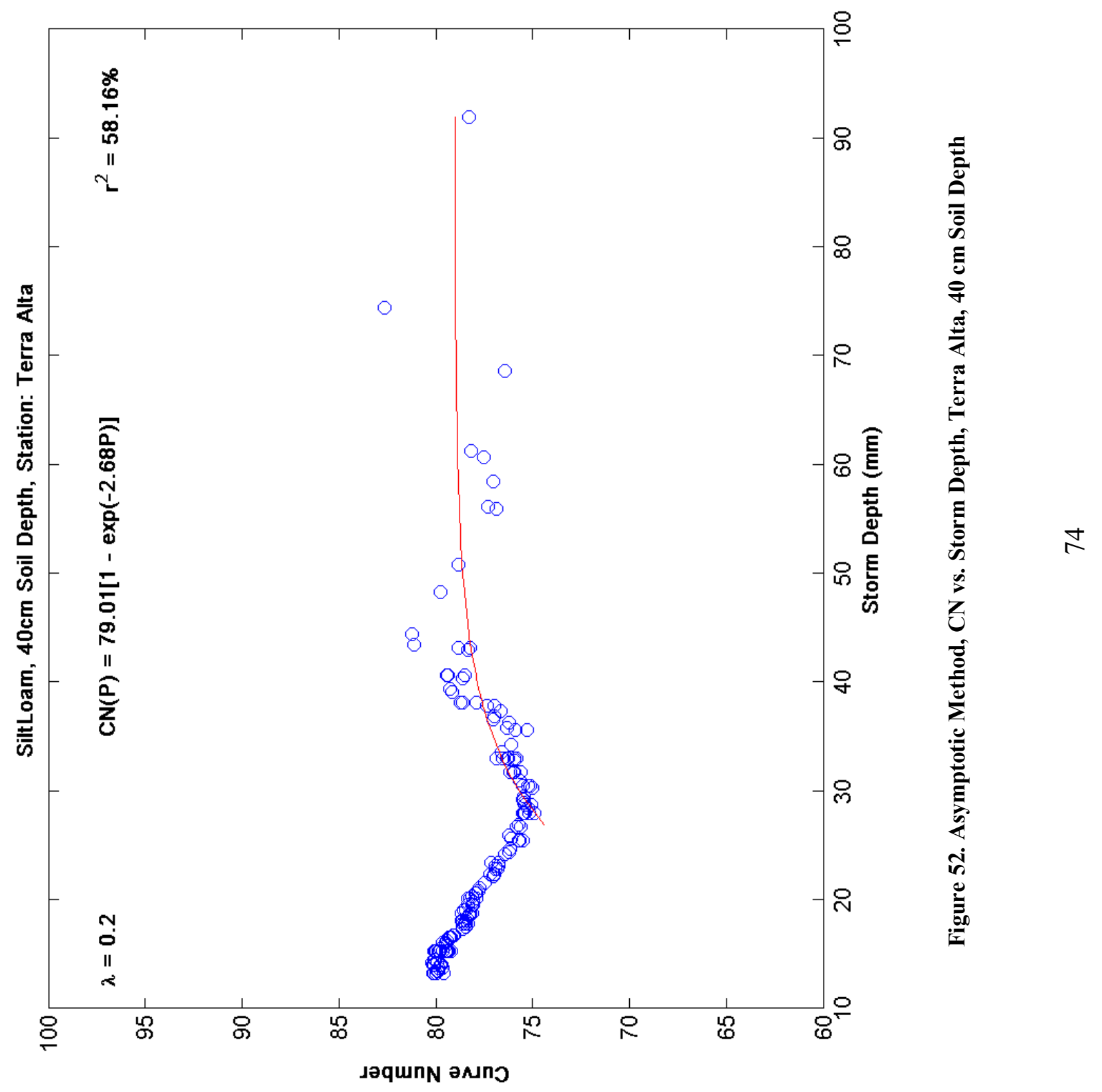




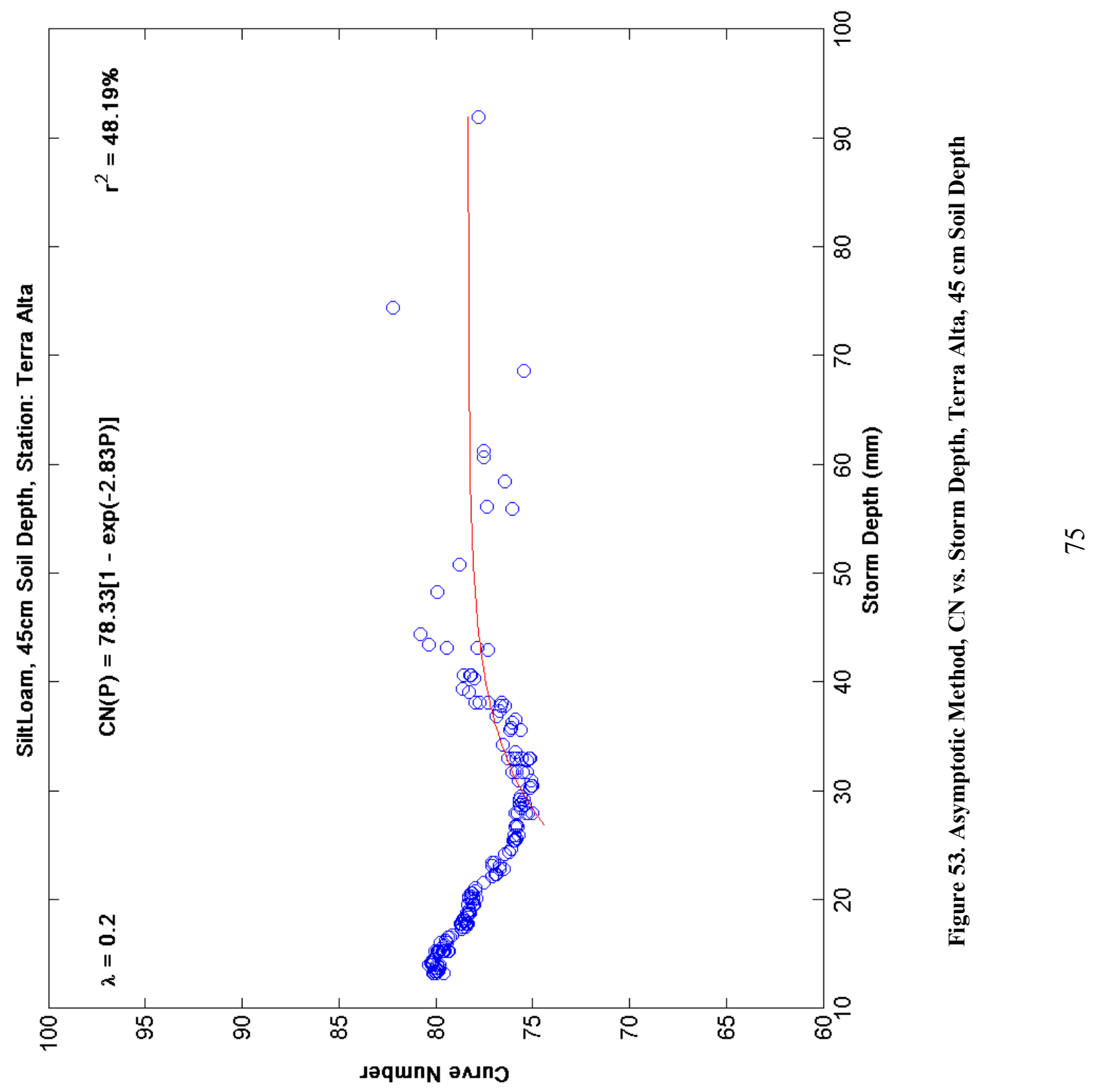




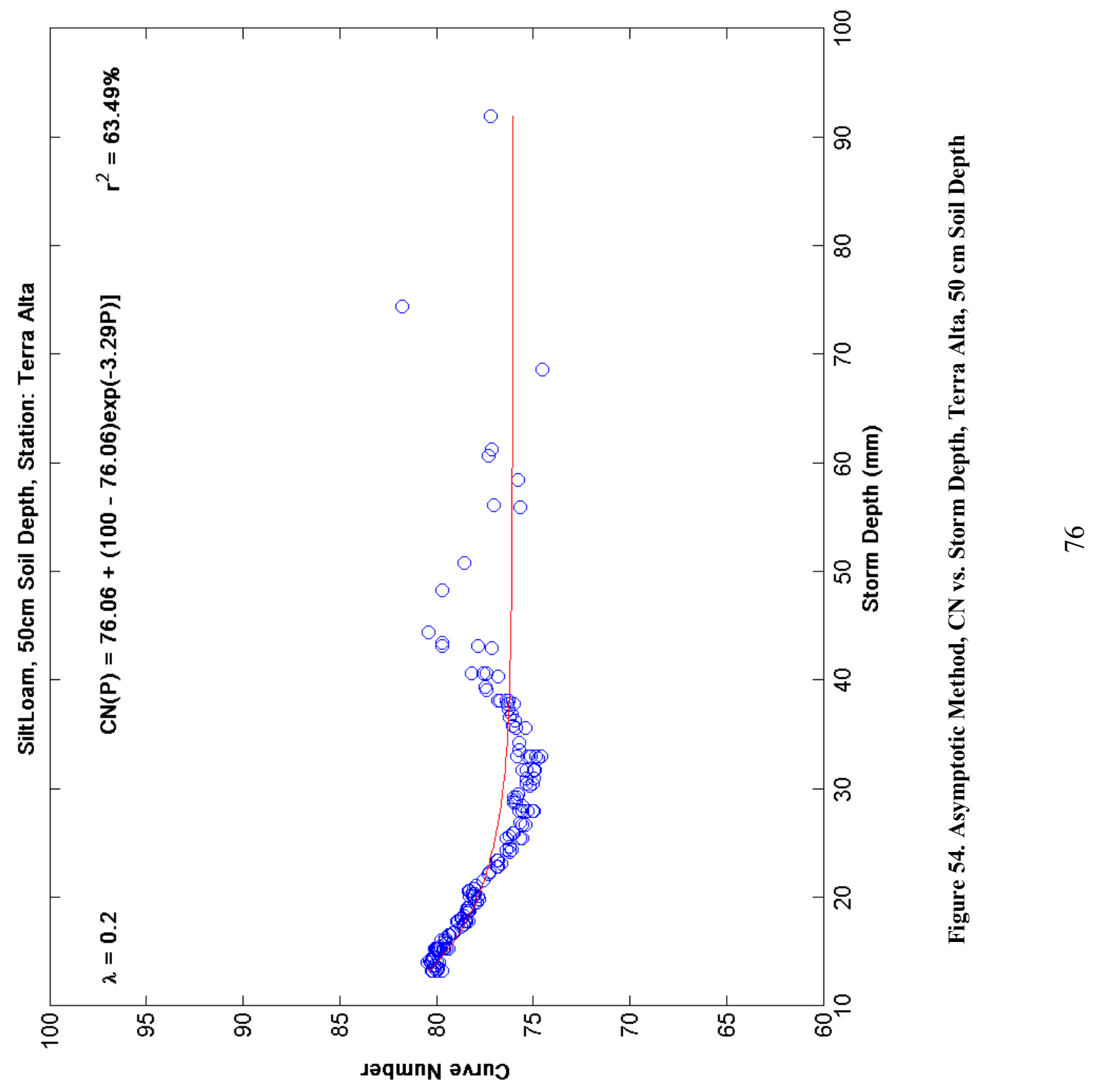




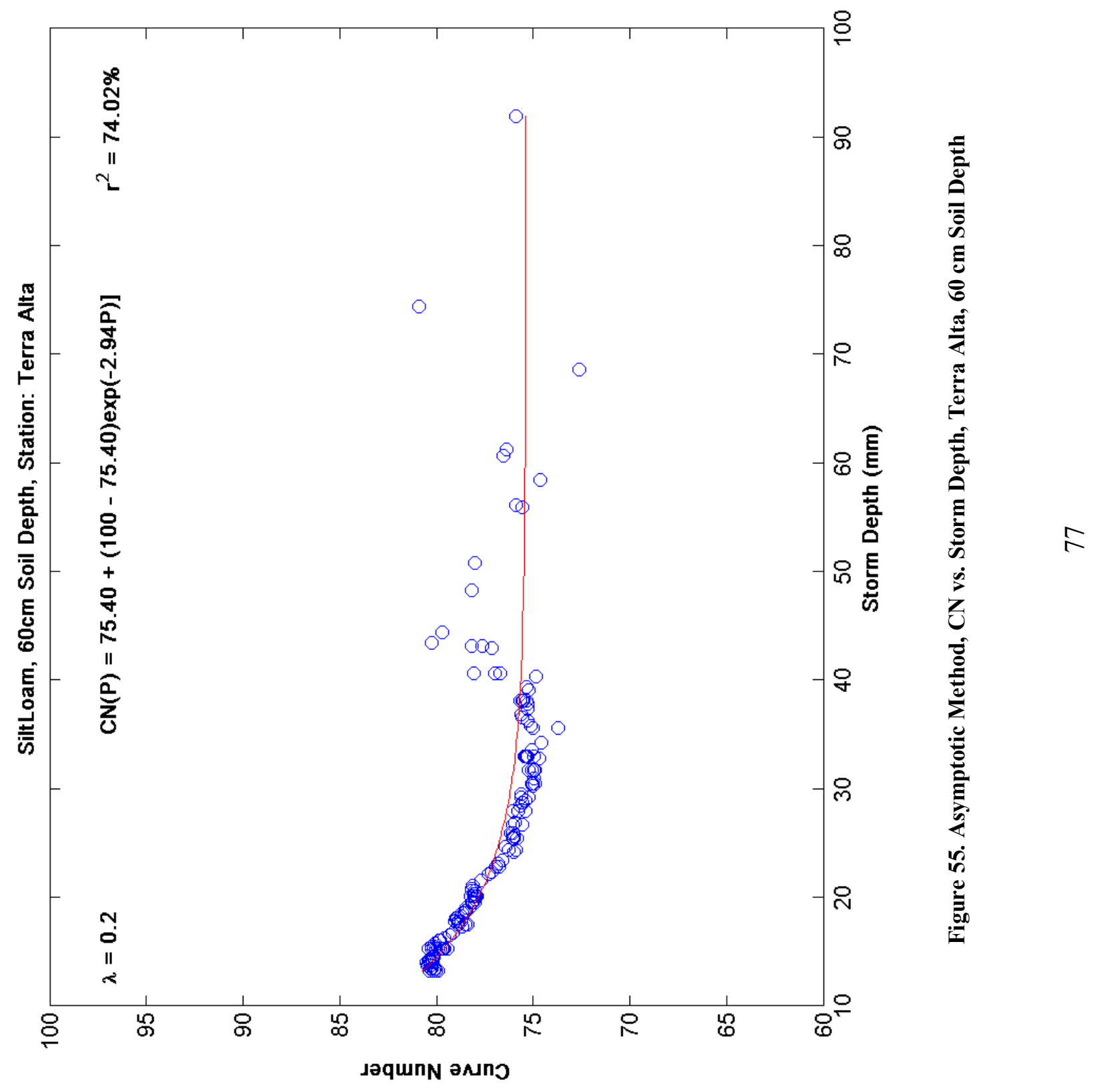




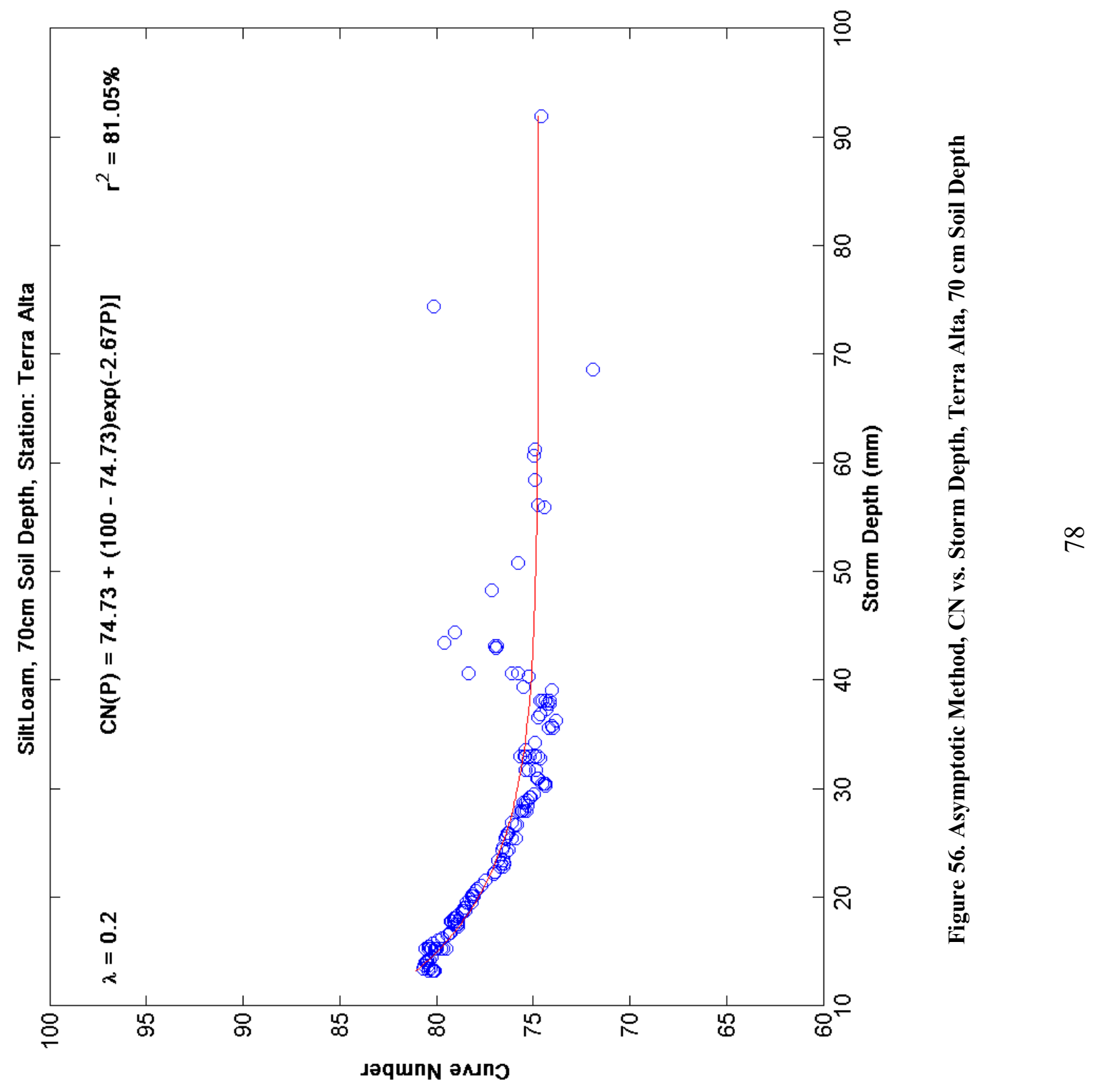




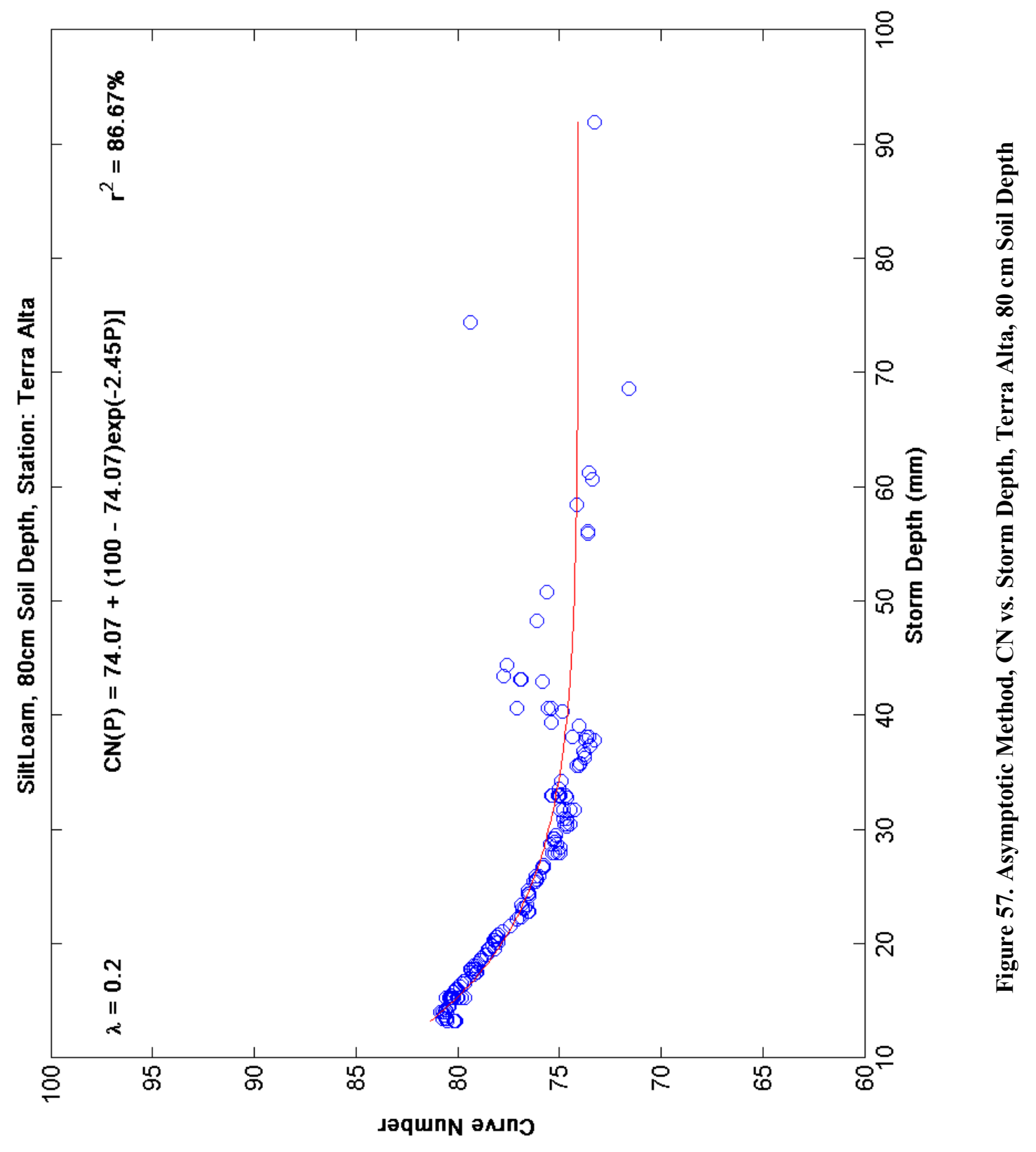




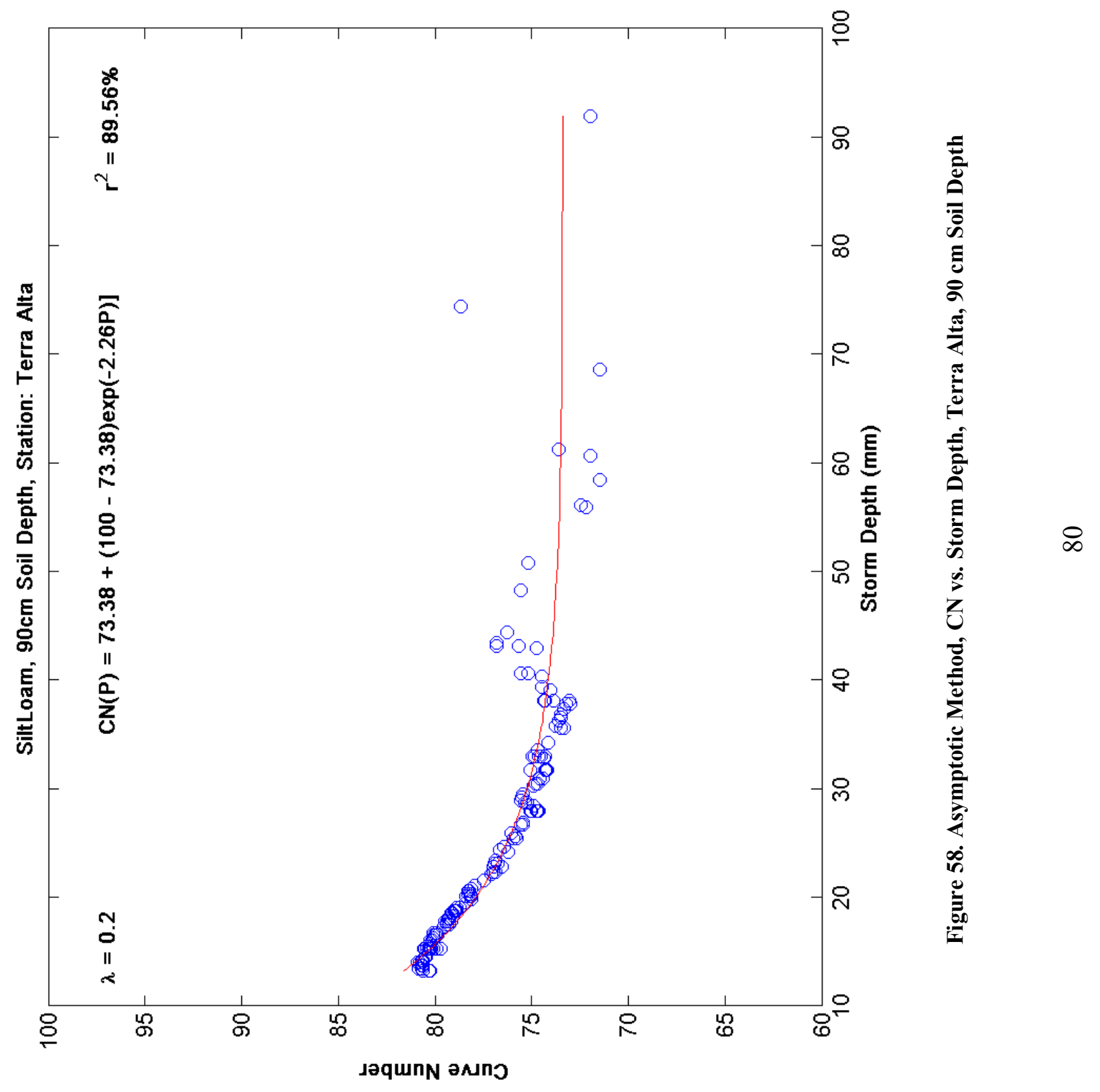




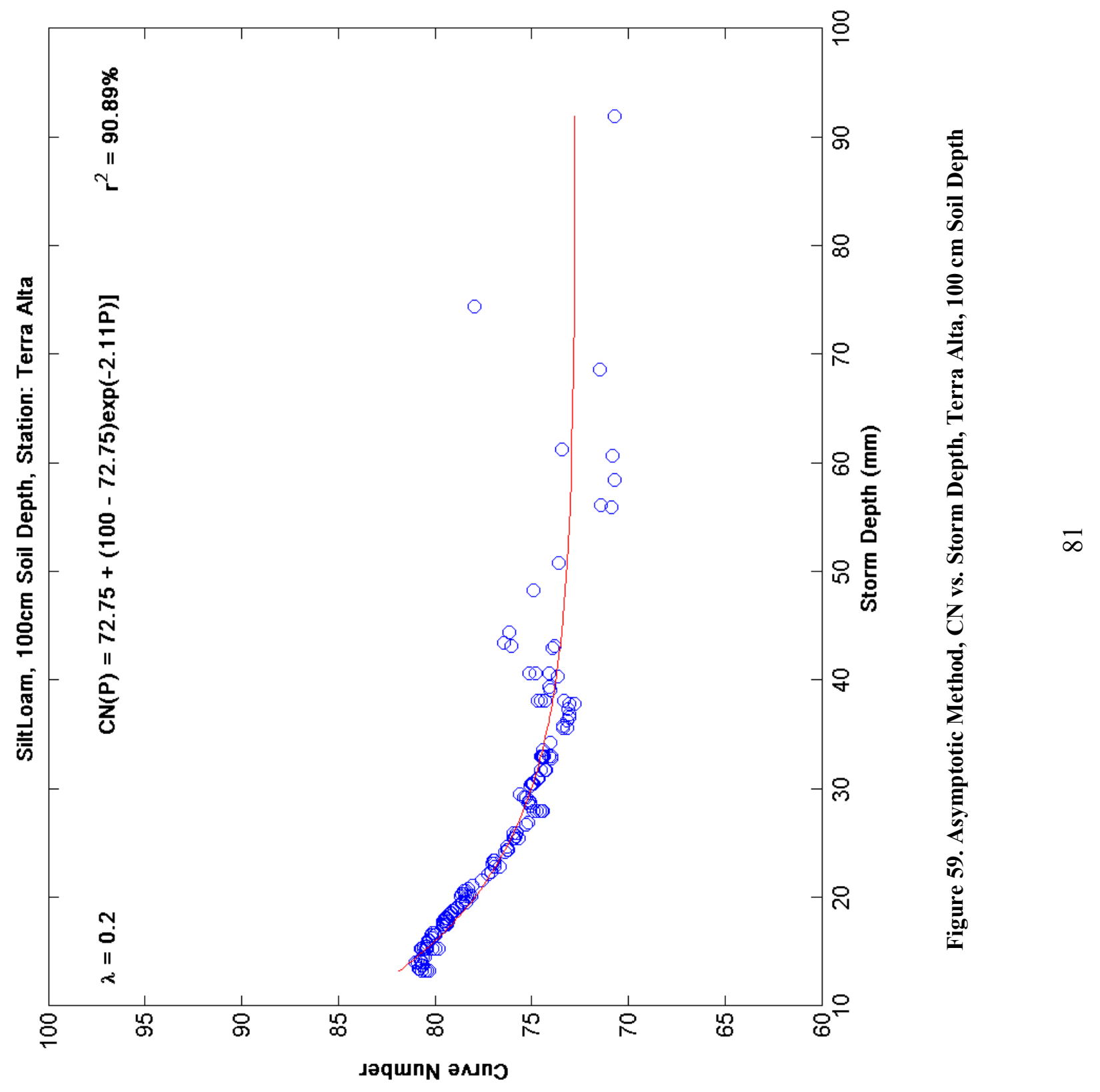




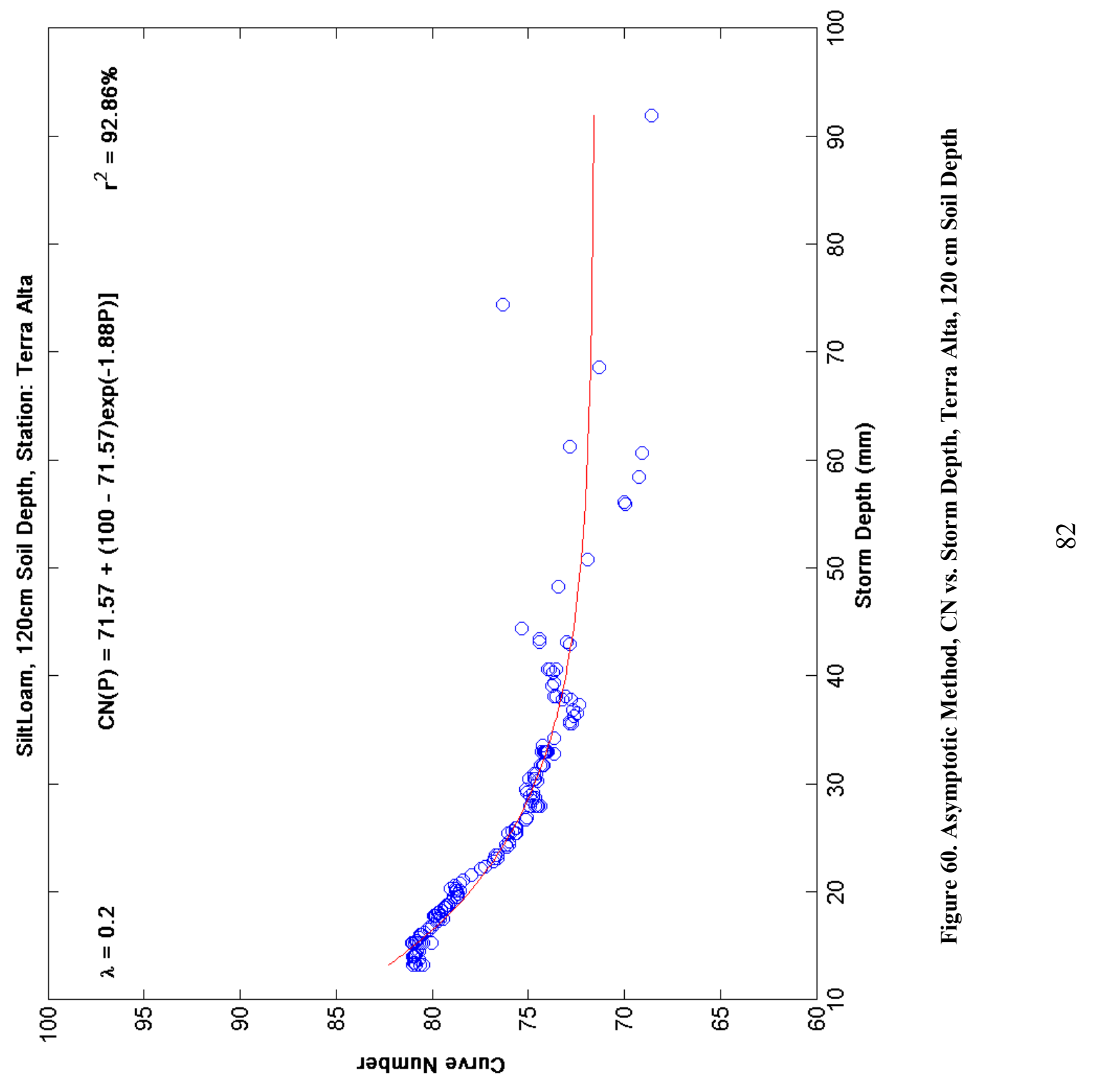




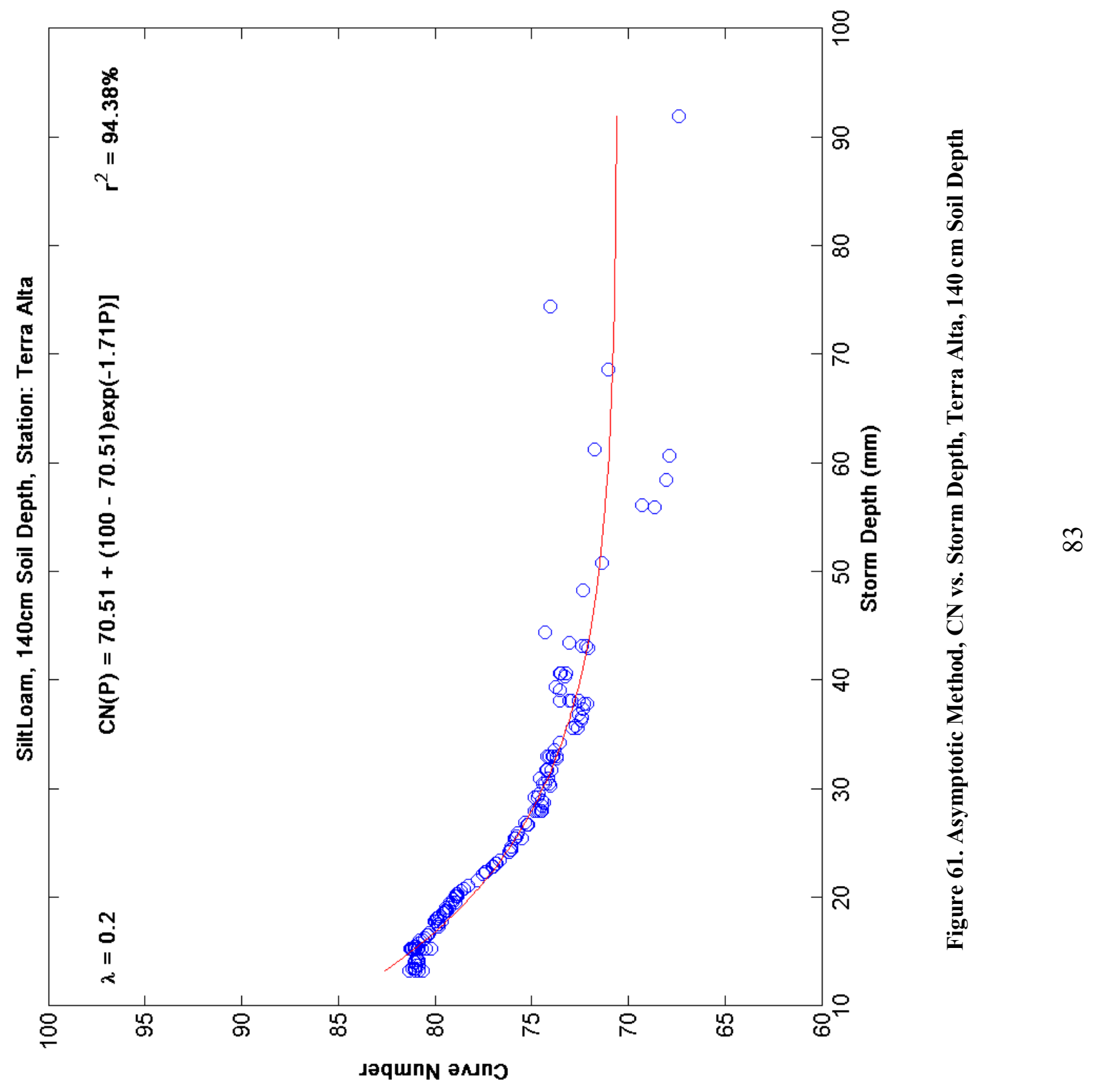




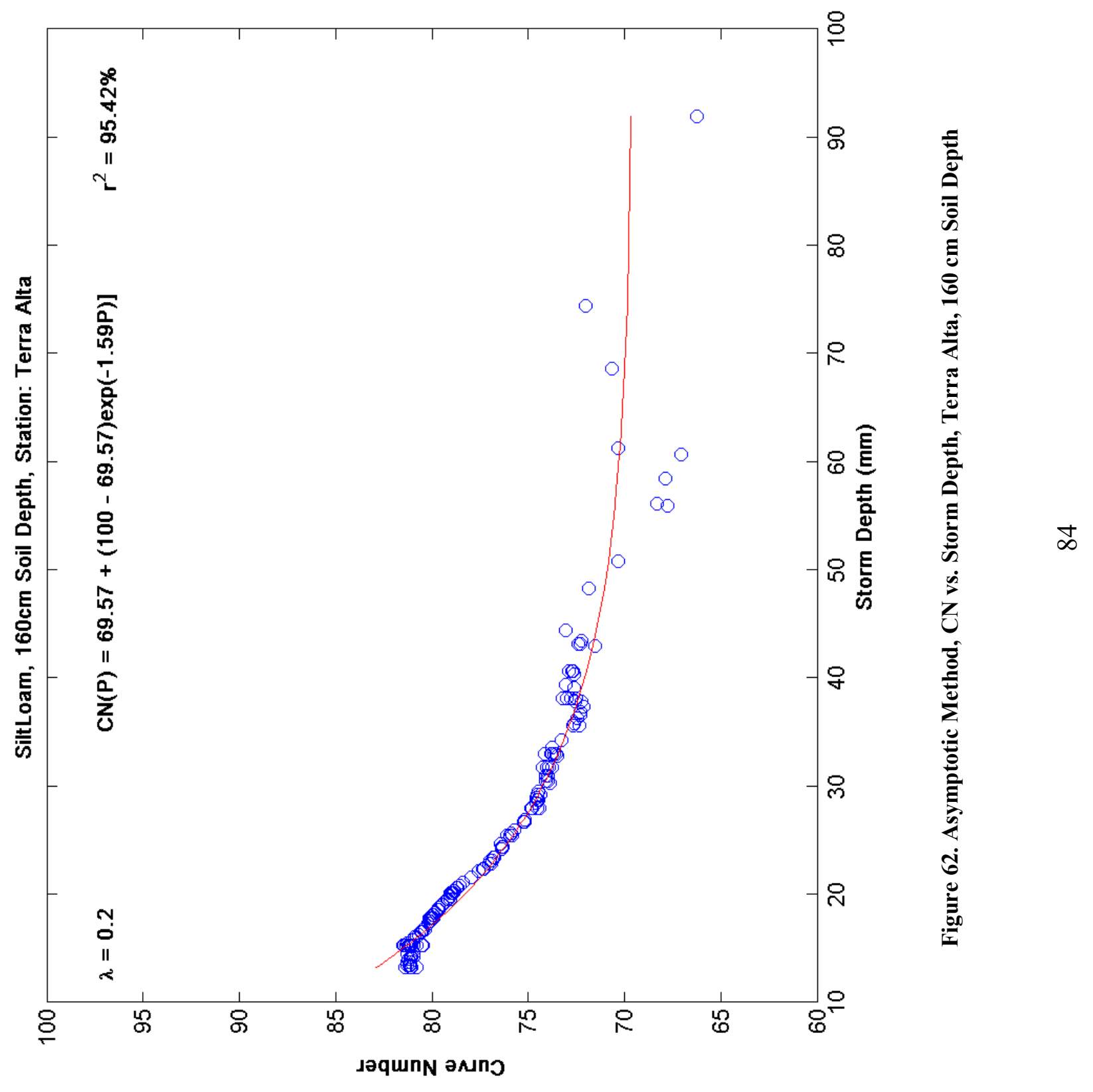




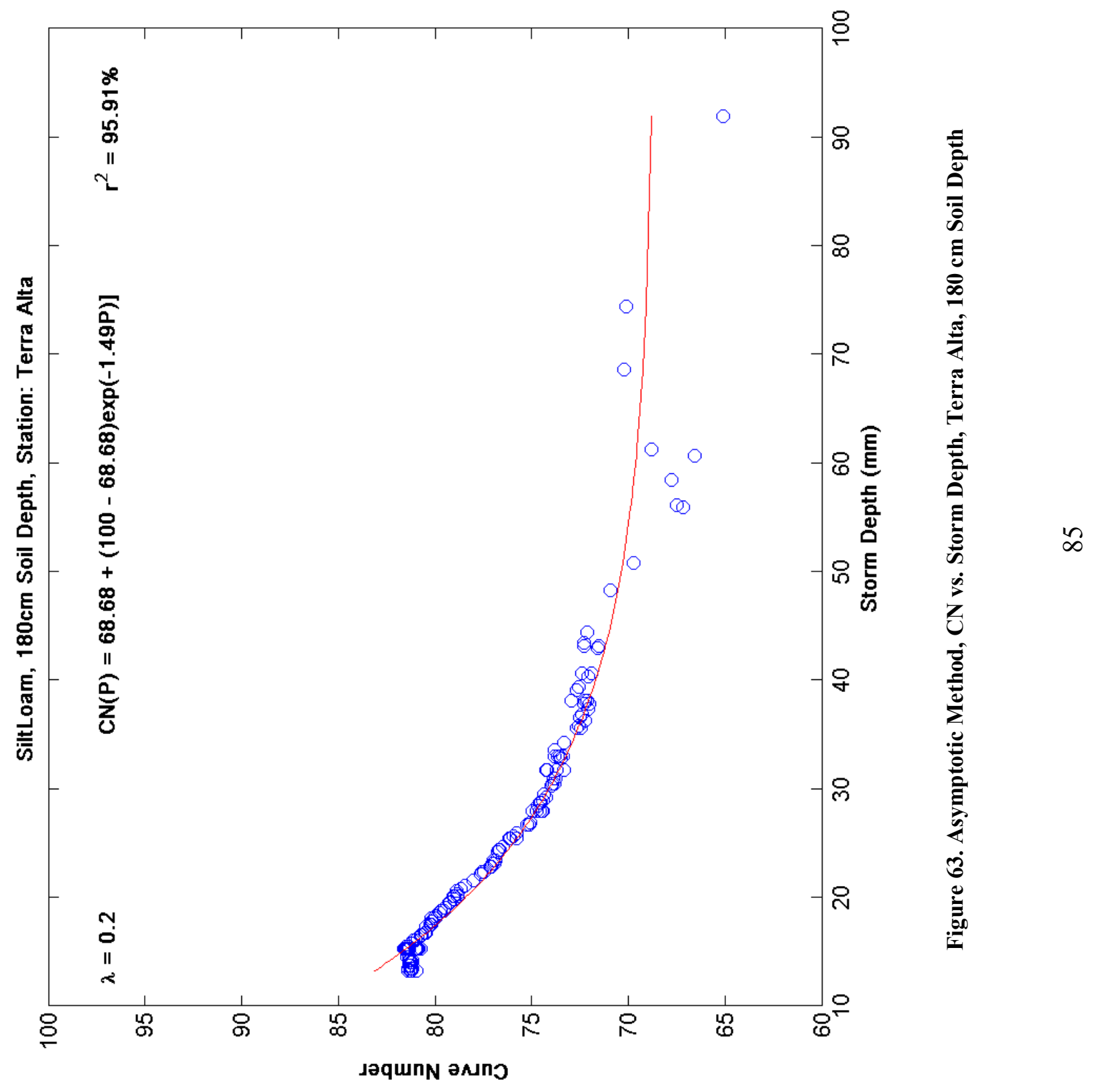




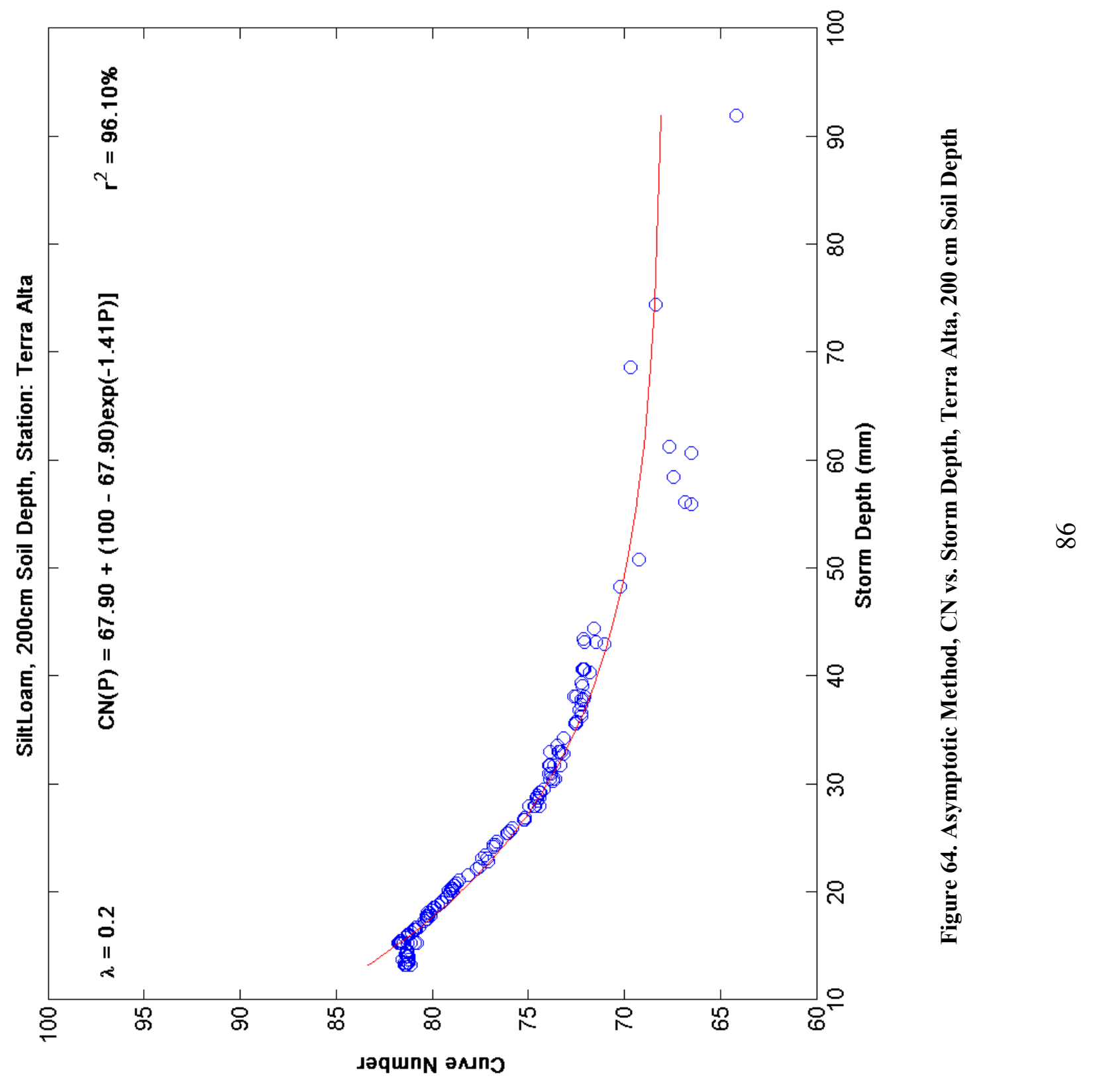


Table 6 lists the average $C N_{\infty}$ values over all soil depths for each gage and soil type. The Dunlow gage value is approximately 2 points higher for the Clay Loam and 3 points higher for the Silt Loam than the other 3 gages (except for the Silt Loam at Terra Alta with $\lambda=0.05)$.

Table 6. Average $C N_{\infty}$ Values for Each Gage

\begin{tabular}{|l|c|c|c|c|}
\cline { 2 - 5 } \multicolumn{1}{c|}{} & \multicolumn{2}{c|}{$\mathbf{0 . 2}$} & \multicolumn{2}{c|}{$\mathbf{0 . 0 5}$} \\
\cline { 2 - 5 } \multicolumn{1}{c|}{} & Clay Loam & Silt Loam & Clay Loam & Silt Loam \\
\hline Terra Alta & 86.98 & 75.59 & 83.60 & 68.34 \\
\hline Beckley & 86.35 & 73.82 & 82.84 & 61.51 \\
\hline Elkins & 86.85 & 73.86 & 82.81 & 59.83 \\
\hline Dunlow & 88.30 & 76.77 & 87.27 & 64.87 \\
\hline
\end{tabular}

This may be explained by noting that on average, according to Figure 11, a greater percentage of the rainfall at the Dunlow gage fell within a shorter time interval (the first five hours) for each storm compared to the other gages. This increased rainfall intensity resulted in slightly lower mean infiltration depths for each soil depth (Figure 65) compared to the other three gages. This effect is analogous to that produced by the WDM Triangular distribution in the Cyclic Method. 

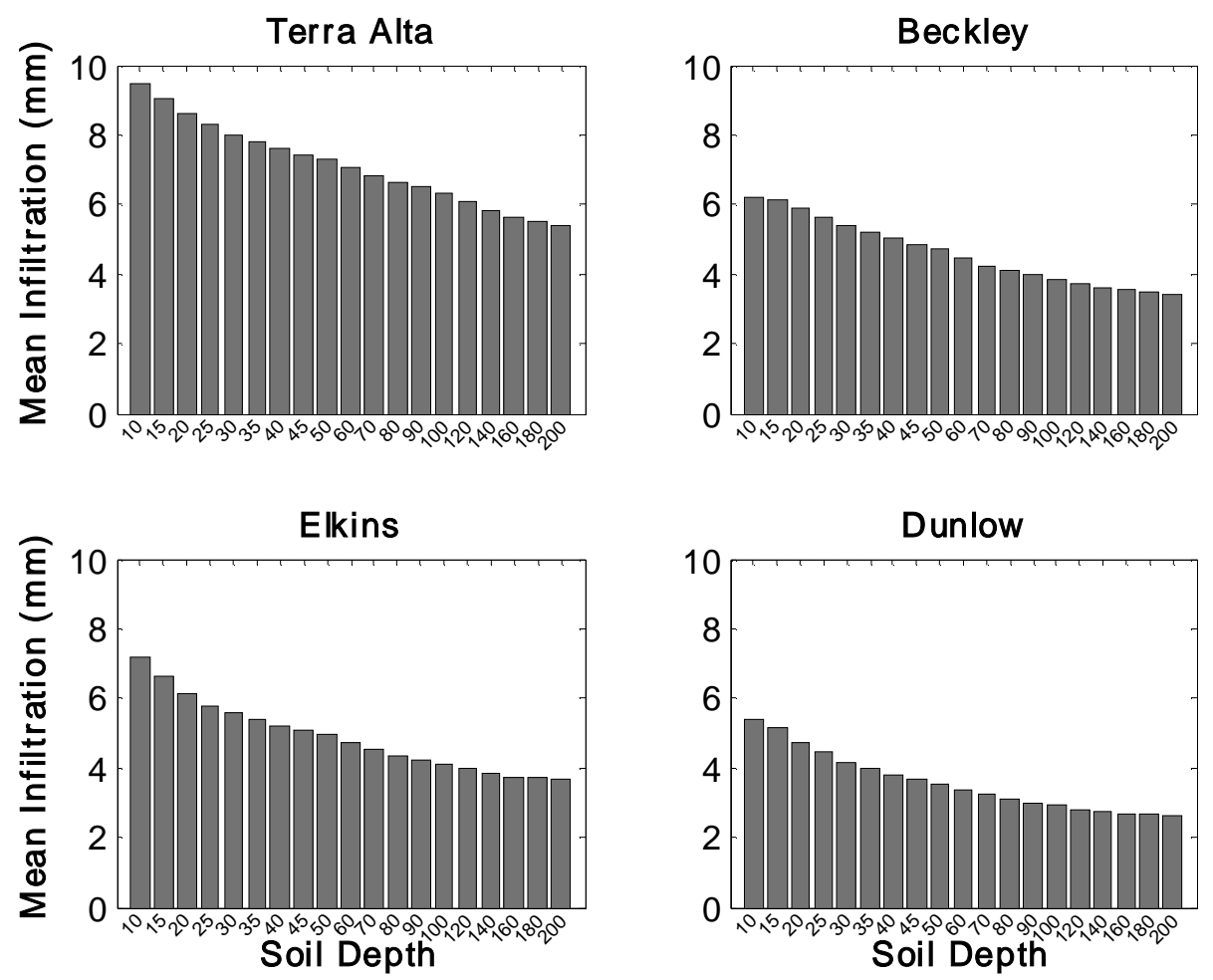

Figure 65. Asymptotic Method Mean Infiltration vs. Soil Depth, Clay Loam

In comparing Figures 45 and 65 it is apparent that in the Cyclic Method, the mean infiltration depth increases with soil depth while the opposite is true for each gage site in the Asymptotic Method. This can be explained by noting the difference between the antecedent lower zone storage $\left(L Z S_{i}\right)$ between the methods for each rainfall-runoff event. In the Cyclic Method, $L Z S_{i}$ was calculated using Equation 13 based on soil depth, residual moisture content, and the initial moisture content according to ARC II (Rawls and Brakensiek, 1986). In the Asymptotic Method, $L Z S_{i}$ was determined at the hour preceding each selected storm event. The calculated $L Z S_{i}$ (Cyclic) was consistently lower than the simulated $L Z S_{i}$ (Asymptotic), especially for the greater soil depths. An example comparison is shown in Figure 66 below for the $200 \mathrm{~cm}$ soil depth. According to Equation 14, an increase in the ratio of the lower zone storage value $\left(L Z S_{i}\right)$ to the lower zone nominal capacity parameter $(L Z S N)$, results in an increase in the infiltration capacity. Therefore, in the Cyclic Method, the infiltration capacity was substantially 
greater than that in the Asymptotic method due to the relatively low value of initial soil moisture storage $\left(L Z S_{i}\right)$ predicted by the ARC II condition.

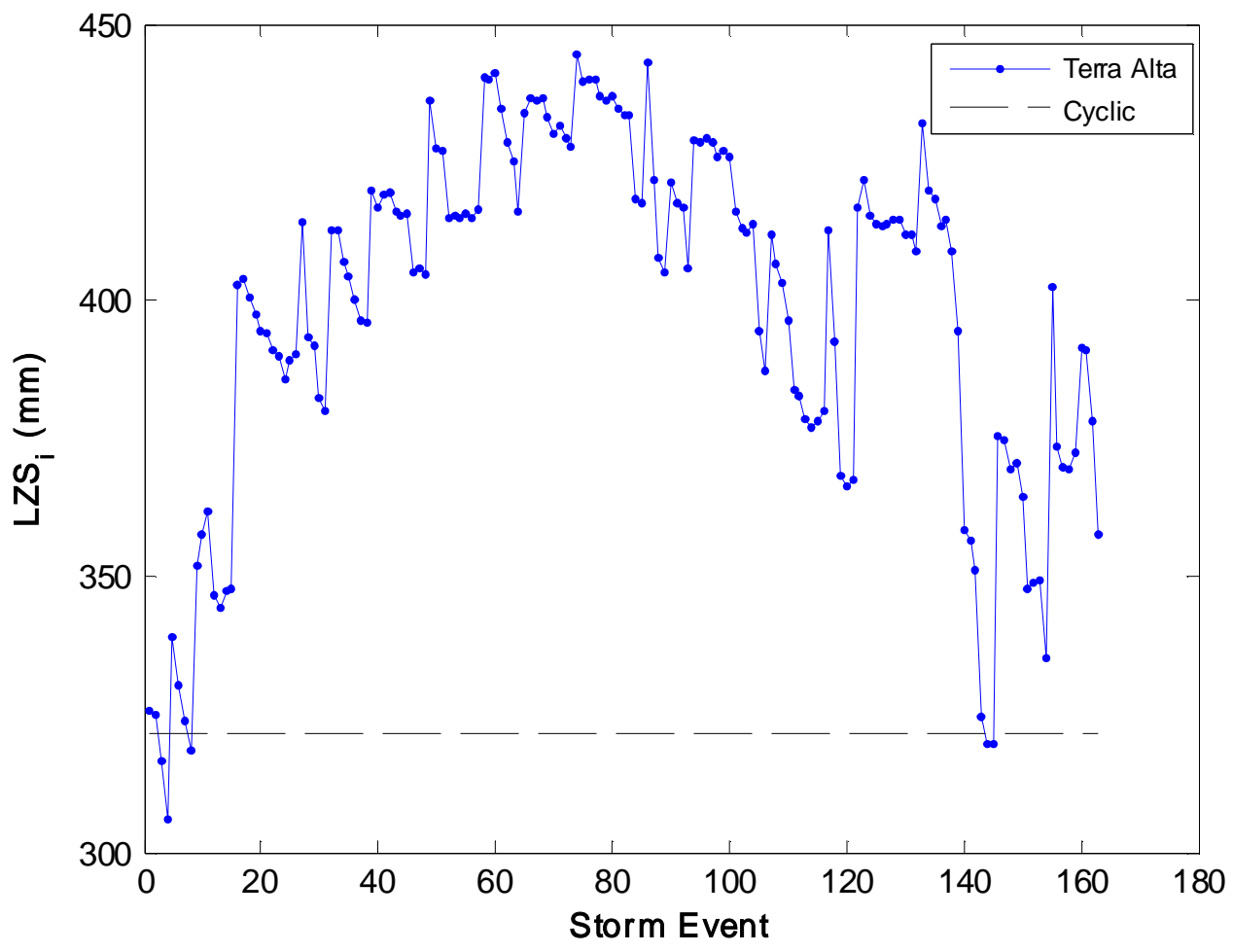

Figure 66. Antecedent LZS, Clay Loam, $200 \mathrm{~cm}$ Soil Depth, Terra Alta

Finally, in comparing Figures $30-37$ to $38-45$, it is evident that $\lambda=0.05$ tends to decrease the $\mathrm{CN}$ at low storm depths, as demonstrated by the Cyclic Method. It should also be noted that the Dunlow gage has the shortest record length with the lowest maximum storm depth $(47 \mathrm{~mm})$. This was at least $20 \mathrm{~mm}$ less than the maximum depths at the other gages.

\subsection{Conclusions}

By comparing the results of each $\mathrm{CN}$ calculation procedure, it is apparent that the $\mathrm{CN}$ is dependent on all of the computational variables listed in Table 3. In the Cyclic and Asymptotic methods, the CN's decreased with increasing soil depth due to the increased soil moisture storage capacity. The Clay Loam soil resulted in higher CN's than the Silt Loam because of the lower value of the INFILT parameter governing the infiltration rate 
in the Clay Loam. The CN's also vary with storm depth, typically approaching a constant value beyond some threshold depth.

Perhaps the most unanticipated result of this study is the apparent dependence of the $\mathrm{CN}$ on storm distribution. In the Cyclic Method, the distributions consisting of the high intensity hourly rainfall intervals (Type II and WDM Triangular) tended to result in greater variation of the $\mathrm{CN}$ with storm depth. This effect was also seen in the Asymptotic Method. Figures 7 and 11 demonstrate the similarity in the distributions of the selected storms from all gages to the Type II and WDM Triangular shapes. In each method, the twenty-four hour distribution that allocates the most of rainfall in the shortest time (Dunlow in the Asymptotic Method and WDM Triangular in the Cyclic Method) resulted in the highest $\mathrm{CN}$ values and the lowest mean infiltration depths.

These findings suggest that the variability of the $\mathrm{CN}$ in time cannot be explained by antecedent soil moisture or rainfall alone and therefore, the use of the $\mathrm{CN}$ method in continuous modeling does not appear to be appropriate. It is suggested that a distinction be made between the classic $\mathrm{CN}$ and continuous $\mathrm{CN}$ 's presently in use by using a different symbol such as $\mathrm{CN}^{*}$. 


\subsection{Summary and Conclusions}

The use of the $\mathrm{CN}$ as a simplification of several parameters in a comprehensive watershed model (HSPF) was investigated with respect to the analysis of the cumulative hydrologic impacts of surface coal mining in West Virginia. A soil physics model was developed to act as a method of translation between CN's and HSPF parameters based on soil hydraulic properties. Curve Numbers were calculated from theoretical HSPF watersheds (parameter sets) using two numerical methods. The first method is based on the soil physics model and uses cyclic storm input to calculate CN's as a function of soil moisture. The second method is based on Hawkins' Asymptotic method of CN determination (1993) where CN's are calculated from ordered rainfall-runoff pairs. Each method found the $\mathrm{CN}$ to be dependent on a number of computational watershed variables including soil type, soil depth, storm depth, and storm distribution. The effect of the initial abstraction ratio of 0.05 vs. 0.2 was found to reduce the bias of high $\mathrm{CN}$ values at low storm depths.

These findings suggest that the hydrologic information inherent to the $\mathrm{CN}$ method is insufficient for the $\mathrm{CN}$ to adequately represent multiple HSPF parameters. Because of its apparent dependence on several watershed variables which are naturally irregular in space and time, the $\mathrm{CN}$ method appears to be unsuitable for continuous rainfall-runoff predictions. Application of the $\mathrm{CN}$ method should be limited to single, event-based runoff estimation as described in the original development of the method. The development of a translation methodology between the $\mathrm{CN}$ and HSPF parameters based on soil physics was successful, however, the use of the CN method with HSPF to simulate the hydrologic impacts of mine sites is not recommended. The effects of longterm land use change in general are best quantified by gathering actual rainfall-runoff data. Accurate simulations of the effects of surface mining using HSPF (or other continuous models) in West Virginia will require several years of hydrologic and meteorological time series records from the mine sites themselves. These records would be extremely valuable for studying the cumulative hydrologic impacts of coal mining by providing the ability to calibrate continuous models to observed data. 


\subsection{References}

Arnold, J.G., Williams, J.R., Srinivasan, R., and King, K.W., 1995. "SWAT: Soil Water Assessment Tool”. Texas A\&M University, Texas Agricultural Experiment Station, Blackland Research Center: 808 East Blackland Road, Temple, TX.

Bicknell, B.R., Imhoff, J.C., Kittle, J.L., Jobes, T.H., and Donigian, A.S., 2001. "Hydrological Simulation Program - Fortran", Version 12, U.S. Environmental Protection Agency, Athens, GA.

Binger, R.L., and Theurer, F.D., 2005. "AnnAGNPS Technical Processes:

Documentation Version 3.2", USDA-ARS, National Sedimentation Laboratory, Oxford, MS.

Borah, D.K. and Bera, M., 2003. "Watershed-scale Hydrologic and Nonpoint-Source Pollution Models: Review of Mathematical Bases". Trans. ASAE 46(6): 1553- 1566

Brakensiek, D.L., Engleman, R.L., and Rawls, W.J., 1981. "Variation within Texture Classes of Soil Water Parameters", Transactions of the ASAE, Vol. 24, No. 2, 335-339.

Brooks, R.H. and Corey, A.T., 1964. "Hydraulic Properties of Porous Media", Hydrology Paper No. 3, Colorado State University, Fort Collins, CO.

Dinicola, R.S., 2001. "Validation of a numerical modeling method for simulating rainfall-runoff relations for headwater basins in western King and Snohomish Counties, Washington," USGS Water-Supply Paper 2495.

Dinicola, R.S., 1990. "Characterization and Simulation of Rainfall-Runoff Relations for Headwater Basins in Western King and Snohomish Counties, Washington," U.S. Geological Survey Water Resources Investigations Report 89-4052, Tacoma, Washington.

Donigian, Jr., A.S., and Davis, H.H., Jr, 1978. "User Manual for Agricultural Runoff Management (ARM) Model", U.S. Environmental Protection Agency, Athens, GA, EPA600/3-78-080.

Donigian, Jr., A.S., Imhoff., J.C., Kittle, Jr., J.L., 1999. "HSPFParm An Interactive Database of HSPF Model Parameters", Version 1.0 beta 5, U.S. Environmental Protection Agency, Washington, DC.

Donigian, A.S., Jr., 2002. "Watershed Model Calibration and Validation, the HSPF Experience." WEF 2002 Specialty Conference Proceedings, Nov. 13-16, Phoenix, AZ.

Doherty, J., 2002. "PEST Surface Water Utilities, Watermark Numerical Computing and Documentation," University of Idaho, September 2002. http://www.sspa.com/pest 
Fletcher, J.J., Eli, R.N., Strager, M.P., Sun, Q., Churchill, J.B., Lamont, S.J., Galya, T., A., and Schaer, A.N., 2004. "The Watershed Characterization and Modeling System (WCMS): Support Tools for Large Watershed CHIA and NPDES Analyses", Proc., Advanced Integration of Geospatial Technologies in Mining and Reclamation, December 7-9, Atlanta, GA.

Green, W.H. and Ampt, G.A., 1911. "Studies on Soil Physics: 1. Flow of Air and Water Through Soils", Journal of Agricultural Sciences, 4:1-24.

Jacobs, J.M., Myers, D.A., and Whitfield, B.M., 2003. "Improved Rainfall/Runoff Estimates using Remotely Sensed Soil Moisture". J. of the American Water Resources Association (JAWRA) 39(2):313-324.

Hawkins, R.H., 1993. “Asymptotic Determination of Curve Numbers from Data”, Journal of Irrigation and Drainage Engineering, Vol. 119, No. 2, p. 334-345.

Hawkins, R.H., Jiang, R., Woodward, D.E., and Hjelmfelt, A.T., 2002. "Runoff Curve Number Method: Examination of the Initial Abstraction Ratio", Proc., USDA-NRCS Hydraulic Engineering Workshop.

Hjelmfelt, A.T., Woodward, D.A., Conaway, G., Plummer, A., Quan, Q.D., and Van Mullen, J., 2001. "Curve Numbers, Recent Developments", Proc., $29^{\text {th }}$ Congress of the Intr. Assoc. for Hydraulic Research, Beijing, China, (CD-ROM).

Hummel, P., Kittle, J., and Gray, M., 2001. "WDMUtil A Tool for Managing Watershed Modeling Time-Series Data", Version 2.0, U.S. Environmental Protection Agency, Washington, DC.

Hydrocomp International, Inc., 1969, Hydrocomp Simulation Programming Operations Manual, Second Edition, Palo Alto, California.

Lagarias, J.C., Reeds, J.A., Wright, M.H., and Wright, P., E., 1998. "Convergence Properties of the Nelder-Mead Simplex Method in Low Dimensions," SIAM Journal of Optimization, Vol. 9 Number 1, pp. 112-147.

Leonard, R.A., Knisel, W.G., and Still, D.A. 1987. "GLEAMS: Groundwater Loading Effects of Agricultural Management Systems". Transactions of the ASAE 30(5): 14031418.

Mathworks, Inc., Copyright 1984-2005. "The Language of Technical Computing”, MATLAB Version 7.0.4.365(R14), Service Pack 2.

Nearing, M.A., Liu, B.Y., Risse, L.M., and Zhang, X., 1996, “Curve Numbers and Green-Ampt Effective Hydraulic Conductivities", Water Resources Bulletin, American Water Resources Association, Vol. 32, No. 1. 
NRCS National Engineering Handbook Part 630 Hydrology, 1993. "Chapter 4: Storm rainfall data", NRCS USDA, Washington, D.C.

Ponce, V.M., and Hawkins, R.H., 1996. "Runoff Curve Number: Has It Reached Maturity?", Journal of Hydrologic Engineering, Vol. 1, No. 1, 11-19.

Rawls, W.J., Brakensiek, D.L., and Miller, N., 1983. "Green-Ampt Infiltration Parameters from Soils Data", Journal of Hydraulic Engineering, Vol. 109, No. 1, American Society of Civil Engineers.

Rawls, W.J., and Brakensiek, D.L., 1986. "Comparison between Green-Ampt and Curve Number Runoff Predictions”, ASAE Paper No. 85-2505, Soil and Water Div., Vol. 29(6).

Rosetta 1999, Version 1.0, Author: Marcel G. Schaap. http://www.ussl.usda.gov/models/rosetta/rosetta.HTM

Rowney, A. C. and MacRae, C.R., 1992. "QUALHYMO User/Technical Reference Manual”, Release 2.1 Continuous Hydrologic Simulation Framework.

Sams, J.I. and Witt, E.C., 1995, "Simulation of streamflow and sediment transport in two surface-coal-mined basins in Fayette County, Pennsylvania", USGS Water-Resources Investigations Report 92-4093.

Soil Conservation Service (SCS), 1986, "Urban Hydrology for Small Watersheds", Technical Release 55 (TR-55), $2^{\text {nd }}$ edition, U.S. Department of Agriculture, Washington, D.C.

Strager, J.M. and Yuill, C.B., 2002. "The West Virginia Gap Analysis Project, Final Report," USGS GAP Analysis Program. ftp://ftp.gap.uidaho.edu/products/west_virginia/report/wvgaprpt.pdf

Strager, M.P., 2005. "Watershed Characterization and Modeling System Version 9.0 Technical Documentation". Prepared for West Virginia Department of Environmental Protection. Natural Resource Analysis Center, West Virginia University, Morgantown, WV.

U.S. Environmental Protection Agency, 2000, "EPA BASINS Technical Note 6", EPA823-R00-012.

Users Manual for an Expert System (HSPEXP) for Calibration of the Hydrological Simulation Program - Fortran, 1994, U.S. Geological Survey Water-Resources Investigations Report 94-4168, Reston, Virginia.

Van Mullem, J.A., 1992. "Soil Moisture and Runoff-Another Look", ASCE Water Forum '92, Proceedings of the Irrigation and Drainage Session, Baltimore, MD. 
Van Mullem, J.A., Woodward, D.E., Hawkins, R.H., and Hjelmfelt, A.T., 2002. "Runoff Curve Number Method: Beyond the Handbook", Proc., USDA-NRCS Hydraulic Engineering Workshop.

Williams, J.R., Dyke, P.T., and Jones, C.A., 1982. "EPIC: A Model for Assessing the Effects of Erosion on Soil Productivity", In Proc. Third Int. Conf. On State-of-the-Art Ecological Modeling, Int. Soc. For Ecological Modeling.

Woodward, D.E., Hawkins, R.H., Hjelmfelt, A.T., Van Mullem, J.A., and Quan, Q.D., 2002. "Curve Number Method: Origins, Application and Limitations", Proc., USDANRCS Hydraulic Engineering Workshop.

Woodward, D.E., and Plummer, A., 2000. "Antecendent Moisture Conditions NRCS View Point", Proc., ASCE-Watershed Management and Operations Management Conference, Fort Collings, CO, June 20-24 . 


\section{Appendix A. HSPF Calibration, Verification, and Parameter Optimization Study}

This is an unpublished technical report prepared by, Dr. Robert N. Eli ${ }^{1}$, Samuel J. Lamont $^{1}$, and Elena Hoeg ${ }^{2}$. Funding for this research was provided by the West Virginia Department of Environmental Protection. Additional support was provided by the Office of Surface Mining, Jim Sams of the USGS, Pittsburgh, PA, and Kate Flynn of the USGS, Reston, Virginia.

${ }^{1}$ Department of Civil and Environmental Engineering, West Virginia University, ${ }^{2}$ Natural Resource Analysis Center, West Virginia University.

\section{Review of HSPF Background and Related Applications}

HSPF was selected as the hydrologic model for CHIA of mine-impacted watersheds in the state of West Virginia because of its wide use and acceptance as a joint watershed and stream water quality model. It is a comprehensive, continuous watershed simulation model, designed to simulate all the water quantity and water quality processes that occur in a watershed (Bicknell, et al., 2001). This includes sediment transport and movement of contaminants overland and through the stream channel system. HSPF has its origins in the Stanford Watershed Model (SWM) developed by Crawford and Linsley (www. hydrocomp.com). This latter model was the first truly comprehensive land surface and subsurface hydrologic processes model that treated every component of the hydrologic cycle. It has been widely adopted in various forms and its hydrologic components have been included in related models, such as the Kentucky Watershed Model. Crawford and Linsley further developed the original SWM model and created HSP, the Hydrocomp Simulation Program, which included sediment transport and water quality simulation. Hydrocomp also developed the ARM (Agricultural Runoff Management Model) and the NPS (Nonpoint Source Pollutant Loading Model) for the EPA (U.S. Environmental Protection Agency) during the early 1970's. In 1976, EPA commissioned Hydrocomp, Inc. to develop a set of simulation modules in standard Fortran that would handle all the functions handled by HSP, plus those within two additional models, ARM and NPS. The intention was to produce a modeling system that was easy to maintain and modify. The result was HSPF, which can be applied to most watersheds using commonly available meteorologic and hydrologic data. HSPF has been applied to a variety of watershed studies, including the U.S.EPA Chesapeake Bay Program, Carson - Truckee River (California, Nevada), Minnesota River Assessment Project, Florida Water Management District, King Co. Washington Management Plan, and others (Donigian, 2003). Other work that relates specifically to various aspects of the calibration methodology used here includes Sams and Witt (1995), and Dinicola (2001). Sams and Witt (1995) utilized HSPF to model two surface-mined watersheds in Fayette County, $\mathrm{Pa}$. The significance of this latter study is the location of these two watersheds, located within and just to the north of the Big Sandy calibration watershed which is one of the calibration watersheds. The Stony Fork Basin is a sub-basin of Big Sandy, and the Poplar Run Basin is located just 15 miles to the north of Big Sandy. The geology, soils, 
topography, and land cover of these two watersheds are very similar to the characteristics of many of the trend station, calibration, and verification watersheds used in the CHIA project. Therefore, the fitting parameters as determined by Sams and Witt (1995), where adopted as a starting point in the calibration processes for the CHIA project. Additional studies of note are those by Al-Abed, et al., (2002), Lohani, et al., (2002), Martin, et al., (1990), Riberio (1996), and Srinivasan, et al., (1998).

\section{Summary of HSPF Basic Capabilities and Characteristics}

The HSPF model has the following general characteristics:

- It is a continuous simulation model (It can simulate streamflow for many years at hourly time increments).

- It can be applied to natural or developed watersheds (including those with surface and underground mine sites).

- Model components simulate both the land surface and subsurface hydrology and water quality processes.

- HSPF utility programs provide time series data management, statistical analysis tools, and graphic display of results.

- Both stream and lake hydraulics and water quality processes can be simulated.

- HSPF is the core watershed model in EPA BASINS and the U.S. Army Corps of Engineers WMS modeling system.

- Development and maintenance of HSPF related software is sponsored by EPA and USGS.

There are three application modules that make up the core of the HSPF hydrologic model (each also includes several sub-modules of importance):

1) PERLND (Simulate a Pervious Land segment)

a) ATEMP (Correct air temperature for elevation difference)

b) SNOW (Simulate the accumulation and melting of snow and ice)

c) PWATER (Simulate water budget for pervious land segments)

2) IMPLND (Perform computations on a segment of impervious land)
a) ATEMP (Same as in PERLND above)
b) SNOW (Same as in IMPLND above)
c) IWATER (Simulate water budget for impervious land segment)

3) RCHRES (Perform computations for a stream reach or mixed reservoir)

a) HYDR (Simulate hydraulic behavior) 
b) ACIDpH (Simulate mine acid drainage in-stream chemistry)

Of the three application modules above, PERLND and RCHRES were used in the calibration phase of the CHIA project. The PERLND module simulates the watershed areas, with each land cover/land use classification category being described by its own unique set of PERLND parameters. The RCHRES module is applied to each stream reach, which is equivalent to a stream segment in the stream drainage network within a given watershed. Each stream reach has its own unique descriptive parameters, which are applied in the RCHRES module. The IMPLND module is for the purpose of simulating impervious areas, such as urban areas. This module was not used since no urban areas larger than a few percent of the total watershed area are encountered in the CHIA project.

\section{CHIA Calibration and Verification Watersheds}

\section{Watershed Selection}

The hydrologic component of the project involves the fitting of HSPF to each of the 235 Trend Station Watersheds identified by WVDEP. They have boundaries defined by stream water quality sampling points, or Trend Stations, located at the watershed outlets. These stream water sampling points generally do not coincide with USGS stream gaging locations that are required for the model calibration process. Therefore, model calibration must be conducted using watersheds that have a gaging station at their outlet, and are also representative of the hydrologic characteristics found in CHIA watersheds. An additional factor is the obvious impracticality of individual calibration of 235 watersheds, regardless of gaging data availability. The only practical approach to finding a set of model parameters for each of the 235 trend station watersheds is to calibrate the model to a selected few watersheds that contain representative characteristics of the whole population of watersheds. It is then assumed that watersheds with similar characteristics have similar model parameters representing those characteristics. It is therefore possible to calibrate a limited number of watersheds as long as their hydrologic characteristics are simulated as separable components in the hydrologic model. The suitability of the parameter sets determined during calibration is tested using a set of verification watersheds that are also representative of the CHIA watersheds. This calibration strategy follows that recommended by Donigian (2002), and successfully employed by Dinicola (1990, 2001). The Dinicola (2001) study involved 12 small watersheds in King and Snohomish Counties, in and near Seattle, Washington. The purpose of this latter study was to model the effects of urbanization on watershed response. Five of the watersheds were selected for use in calibration, characterized by various degrees of development. The calibration process proceeded with the intent to arrive at a consistent set of parameters across all 5 watersheds for each land use category. The study was successful in that it demonstrated that satisfactory model performance could be achieved by using common land use categories with single valued parameter sets. The approach used in the CHIA calibration study follows Dinicola's lead in maintaining a single valued set of model parameter values for each land use category.

The calibration and verification watersheds lie within the coal regions and either encompass or are adjacent to trend station watersheds. Figure 1 shows the locations of 
the trend station watersheds within the state of West Virginia, including the five watersheds selected for calibration purposes. It will be noted that the Twelve Pole Creek, Clear Fork, Buffalo Creek, and Big Sandy watersheds contain trend station watersheds in whole or in part. Big Sandy lies partially in the state of Pennsylvania, and therefore only the West Virginia portion contains trend station watersheds. Tygart Valley at Elkins does not contain trend station watersheds, but lies adjacent to trend station watersheds on its western boundary. Figure 2 shows the location of five verification watersheds which are used to test the modeling parameters determined in the calibration process. These include Big Sandy (same as the calibration watershed, except using a different meteorological record), Tygart Valley at Belington, Tygart Valley at Daily, Piney Creek, and Panther Creek. It will be noted that the two Tygart Valley verification watersheds are a superset and subset of Tygart Valley at Elkins, respectively. These latter two verification watersheds are defined by different gaging locations along the same stream, and hence share a portion of the same watershed. The Big Sandy watershed is present in both the calibration and verification watershed groups to provide for error checking.

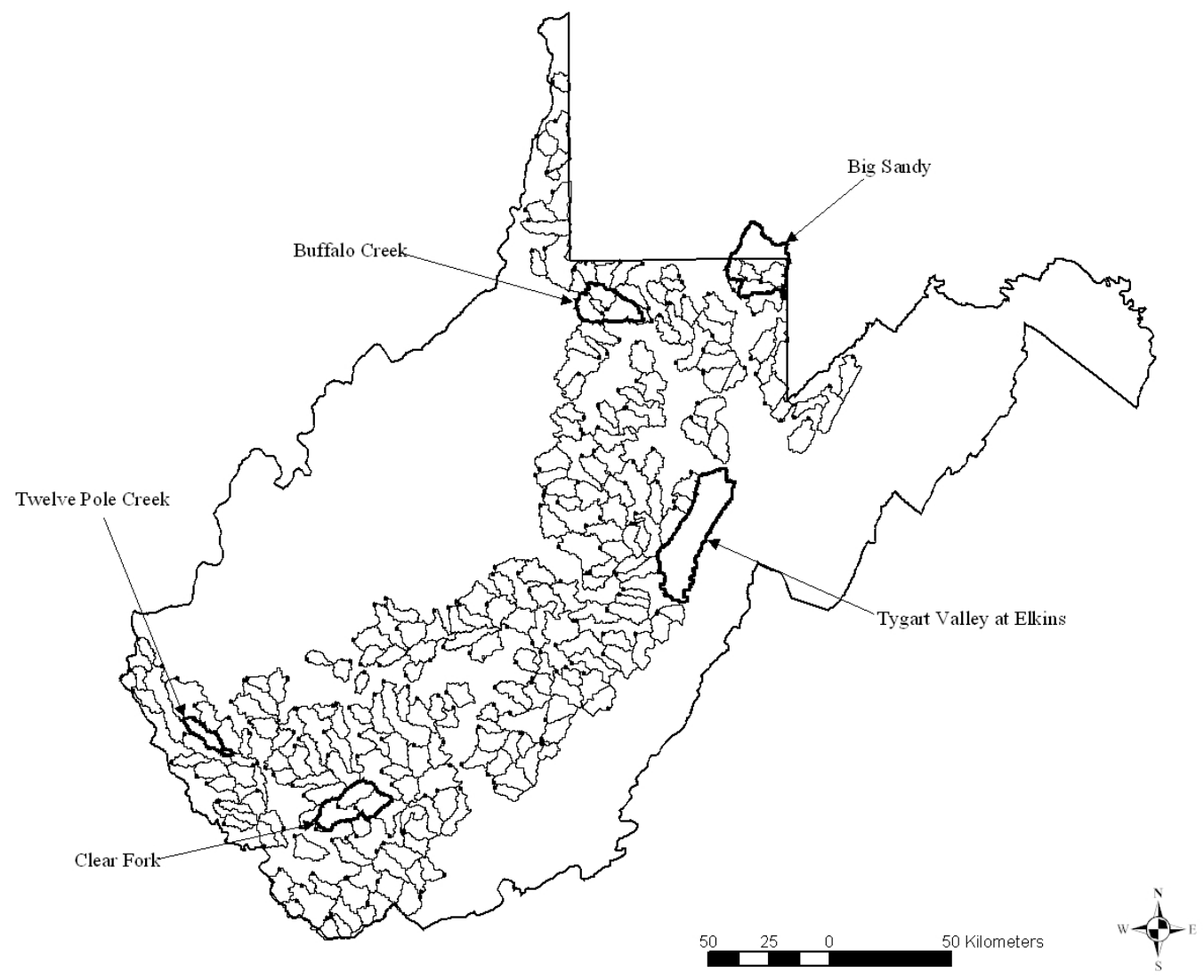

Figure 1 : West Virginia CHIA Trend Stations and Calibration Watersheds. 


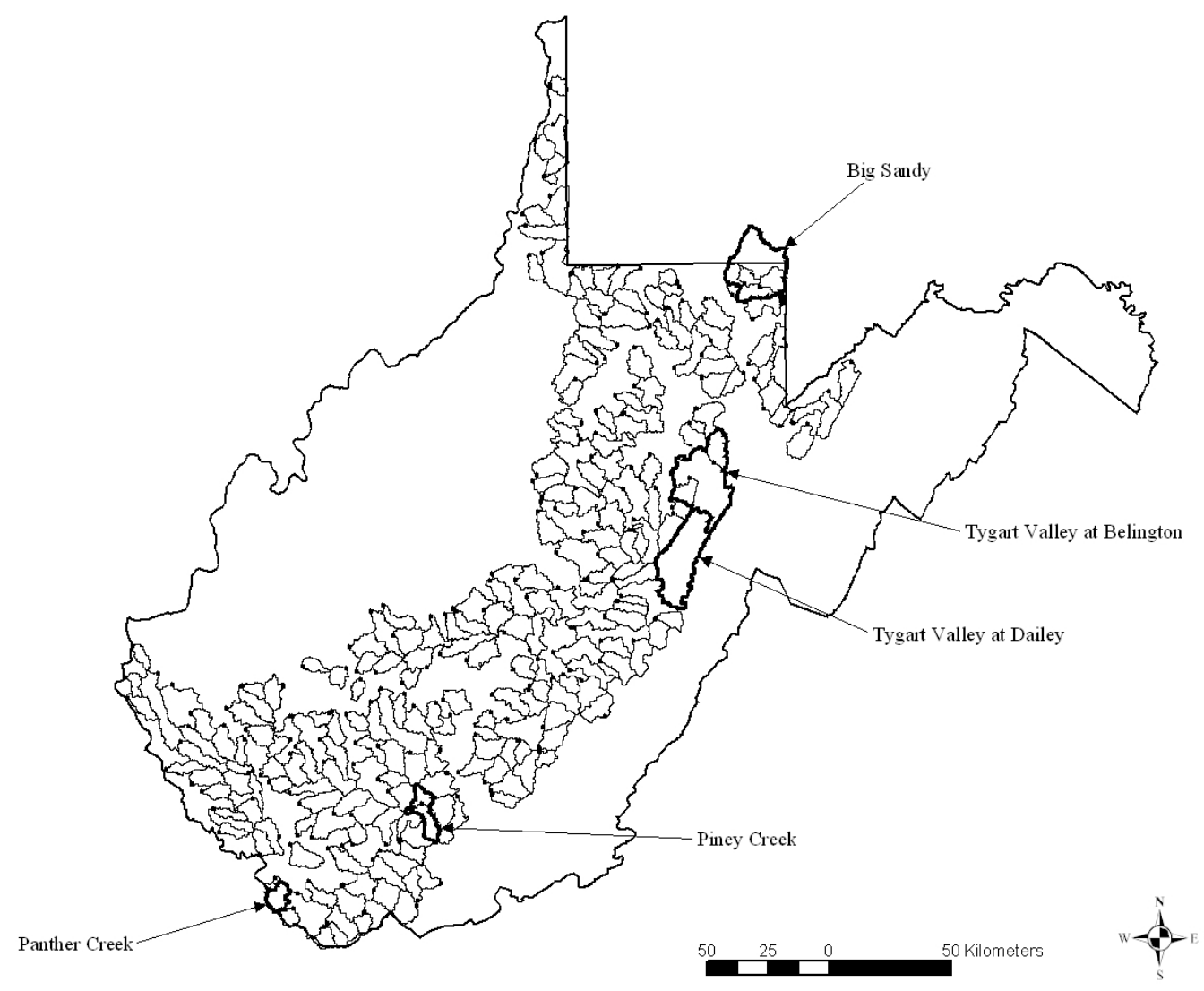

Figure 2 : West Virginia CHIA Trend Stations and Verification Watersheds

\section{Watershed Characteristics}

The calibration and verification watersheds, shown in Figures 1 and 2, required stream flow gaging data to support the HSPF model fitting process. Table 1 lists the watersheds along with the available USGS stream flow record and corresponding gage number. 
Table 1 : List of Calibration and Verification Watershed Available Gaging Records.

\begin{tabular}{|c|c|c|c|c|}
\hline & Watersheds & \multicolumn{2}{|c|}{ Stream Flow Record } & \multirow{2}{*}{ Gage Number } \\
\hline & Calibration & From & To & \\
\hline 1 & Twelve Pole Creek & $10 / 01 / 1964$ & $09 / 30 / 2000$ & 03206600 \\
\hline 2 & Buffalo Creek & 06/03/1907 & $09 / 30 / 2000$ & 03061500 \\
\hline 3 & Tygart River at Elkins & $10 / 01 / 1944$ & $09 / 30 / 2000$ & 03050500 \\
\hline 4 & Clear Fork & $06 / 28 / 1974$ & $9 / 30 / 200$ & 03202750 \\
\hline \multirow[t]{2}{*}{5} & Big Sandy & $05 / 07 / 1909$ & $09 / 30 / 2000$ & 03070500 \\
\hline & Verification & & & \\
\hline 1 & Panther Creek & $08 / 01 / 1946$ & $09 / 30 / 1986$ & 03213500 \\
\hline 2 & Tygart River at Belington & $06 / 05 / 1907$ & $09 / 30 / 2000$ & 03051000 \\
\hline 3 & Tygart River at Dailey & $04 / 20 / 1915$ & $09 / 30 / 2000$ & 03050000 \\
\hline 4 & Piney Creek & $08 / 21 / 1951$ & $09 / 30 / 1982$ & 03185000 \\
\hline 5 & Big Sandy & & see above & \\
\hline
\end{tabular}

The land use/cover classifications are based on 1993 GAP data. The classifications used are:

1. Forest
a. Steep Slope
b. Moderate Slope
c. Mild Slope

2. Barren

3. Mined

4. Pasture/Grassland

5. Row Crop/Agriculture

6. Shrubland

7. Surface Water

8. Urban/Developed

9. Wetland

It should be noted that a total of 11 classifications result due to the forested slope subcategories, which are treated as separate classifications. Table 2 lists the total watershed area and distribution of areas in the forest slope classifications for each of the calibration watersheds, illustrating the predominance of the forest category. 
Table 2 : Slope Distribution for Calibration Watersheds

\begin{tabular}{|l|l|l|l|l|l|l|}
\hline Watershed & $\begin{array}{l}\text { Total Area } \\
\text { (acres) }\end{array}$ & $\begin{array}{l}\text { Total Forested } \\
\text { Area (acres) }\end{array}$ & $\begin{array}{l}\text { \% } \\
\text { Forested }\end{array}$ & $\begin{array}{l}\text { \% Mild } \\
\text { Forest }\end{array}$ & $\begin{array}{l}\text { \% Moderate } \\
\text { Forest }\end{array}$ & $\begin{array}{l}\text { \% Steep } \\
\text { Forest }\end{array}$ \\
\hline $\begin{array}{l}\text { Twelve Pole } \\
\text { Creek }\end{array}$ & 23646 & 20402 & 86 & 10 & 16 & 74 \\
\hline Buffalo Creek & 72257 & 57590 & 80 & 19 & 28 & 53 \\
\hline $\begin{array}{l}\text { Tygart Valley at } \\
\text { Elkins }\end{array}$ & 172642 & 137950 & 80 & 16 & 22 & 62 \\
\hline Clear Fork & 79862 & 71455 & 89 & 7 & 10 & 83 \\
\hline Big Sandy & 123027 & 96713 & 79 & 61 & 29 & 10 \\
\hline
\end{tabular}

Each of the calibration watersheds has a mining history. Figure 3 shows the relative cumulative percentages of surface and underground mining in the calibration watersheds, as documented in annual mine permit application records. It should be noted that significant historical mining is not documented on these watersheds, but is known to be present. As an example, it is known that much of the Pittsburgh coal is mined out under Buffalo Creek watershed, yet it does not appear in the available mapping database. The only mined areas used in the calibration study are those classified as "mined" land in the 1993 GAP database. These latter areas are known not to be accurately classified; however, they were used since there was little to be gained by trying to include other sources of mined land data. Much of the historical mined land is reclaimed, or is overgrown with vegetation, and therefore is now classified as forest, shrubland, or pasture/grassland. Since the purpose of conducting a baseline calibration is to provide a reference condition, against which the effects of new mining can be compared, it serves no useful purpose to try to identify the historical mined areas in an effort to correct the GAP data. The difficulties in trying to treat historical mined areas as a unique classification is not warranted since the HSPF model is a lumped parameter model for which small differentiation in parameters over limited areas has no significant effect on the baseline model output (this behavior was adequately demonstrated during the calibration study to be discussed later). Therefore, the mined classification in the 1993 GAP is retained since it is an integral part of the data set, and its area must be conserved. Likewise, the surface water classification was modeled as a land surface category in order to conserve watershed drainage area. The surface water areas involved are very small and have no impact on the baseline calibration. 


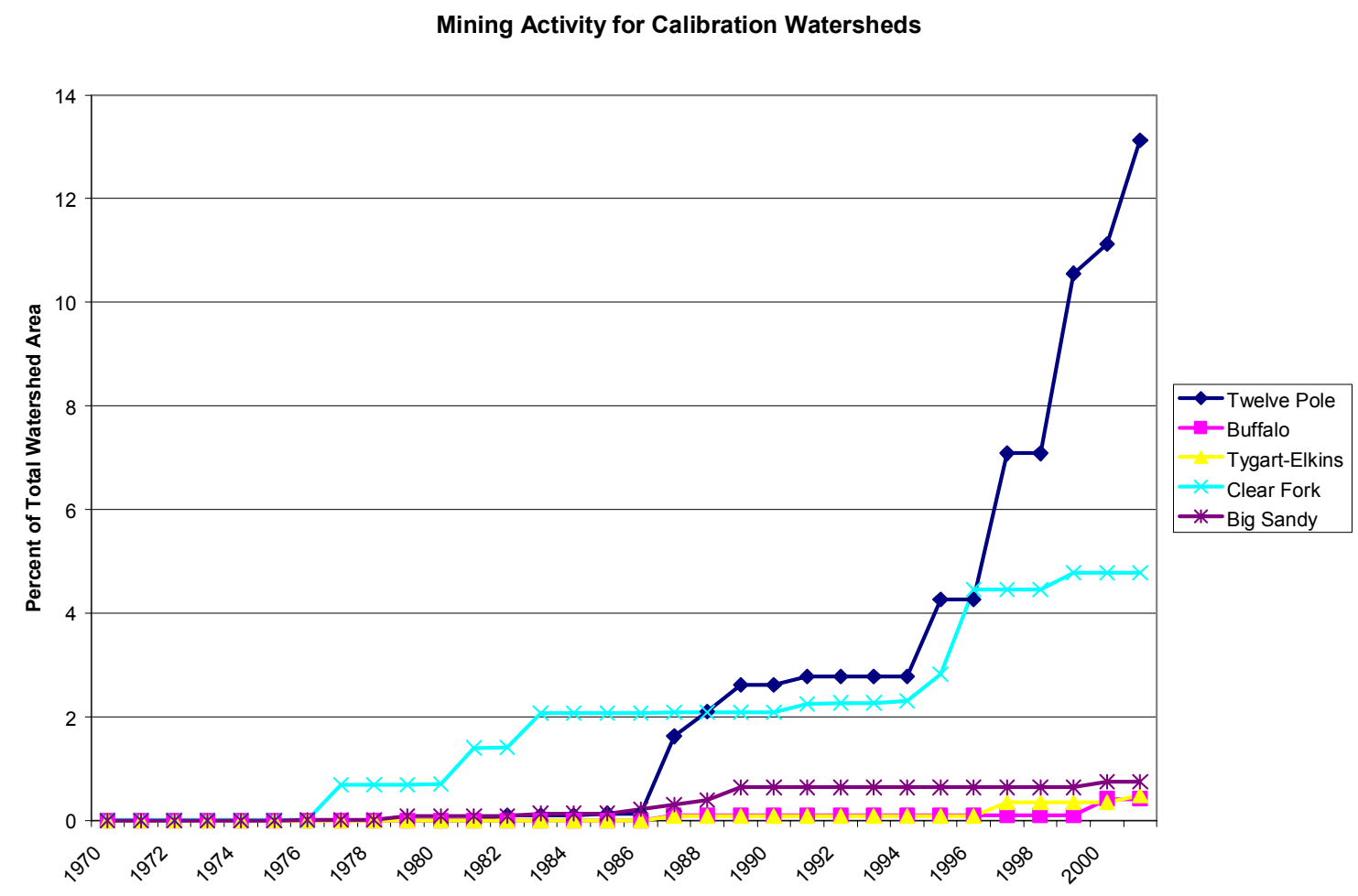

Figure 3 : Calibration Watershed Mining History (from WVDEP Permit Records).

\section{HSPF Meteorologic Data Input Requirements}

Meteorologic data required to run HSPF for the calibration process included PET, TEMP, and PREC (potential evapotranspiration, average air temperature, and precipitation). The values for PET and TEMP are estimated from daily maximum and minimum air temperatures (TMAX and TMIN). These data are supplied by NCDC (National Climatic Data Center) and downloaded from the internet (or obtained from a secondary supplier). PET is estimated using a HSPF data utility program called WDMUtil (using the Hamon formula). HSPF uses an hourly time increment for precipitation data input. The precipitation data was supplied under contract by Zedx Inc., which is formatted into average hourly values for each of $5 \mathrm{~km}$ grid squares covering the state of West Virginia and portions of surrounding states for the period from 1948 through 2000 (see Figure 4). The daily streamflow data was downloaded from a USGS internet web site. Snow cover was simulated using the temperature-index method option within HSPF. 


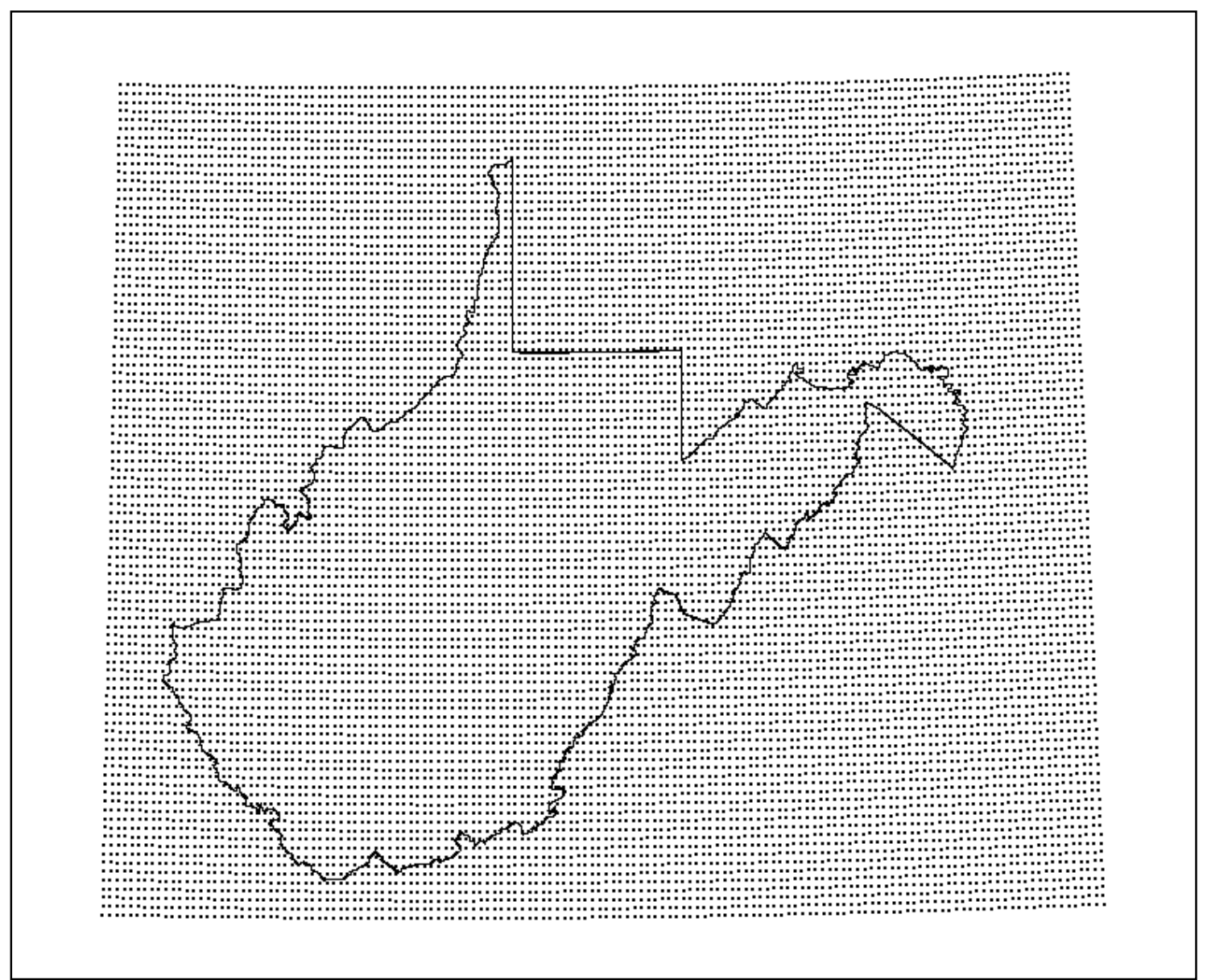

Figure 4 : Geo-located 5 km Grid Square Centers for the Zedx Hourly Precipitation Data.

\section{HSPF Model Calibration and Verification Procedures}

\section{Application of EPA BASINS in the Calibration Process}

The HSPF model is typically applied to a watershed using BASINS (USEPA, 1999) because of its built-in spatial data base and analysis tools that greatly simplify the input data preprocessing. BASINS automates much of what was formally a very tedious text editing process of building the HSPF user control input (uci) file, by taking the user through a much simpler Windows-based data entry process. The BASINS version of HSPF works reasonably well for general purpose water quality applications but does not have an acceptable acid mine drainage (AMD) water quality (chemistry) modeling capability. The BASINS user interface still requires considerable investment in user time to overcome a steep learning curve. It requires familiarity with four separate pieces of software to prepare the input data, edit the user control input (uci) file, then execute the model, and finally, analyze the results. These latter shortcomings has been addressed by expanding the capability of WCMS to include all of the HSPF modeling and data analysis tools in a single simplified user interface.

It was necessary to conduct the trend station watershed calibration study using BASINS to process the spatial data, and to generate the uci (user control input) files, since the corresponding WCMS tools were still under development during the initial 
phases of the CHIA project. In its default form, BASINS provides for automated watershed closure and subdivision using the 1:100,000 scale national DEM. Initially, corrected 1:24,000 DEM (30 m resolution) coverage for West Virginia was substituted to provide the resolution thought needed for the WVDEP-CHIA HSPF model.

Additionally, the existing DLG of the stream networks within BASINS was upgraded to the 14 digit NHD (National Hydrologic Database standard). These modifications then matched the topographic and stream network data resolution to that of the standard 7.5 min. USGS quadrangle map, instead of the 1:100,000 scale map base. Ironically, limitations within the HSPF code ultimately dictated a return to a 1:100,000 scale, and a corresponding 8 digit NHD stream network resolution. As will be presented later, modeling accuracy was not significantly affected due to the lumped parameter characteristics of HSPF.

\section{Watershed Segmentation for HSPF Model Calibration}

Segmentation of each calibration watershed into sub-watersheds was based on selection of a sub-watershed size that yields a maximum of approximately 10 subwatersheds. This was a requirement for calibration only, since the calibration method used limits the number of sub-watersheds and their associated stream segments. Figure 5 shows the Twelve Pole Creek watershed segmented based on a 100 hectare subwatershed area threshold, yielding 59 sub-watersheds. This is approximately equivalent to the resolution initially planned for use in the WCMS-HSPF model implementation. This is compared to the segmentation of Twelve Pole Creek using a 600 hectare threshold area, as shown in Figure 6, which is representative of the approximate number of subwatersheds used for the 5 calibration watersheds. Experience of other investigators (personal communication, Kate Flynn, USGS, 2003), points out that the model calibration parameters are not significantly different for coarse segmentation as compared to a fine (high resolution) segmentation of the watershed, as long as the grouped option of assigning the PERLND properties is used (explained later). Independent testing of this thesis was confirmed by simulation comparisons. Figure 7 shows the output of a HSPF simulation for Twelve Pole Creek using 59 and 5 sub-watersheds, respectively, with all other parameters and inputs held constant. The only noticeable difference between the hydrographs is the slightly higher estimation of storm peaks by the $5 \mathrm{sub}$-watershed model, which is considered of minor significance for calibration purposes. The calibration and verification HSPF watershed models used the 600 hectare threshold criteria for segmentation in order to meet the requirements of the HSPEXP software used for the calibration process (Users Manual, HSPEXP, (1994)). Final segmentation of the trend station watersheds will be done at the 1:100,000 map scale and 8 digit NHD stream network resolutions. This level of detail corresponds to that necessary to sufficiently represent the watershed hydrology and to support the modeling of in-stream chemistry of mine acid drainage. 


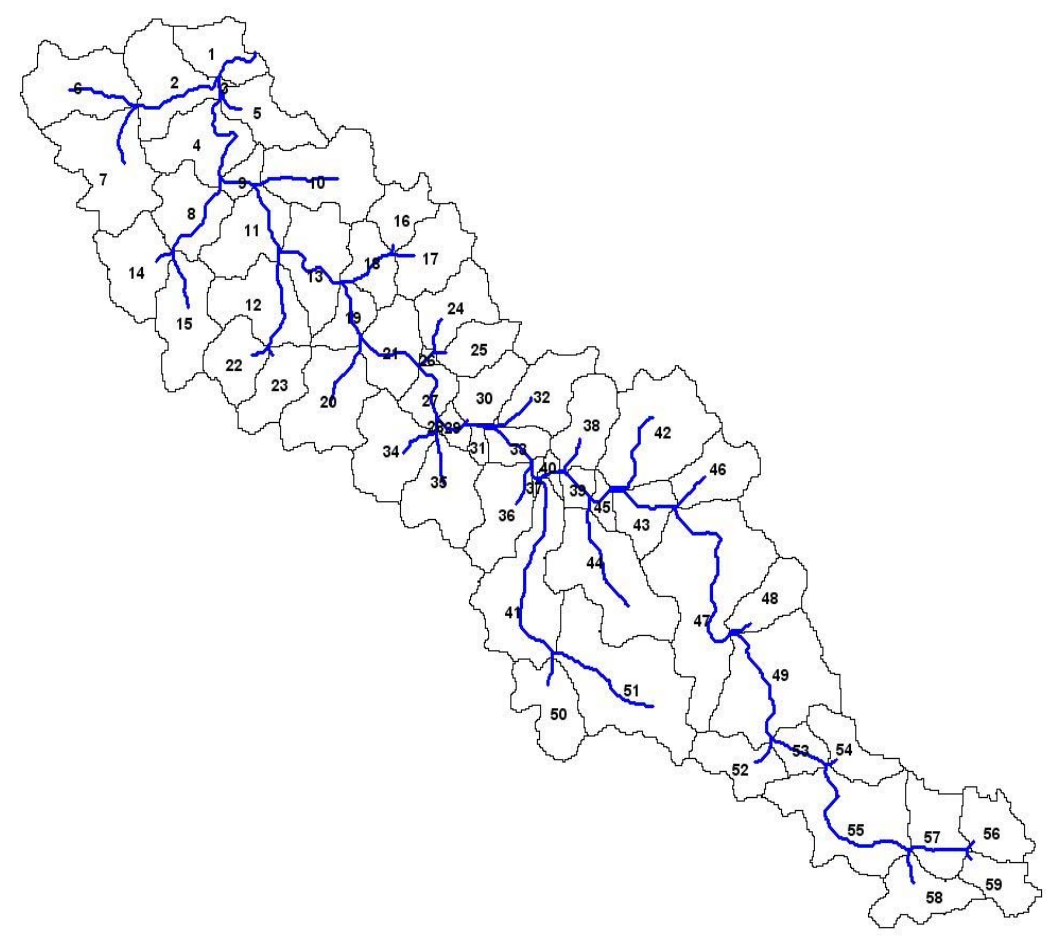

Figure 5 : Twelve Pole Creek Watershed with a 100 ha Threshold Area (59 Sub-Watersheds)

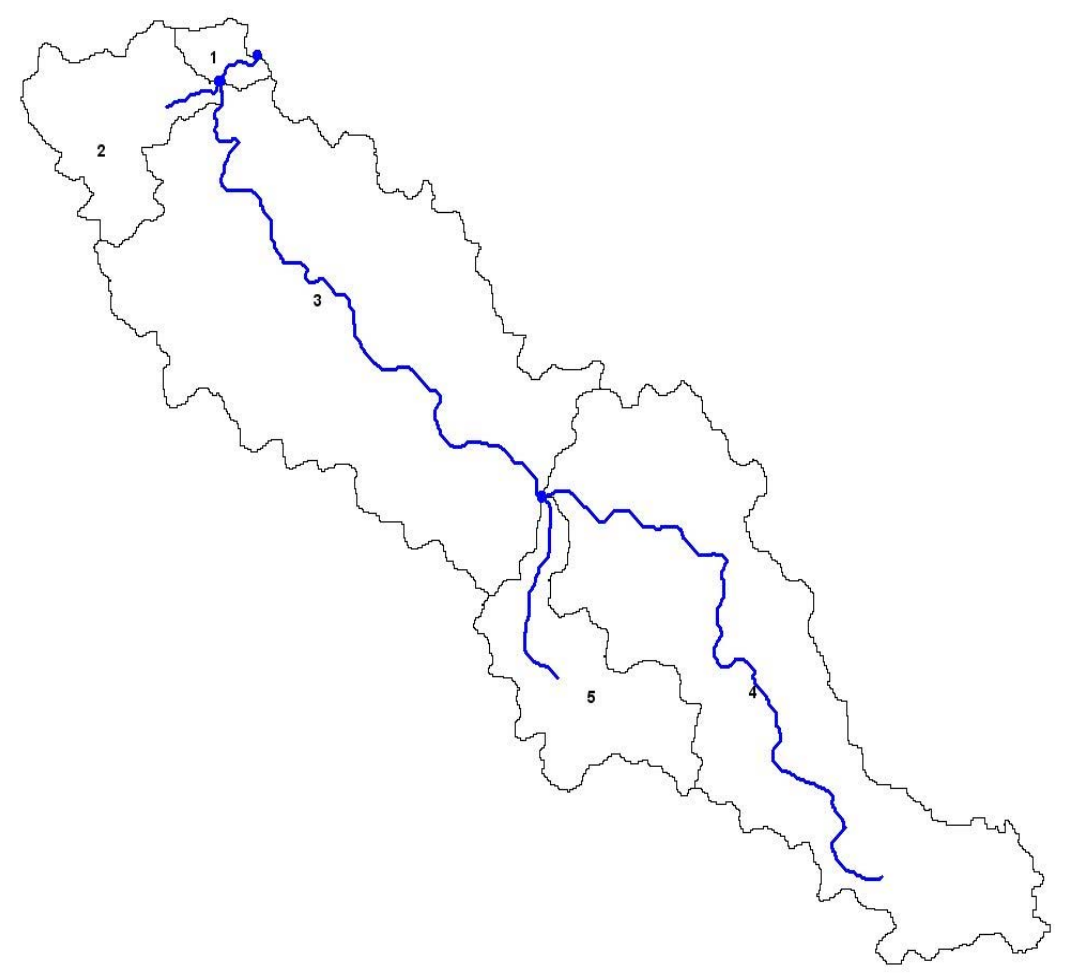

Figure 6 : Twelve Pole Creek watershed with a 600 ha threshold area (5 sub-watersheds) 


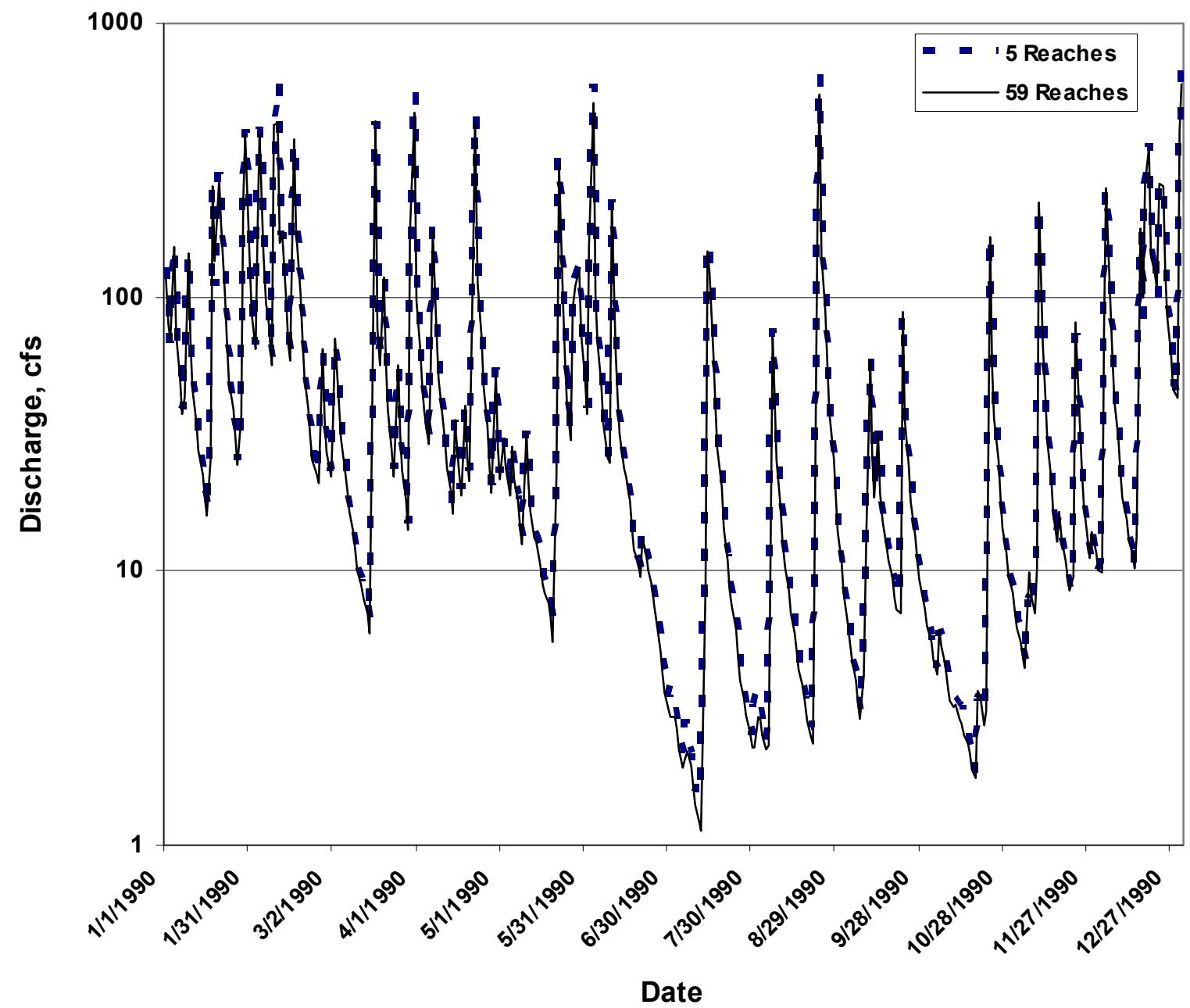

Figure 7 : A Comparison of Hydrographs for the Simulation of Twelve Pole Creek

\section{PERLND Grouping Within the HSPF-CHIA Model}

Within the HSPF-CHIA model, the grouping approach to modeling each PERLND (one for each land use/cover classification) was selected since it accumulates all areas of like land use/cover classification within the watershed into a single PERLND. This effectively reduces model complexity and the number of parameters that must be calibrated. Figure 8 illustrates the principle behind the distribution of PERLND outflows based on the percent area of its land use/cover classification contained within each subwatershed. Each sub-watershed has a single stream segment (RCHRES) to which its outflow is assigned. Each PERLND outflow to a particular stream segment is based on the fraction of its land use/cover classification area contained in the contributing subwatershed. 


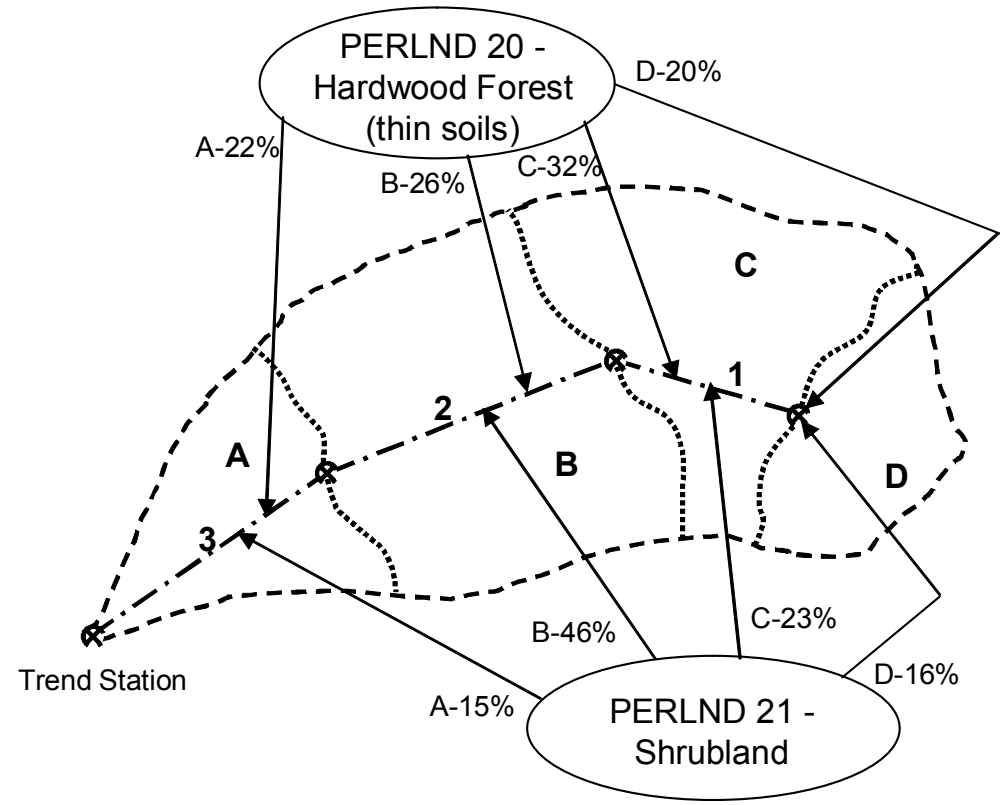

Group option for PERLND definition

Figure 8 : Grouping Land Use/Cover Classifications across Sub-watershed Boundaries.

\section{Implementation of Land Use/Cover Classifications in PERLND Grouping}

Figure 9 illustrates how the 11 different land use/cover classifications selected for the HSPF-CHIA model are implemented. Since the Forest classification is by far the most prevalent on each trend station watershed, it is subdivided into three slope categories, steep, moderate, and mild. The remaining 8 categories are not subdivided by slope, since their portion of the watershed area is typically a small percentage. Preliminary calibration experience seemed to point out a need to provide slope differentiation in the most prevailing classification, since it was logical to assume that there are significant hydrologic response differences between steep and milder slopes for the forest classification. The forest data slope categories were computed using the underlying DEM, and then incorporated into the land use/cover classification GIS layer, which is based on the 1993 GAP data (Strager and Yuill, 2002). Each grid cell is classified according to one of the 11 assigned land use/cover classifications. Within each sub-watershed the area associated with each classification is assigned to its corresponding PERLND, and a record is maintained of which stream segment receives the outflow from that area (see Figure 8). 


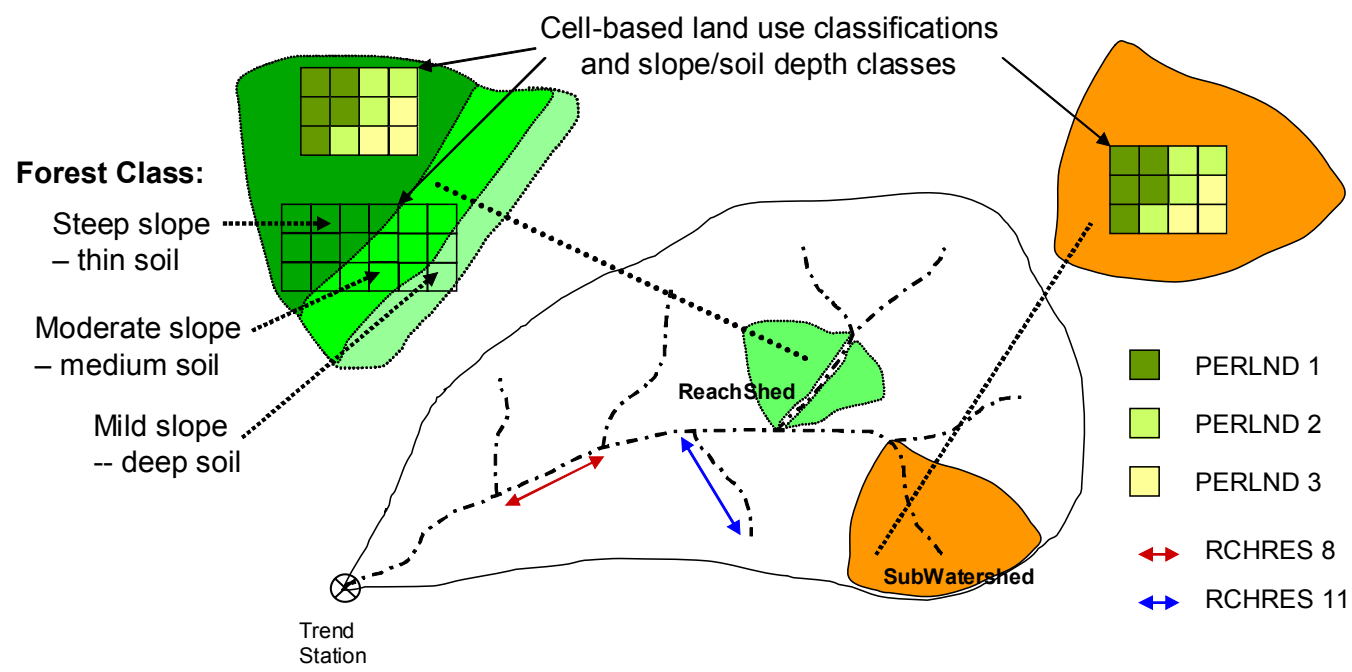

Segmentation Based on NHD Stream Drainage Network Representation in WCMS.

Figure 9 : Illustration of Assignment of Land Use/Cover Classification in PERLND Grouping.

\section{Manual Calibration and Verification Using HSPEXP}

In order to begin the HSPF-CHIA calibration, initial values of selected calibration parameters needed to be assigned. These initial values were based on a review of parameters from other calibration studies within the Mid-Atlantic region, as determined from the HSPFParm, (1999) database (a database maintained by EPA as part of the BASINS software package), and values from similar studies (Sams, et al., (1995)), including EPA BASINS Technical Note 6, (2000). Personal communications with Kate Flynn of the USGS, Reston, in 2003 resulted in a calibration procedure that uses a single HSPF uci that is designed to combine all of the calibration watersheds into a single HSPF model run. Following a combined HSPF model run, the current calibration parameters could then be checked for suitability using a utility program called HSPEXP (USGS Report 94-4168, (1994)). This approach resulted in the creation of a single uci for Twelve Pole Creek, Buffalo Creek, Tygart Valley at Elkins, Clear Fork, and Big Sandy (Figure 1). Some simplifications were required since HSPEXP has a limit on the number of PERLND's and RCHRES's it can handle at one time, which is the reason for the 600 hectare threshold watershed subdivision used for calibration (Figure 6). Successful HSPF calibration runs were made using the combined uci within the HSPEXP software. A second combined uci was created for the 5 verification watersheds: Panther Creek, Piney Creek, Tygart Valley at Belington, Tygart Valley at Daily, and Big Sandy (Figure 2). 
Table 3 shows the manual calibration results for the calibration watersheds, while Table 4 shows the corresponding results for the verification watersheds. The performance of the model is evaluated in HSPEXP by a number of statistics that are included in both tables. The statistics are based on average annual values, and show that, in most cases, the total runoff depths in each of the categories are in good agreement. The data available for calibration is considered the bare minimum for HSPF applications; therefore, it was impossible to meet the standard error criteria limits in all cases. However, since the application of HSPF for CHIA is a comparative analysis between the baseline hydrology and water quality, to that following additional mining, absolute accuracy is less important than comparative accuracy. The calibration errors are considered acceptable for the needs of CHIA, when used in the comparative analysis mode.

To provide additional calibration confidence, a detailed model performance analysis and parameter optimization study was conducted using independent optimization software (see following section). 
Table 3 : HSPF Model Calibration Statistics, Simulation Period: 1/1/1985-1/1/1990.

\begin{tabular}{|l|c|c|}
\cline { 2 - 3 } \multicolumn{1}{c|}{} & \multicolumn{2}{c|}{ TWELVE POLE CREEK } \\
\cline { 2 - 3 } \multicolumn{1}{c|}{} & Simulated & Observed \\
\hline Total runoff, in inches & 107.3 & 102.9 \\
\hline Total of highest $10 \%$ flows, in inches & 58.25 & 57.3 \\
\hline Total of lowest $50 \%$ flows, in inches & 6.91 & 5.39 \\
\hline Evapotranspiration, in inches & Simulated & Potential \\
\hline Baseflow recession rate & 123.7 & 131.8 \\
\hline Summer flow volume, in inches & Simulated & Observed \\
\hline Winter flow volume, in inches & 0.92 & 0.91 \\
\hline & 8.39 & 6.68 \\
\hline Error in total volume & 50.67 & 49.33 \\
\hline Error in low flow recession & Current & Criteria \\
\hline Error in 50\% lowest flows & 4.3 & 10 \\
\hline Error in 10\% highest flows & -0.01 & 0.01 \\
\hline Seasonal volume error & 28.3 & 10 \\
\hline
\end{tabular}

\begin{tabular}{|c|c|}
\hline \multicolumn{2}{|c|}{ BUFFALO CREEK } \\
\hline Simulated & Observed \\
\hline 123.9 & 121.21 \\
\hline 66.7 & 63.11 \\
\hline 9.58 & 10.33 \\
\hline Simulated & Potential \\
\hline 148.5 & 153.7 \\
\hline Simulated & Observed \\
\hline 0.91 & 0.92 \\
\hline 10.4 & 13.13 \\
\hline 46.14 & 46.6 \\
\hline Current & Criteria \\
\hline 2.2 & 10 \\
\hline 0.01 & 0.01 \\
\hline-7.2 & 10 \\
\hline 5.7 & 15 \\
\hline 19.8 & 15 \\
\hline
\end{tabular}

\begin{tabular}{|c|c|}
\hline \multicolumn{2}{|c|}{ TYGART VALLEY AT ELKINS } \\
\hline Simulated & Observed \\
\hline 179.4. & 167.544 \\
\hline 89.22 & 78.442 \\
\hline 17.98 & 18.503 \\
\hline Simulated & Potential \\
\hline 140.1 & 142.2 \\
\hline Simulated & Observed \\
\hline 0.9 & 0.91 \\
\hline 23.97 & 22.74 \\
\hline 54.1 & 53.89 \\
\hline Current & Criteria \\
\hline 7.1 & 10 \\
\hline 0.01 & 0.01 \\
\hline-2.8 & 10 \\
\hline 13.7 & 15 \\
\hline 5 & 10 \\
\hline
\end{tabular}

\begin{tabular}{|l|c|c|}
\cline { 2 - 3 } \multicolumn{1}{c|}{} & \multicolumn{2}{c|}{ CLEAR FORK } \\
\cline { 2 - 3 } \multicolumn{1}{c|}{} & Simulated & Observed \\
\hline Total runoff, in inches & 113.9 & 109.298 \\
\hline Total of highest 10\% flows, in inches & 58.27 & 54.427 \\
\hline Total of lowest 50\% flows, in inches & 8.75 & 9.451 \\
\hline Evapotranspiration, in inches & Simulated & Potential \\
\hline Baseflow recession rate & 149.7 & 154.6 \\
\hline Summer flow volume, in inches & Simulated & Observed \\
\hline Winter flow volume, in inches & 0.91 & 0.93 \\
\hline Error in total volume & 6.76 & 6.904 \\
\hline Error in low flow recession & 43.56 & 44.658 \\
\hline Error in 50\% lowest flows & Current & Criteria \\
\hline Error in 10\% highest flows & 4.2 & 10 \\
\hline Seasonal volume error & 0.02 & 0.01 \\
\hline
\end{tabular}

\begin{tabular}{|c|c|}
\hline \multicolumn{2}{|c|}{ BIG SANDY } \\
\hline Simulated & Observed \\
\hline 179 & 173.25 \\
\hline 86.62 & 76.686 \\
\hline 19.37 & 21.924 \\
\hline Simulated & Potential \\
\hline 118.7 & 120 \\
\hline Simulated & Observed \\
\hline 0.92 & 0.92 \\
\hline 20.55 & 19.729 \\
\hline 51.44 & 63.8 \\
\hline Current & Criteria \\
\hline 3.7 & 10 \\
\hline 0 & 0.01 \\
\hline-11.6 & 10 \\
\hline 13 & 15 \\
\hline 23.6 & 10 \\
\hline
\end{tabular}


Table 4 : HSPF Model Verification Statistics, Simulation Period: 1/1/1976-12/31/1981.

\begin{tabular}{|l|c|c|}
\cline { 2 - 3 } \multicolumn{1}{c|}{} & \multicolumn{2}{c|}{ TYGART VALLEY BELINGTON } \\
\cline { 2 - 3 } \multicolumn{1}{c|}{} & Simulated & Observed \\
\hline Total runoff, in inches & 149.9 & 162.593 \\
\hline Total of highest $10 \%$ flows, in inches & 66.42 & 66.21 \\
\hline Total of lowest $50 \%$ flows, in inches & 14.48 & 20.134 \\
\hline Evapotranspiration, in inches & Simulated & Potential \\
\hline Baseflow recession rate & 113.3 & 114.5 \\
\hline Summer flow volume, in inches & Simulated & Observed \\
\hline Winter flow volume, in inches & 0.87 & 0.91 \\
\hline & 15.18 & 21.151 \\
\hline Error in total volume & 60.87 & 63.773 \\
\hline Error in low flow recession & Current & Criteria \\
\hline Error in 50\% lowest flows & -7.8 & 10 \\
\hline Error in 10\% highest flows & 0.04 & 0.01 \\
\hline Seasonal volume error & -28.1 & 10 \\
\hline
\end{tabular}

\begin{tabular}{|c|c|}
\hline \multicolumn{2}{|c|}{ PINEY CREEK } \\
\hline Simulated & Observed \\
\hline 114.7 & 90.047 \\
\hline 56.48 & 35.638 \\
\hline 10.53 & 12.745 \\
\hline Simulated & Potential \\
\hline 104.1 & 108.6 \\
\hline Simulated & Observed \\
\hline 0.88 & 0.92 \\
\hline 10.01 & 11.037 \\
\hline 43.04 & 33.556 \\
\hline Current & Criteria \\
\hline 27.4 & 10 \\
\hline 0.04 & 0.01 \\
\hline-17.4 & 10 \\
\hline 58.5 & 15 \\
\hline 37.6 & 10 \\
\hline
\end{tabular}

\begin{tabular}{|c|c|}
\hline PANTHER CREEK \\
\hline Simulated & Observed \\
\hline 102.4 & 102.117 \\
\hline 56.51 & 54.585 \\
\hline 7.05 & 8.586 \\
\hline Simulated & Potential \\
\hline 134.8 & 137.5 \\
\hline Simulated & Observed \\
\hline 0.9 & 0.9 \\
\hline 5.36 & 8.489 \\
\hline 39.84 & 40.357 \\
\hline Current & Criteria \\
\hline 0.3 & 10 \\
\hline 0 & 0.01 \\
\hline-17.9 & 10 \\
\hline 3.5 & 15 \\
\hline 35.6 & 10 \\
\hline
\end{tabular}

\begin{tabular}{|l|c|c|}
\cline { 2 - 3 } \multicolumn{1}{c|}{} & \multicolumn{2}{c|}{ BIG SANDY } \\
\cline { 2 - 3 } \multicolumn{1}{c|}{} & Simulated & Observed \\
\hline Total runoff, in inches & 147.6 & 163.32 \\
\hline Total of highest $10 \%$ flows, in inches & 79.67 & 66.886 \\
\hline Total of lowest $50 \%$ flows, in inches & 11.12 & 19.971 \\
\hline Evapotranspiration, in inches & Simulated & Potential \\
\hline Baseflow recession rate & 92.51 & 93.3 \\
\hline Summer flow volume, in inches & Simulated & Observed \\
\hline Winter flow volume, in inches & 0.9 & 0.91 \\
\hline Error in total volume & 15.31 & 21.403 \\
\hline Error in low flow recession & 55.42 & 62.554 \\
\hline Error in 50\% lowest flows & Current & Criteria \\
\hline Error in 10\% highest flows & -9.6 & 10 \\
\hline Seasonal volume error & 0.01 & 0.01 \\
\hline
\end{tabular}

\begin{tabular}{|c|c|}
\hline \multicolumn{2}{|c|}{ TYGART VALLEY DAILEY } \\
\hline Simulated & Observed \\
\hline 158.9 & 157.525 \\
\hline 72.69 & 66.621 \\
\hline 14.4 & 18.782 \\
\hline Simulated & Potential \\
\hline 109.6 & 110.3 \\
\hline Simulated & Observed \\
\hline 0.88 & 0.9 \\
\hline 15.85 & 20.686 \\
\hline 63.75 & 63.183 \\
\hline Current & Criteria \\
\hline 0.9 & 10 \\
\hline 0.02 & 0.01 \\
\hline-23.3 & 10 \\
\hline 9.1 & 15 \\
\hline 24.3 & 10 \\
\hline
\end{tabular}

\section{HSPF-CHIA Calibration Performance Evaluation and Optimization Study}

\section{Performance Evaluation Procedures}

There are a number of publications dealing with the evaluation of watershed model performance. Although no uniform criteria have been established, the general view is that it is advisable to report several criteria in order to more objectively quantify the performance of a given hydrological model. Following criteria were used to determine an optimum set of HSPF parameters and to estimate the predictive ability of the model.

The first two, the Deviation of Runoff Volumes, $D_{V}$, and the Coefficient of Efficiency (known also as the Nash-Sutcliffe coefficient), $E$, are suggested by the ASCE Task Committee on Definition of Criteria for Evaluation of Watershed Models (ASCE, 1993):

Deviation of Runoff Volume, $\boldsymbol{D}_{\boldsymbol{V}}$ (Martinec and Rango, 1989)

$$
D_{V}=\frac{V-V_{S}}{V}
$$

where: $V$ - the total observed runoff volume for the simulation period $V_{S}-$ the total simulated runoff volume for the simulation period. 
It should be noted that for a perfect model, $D_{V}$ equals zero. A hydrological model is considered very good if $D_{V}<0.1$, good if $0.1<D_{V}<0.15$ and fair if $0.15<D_{V}<0.25$.

Coefficient of Efficiency, $\boldsymbol{E}$ (Nash and Sutcliffe, 1970)

$$
E=1.0-\frac{\sum_{i=1}^{N}\left(O_{i}-S_{i}\right)^{2}}{\sum_{i=1}^{N}\left(O_{i}-\bar{O}\right)^{2}}
$$

where: $O_{i}-$ the observed daily discharge

$S_{i}$ - the model simulated daily discharge

$\bar{O}$-the average observed discharge

$N$ - the number of discharges values.

The Coefficient of Efficiency is the ratio of the Mean Square Error (MSE) to the variance in the observed data subtracted from unity and it ranges from unity (ideal model) to minus infinity (poor model). When $E=0$ the square differences between the model simulation and the observation is equal to the variability in the observed data, which means that the observed mean, $\bar{O}$, is as good a predictor as the model.

Legates and McCabe (1999) suggested using several other criteria that would give a better representation of the efficacy of model simulations and recommended a wide range of statistics to be reported including the observed and simulated means and standard deviations.

Modified Coefficient of Efficiency, E1 (Legates and McCabe, 1999)

$$
E 1=1.0-\frac{\sum_{i=1}^{N}\left|O_{i}-S_{i}\right|}{\sum_{i=1}^{N}\left|O_{i}-\bar{O}\right|}
$$

The Modified Coefficient of Efficiency has a meaning similar to the Coefficient of Efficiency but it is considered preferable because it reduces the effect of squaring in statistics by giving errors and differences their appropriate weight.

In a similar way, the Index of Agreement (Willmott, 1981), another descriptive relative error measure that reflects agreement between simulated and observed values, was proposed in adjusted form, namely the Modified Index of Agreement, $d 1$, in order to eliminate squared values of errors.

Modified Index of Agreement, $\boldsymbol{d} \mathbf{1}$ (Legates and McCabe, 1999)

$$
d 1=1.0-\frac{\sum_{i=1}^{N}\left|O_{i}-S_{i}\right|}{\sum_{i=1}^{N}\left(\left|S_{i}-\bar{O}\right|+\left|O_{i}-\bar{O}\right|\right)}
$$


The Modified Index of Agreement varies from 0.0 for a full disagreement of simulated and observed values to 1.0 for a perfect model.

The use of two non-negative statistics is also recommended in order to arrive at a more comprehensive model evaluation (Willmott, 1984 and Legates, 1999). These absolute error measures (the error in the units of variable) are the Mean Absolute Error $(M A E)$ and the Square-root of the Mean Square Error (RMSE).

Mean Absolute Error, $M A E$ (Willmott, 1984)

$$
M A E=N^{-1}\left[\sum_{i=1}^{N}\left|O_{i}-S_{i}\right|\right]
$$

Compared to RMSE, the MAE is less sensitive to extreme values. Generally, RMSE is bigger than $M A E$ and, thus, the relative degree of difference between them represents the extent of the variance of absolute errors.

Square-root of the Mean Square error, RMSE (Willmott, 1984)

$$
R M S E=\left[N^{-1} \sum_{i=1}^{N}\left(O_{i}-S_{i}\right)^{2}\right]^{0.5}
$$

The advantage of RMSE is that it provides valuable information about sources of error. Willmott (1981) recommended portioning RMSE into "systematic" $\left(R M S E_{s}\right)$ and "unsystematic" $\left(R M S E_{u}\right)$ error components in order to determine the nature of error. The relationship is expressed in the following equation (Willmott, 1984):

$$
R M S E^{2}=R M S E_{s}^{2}+R M S E_{u}{ }^{2}
$$

$R M S E_{s}$ is actually the bias or deviation of the linear regression line slope on an observed versus simulated plot from a $45 \mathrm{deg}$. line and, therefore, it indicates the ability of a model to replicate variations in observed data. $R M S E_{u}$ is a component responsible for random variations.

"Systematic" portion of the $R M S E, R M S E_{s}$ (Willmott, 1984)

$$
\operatorname{RMSE}_{s}=\left[N^{-1} \sum_{i=1}^{N}\left(\bar{S}_{i}-O_{i}\right)^{2}\right]^{0.5}
$$

and

"Unsystematic" portion of the $\boldsymbol{R M S E}, \boldsymbol{R M S E _ { u }}$ (Willmott, 1984)

$$
R M S E_{u}=\left[N^{-1} \sum_{i=1}^{N}\left(S_{i}-\bar{S}_{i}\right)^{2}\right]^{0.5}
$$

where: $\bar{S}_{i}=a+b O_{i}$ 
$a$ and $b$ are parameters of a linear regression between observed and simulated values. For a good model performance, $R M S E_{s}$ should be low and $R M S E_{u}$ should approach $R M S E$, which itself should be low.

Another widely used statistic is the Coefficient of Determination, $R^{2}$. Although it has been argued by Willmott (1984) and Legates (1999) that the Coefficient of Determination has a lack of sensitivity to additive and proportional differences between observed and model simulated values, and is sensitive to outliers (extreme values), it remains a quite popular and commonly reported criterion.

Coefficient of Determination, $\boldsymbol{R}^{\mathbf{2}}$ (Legates and McCabe, 1999)

$$
R^{2}=\left\{\frac{\sum_{i=1}^{N}\left(O_{i}-\bar{O}\left(S_{i}-\bar{S}\right)\right)}{\left[\sum_{i=1}^{N}\left(O_{i}-\bar{O}\right)^{2}\right]^{0.5}\left[\sum_{i=1}^{N}\left(S_{i}-\bar{S}\right)^{2}\right]^{0.5}}\right\}
$$

The Coefficient of Determination ranges from 0.0 (poor model) to 1.0 (perfect model). It expresses the proportion of the total variance in the observed data that can be explained by the model.

Described criteria in combination with provided standard deviations and means and data-display graphics should be sufficient to evaluate the performance of a hydrological model (Donigian, 2002).

\section{Optimization of the HSPF Parameters using PEST Software}

As explained above, starting values of HSPF parameters for the manual calibration procedure were determined based on other studies, calibration watershed characteristics, and suggested parameter ranges in BASINS Technical Note \#6. Each of eleven (11) PERLNDs was assigned an individual set of parameters. The model was then manually calibrated using the HSPEXP program. The resulting parameter sets were assumed to be the calibrated values and served as the starting point for the optimization study.

The final adjustment of parameters and calibration was preformed using the PEST optimization software program (Doherty, 2002). The PEST program adjusts specified HSPF parameters until the differences between gaged flows and the model's simulated flows are minimized according to specified multiobjective criteria.

A sensitivity study was first done to see if separation of the FOREST land-use category into three different PERLNDs according to surface slopes results in significant improvement in the performance of the model. HSPF parameters that could be influenced by surface slopes, as they are described in the BASINS Technical Note \#6, were LZSN, INFILT, UZSN, INTFW, AGWRC, and IRC (note: parameter definitions are given in Bicknell, et al, 2001). PEST optimization was done twice for each of the specified parameters. In the first run one of the above parameters was set to be the same value for 
all three forest PERLNDs. A second run specified that a parameter for each Forest PERLND would have independent value and not necessarily the same as those of other two. The statistical data, which are summarized in Table 5, show that slope differentiation yields no significant improvement in the performance of the model. That raises the question of the usefulness of categorizing the Forest land-use/cover by surface slope. If this differentiation were ignored, then there would be essentially a single landuse/cover classification on many of the trend station watersheds, leaving little flexibility in applying the model. Since leaving the differentiation in the model does not effect the calibration one way or another, it was decided to retain the three slope categories to allow potential future flexibility in application of the HSPF-CHIA model.

Table 5 : Selected Error Statistics Comparing a Single Forest Slope Land-use/cover Category with Subdivision Based on Slope.

\begin{tabular}{|c|c|c|c|c|c|c|c|}
\hline \multirow{2}{*}{$\begin{array}{l}\text { TWELVEPOLE CREEK } \\
\text { Initial parameters }\end{array}$} & $E$ & $\mathrm{E} 1$ & $D_{v}$ & d1 & $\mathrm{R}^{2}$ & RMSE,cfs & MAE,cfs \\
\hline & 0.42 & 0.38 & 0.17 & 0.70 & 0.71 & 86 & 33 \\
\hline LZSN & 0.42 & 0.38 & 0.19 & 0.70 & 0.71 & 87 & 33 \\
\hline LZSN (three FOREST categories) & 0.42 & 0.38 & 0.18 & 0.70 & 0.71 & 86 & 32 \\
\hline AGWRC & 0.44 & 0.40 & 0.16 & 0.70 & 0.71 & 85 & 32 \\
\hline AGWRC (three FOREST categories) & 0.44 & 0.40 & 0.16 & 0.70 & 0.71 & 85 & 32 \\
\hline IRC & 0.45 & 0.38 & 0.16 & 0.69 & 0.70 & 89 & 33 \\
\hline IRC (three FORES categories) & 0.45 & 0.38 & 0.16 & 0.69 & 0.70 & 84 & 33 \\
\hline INTFW & 0.45 & 0.39 & 0.17 & 0.70 & 0.71 & 84 & 32 \\
\hline INTFW (three FOREST categories) & 0.45 & 0.39 & 0.17 & 0.70 & 0.71 & 84 & 32 \\
\hline UZNS seasonal & 0.51 & 0.42 & 0.14 & 0.71 & 0.73 & 79 & 31 \\
\hline UZNS seasonal (three FOREST cat.) & 0.51 & 0.42 & 0.14 & 0.71 & 0.73 & 79 & 31 \\
\hline INFILT & 0.52 & 0.41 & 0.15 & 0.69 & 0.73 & 78 & 31 \\
\hline INFILT (three FOREST categories) & 0.52 & 0.42 & 0.15 & 0.69 & 0.73 & 78 & 31 \\
\hline BUFFALO CREEK & $\mathrm{E}$ & $\mathrm{E} 1$ & $\mathrm{D}_{\mathrm{v}}$ & $\mathrm{d} 1$ & $\mathrm{R}^{2}$ & RMSE,cfs & MAE,cfs \\
\hline Initial parameters & 0.49 & 0.47 & 0.02 & 0.74 & 0.75 & 233 & 92 \\
\hline LZSN & 0.49 & 0.47 & 0.04 & 0.74 & 0.75 & 238 & 93 \\
\hline LZSN (three FOREST categories) & 0.49 & 0.47 & 0.02 & 0.74 & 0.75 & 232 & 92 \\
\hline AGWRC & 0.44 & 0.40 & 0.16 & 0.70 & 0.71 & 235 & 92 \\
\hline AGWRC (three FOREST categories) & 0.44 & 0.40 & 0.16 & 0.70 & 0.71 & 233 & 92 \\
\hline IRC & 0.51 & 0.46 & 0.02 & 0.72 & 0.74 & 228 & 93 \\
\hline IRC (three FORES categories) & 0.51 & 0.46 & 0.02 & 0.72 & 0.74 & 228 & 93 \\
\hline INTFW & 0.53 & 0.47 & 0.02 & 0.74 & 0.76 & 224 & 92 \\
\hline INTFW (three FOREST categories) & 0.53 & 0.47 & 0.02 & 0.74 & 0.76 & 224 & 92 \\
\hline UZSN seasonal & 0.53 & 0.47 & 0.00 & 0.73 & 0.75 & 225 & 92 \\
\hline UZSN seasonal (three FOREST cat.) & 0.53 & 0.47 & 0.00 & 0.73 & 0.75 & 225 & 92 \\
\hline INFILT & 0.58 & 0.47 & 0.01 & 0.72 & 0.76 & 211 & 91 \\
\hline INFILT (three FOREST categories) & 0.58 & 0.47 & 0.01 & 0.72 & 0.76 & 211 & 91 \\
\hline TYGART VALLEY (Elk) & $\mathrm{E}$ & E1 & $D_{v}$ & d1 & $\mathrm{R}^{2}$ & RMSE,cfs & MAE,cfs \\
\hline Initial parameters & 0.19 & 0.34 & 0.09 & 0.68 & 0.64 & 819 & 334 \\
\hline LZSN & 0.19 & 0.34 & 0.10 & 0.68 & 0.64 & 830 & 336 \\
\hline LZSN (three FOREST categories) & 0.20 & 0.34 & 0.09 & 0.68 & 0.65 & 815 & 332 \\
\hline AGWRC & 0.21 & 0.35 & 0.09 & 0.68 & 0.65 & 810 & 325 \\
\hline AGWRC (three FOREST categories) & 0.21 & 0.35 & 0.09 & 0.68 & 0.65 & 810 & 326 \\
\hline IRC & 0.23 & 0.35 & 0.09 & 0.67 & 0.63 & 799 & 328 \\
\hline
\end{tabular}




\begin{tabular}{|c|c|c|c|c|c|c|c|}
\hline IRC (three FOREST categories) & 0.23 & 0.35 & 0.09 & 0.67 & 0.63 & 799 & 328 \\
\hline UZSN seasonal & 0.26 & 0.37 & 0.08 & 0.69 & 0.66 & 784 & 315 \\
\hline UZSN seasonal (three FOREST cat.) & 0.26 & 0.37 & 0.08 & 0.69 & 0.66 & 784 & 315 \\
\hline INTFW & 0.31 & 0.38 & 0.09 & 0.69 & 0.68 & 754 & 314 \\
\hline INTFW (three FOREST categories) & 0.31 & 0.38 & 0.09 & 0.69 & 0.68 & 761 & 316 \\
\hline \multirow{2}{*}{$\begin{array}{l}\text { INFLT } \\
\text { INFILT (three FOREST categories) }\end{array}$} & 0.57 & 0.45 & 0.08 & 0.71 & 0.76 & 599 & 278 \\
\hline & 0.56 & 0.45 & 0.08 & 0.71 & 0.76 & 602 & 278 \\
\hline \multirow{2}{*}{$\begin{array}{l}\text { CLEAR FORK } \\
\text { Initial parameters }\end{array}$} & $E$ & E1 & $D_{v}$ & $\mathrm{~d} 1$ & $\mathrm{R}^{2}$ & RMSE,cfs & MAE,cfs \\
\hline & 0.46 & 0.42 & 0.07 & 0.72 & 0.74 & 215 & 97 \\
\hline LZSN & 0.46 & 0.42 & 0.07 & 0.72 & 0.74 & 216 & 97 \\
\hline LZSN (three FOREST categories) & 0.47 & 0.42 & 0.07 & 0.72 & 0.74 & 214 & 96 \\
\hline AGWRC & 0.47 & 0.44 & 0.07 & 0.72 & 0.74 & 213 & 92 \\
\hline AGWRC (three FOREST categories) & 0.47 & 0.44 & 0.07 & 0.72 & 0.74 & 213 & 92 \\
\hline INTFW & 0.49 & 0.43 & 0.07 & 0.72 & 0.75 & 209 & 94 \\
\hline INTFW (three FOREST categories) & 0.49 & 0.43 & 0.07 & 0.72 & 0.75 & 206 & 96 \\
\hline IRC & 0.51 & 0.43 & 0.07 & 0.71 & 0.74 & 205 & 93 \\
\hline IRC (three FORES categories) & 0.51 & 0.43 & 0.07 & 0.71 & 0.74 & 205 & 93 \\
\hline UZSN seasonal & 0.49 & 0.46 & 0.05 & 0.73 & 0.74 & 208 & 90 \\
\hline UZSN seasonal (three FOREST cat.) & 0.49 & 0.46 & 0.05 & 0.73 & 0.74 & 208 & 90 \\
\hline INFILT & 0.59 & 0.47 & 0.06 & 0.72 & 0.77 & 189 & 88 \\
\hline INFILT (three FOREST categories) & 0.59 & 0.47 & 0.06 & 0.72 & 0.77 & 189 & 88 \\
\hline \multirow{2}{*}{$\begin{array}{l}\text { BIG SANDY } \\
\text { Initial parameters }\end{array}$} & $E$ & E1 & $D_{v}$ & $\mathrm{~d} 1$ & $\mathrm{R}^{2}$ & RMSE,cfs & MAE,cfs \\
\hline & 0.38 & 0.37 & 0.00 & 0.69 & 0.71 & 505 & 230 \\
\hline LZSN & 0.38 & 0.37 & 0.00 & 0.69 & 0.71 & 512 & 233 \\
\hline LZSN (three FOREST categories) & 0.38 & 0.37 & 0.00 & 0.69 & 0.71 & 505 & 230 \\
\hline AGWRC & 0.40 & 0.38 & 0.01 & 0.70 & 0.71 & 500 & 225 \\
\hline AGWRC (three FOREST categories) & 0.40 & 0.38 & 0.00 & 0.70 & 0.71 & 500 & 225 \\
\hline IRC & 0.43 & 0.41 & 0.00 & 0.70 & 0.70 & 487 & 214 \\
\hline IRC (three FOREST categories) & 0.43 & 0.41 & 0.00 & 0.70 & 0.70 & 491 & 218 \\
\hline UZSN seasonal & 0.38 & 0.39 & 0.01 & 0.70 & 0.70 & 507 & 220 \\
\hline UZSN seasonal (three FOREST categories) & 0.38 & 0.39 & 0.01 & 0.70 & 0.70 & 507 & 220 \\
\hline INTFW & 0.48 & 0.41 & 0.00 & 0.71 & 0.74 & 462 & 213 \\
\hline INTFW (three FOREST categories) & 0.48 & 0.41 & 0.00 & 0.71 & 0.74 & 468 & 216 \\
\hline INFILT & 0.57 & 0.48 & 0.01 & 0.73 & 0.76 & 422 & 189 \\
\hline INFILT (three FOREST categories) & 0.58 & 0.48 & 0.01 & 0.72 & 0.76 & 417 & 188 \\
\hline
\end{tabular}

In the following calibration and sensitivity study all three PERLNDs of the Forest land-use/cover classification were relegated to the same set of parameters, thus reducing the number of calibrated sets of parameters from eleven (11) to nine (9).

A second sensitivity study was performed on each of the parameters in the set of the Forest PERLND segments. During every PEST optimization and simulation run one of these parameters was calibrated independently (the rest of parameters in a set were fixed at initially calibrated values) and statistics of the model performance were calculated. Analysis of the statistics allowed the determination of a group of parameters that were the most influential with respect to the performance of the model. The improvement in value of the Coefficient of Determination, $E$, and the Modified Coefficient of Determination, E1, for optimized parameters INFILT, UZSN, INTFW, and 
IRC was more dramatic than for the other parameters. Table 6 shows the statistics for each parameter, as it alone is optimized.

Table 6 : Summary of Individual Parameter Optimization Statistics

\begin{tabular}{|c|c|c|c|c|c|c|c|}
\hline TWELVEPOLE CREEK & $E$ & E1 & $D_{v}$ & d1 & $\mathrm{R}^{2}$ & RMSE (cfs) & MAE (cfs) \\
\hline Initial parameters & 0.42 & 0.38 & 0.17 & 0.70 & 0.71 & 85.91 & 32.63 \\
\hline LZSN & 0.41 & 0.37 & 0.19 & 0.70 & 0.71 & 87.10 & 33.16 \\
\hline AGWETP & 0.42 & 0.38 & 0.16 & 0.70 & 0.71 & 85.96 & 32.64 \\
\hline LZETP & 0.42 & 0.38 & 0.17 & 0.70 & 0.71 & 85.91 & 32.63 \\
\hline DEEPFR & 0.43 & 0.39 & 0.10 & 0.70 & 0.71 & 85.44 & 31.97 \\
\hline BASETP & 0.43 & 0.38 & 0.17 & 0.70 & 0.71 & 85.62 & 32.48 \\
\hline AGWRC & 0.44 & 0.40 & 0.16 & 0.70 & 0.71 & 84.87 & 31.65 \\
\hline IRC & 0.45 & 0.38 & 0.16 & 0.69 & 0.70 & 83.99 & 32.67 \\
\hline INTFW & 0.45 & 0.39 & 0.17 & 0.70 & 0.71 & 83.80 & 32.03 \\
\hline UZNS seasonal & 0.51 & 0.42 & 0.14 & 0.71 & 0.73 & 78.90 & 30.72 \\
\hline INFILT & 0.52 & 0.41 & 0.15 & 0.69 & 0.73 & 78.14 & 30.74 \\
\hline BUFFALO CREEK & $\mathrm{E}$ & E1 & $D_{v}$ & d1 & $\mathrm{R}^{2}$ & RMSE (cfs) & MAE (cfs) \\
\hline Initial parameters & 0.49 & 0.47 & 0.02 & 0.74 & 0.75 & 233.41 & 92.12 \\
\hline LZSN & 0.47 & 0.46 & 0.04 & 0.74 & 0.75 & 237.51 & 92.96 \\
\hline AGWETP & 0.49 & 0.47 & 0.02 & 0.74 & 0.75 & 233.61 & 92.22 \\
\hline LZETP & 0.49 & 0.47 & 0.02 & 0.74 & 0.75 & 233.41 & 92.12 \\
\hline DEEPFR & 0.49 & 0.46 & 0.05 & 0.74 & 0.75 & 232.77 & 92.50 \\
\hline BASETP & 0.49 & 0.47 & 0.02 & 0.74 & 0.75 & 232.31 & 91.55 \\
\hline AGWRC & 0.50 & 0.48 & 0.01 & 0.74 & 0.75 & 230.61 & 89.35 \\
\hline IRC & 0.51 & 0.46 & 0.02 & 0.72 & 0.74 & 227.84 & 92.87 \\
\hline INTFW & 0.53 & 0.47 & 0.02 & 0.74 & 0.76 & 223.82 & 91.54 \\
\hline UZSN seasonal & 0.53 & 0.47 & 0.00 & 0.73 & 0.75 & 224.51 & 91.81 \\
\hline INFILT & 0.58 & 0.47 & 0.01 & 0.72 & 0.76 & 211.15 & 91.02 \\
\hline \multirow{2}{*}{$\begin{array}{l}\text { TYGART VALLEY (Elk) } \\
\text { Initial parameters }\end{array}$} & $E$ & E1 & $D_{v}$ & d1 & $\mathrm{R}^{2}$ & RMSE (cfs) & $\mathrm{MAE}$ (cfs) \\
\hline & 0.19 & 0.34 & 0.09 & 0.68 & 0.64 & 819.49 & 333.74 \\
\hline LZSN & 0.17 & 0.33 & 0.10 & 0.68 & 0.64 & 829.87 & 335.68 \\
\hline AGWETP & 0.19 & 0.34 & 0.09 & 0.68 & 0.64 & 819.90 & 333.86 \\
\hline LZETP & 0.19 & 0.34 & 0.09 & 0.68 & 0.64 & 819.49 & 333.74 \\
\hline DEEPFR & 0.20 & 0.34 & 0.03 & 0.68 & 0.64 & 817.63 & 334.43 \\
\hline BASETP & 0.20 & 0.34 & 0.09 & 0.68 & 0.65 & 814.80 & 331.79 \\
\hline AGWRC & 0.21 & 0.35 & 0.09 & 0.68 & 0.65 & 809.71 & 325.25 \\
\hline IRC & 0.23 & 0.35 & 0.09 & 0.67 & 0.63 & 798.99 & 328.13 \\
\hline UZSN seasonal & 0.26 & 0.37 & 0.08 & 0.69 & 0.66 & 784.24 & 315.50 \\
\hline INTFW & 0.31 & 0.38 & 0.09 & 0.69 & 0.68 & 754.30 & 313.57 \\
\hline INFLT & 0.57 & 0.45 & 0.08 & 0.71 & 0.76 & 598.78 & 278.10 \\
\hline \multirow{2}{*}{$\begin{array}{l}\text { CLEAR FORK } \\
\text { Initial parameters }\end{array}$} & $\mathrm{E}$ & E1 & $\mathrm{D}_{\mathrm{v}}$ & d1 & $\mathrm{R}^{2}$ & RMSE (cfs) & MAE (cfs) \\
\hline & 0.46 & 0.42 & 0.07 & 0.72 & 0.74 & 215.47 & 96.65 \\
\hline LZSN & 0.45 & 0.41 & 0.07 & 0.72 & 0.74 & 225.16 & 96.94 \\
\hline AGWETP & 0.46 & 0.41 & 0.07 & 0.72 & 0.74 & 215.65 & 96.84 \\
\hline LZETP & 0.46 & 0.42 & 0.07 & 0.72 & 0.74 & 215.47 & 96.65 \\
\hline DEEPFR & 0.46 & 0.42 & 0.01 & 0.72 & 0.74 & 214.58 & 96.54 \\
\hline BASETP & 0.47 & 0.42 & 0.07 & 0.72 & 0.74 & 214.22 & 95.75 \\
\hline
\end{tabular}




\begin{tabular}{|l|r|r|r|r|r|r|r|}
\hline AGWRC & 0.47 & 0.44 & 0.07 & 0.72 & 0.74 & 212.82 & 92.47 \\
\hline INTFW & 0.49 & 0.43 & 0.07 & 0.72 & 0.75 & 208.71 & 94.27 \\
\hline UZSN seasonal & 0.49 & 0.46 & 0.05 & 0.73 & 0.74 & 208.27 & 89.96 \\
\hline IRC & 0.51 & 0.43 & 0.07 & 0.71 & 0.74 & 205.35 & 93.43 \\
\hline INFILT & 0.59 & 0.47 & 0.06 & 0.72 & 0.77 & 188.56 & 87.52 \\
\hline \multirow{2}{*}{$\begin{array}{l}\text { BIG SANDY } \\
\text { Initial parameters }\end{array}$} & $\mathrm{E}$ & $\mathrm{E} 1$ & \multicolumn{1}{|c|}{$\mathrm{D}_{\mathrm{v}}$} & $\mathrm{d} 1$ & $\mathrm{R}^{2}$ & $\mathrm{RMSE}$ (cfs) & MAE (cfs) \\
\cline { 2 - 8 } LZSN & 0.38 & 0.37 & 0.00 & 0.69 & 0.71 & 505.24 & 229.67 \\
\hline AGWETP & 0.37 & 0.36 & 0.01 & 0.69 & 0.71 & 512.18 & 232.80 \\
\hline LZETP & 0.38 & 0.37 & 0.00 & 0.69 & 0.71 & 505.50 & 229.84 \\
\hline DEEPFR & 0.38 & 0.37 & 0.00 & 0.69 & 0.71 & 505.24 & 229.67 \\
\hline BASETP & 0.38 & 0.35 & 0.06 & 0.69 & 0.70 & 506.13 & 234.78 \\
\hline UZSN seasonal & 0.38 & 0.37 & 0.00 & 0.69 & 0.71 & 503.27 & 228.01 \\
\hline AGWRC & 0.38 & 0.39 & 0.01 & 0.70 & 0.70 & 506.67 & 219.97 \\
\hline IRC & 0.40 & 0.38 & 0.00 & 0.70 & 0.71 & 499.81 & 225.36 \\
\hline INTFW & 0.43 & 0.41 & 0.00 & 0.70 & 0.70 & 486.69 & 213.69 \\
\hline INFILTR & 0.48 & 0.41 & 0.00 & 0.71 & 0.74 & 461.64 & 212.58 \\
\hline
\end{tabular}

In a next step of the calibration and sensitivity analysis, the PEST program was setup to optimize all eleven parameters for each of nine (9) PERLNDs in the same run (the Forest Land categories were constrained to use an identical parameter set). The final optimized parameter values are presented in Table 7 and the statistical data from this run are shown in Table 9 as run \# 1. Although the deviations of runoff volume, $D_{v}$, predominately show a good model performance, values of Coefficient of Efficiency, $E$, are not very high for the calibration watersheds and somewhat lower for the verification watersheds.

Table 7 : PEST Optimized Parameters Values for 11 PERLND Segments.

\begin{tabular}{|c|c|c|c|c|c|c|c|c|c|c|c|c|}
\hline \multirow[b]{2}{*}{ \# } & \multirow{2}{*}{$\begin{array}{l}\text { PERLND } \\
\text { SEGMENT }\end{array}$} & \multicolumn{11}{|c|}{ PARAMETERS } \\
\hline & & $\begin{array}{l}\text { LZSN } \\
\text { (in) }\end{array}$ & $\begin{array}{l}\text { INFILT } \\
\text { (in/hr) }\end{array}$ & $\begin{array}{l}\text { KVARY } \\
(1 / \text { in })\end{array}$ & $\begin{array}{l}\text { AGWCR } \\
\text { (1/day) }\end{array}$ & DEEPFR & BASETP & AGWETP & $\begin{array}{l}\text { UZSN } \\
\text { (in) }\end{array}$ & INTFW & $\begin{array}{l}\text { IRC } \\
\text { (1/day) }\end{array}$ & LZETP \\
\hline 1 & $\begin{array}{l}\text { Forest Land } \\
\text { Steep }\end{array}$ & 4.99 & 0.012 & 0.001 & 0.938 & 0.21 & 0.02 & 0.0099 & 0.499 & 3.5 & 0.27 & 0.599 \\
\hline 2 & $\begin{array}{l}\text { Forest Land } \\
\text { Moderate }\end{array}$ & 4.99 & 0.012 & 0.001 & 0.938 & 0.21 & 0.02 & 0.0099 & 0.499 & 3.5 & 0.27 & 0.599 \\
\hline 3 & $\begin{array}{l}\text { Forest Land } \\
\text { Mild }\end{array}$ & 4.99 & 0.012 & 0.001 & 0.938 & 0.21 & 0.02 & 0.0099 & 0.499 & 3.5 & 0.27 & 0.599 \\
\hline 4 & $\begin{array}{l}\text { Pasture/ } \\
\text { Grassland }\end{array}$ & 4.99 & 0.020 & 0.0010 & 0.938 & 0.21 & 0.02 & 0.0099 & 0.704 & 3.5 & 0.27 & 0.462 \\
\hline 5 & $\begin{array}{l}\text { Urban/ } \\
\text { Developed }\end{array}$ & 4.86 & 0.004 & 0.0090 & 0.933 & 0.21 & 0.02 & 0.0099 & 0.868 & 4.2 & 0.28 & 0.205 \\
\hline 6 & Mined Land & 6.93 & 0.020 & 0.0020 & 0.934 & 0.21 & 0.02 & 0.0099 & 0.502 & 3.5 & 0.26 & 0.209 \\
\hline 7 & $\begin{array}{l}\text { Barren } \\
\text { Land }\end{array}$ & 5.71 & 0.014 & 0.0190 & 0.971 & 0.21 & 0.02 & 0.0099 & 0.271 & 5.0 & 0.30 & 0.453 \\
\hline 8 & $\begin{array}{l}\text { Surface } \\
\text { Water }\end{array}$ & 4.33 & 0.037 & 0.0010 & 0.912 & 0.21 & 0.02 & 0.0099 & 0.974 & 2.1 & 0.24 & 0.115 \\
\hline 9 & $\begin{array}{l}\text { Row Crop } \\
\text { Agricult. }\end{array}$ & 4.97 & 0.020 & 0.0060 & 0.938 & 0.21 & 0.02 & 0.0099 & 0.500 & 3.7 & 0.26 & 0.319 \\
\hline 10 & Wetland & 6.99 & 0.007 & 0.0060 & 0.953 & 0.21 & 0.02 & 0.0099 & 0.967 & 3.8 & 0.26 & 0.501 \\
\hline
\end{tabular}


The final PEST calibration was done using the parameters INFILT, UZSN, INTFW, and IRC as variables, while holding the remaining parameters fixed at their original values within the Forest land-use/cover PERLND. These parameters are those identified earlier to be the most influential in the sensitivity study. Forest is the major land-use/cover for all the calibration watersheds, and therefore, its parameters will be the most influential. Table 8 list the values of the optimized parameters and compares them to values obtained by other investigators in unrelated calibration studies.

The analyzed statistics, which are summarized in Table 9 as a run \#2, show a good model performance with the Coefficient of Efficiency, $E$, the possible range of which is from minus unity (poor model) to 1.0 (perfect model), at 0.57 for the entire simulation period of six years for 5 calibration watersheds. This is in a range of values reported by similar investigations. The deviation of total runoff volume for four of the watersheds is less then $15 \%$ which is rated as good performance.

Table 8 : Comparison of the Final Set of Parameters for the Forest PERLND categories with those reported by other studies.

\begin{tabular}{|c|c|c|c|c|c|c|c|c|}
\hline Parameter & Units & $\begin{array}{c}\text { Optimized } \\
\text { value }\end{array}$ & $\begin{array}{c}\text { Moore et al. } \\
1988\end{array}$ & $\begin{array}{c}\text { Chew et al. } \\
1991\end{array}$ & $\begin{array}{c}\text { Laroche et } \\
\text { al. } \\
1996\end{array}$ & $\begin{array}{c}\text { Srinivasan et al. } \\
1999\end{array}$ & $\begin{array}{c}\text { Engelmann } \\
1999 \\
\end{array}$ & $\begin{array}{c}\text { Doherty et al. } \\
2003\end{array}$ \\
\hline LZSN & in & 3 & 4.9 & 5 & 14 & $5.12-5.9$ & 3.82 & $2-2.58$ \\
\hline INFILT & in $/ \mathrm{hr}$ & 0.0634 & 0.004-0.0196 & $0.063-0.14$ & 0.23 & $0.039-0.39$ & 0.0394 & $0.028-0.071$ \\
\hline UZSN & in & $0.96^{\mathrm{s}}$ & 0.197 & $0.016-0.043$ & 0.756 & $0.31-0.75$ & 0.7 & $1.55-2$ \\
\hline KVARY & in-1 & 3 & ---- & ---- & 0.06 & --- & 0.61 & ---- \\
\hline AGWRC & day $^{-1}$ & 0.983 & 0.98 & ----- & 0.99 & $0.8-0.9$ & 0.99 & $0.942-0.988$ \\
\hline INFEXP & & 2 & ----- & ----- & 0 & ----- & 2 & ---- \\
\hline INTFW & & 2.62 & 1 & ----- & 9.83 & $0.8-3.0$ & 0.5 & $1-1.31$ \\
\hline INFILD & & $2^{*}$ & ----- & ----- & 1.99 & ----- & 1 & ----- \\
\hline IRC & day $^{-1}$ & 0.5 & 0.1 & ----- & 0 & ---- & ---- & $0.499-0.533$ \\
\hline LZETP & & $0.5^{\mathrm{s}}$ & $0.3-0.55$ & ----- & $0-0.8$ & $0.1-0.8$ & 0.42 & 0.5 \\
\hline DEEPFR & & 0.2 & ---- & ---- & ---- & ---- & 0.1 & 0.1 (fixed) \\
\hline BASETP & & 0.05 & ---- & ---- & ---- & ---- & 0.02 & $0.157-0.182$ \\
\hline AGWETP & & $0.01^{*}$ & ------ & ----- & ----- & ----- & 0 & $0.02-0.027$ \\
\hline
\end{tabular}

\begin{tabular}{|l|c|c|c|c|c|c|c|c|c|c|c|c|}
\hline & Jan & Feb & Mar & April & May & June & July & Aug & Sept & Oct & Nov & Dec \\
\hline UZSN & 1.66 & 1.54 & 1.28 & 0.92 & 0.56 & 0.33 & 0.26 & 0.38 & 0.66 & 1.01 & 1.36 & 1.59 \\
\hline LZETP & 0.056 & 0.006 & 0.089 & 0.28 & 0.53 & 0.78 & 0.95 & 0.99 & 0.9 & 0.73 & 0.47 & 0.23 \\
\hline
\end{tabular}

The verification study used the five watersheds shown in Figure 2. The precipitation data were taken from the five year period between 1971 and 1975. The HSPF runs were performed using two sets of parameters that were the results of optimization runs \#1 and \#2, described above. A summary of statistics for the verification watersheds is included in Table 9. 


\section{Conclusions of the HSPF Model Performance Evaluation}

Two sets of HSPF parameters were developed by means of PEST optimization runs. An additional set was obtained by a manual calibration by using the HSPEXP. These sets are defined and presented in Table 9:

Run \# 1 - All parameters for nine (9) PERLND segments were optimized jointly using PEST.

Run \# 2 - Optimization was done for the most sensitive parameters and only for Forest land-use/cover with all slope categories treated as equivalent.

Run \# 3 - All parameters for eleven (11) PERLNDs were manually calibrated with the guidance of the HSPFEXP program.

A comparison of the statistics of the HSPF model performances for three runs above includes the means and standard deviations of the predicted and actual discharges during the period of the calibration. Run \#1 has an average error of less then $10 \%$ for all calibration watersheds and three of the verification watersheds. For Run \#2, the simulated mean is less than $12 \%$ for calibration watersheds and less than $15 \%$ for four of the verification watersheds. Statistics for Run \# 3 indicate less then $13 \%$ average error for the calibration watersheds and less then $13 \%$ for four of the verification watersheds. For all three runs, verification watersheds Piney and Big Sandy (1971-1975) show the highest average error, $13-22 \%$. Comparison of observed and predicted standard deviations demonstrates that all three runs do not give a good description of observed flow variance, with an especially poor performance noted on Tygart (Elkins) and Big Sandy calibration watersheds, and Tygart (Belington), Tygart (Dailey) and Big Sandy verification watersheds.

Deviations of total runoff volume $\left(D_{v}\right)$ over the entire simulation period for every run gives an uneven picture, with the model performance varying from very good to just fair, depending on the watershed. For example, for the Big Sandy watershed all three runs indicate a good model performance with $D_{v}$ less than 10 percent for the simulation period, but for the verification period for the same watershed, the performance can be classified only as fair. Generally, averaging performances of all watersheds involved (calibration and verification), run \# 3 produced the smallest runoff deviations and run \# 2 the largest.

For years, correlation-based statistics such as the Coefficient of Determination, $\mathrm{R}^{2}$, which describes the degree of collinearity between model predictions and observations, were the most popular measurements of demonstrating the accuracy of a hydrologic model. Although it was pointed out by some investigations (Willmott, 1981; Willmott, 1984; Willmott et al., 1985; Legates and McCabe, 1999) that these kinds of measurements have limitations and may mislead a model evaluation, these statistics remain widely used and reported. Donigian (2002), based on his many years of experience working with the HSPF, derived a chart (see Figure 10) that evaluates model performance by ranges of values of the Coefficient of Determination. According to this table, run \# 2 outperformed the other two runs. By Donigian's standards, run \# 2 demonstrated good performance for calibration watersheds and very good performance for verification watersheds.

Slight differences in the Modified Index of Agreement, in run \# 2, that produced slightly higher values as compared to the other runs are of minimal use in determining best performance. However, both the Coefficient of Efficiency, E, and the Modified 
Coefficient of Efficiency, E1, which are suggested as the most appropriate relative error available (Legates, 1999) show better (higher) values for run \# 2. Also, $E$ and $E 1$ of run \# 2 are more consistent for all considered watersheds. Runs \# 1 and \#3 produce negative $E$ for the verification Piney Creek watershed, which indicates that the observed mean is a better predictor than the model.

At first glance the magnitudes of absolute error statistics $M A E$ and $R M S E$ are lower for run \# 2. However, further segmentation of RMSE into systematic and unsystematic sources of error presents a different picture with runs \#1 and \#3 having a smaller systematic and higher unsystematic error values than run \# 2, and therefore, they have a higher potential accuracy.

The conclusion, with regard to selection of the best parameter set, of the three sets compared above, remains to be determined at the time of this report. Overall, runs \#2 and $\# 3$ have positive features, with run $\# 2$ yielding the best statistical results. Currently, the run \#2 parameter set is being used in the WCMS-HSPF model. 


\begin{tabular}{|c|c|c|c|c|c|c|c|c|c|c|c|c|c|c|c|c|c|c|c|c|c|c|c|c|c|c|c|c|}
\hline 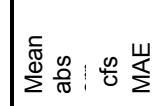 & $m$ & $\begin{array}{c}\text { ș } \\
\text { ch }\end{array}$ & & 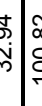 & $\mid \begin{array}{l}0 \\
0 \\
0\end{array}$ & $\begin{array}{l}\infty \\
\infty \\
\infty \\
\infty\end{array}$ & 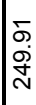 & & $\begin{array}{l}8 \\
\dot{j} \\
0 \\
m\end{array}$ & 志 & 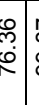 & & 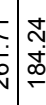 & & $\stackrel{m}{=}$ & & & 勇 & 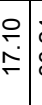 & 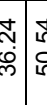 & $\begin{array}{l}\vdots \\
\vdots \\
\vdots\end{array}$ & 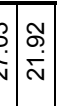 & $\underset{\sim}{\infty}$ & & & 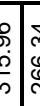 & & 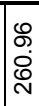 \\
\hline 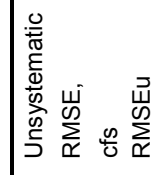 & & 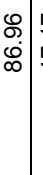 & 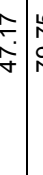 & & & & $\mid \begin{array}{l}8 \\
o \\
\infty \\
o\end{array}$ & 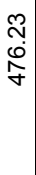 & 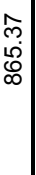 & & 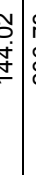 & 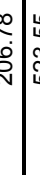 & 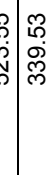 & & $\mathfrak{v}$ & & & 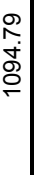 & \begin{tabular}{l}
$\stackrel{0}{0}$ \\
$\vdots$ \\
\hdashline
\end{tabular} & & & $\begin{array}{ll}0 \\
\dot{b} \\
\dot{b}\end{array}$ & ్ָల్ల & & & & 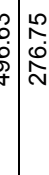 & 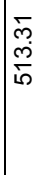 \\
\hline 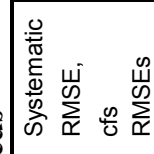 & $=$ & | & 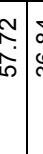 & $\begin{array}{l}\vdots \\
0 \\
\vdots \\
\vdots\end{array}$ & {$\left[\begin{array}{ll}5 \\
5 \\
0 \\
6 \\
15\end{array}\right.$} & ف̊ & $\mid \begin{array}{l}\infty \\
\infty \\
\infty \\
\infty \\
\infty\end{array}$ & 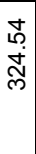 & 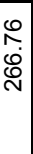 & 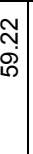 & No & 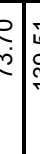 & 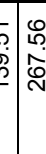 & & $\mp$ & ֶָָ & & - & & & & 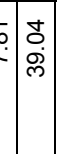 & 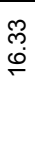 & & 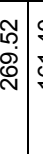 & & & 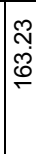 \\
\hline 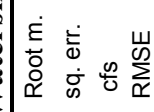 & $\circ$ & 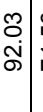 & 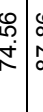 & ר & 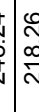 & 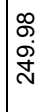 & 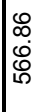 & $\begin{array}{l}q \\
0 \\
0 \\
i\end{array}$ & $\begin{array}{l}0 \\
0 \\
0 \\
0\end{array}$ & 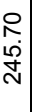 & , & مُ & 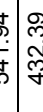 & ?ִ & 10 & & 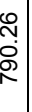 & 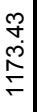 & $\begin{array}{ll}0 \\
0 \\
0 \\
0\end{array}$ & 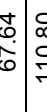 & : & 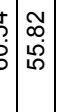 & $\begin{array}{l}\bar{\infty} \\
\dot{\infty} \\
\dot{\omega}\end{array}$ & & & & 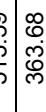 & 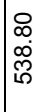 \\
\hline 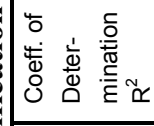 & 0 & 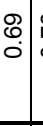 & $\begin{array}{l}0 \\
0 \\
0\end{array}$ & 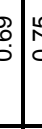 & $\begin{array}{l}n \\
0 \\
0\end{array}$ & $\stackrel{\substack{0 \\
0}}{0}$ & $\stackrel{\infty}{\infty}$ & $\stackrel{\substack{\infty \\
0}}{0}$ & $\stackrel{\leftrightarrow}{\circ}$ & $\begin{array}{l}0 \\
\text { i } \\
0\end{array}$ & $\begin{array}{ll}0 \\
0 \\
0\end{array}$ & $\begin{array}{lll}N \\
b\end{array}$ & 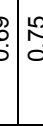 & \begin{tabular}{l}
$\infty$ \\
\hdashline \\
0
\end{tabular} & & ? & $\begin{array}{c}\infty \\
\infty \\
\infty\end{array}$ & $\stackrel{\bullet}{:}$ & $\begin{array}{l}\text { } \\
0 \\
0\end{array}$ & 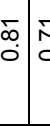 & 5 & 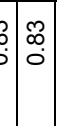 & 落 & 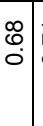 & 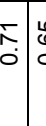 & & 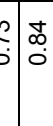 & $\begin{array}{l}0 \\
0 \\
0\end{array}$ \\
\hline 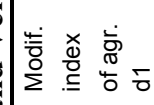 & $\infty$ & : & \begin{tabular}{l}
$N$ \\
\hdashline \\
$O$
\end{tabular} & î & $\tilde{\imath}$ & i & 苂 & $\stackrel{0}{4}$ & $\stackrel{8}{\circ}$ & $\begin{array}{l}\infty \\
: \\
:\end{array}$ & : & 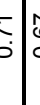 & jo & 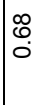 & $\infty$ & $\widehat{0}$ & 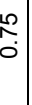 & $\hat{o}$ & 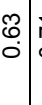 & $\begin{array}{l}\pi \\
0\end{array}$ & 芶 & $\begin{array}{l}\qquad \\
\vdots \\
0\end{array}$ & $\begin{array}{l}\hat{A} \\
0\end{array}$ & $\stackrel{8}{\circ}$ & $\begin{array}{c}\bar{r} \\
\hat{0}\end{array}$ & & & : \\
\hline 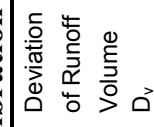 & r & $\stackrel{5}{5}$ & 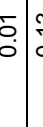 & $\frac{0}{2}$ & 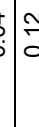 & : & Oे & 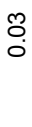 & $\begin{array}{l}\infty \\
0 \\
0 \\
0\end{array}$ & $\begin{array}{l}\overline{0} \\
\dot{0}\end{array}$ & $\frac{0}{0}:$ & : & : & 8 & & 을 & $\nabla$ & $\hat{0}$ & $\stackrel{0}{0}$ & & N & $\begin{array}{l}0 \\
:\end{array}$ & ஜ & $\stackrel{5}{\circ}$ & స్ָి & & & ¿ \\
\hline 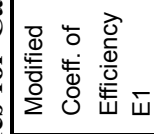 & 0 & 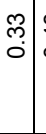 & 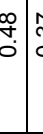 & $\stackrel{n}{b}$ & $\underset{d}{\infty}$ & $\int_{0}^{0}$ & 棺 & 号 & $\hat{ָ ָ ̃ ~}$ & స్ల్ & $\begin{array}{l}0 \\
0 \\
0\end{array}$ & 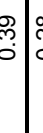 & ำ & ల్లై & & $\bar{m}$ & stists & ָ⿳亠丷⿵冂丶 & $\bar{\sigma}_{0}$ & ֻ & $\frac{ \pm}{5}$ & 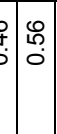 & 趈 & ঙ্ণ & 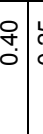 & & & @্ল \\
\hline 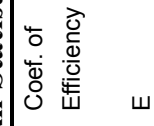 & in & 苞 & $\underset{b}{6}$ & b. & $\begin{array}{ll}4 \\
0\end{array}$ & D্ & ¿. & $\stackrel{\circ}{\circ}$ & $\begin{array}{l}8 \\
0 \\
0\end{array}$ & 足 & ? & 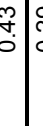 & Sִ & 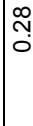 & & 8 & : & 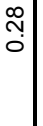 & 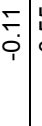 & 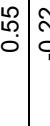 & $\begin{array}{c}\text { N. } \\
\vdots \\
\end{array}$ & \begin{tabular}{|c|c|} 
\\
$\dot{5}$ & 0 \\
0 & 0 \\
\end{tabular} & @ & $\stackrel{⿱}{\circ}$ & fo & & & 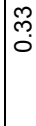 \\
\hline 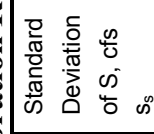 & + & $\begin{array}{l}\text { : } \\
\stackrel{2}{\grave{d}} \\
\end{array}$ & 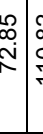 & 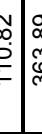 & $\begin{array}{l}\infty \\
\infty \\
\infty \\
\infty\end{array}$ & 尔 & 象 & 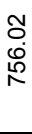 & $\begin{array}{l}2 \\
2 \\
0 \\
0 \\
0\end{array}$ & 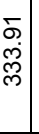 & సֶ. & 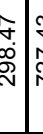 & ?a & : & 寸 & : & $f$ & | & مُ & & & 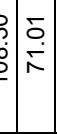 & iु & 容 & 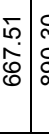 & & 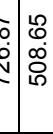 & $\begin{array}{l}\hat{\alpha} \\
\dot{0} \\
\stackrel{i}{r}\end{array}$ \\
\hline 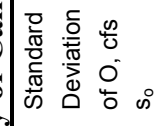 & m & ָָ & 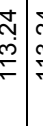 & 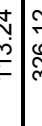 & 3 & 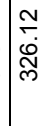 & 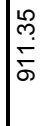 & 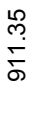 & 岕 & 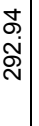 & 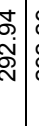 & స్ & 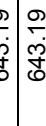 & $\stackrel{9}{m}$ & m & ָָ & శి & 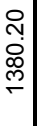 & \begin{tabular}{ll} 
\\
$\vdots$ \\
0 \\
\hdashline
\end{tabular} & & & 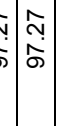 & 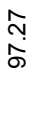 & 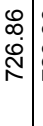 & 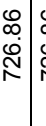 & & $\begin{array}{ll}0 \\
\dot{0} \\
\dot{0} \\
0 \\
0 \\
0 \\
0\end{array}$ & $\begin{array}{l}\bar{\sigma} \\
\dot{0} \\
0\end{array}$ \\
\hline 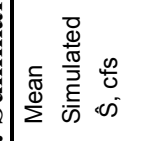 & $\mathbf{N}$ & 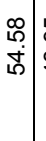 & 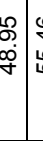 & 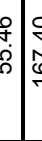 & 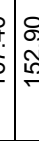 & $\stackrel{8}{\stackrel{8}{2}}$ & 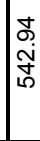 & 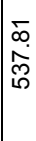 & 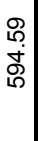 & 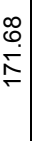 & : & 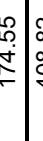 & 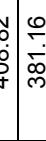 & $\stackrel{8}{\circ}$ & & $\underset{\infty}{\infty}$ & & 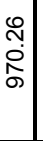 & $\begin{array}{ll} \\
\overline{0} \\
\infty \\
\infty\end{array}$ & & 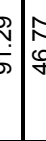 & 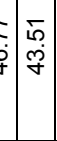 & $\begin{array}{l}\infty \\
\stackrel{\infty}{\infty} \\
\stackrel{f}{f}\end{array}$ & 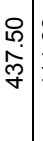 & \begin{tabular}{l|l}
8 \\
$\dot{+}$ \\
$\dot{\sigma}$
\end{tabular} & & 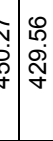 & 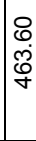 \\
\hline 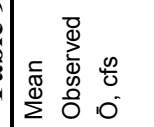 & - & ָై & 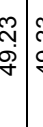 & 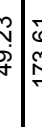 & 5 & $\stackrel{\overline{0}}{\stackrel{\Sigma}{2}}$ & 号 & 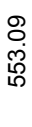 & 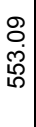 & $\begin{array}{l}\bar{\delta} \\
\dot{0} \\
\\
\end{array}$ & $\begin{array}{l}\overline{6} \\
6 \\
6 \\
6 \\
-\end{array}$ & 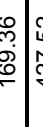 & 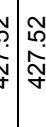 & ס. & -1 & & & 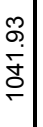 & 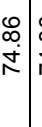 & 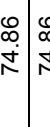 & & 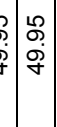 & $\begin{array}{l}\text { ஜ } \\
\text { ఠ্ } \\
\end{array}$ & $\begin{array}{c}5 \\
\frac{5}{6} \\
5\end{array}$ & 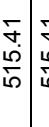 & & 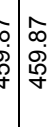 & \\
\hline & $\left|\begin{array}{c}\frac{0}{0} \\
0 \\
\frac{d}{5} \\
\frac{5}{3}\end{array}\right|$ & 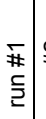 & & $\begin{array}{l}0 \\
\vdots \\
\vdots \\
\vdots \\
2\end{array}$ & 15 & 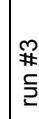 & 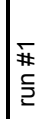 & $\begin{array}{l}\text { \# } \\
\stackrel{\text { I }}{2}\end{array}$ & $\begin{array}{l}\text { 年 } \\
\text { 至 }\end{array}$ & 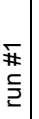 & 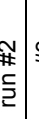 & 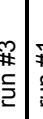 & & & & & & 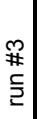 & $\begin{array}{l}\text { F } \\
\text { 三 }\end{array}$ & & 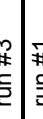 & 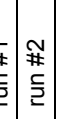 & & & $\#$ & $\begin{array}{l}0 \\
c \\
c\end{array}$ & 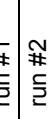 & \\
\hline & 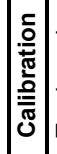 & 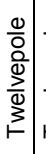 & 吾 & 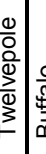 & & 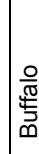 & 崖 & 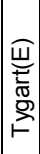 & $\mid$ & 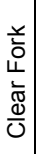 & 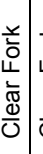 & 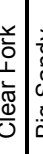 & 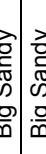 & & & & & 产 & 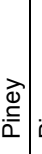 & $\frac{c}{0}$ & 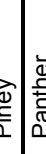 & 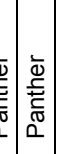 & 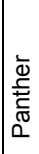 & 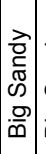 & $\stackrel{\square}{\square}$ & $\begin{array}{lll}0 \\
0 \\
0\end{array}$ & 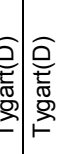 & \\
\hline
\end{tabular}


Figure 10 : R and R2 Value Ranges for Model Performance (Donigian, A., 2002)

\begin{tabular}{|c|c|c|c|c|c|}
\hline $\mathrm{R}$ & $\leftarrow 0.75 \square$ & 0.80 & 0.85 & 0.90 & 0.95 \\
\hline$R^{2}$ & $\longleftarrow 0.6$ & $\overline{\bar{\nu}}$ & 0.7 & 0.8 & 0.9 \\
\hline Daily Flows & Poor & $\mathrm{Fa}$ & \multicolumn{2}{|c|}{ Good } & Very Good \\
\hline Monthly Flows & Poo & & Fair & Good & Very \\
\hline
\end{tabular}




\section{References}

Al-Abed, N.A., and H.R. Whiteley, 2002, "Calibration of the Hydrologic Simulation Program Fortran (HSPF) Model Using Automatic Calibration and Geographical Information Systems," Hydrologic Processes, Vol. 16, 3169-3188.

American Society of Civil Engineers, 1993, "Criteria for Evaluation of Watershed Models," ASCE Task Committee on Definition of Criteria for Evaluation of Watershed Models. J. Irrigation and Drainage, 119(3):429-442.

Bicknell, B.R., Imhoff, J., C., Kittle, J., L., Jr., Jobes, T., H., Donigian, A., S., Jr., 2001, Hydrological Simulation Program - Fortran, HSPF Version 12 User's Manual, U.S. EPA, Athens, Georgia, March 2001.

Dinicola, R.S., 2001, "Validation of a numerical modeling method for simulating rainfall-runoff relations for headwater basins in western King and Snohomish Counties, Washington," USGS Water-Supply Paper 2495.

Dinicola, R.S., 1990, "Characterization and Simulation of Rainfall-Runoff Relations for Headwater Basins in Western King and Snohomish Counties, Washington," U.S. Geological Survey Water Resources Investigations Report 89-4052, Tacoma, Washington.

Doherty, J., 2002, "PEST Surface Water Utilities, Watermark Numerical Computing and Documentation," University of Idaho, September 2002. http://www.sspa.com/pest

Donigian, A.S., Jr., 2003, NRAC - HSPF Training Workshop, Aqua Terra Consultants, Morgantown, WV, March 4-6.

Donigian, A.S., Jr., 2002, "Watershed Model Calibration and Validation, the HSPF Experience." WEF 2002 Specialty Conference Proceedings, Nov. 13-16, Phoenix, AZ.

EPA BASINS Technical Note 6, 2000, U.S. Environmental Protection Agency, EPA823-R00-012, July, 2000.

HSPFParm: An Interactive Database of HSPF Model Parameters, Version 1.0. EPA-823R-99-004, April, 1999, U.S. EPA, Washington, D.C.

Legates, D.R., and G.J. McCabe, 1999, "Evaluating the Use of "Goodness of Fit" Measures in Hydrologic and Hydroclimatic Model Validation," Water Resource Research, 35:233-241.

Lohani, V., D.F. Kibler, and J. Chanat, 2002, "Constructing a Problem Solving Environmental Tool for Hydrologic Assessment of Land Use Change," Journal of the American Water Resources Association, Vol. 38, No. 2, April, p. 439 - 452. 
Martin, J.D., R.F. Duwelius, and C.G. Crawford, 1990, "Effects of Surface Coal Mining and Reclamation on the Geohydrology of Six Small Watersheds in West-Central Indiana," U.S.G.S. Water Supply Paper 2368, Chapter B.

Martinec, J and A. Rango, 1989, "Merits of Statistical Criteria for the Performance of Hydrological Models," Water Resources Bulletin, 25(2):421-431.

Nash, J.E., and J.V. Sutcliffe, 1970, "River flow forecasting through conceptual models: Part I- A discussion of principles,” J.Hydrology, 10, 282-290.

Ribeiro, C.T., 1996, "Impact of Land Use on Water Resources: Integrating HSPF and a raster-vector GIS," HydroGIS 96: Application of Geographic Information Systems in Hydrology and Water Resources Management, Proceedings of the Vienna Conference, April 1996, IAHS Publ. no. 235.

Sams, J.I. and Witt, E.C., 1995, "Simulation of streamflow and sediment transport in two surface-coal-mined basins in Fayette County, Pennsylvania", USGS Water-Resources Investigations Report 92-4093.

Srinivasan, M.S., J.M. Hamlett, R.L. Day, J.I. Sams, and G.W. Petersen, 1998, "Hydrologic Modeling of Two Glaciated Watersheds in Northeast Pennsylvania," Journal of the American Water Resources Association, Vol. 34, No. 4, p. 963 - 978.

Strager, Jacquelyn M. and Charles B. Yuill, 2002, “The West Virginia Gap Analysis Project, Final Report," USGS GAP Analysis Program. ftp://ftp.gap.uidaho.edu/products/west_virginia/report/wvgaprpt.pdf

Users Manual for an Expert System (HSPEXP) for Calibration of the Hydrological Simulation Program - Fortran, 1994, U.S. Geological Survey Water-Resources Investigations Report 94-4168, Reston, Virginia.

Willmott, C. J., 1981, “On the Validation of Models,” Physical Geography, 2:184-194

Willmott, C.J., 1984, "On the Evaluation of the Model Performance in Physical Geography," Spatial Statistics and Models, Gaile, G.L. and C.J. Willmott (eds), D. Reidel, Dordrecht, 443-460.

Willmott, C.J., S.G. Ackleson, R.E. Davis, J.J. Feddema, K.M. Klink, D.R. Legates, J. O'Donnell, and C.M.Rowe, 1985, "Statistics for The Evaluation and Comparison of Models," J.Geophys. Res., 90:8995-9005. 


\section{Appendix B. Final Calibration User's Control Input File (UCI)}

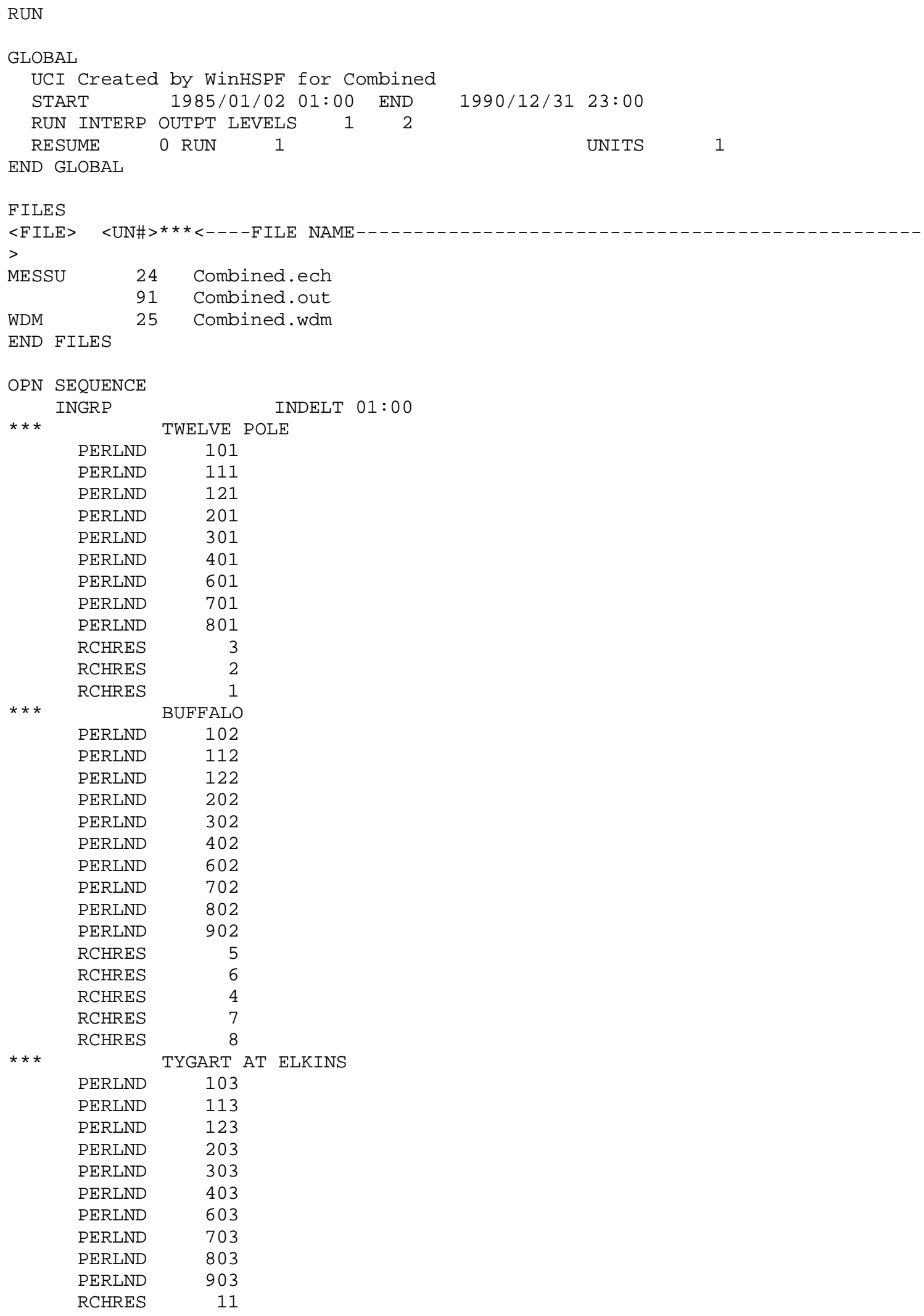




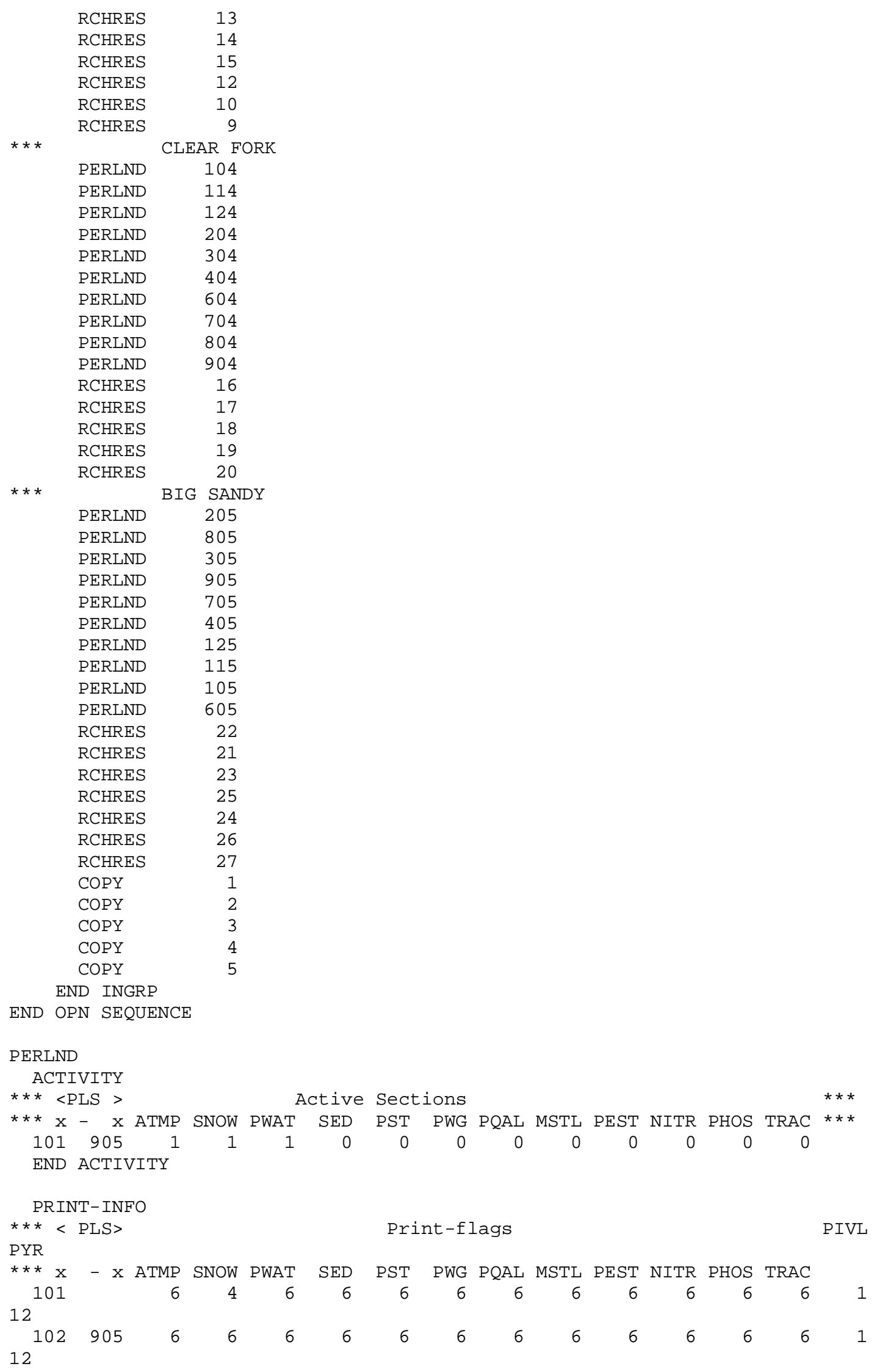




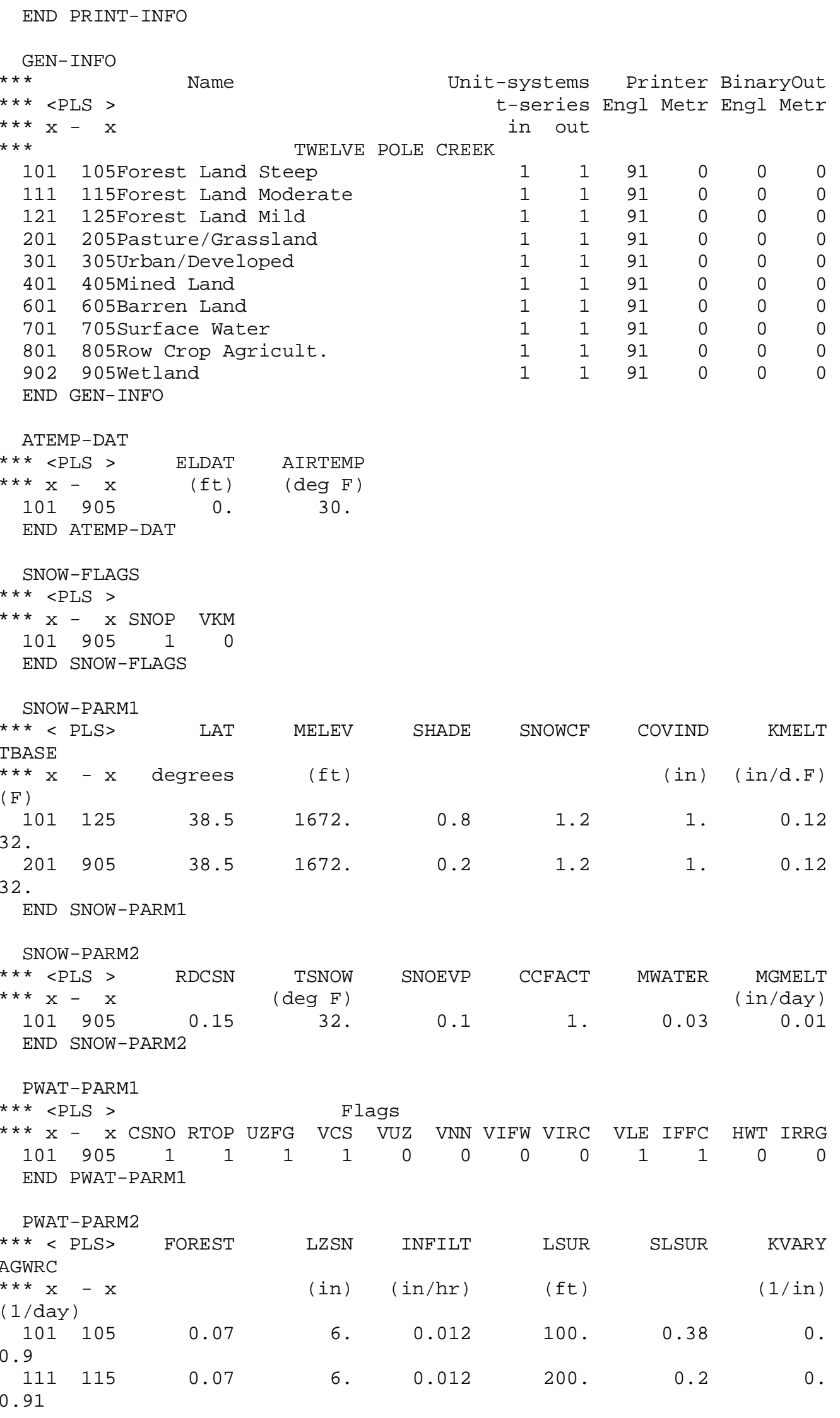




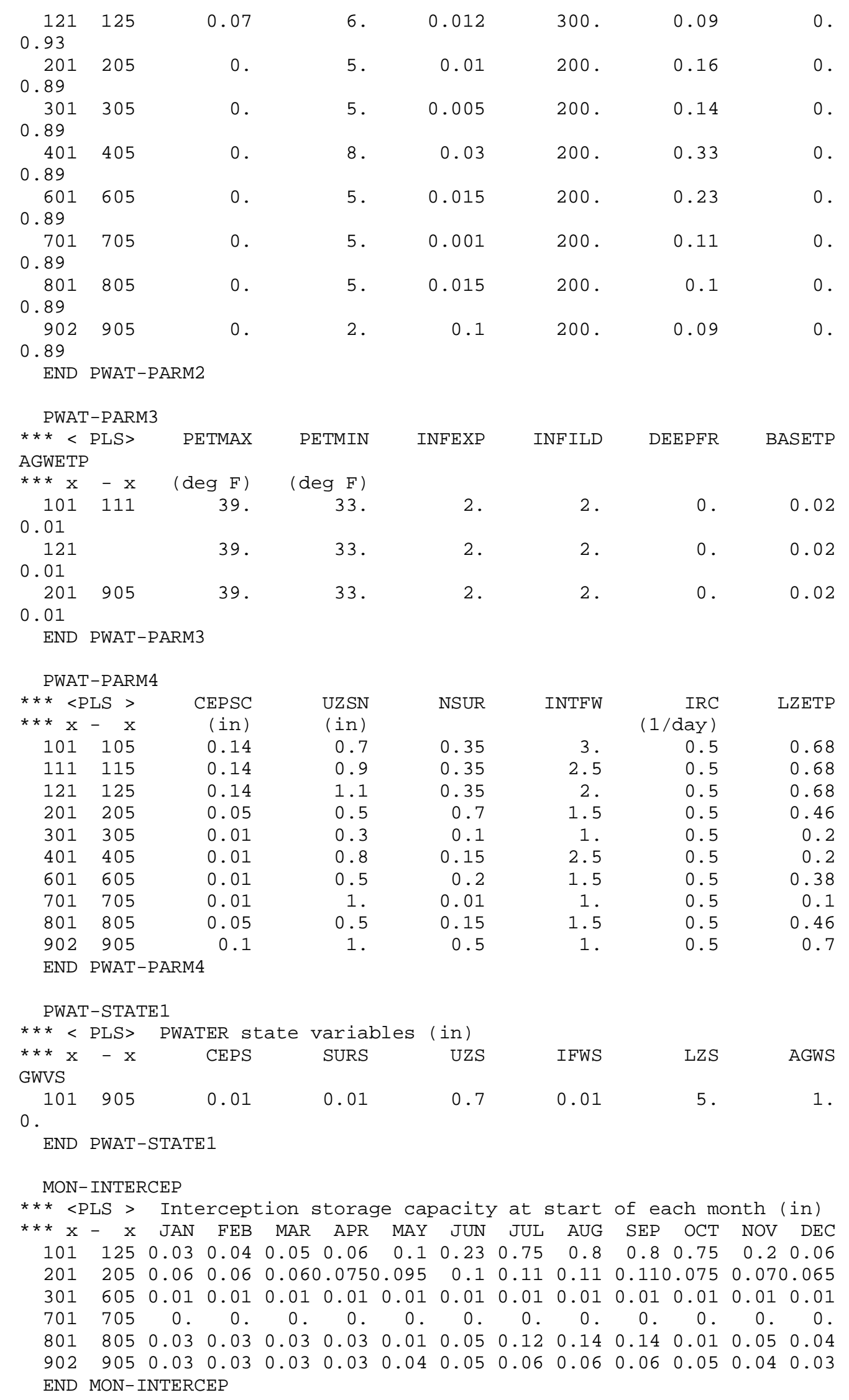




\begin{abstract}
MON-LZETPARM

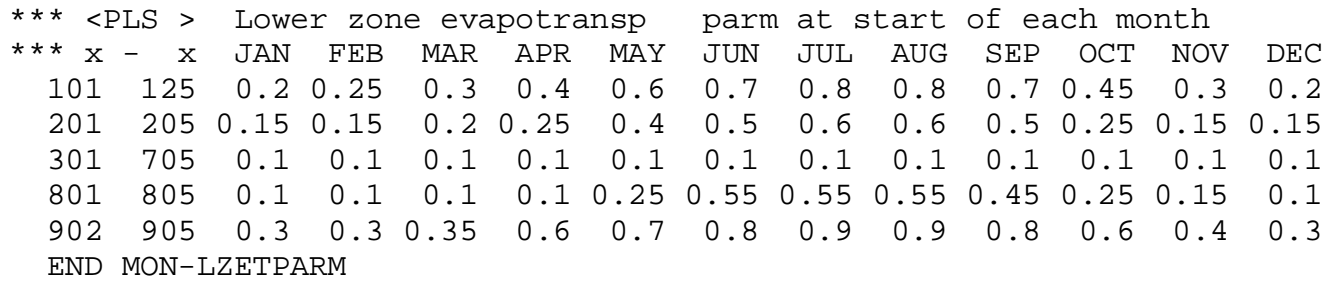

END PERLND

RCHRES

ACTIVITY

$\star \star \star$ RCHRES Active sections

$\star \star \star x-x$ HYFG ADFG CNFG HTFG SDFG GQFG OXFG NUFG PKFG PHFG

$\begin{array}{llllllllllll}1 & 27 & 1 & 0 & 0 & 0 & 0 & 0 & 0 & 0 & 0 & 0\end{array}$

END ACTIVITY

PRINT-INFO

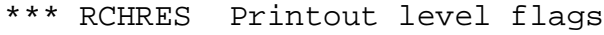

$\star \star \star x-x$ HYDR ADCA CONS HEAT SED GQL OXRX NUTR PLNK PHCB PIVL PYR END PRINT-INFO

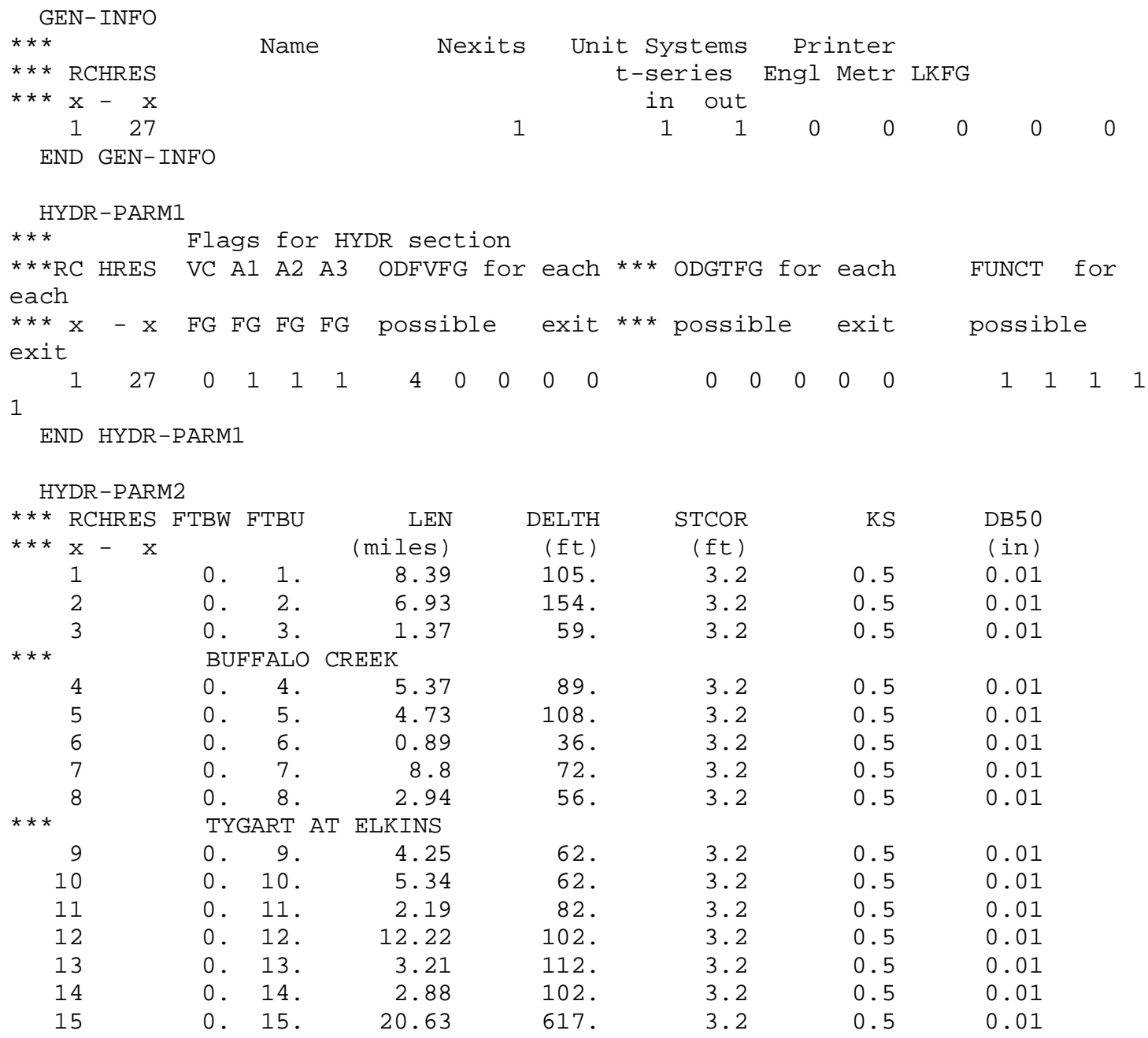




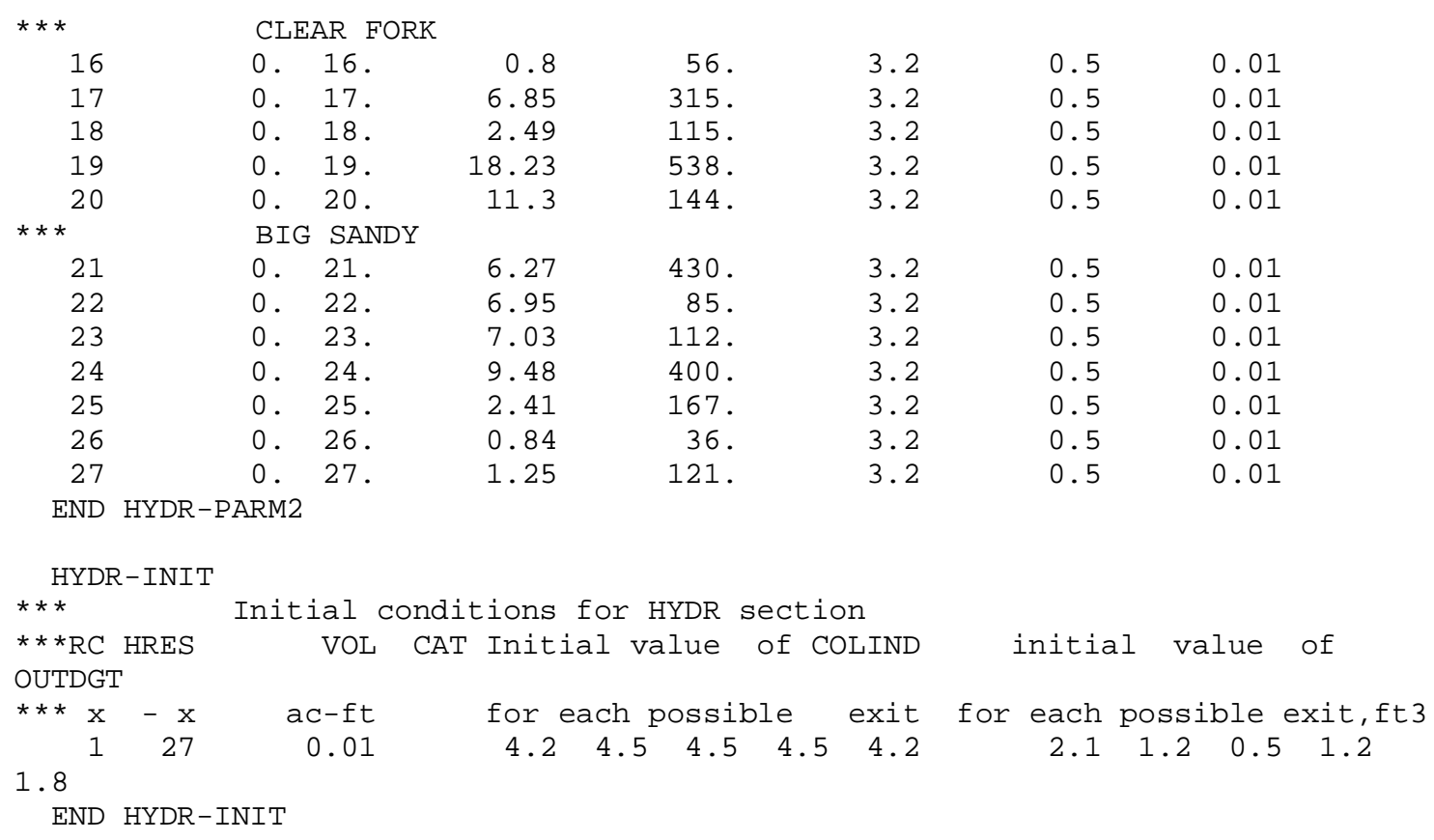

END RCHRES

FTABLES

\begin{tabular}{|c|c|c|c|c|}
\hline $\begin{array}{l}\text { FTABLE } \\
\text { rows cols }\end{array}$ & 3 & & & 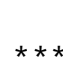 \\
\hline 4 & & & & \\
\hline depth & area & volume & outflow1 & 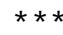 \\
\hline 0 . & 26.75 & 0 . & 0 . & \\
\hline 0.18 & 27.04 & 4.72 & 3.39 & \\
\hline 1.76 & 29.7 & 49.57 & 156.57 & \\
\hline 2.2 & 34.12 & 62.78 & 226.99 & \\
\hline 2.74 & 91.68 & 112.59 & 293.98 & \\
\hline 3.29 & 93.52 & 163.42 & 539.09 & \\
\hline 56.54 & 272.34 & 9903. & 237376.95 & \\
\hline 109.78 & 451.16 & 29163.13 & 017580.19 & \\
\hline END FTABLE & 3 & & & \\
\hline
\end{tabular}

\begin{tabular}{|c|c|c|c|c|}
\hline FTABLE & 2 & & & \\
\hline rows cols & & & & $\star \star \star$ \\
\hline 8 & & & & \\
\hline depth & area & volume & outflow1 & $\star \star \star$ \\
\hline 0 . & 2.36 & 0 . & 0 . & \\
\hline 0.1 & 2.4 & 0.25 & 0.9 & \\
\hline 1.05 & 2.71 & 2.66 & 41.33 & \\
\hline 1.31 & 3.23 & 3.38 & 59.96 & \\
\hline 1.64 & 8.43 & 6.12 & 79. & \\
\hline 1.97 & 8.65 & 8.92 & 145.43 & \\
\hline 33.79 & 29.75 & 620.02 & 72022.73 & \\
\hline 65.62 & 50.85 & 1902.67 & 324306.72 & \\
\hline END FTABLE & 2 & & & \\
\hline FTABLE & 1 & & & \\
\hline rows cols & & & & $\star \star \star *$ \\
\hline 8 & & & & \\
\hline depth & area & volume & outflow1 & $\star \star \star$ \\
\hline 0 & 61.02 & 0. & 0 & \\
\hline 0.26 & 61.55 & 16.2 & 9.47 & \\
\hline
\end{tabular}




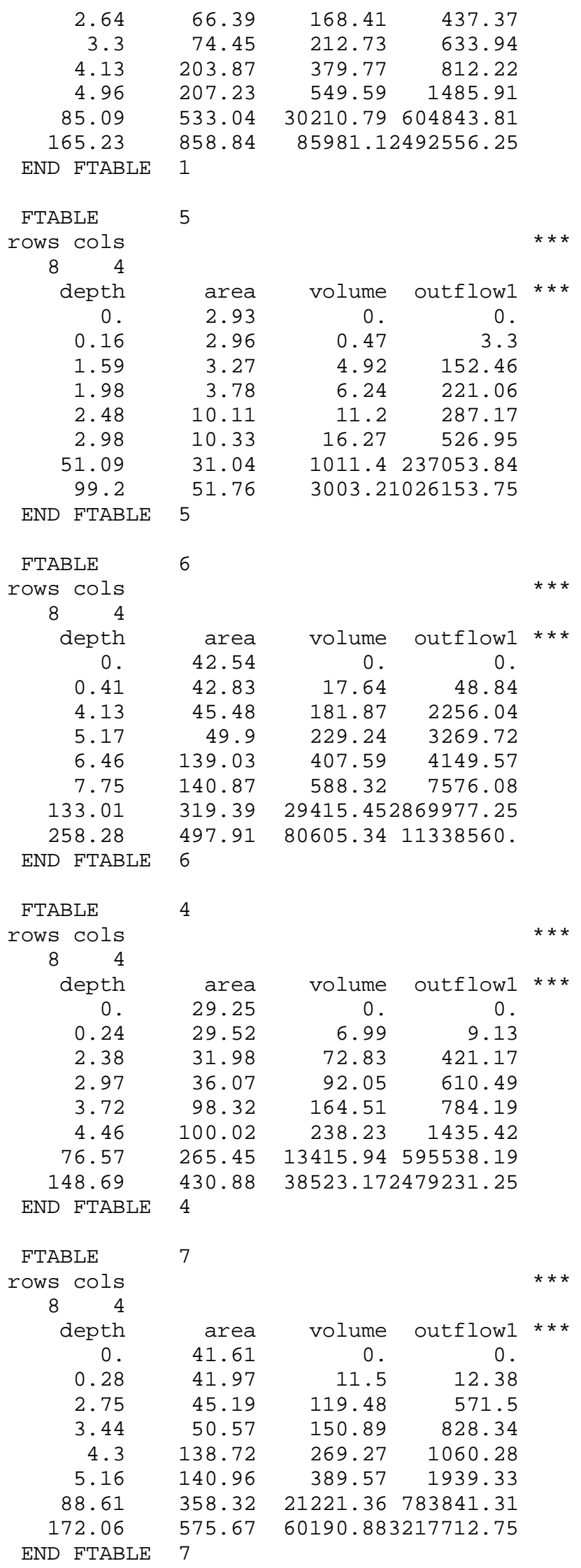




\begin{tabular}{|c|c|c|c|c|}
\hline FTABLE & 8 & & & \\
\hline rows cols & & & & $\star \star \star$ \\
\hline 8 & & & & \\
\hline depth & area & volume & outflow1 & $\star \star \star$ \\
\hline 0 . & 115.93 & 0 . & 0 & \\
\hline 0.39 & 116.75 & 45.22 & 26.38 & \\
\hline 3.89 & 124.22 & 466.73 & 1218.51 & \\
\hline 4.86 & 136.65 & 588.45 & 1766.01 & \\
\hline 6.07 & 379.91 & 1046.79 & 2243.88 & \\
\hline 7.29 & 385.09 & 1511.42 & 4097.78 & \\
\hline 125.12 & 887.77 & 76500.761 & 566379.25 & \\
\hline 242.95 & 1390.45 & 210720.06 & 6223554 . & \\
\hline END FTABLE & 8 & & & \\
\hline FTABLE & 11 & & & \\
\hline rows cols & & & & $\star \star \star$ \\
\hline 84 & & & & \\
\hline depth & area & volume & outflow1 & $\star \star \star$ \\
\hline 0 . & 122.09 & 0 . & 0 . & \\
\hline 0.56 & 122.81 & 68.23 & 99.69 & \\
\hline 5.57 & 129.3 & 700.37 & 4607.33 & \\
\hline 6.97 & 140.11 & 881.74 & 6677.47 & \\
\hline 8.71 & 394.2 & 1564.23 & 8429.71 & \\
\hline 10.45 & 398.71 & 2254.56 & 15373.69 & \\
\hline 179.35 & 835.76 & 106507.48 & 5592222 . & \\
\hline 348.25 & 1272.82 & 284580.31 & 21502960 & \\
\hline END FTABLE & 11 & & & \\
\hline FTABLE & 13 & & & \\
\hline rows cols & & & & $\star \star \star$ \\
\hline 8 & & & & \\
\hline depth & area & volume & outflow1 & $\star \star \star$ \\
\hline 0 . & 245.58 & 0 . & 0 . & \\
\hline 0.51 & 247.1 & 126.09 & 64.26 & \\
\hline 5.12 & 260.75 & 1295.82 & 2969.25 & \\
\hline 6.4 & 283.5 & 1631.91 & 4303.36 & \\
\hline 8 . & 795.53 & 2896.78 & 5440.34 & \\
\hline 9.6 & 805.01 & 4176.82 & 9924.75 & \\
\hline 164.75 & 1724.57 & 200411.5 & 3649837 . & \\
\hline 319.9 & 2644.13 & 539318.13 & 14140778 & \\
\hline END FTABLE & 13 & & & \\
\hline FTABLE & 14 & & & \\
\hline rows cols & & & & $\star \star \star$ \\
\hline 8 & & & & \\
\hline depth & area & volume & outflow1 & $\star \star \star$ \\
\hline 0 . & 15.32 & 0 . & 0 . & \\
\hline 0.22 & 15.47 & 3.32 & 8.29 & \\
\hline 2.16 & 16.83 & 34.7 & 382.43 & \\
\hline 2.7 & 19.09 & 43.88 & 554.36 & \\
\hline 3.37 & 51.82 & 78.51 & 713.88 & \\
\hline 4.05 & 52.76 & 113.78 & 1307.44 & \\
\hline 69.47 & 144.19 & 6556.01 & 552488.75 & \\
\hline 134.89 & 235.61 & 18979.622 & 2321737.25 & \\
\hline END FTABLE & 14 & & & \\
\hline FTABLE & 15 & & & \\
\hline rows cols & & & & $\star \star \star$ \\
\hline $8 \quad 4$ & & & & \\
\hline depth & area & volume & outflow1 & $\star \star \star$ \\
\hline 0 . & 320.65 & 0. & 0 & \\
\hline 0.43 & 322.82 & 139.27 & 71.14 & \\
\hline
\end{tabular}




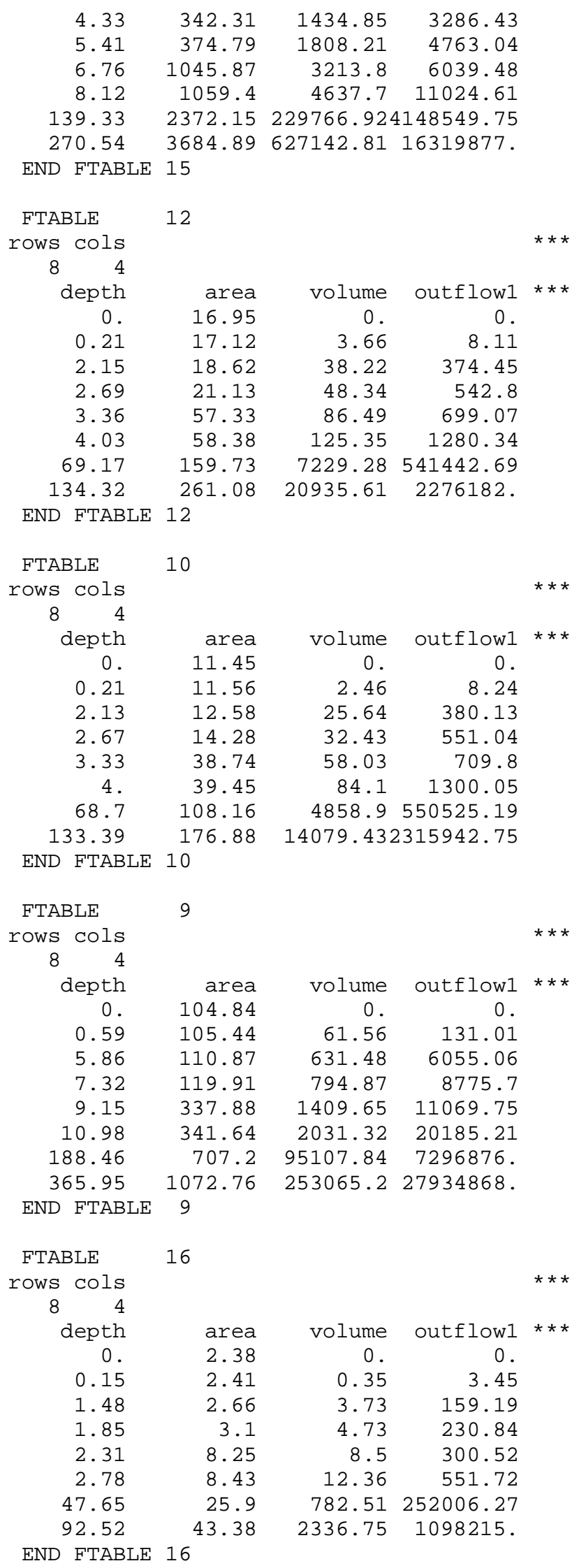




\begin{tabular}{|c|c|c|c|c|}
\hline FTABLE & 17 & & & \\
\hline rows cols & & & & $\star \star \star *$ \\
\hline 8 & & & & \\
\hline depth & area & volume & outflow1 & $\star \star \star$ \\
\hline 0 . & 38.15 & 0 . & 0 & \\
\hline 0.22 & 38.52 & 8.52 & 10.4 & \\
\hline 2.22 & 41.85 & 88.91 & 479.96 & \\
\hline 2.78 & 47.39 & 112.42 & 695.73 & \\
\hline 3.47 & 128.77 & 201.07 & 895.23 & \\
\hline 4.17 & 131.08 & 291.32 & 1639.29 & \\
\hline 71.55 & 355.02 & 16667.86 & 688793.06 & \\
\hline 138.93 & 578.95 & 48133.372 & 2886226.75 & \\
\hline END FTABLE & 17 & & & \\
\hline FTABLE & 18 & & & \\
\hline rows cols & & & & $\star \star \star$ \\
\hline 84 & & & & \\
\hline depth & area & volume & outflow1 & $\star \star \star$ \\
\hline 0 . & 18.03 & 0 . & 0 & \\
\hline 0.26 & 18.19 & 4.78 & 18.1 & \\
\hline 2.64 & 19.62 & 49.69 & 835.35 & \\
\hline 3.3 & 22.01 & 62.76 & 1210.8 & \\
\hline 4.12 & 60.26 & 112.05 & 1551.38 & \\
\hline 4.95 & 61.26 & 162.15 & 2838.2 & \\
\hline 84.94 & 157.65 & 8917.231 & 1155685.88 & \\
\hline 164.92 & 254.05 & 25382.83 & 4763437 . & \\
\hline END FTABLE & 18 & & & \\
\hline FTABLE & 19 & & & \\
\hline rows cols & & & & $\star \star \star$ \\
\hline 8 & & & & \\
\hline depth & area & volume & outflow1 & $\star \star \star$ \\
\hline 0 . & 170.84 & 0 . & 0 . & \\
\hline 0.31 & 172.22 & 53.44 & 24.64 & \\
\hline 3.12 & 184.61 & 553.68 & 1137.87 & \\
\hline 3.89 & 205.26 & 698.8 & 1649.2 & \\
\hline 4.87 & 565.87 & 1245.51 & 2105.1 & \\
\hline 5.84 & 574.48 & 1800.61 & 3848.08 & \\
\hline 100.28 & 1409.06 & 95457.15 & 1523058.5 & \\
\hline 194.71 & 2243.64 & 267926.5 & 6178898.5 & \\
\hline END FTABLE & 19 & & & \\
\hline FTABLE & 20 & & & \\
\hline rows cols & & & & $\star \star \star$ \\
\hline 8 & & & & \\
\hline depth & area & volume & outflow1 & $\star \star \star$ \\
\hline 0 & 173.92 & 0 . & 0 . & \\
\hline 0.43 & 175.1 & 75.06 & 45.59 & \\
\hline 4.3 & 185.7 & 773.43 & 2106.04 & \\
\hline 5.38 & 203.38 & 974.71 & 3052.3 & \\
\hline 6.72 & 567.42 & 1732.47 & 3870.72 & \\
\hline 8.07 & 574.78 & 2500.13 & 7065.88 & \\
\hline 138.45 & 1289.16 & 124015.96 & 2661241.5 & \\
\hline 268.84 & 2003.54 & 338677 . & 10474989. & \\
\hline END FTABLE & 20 & & & \\
\hline FTABLE & 22 & & & \\
\hline rows cols & & & & $\star \star \star$ \\
\hline 84 & & & & \\
\hline depth & area & volume & outflow1 & $\star \star \star$ \\
\hline 0 & 37.21 & 0 & 0. & \\
\hline 0.23 & 37.56 & 8.66 & 14.5 & \\
\hline
\end{tabular}




\begin{tabular}{|c|c|c|c|c|}
\hline & & & & \\
\hline 2.32 & 40.73 & 90.26 & 669.25 & \\
\hline 2.9 & 46.01 & 114.1 & 970.09 & \\
\hline 3.62 & 125.27 & 203.98 & 1246.95 & \\
\hline 4.34 & 127.47 & 295.46 & 2282.83 & \\
\hline 74.56 & 341.01 & 16742.31 & 951819.56 & \\
\hline 144.77 & 554.54 & 48182.423 & 3972628.25 & \\
\hline END FTABLE & 22 & & & \\
\hline FTABLE & 21 & & & \\
\hline rows cols & & & & $\star \star \star$ \\
\hline 84 & & & & \\
\hline depth & area & volume & outflow1 & $\star \star \star$ \\
\hline 0 & 62.88 & 0 . & 0 & \\
\hline 0.3 & 63.4 & 19.23 & 14.76 & \\
\hline 3.05 & 68.01 & 199.3 & 681.38 & \\
\hline 3.81 & 75.71 & 251.56 & 987.57 & \\
\hline 4.76 & 208.53 & 448.48 & 1261.2 & \\
\hline 5.71 & 211.73 & 648.44 & 2305.7 & \\
\hline 98.02 & 522.72 & 34545.57 & 916033.31 & \\
\hline 190.32 & 833.7 & 97148.513 & 3724290.75 & \\
\hline END FTABLE & 21 & & & \\
\hline FTABLE & 23 & & & \\
\hline rows cols & & & & $\star \star \star$ \\
\hline 8 & & & & \\
\hline depth & area & volume & outflow1 & $\star \star \star$ \\
\hline 0 & 100.44 & 0 & 0 & \\
\hline 0.41 & 101.14 & 41.31 & 43.5 & \\
\hline 4.1 & 107.42 & 426.02 & 2009.29 & \\
\hline 5.12 & 117.9 & 537. & 2912.09 & \\
\hline 6.4 & 328.38 & 954.84 & 3696.28 & \\
\hline 7.69 & 332.75 & 1378.27 & 6748.72 & \\
\hline 131.94 & 756.11 & 69024.21 & 2559600 . & \\
\hline 256.19 & 1179.48 & 189273.97 & 10119986 & \\
\hline END FTABLE & 23 & & & \\
\hline FTABLE & 25 & & & \\
\hline rows cols & & & & $\star \star \star$ \\
\hline 84 & & & & \\
\hline depth & area & volume & outflow1 & $\star \star \star$ \\
\hline 0 . & 15.15 & 0 & 0 & \\
\hline 0.48 & 15.24 & 7.24 & 116.1 & \\
\hline 4.77 & 16.12 & 74.52 & 5364.22 & \\
\hline 5.96 & 17.58 & 93.87 & 7774.4 & \\
\hline 7.45 & 49.2 & 166.72 & 9840.63 & \\
\hline 8.94 & 49.81 & 240.47 & 17956.77 & \\
\hline 153.44 & 108.71 & 11694.2 & 6666999.5 & \\
\hline 297.95 & 167.62 & 31659.68 & 25997188 & \\
\hline END FTABLE & 25 & & & \\
\hline FTABLE & 24 & & & \\
\hline rows cols & & & & $\star \star \star$ \\
\hline 8 & & & & \\
\hline depth & area & volume & outflow1 & $\star \star \star$ \\
\hline 0 . & 12.76 & 0 . & 0 . & \\
\hline 0.22 & 12.88 & 2.76 & 11.48 & \\
\hline 2.15 & 14.01 & 28.78 & 529.96 & \\
\hline 2.69 & 15.9 & 36.4 & 768.22 & \\
\hline 3.36 & 43.14 & 65.13 & 989.37 & \\
\hline 4.03 & 43.93 & 94.38 & 1812.01 & \\
\hline 69.21 & 120.18 & 5442.84 & 766210.81 & \\
\hline 134.4 & 196.43 & 15761.533 & 3220936.75 & \\
\hline END FTABL & 24 & & & \\
\hline
\end{tabular}




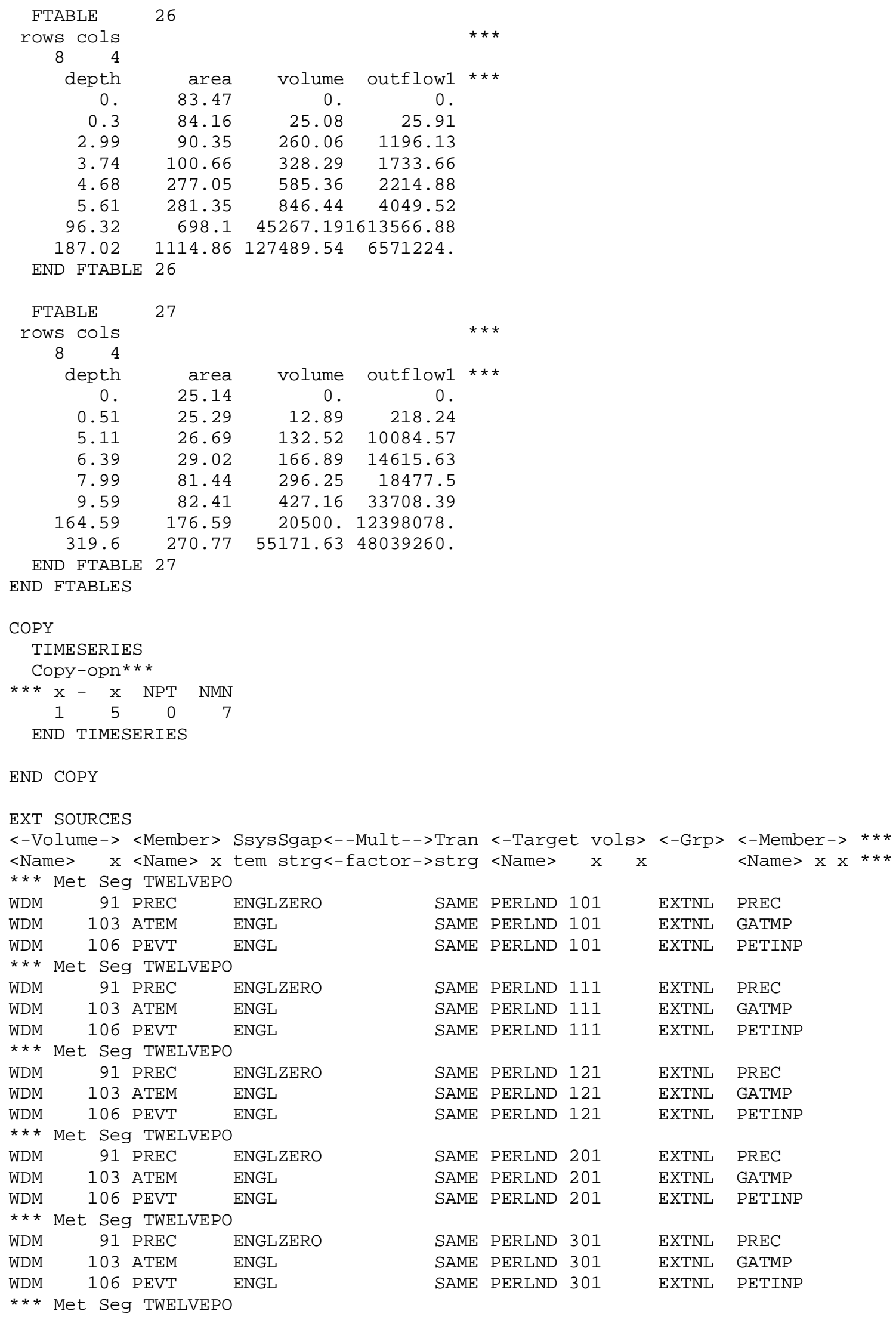




\begin{tabular}{|c|c|c|}
\hline WDM & 91 PREC & ENGLZERO \\
\hline WDM & 103 ATEM & ENGL \\
\hline WDM & $106 \mathrm{PEVT}$ & ENGL \\
\hline$\star \star \star$ & \multicolumn{2}{|c|}{ Met Seg TWELVEPO } \\
\hline WDM & 91 PREC & ENGLZERO \\
\hline WDM & 103 ATEM & ENGL \\
\hline WDM & 106 PEVT & ENGL \\
\hline$\star \star \star$ & \multicolumn{2}{|c|}{ Met Seg TWELVEPO } \\
\hline WDM & $91 \mathrm{PREC}$ & ENGLZERO \\
\hline WDM & 103 ATEM & ENGL \\
\hline WDM & 106 PEVT & ENGL \\
\hline$\star \star \star$ & \multicolumn{2}{|c|}{ Met Seg TWELVEPO } \\
\hline WDM & $91 \mathrm{PREC}$ & ENGLZERO \\
\hline WDM & 103 ATEM & ENGL \\
\hline WDM & $106 \mathrm{PEVT}$ & ENGL \\
\hline$\star \star \star$ & \multicolumn{2}{|l|}{ Met Seg BUFF } \\
\hline WDM & 211 PREC & ENGLZERO \\
\hline WDM & 203 ATEM & ENGL \\
\hline WDM & 206 PEVT & ENGL \\
\hline$\star \star \star$ & \multicolumn{2}{|l|}{ Met Seg BUFF } \\
\hline WDM & 211 PREC & ENGLZERO \\
\hline WDM & 203 ATEM & ENGL \\
\hline WDM & 206 PEVT & ENGL \\
\hline$\star \star \star$ & \multicolumn{2}{|l|}{ Met Seg BUFF } \\
\hline WDM & $211 \mathrm{PREC}$ & ENGLZERO \\
\hline WDM & 203 ATEM & ENGL \\
\hline WDM & 206 PEVT & ENGL \\
\hline$\star \star \star$ & \multicolumn{2}{|l|}{ Met Seg BUFF } \\
\hline WDM & 211 PREC & ENGLZERO \\
\hline WDM & 203 ATEM & ENGL \\
\hline WDM & 206 PEVT & ENGL \\
\hline$\star \star \star$ & \multicolumn{2}{|l|}{ Met Seg BUFF } \\
\hline WDM & 211 PREC & ENGLZERO \\
\hline WDM & 203 ATEM & ENGL \\
\hline WDM & 206 PEVT & ENGL \\
\hline$\star \star \star$ & \multicolumn{2}{|l|}{ Met Seg BUFF } \\
\hline WDM & 211 PREC & ENGLZERO \\
\hline WDM & 203 ATEM & ENGL \\
\hline WDM & 206 PEVT & ENGL \\
\hline$\star \star \star ~$ & \multicolumn{2}{|l|}{ Met Seg BUFF } \\
\hline WDM & 211 PREC & ENGLZERO \\
\hline WDM & 203 ATEM & ENGL \\
\hline WDM & 206 PEVT & ENGL \\
\hline$\star \star \star$ & \multicolumn{2}{|l|}{ Met Seg BUFF } \\
\hline WDM & 211 PREC & ENGLZERO \\
\hline WDM & 203 ATEM & ENGL \\
\hline WDM & 206 PEVT & ENGL \\
\hline$\star \star \star$ & \multicolumn{2}{|l|}{ Met Seg BUFF } \\
\hline WDM & 211 PREC & ENGLZERO \\
\hline WDM & 203 ATEM & ENGL \\
\hline WDM & 206 PEVT & ENGL \\
\hline$\star \star \star$ & \multicolumn{2}{|l|}{ Met Seg BUFF } \\
\hline WDM & 211 PREC & ENGLZERO \\
\hline WDM & 203 ATEM & ENGL \\
\hline WDM & 206 PEVT & ENGL \\
\hline$\star \star \star$ & \multicolumn{2}{|c|}{ Met Seg TV ELKIN } \\
\hline WDM & 311 PREC & ENGLZERO \\
\hline WDM & 303 ATEM & ENGL \\
\hline WDM & $306 \mathrm{PEVT}$ & ENGL \\
\hline$\star \star \star$ & \multicolumn{2}{|c|}{ Met Seg TV ELKIN } \\
\hline WDM & 311 PREC & ENGLZERO \\
\hline WDM & 303 ATEM & ENGL \\
\hline WDM & 306 PEVT & ENGL \\
\hline
\end{tabular}

\begin{tabular}{|c|c|c|c|c|}
\hline SAME & PERLND & 401 & EXTNL & PREC \\
\hline SAME & PERLND & 401 & EXTNL & GATMP \\
\hline SAME & PERLND & 401 & EXTNL & PETINP \\
\hline SAME & PERLND & 601 & EXTNL & PREC \\
\hline SAME & PERLND & 601 & EXTNL & GATMP \\
\hline SAME & PERLND & 601 & EXTNL & PETINP \\
\hline SAME & PERLND & 701 & EXTNL & PREC \\
\hline SAME & PERLND & 701 & EXTNL & GATMP \\
\hline SAME & PERLND & 701 & EXTNL & PETINP \\
\hline SAME & PERLND & 801 & EXTNL & PREC \\
\hline SAME & PERLND & 801 & EXTNL & GATMP \\
\hline SAME & PERLND & 801 & EXTNL & PETINP \\
\hline SAME & PERLND & 102 & EXTNL & PREC \\
\hline SAME & PERLND & 102 & EXTNL & GATMP \\
\hline SAME & PERLND & 102 & EXTNL & PETINP \\
\hline SAME & PERLND & 112 & EXTNL & PREC \\
\hline SAME & PERLND & 112 & EXTNL & GATMP \\
\hline SAME & PERLND & 112 & EXTNL & PETINP \\
\hline SAME & PERLND & 122 & EXTNL & PREC \\
\hline SAME & PERLND & 122 & EXTNL & GATMP \\
\hline SAME & PERLND & 122 & EXTNL & PETINP \\
\hline SAME & PERLND & 202 & EXTNL & PREC \\
\hline SAME & PERLND & 202 & EXTNL & GATMP \\
\hline SAME & PERLND & 202 & EXTNL & PETINP \\
\hline SAME & PERLND & 302 & EXTNL & PREC \\
\hline SAME & PERLND & 302 & EXTNL & GATMP \\
\hline SAME & PERLND & 302 & EXTNL & PETINP \\
\hline SAME & PERLND & 402 & EXTNL & PREC \\
\hline SAME & PERLND & 402 & EXTNL & GATMP \\
\hline SAME & PERLND & 402 & EXTNL & PETINP \\
\hline SAME & PERLND & 602 & EXTNL & PREC \\
\hline SAME & PERLND & 602 & EXTNL & GATMP \\
\hline SAME & PERLND & 602 & EXTNL & PETINP \\
\hline SAME & PERLND & 702 & EXTNL & PREC \\
\hline SAME & PERLND & 702 & EXTNL & GATMP \\
\hline SAME & PERLND & 702 & EXTNL & PETINP \\
\hline SAME & PERLND & 802 & EXTNL & PREC \\
\hline SAME & PERLND & 802 & EXTNL & GATMP \\
\hline SAME & PERLND & 802 & EXTNL & PETINP \\
\hline SAME & PERLND & 902 & EXTNL & PREC \\
\hline SAME & PERLND & 902 & EXTNL & GATMP \\
\hline SAME & PERLND & 902 & EXTNL & PETINP \\
\hline SAME & PERLND & 103 & EXTNL & PREC \\
\hline SAME & PERLND & 103 & EXTNL & GATMP \\
\hline SAME & PERLND & 103 & EXTNL & PETINP \\
\hline SAME & PERLND & 113 & EXTNL & PREC \\
\hline SAME & PERLND & 113 & EXTNL & GATMP \\
\hline SAME & PERLND & 113 & EXTNL & PETINP \\
\hline
\end{tabular}




\begin{tabular}{|c|c|c|}
\hline WDM & 311 PREC & ENGLZERO \\
\hline WDM & 303 ATEM & ENGL \\
\hline WDM & 306 PEVT & ENGL \\
\hline \multicolumn{3}{|c|}{$\star \star \star$ Met Seg TV ELKIN } \\
\hline WDM & 311 PREC & ENGLZERO \\
\hline WDM & 303 ATEM & ENGL \\
\hline WDM & 306 PEVT & ENGL \\
\hline \multicolumn{3}{|c|}{$\star \star \star$ Met Seg TV ELKIN } \\
\hline WDM & 311 PREC & ENGLZERO \\
\hline WDM & 303 ATEM & ENGL \\
\hline WDM & 306 PEVT & ENGL \\
\hline \multicolumn{3}{|c|}{$\star \star \star$ Met Seg TV ELKIN } \\
\hline WDM & 311 PREC & ENGLZERO \\
\hline WDM & 303 ATEM & ENGL \\
\hline WDM & 306 PEVT & ENGL \\
\hline \multicolumn{3}{|c|}{$\star \star \star$ Met Seg TV ELKIN } \\
\hline WDM & 311 PREC & ENGLZERO \\
\hline WDM & 303 ATEM & ENGL \\
\hline WDM & 306 PEVT & ENGL \\
\hline \multicolumn{3}{|c|}{$\star \star \star$ Met Seg TV ELKIN } \\
\hline WDM & 311 PREC & ENGLZERO \\
\hline WDM & 303 ATEM & ENGL \\
\hline WDM & 306 PEVT & ENGL \\
\hline \multicolumn{3}{|c|}{$\star \star \star$ Met Seg TV ELKIN } \\
\hline WDM & 311 PREC & ENGLZERO \\
\hline WDM & 303 ATEM & ENGL \\
\hline WDM & 306 PEVT & ENGL \\
\hline \multicolumn{3}{|c|}{$\star \star \star$ Met Seg TV ELKIN } \\
\hline WDM & 311 PREC & ENGLZERO \\
\hline WDM & 303 ATEM & ENGL \\
\hline WDM & 306 PEVT & ENGL \\
\hline \multicolumn{3}{|l|}{$\star \star \star$} \\
\hline WDM & 411 PREC & ENGLZERO \\
\hline WDM & 403 ATEM & ENGL \\
\hline WDM & 406 PEVT & ENGL \\
\hline \multicolumn{3}{|l|}{$\star \star \star$} \\
\hline WDM & 411 PREC & ENGLZERO \\
\hline WDM & 403 ATEM & ENGL \\
\hline WDM & 406 PEVT & ENGL \\
\hline \multicolumn{3}{|l|}{$\star \star \star$} \\
\hline WDM & 411 PREC & ENGLZERO \\
\hline WDM & 403 ATEM & ENGL \\
\hline WDM & 406 PEVT & ENGL \\
\hline \multicolumn{3}{|l|}{$\star \star \star$} \\
\hline WDM & 411 PREC & ENGLZERO \\
\hline WDM & 403 ATEM & ENGL \\
\hline WDM & 406 PEVT & ENGL \\
\hline \multicolumn{3}{|c|}{ Seg CLEAR } \\
\hline WDM & 411 PREC & ENGLZERO \\
\hline WDM & 403 ATEM & ENGL \\
\hline WDM & 406 PEVT & ENGL \\
\hline \multicolumn{3}{|l|}{$\star \star \star$} \\
\hline WDM & 411 PREC & ENGLZERO \\
\hline WDM & 403 ATEM & ENGL \\
\hline WDM & 406 PEVT & ENGL \\
\hline \multicolumn{3}{|c|}{$\star \star \star \mathrm{M}$} \\
\hline WDM & 411 PREC & ENGLZERO \\
\hline WDM & 403 ATEM & ENGL \\
\hline WDM & 406 PEVT & ENGL \\
\hline \multicolumn{3}{|c|}{$\star \star \star$ Met Seg CLEAR FO } \\
\hline WDM & 411 PREC & ENGLZERO \\
\hline WDM & 403 ATEM & ENGL \\
\hline
\end{tabular}

\begin{tabular}{|c|c|c|c|c|}
\hline SAME & PERLND & 123 & EXTNL & PREC \\
\hline SAME & PERLND & 123 & EXTNL & GATMP \\
\hline SAME & PERLND & 123 & EXTNL & PETINP \\
\hline SAME & PERLND & 203 & EXTNL & PREC \\
\hline SAME & PERLND & 203 & EXTNL & GATMP \\
\hline SAME & PERLND & 203 & EXTNL & PETINP \\
\hline SAME & PERLND & 303 & EXTNL & PREC \\
\hline SAME & PERLND & 303 & EXTNL & GATMP \\
\hline SAME & PERLND & 303 & EXTNL & PETINP \\
\hline SAME & PERLND & 403 & EXTNL & PREC \\
\hline SAME & PERLND & 403 & EXTNL & GATMP \\
\hline SAME & PERLND & 403 & EXTNL & PETINP \\
\hline SAME & PERLND & 603 & EXTNL & PREC \\
\hline SAME & PERLND & 603 & EXTNL & GATMP \\
\hline SAME & PERLND & 603 & EXTNL & PETINP \\
\hline SAME & PERLND & 703 & EXTNL & PREC \\
\hline SAME & PERLND & 703 & EXTNL & GATMP \\
\hline SAME & PERLND & 703 & EXTNL & PETINP \\
\hline SAME & PERLND & 803 & EXTNL & PREC \\
\hline SAME & PERLND & 803 & EXTNL & GATMP \\
\hline SAME & PERLND & 803 & EXTNL & PETINP \\
\hline SAME & PERLND & 903 & EXTNL & PREC \\
\hline SAME & PERLND & 903 & EXTNL & GATMP \\
\hline SAME & PERLND & 903 & EXTNL & PETINP \\
\hline SAME & PERLND & 104 & EXTNL & PREC \\
\hline SAME & PERLND & 104 & EXTNL & GATMP \\
\hline SAME & PERLND & 104 & EXTNL & PETINP \\
\hline SAME & PERLND & 114 & EXTNL & PREC \\
\hline SAME & PERLND & 114 & EXTNL & GATMP \\
\hline SAME & PERLND & 114 & EXTNL & PETINP \\
\hline SAME & PERLND & 124 & EXTNL & PREC \\
\hline SAME & PERLND & 124 & EXTNL & GATMP \\
\hline SAME & PERLND & 124 & EXTNL & PETINP \\
\hline SAME & PERLND & 204 & EXTNL & PREC \\
\hline SAME & PERLND & 204 & EXTNL & GATMP \\
\hline SAME & PERLND & 204 & EXTNL & PETINP \\
\hline SAME & PERLND & 304 & EXTNL & PREC \\
\hline SAME & PERLND & 304 & EXTNL & GATMP \\
\hline SAME & PERLND & 304 & EXTNL & PETINP \\
\hline SAME & PERLND & 404 & EXTNL & PREC \\
\hline SAME & PERLND & 404 & EXTNL & GATMP \\
\hline SAME & PERLND & 404 & EXTNL & PETINP \\
\hline SAME & PERLND & 604 & EXTNL & PREC \\
\hline SAME & PERLND & 604 & EXTNL & GATMP \\
\hline SAME & PERLND & 604 & EXTNL & PETINP \\
\hline SAME & PERLND & 704 & EXTNL & PREC \\
\hline SAME & PERLND & 704 & EXTNL & GATMP \\
\hline
\end{tabular}




\begin{tabular}{|c|c|c|c|c|c|c|c|c|}
\hline $\begin{array}{l}\text { WDM } \\
\star \star \star\end{array}$ & $\begin{array}{c}406 \text { PEVT } \\
\text { Met Seg CLEA }\end{array}$ & $\mathrm{R} F \mathrm{FO}^{\mathrm{ENGL}}$ & SAME & PERLND & 704 & & EXTNL & PETINP \\
\hline WDM & 411 PREC & ENGLZERO & SAME & PERLND & 804 & & EXTNL & PREC \\
\hline WDM & 403 ATEM & ENGL & SAME & PERLND & 804 & & EXTNL & GATMP \\
\hline WDM & 406 PEVT & ENGL & SAME & PERLND & 804 & & EXTNL & PETINP \\
\hline$\star \star \star$ & Met Seg CLEA & $\mathrm{ARO}$ & & & & & & \\
\hline WDM & 411 PREC & ENGLZERO & SAME & PERLND & 904 & & EXTNL & PREC \\
\hline WDM & 403 ATEM & ENGL & SAME & PERLND & 904 & & EXTNL & GATMP \\
\hline WDM & 406 PEVT & ENGL & SAME & PERLND & 904 & & EXTNL & PETINP \\
\hline$\star \star \star$ & Met Seg BIG & SAND, P I : GATMP & 3, PI : PETII & $\mathrm{NP}=0.83$ & & & & \\
\hline WDM & 511 PREC & ENGLZERO & SAME & PERLND & 105 & & EXTNL & PREC \\
\hline WDM & 503 ATEM & ENGL & $0.83 \mathrm{SAME}$ & PERLND & 105 & & EXTNL & GATMP \\
\hline WDM & $506 \mathrm{PEVT}$ & ENGL & $0.83 \mathrm{SAME}$ & PERLND & 105 & & EXTNL & PETINP \\
\hline$\star \star \star$ & Met Seg BIG & SAND , P I : GATMP & 3, PI : PETII & $\mathrm{NP}=0.83$ & & & & \\
\hline WDM & 511 PREC & ENGLZERO & SAME & PERLND & 115 & & EXTNL & PREC \\
\hline WDM & 503 ATEM & ENGL & $0.83 \mathrm{SAME}$ & PERLND & 115 & & EXTNL & GATMP \\
\hline WDM & 506 PEVT & ENGL & $0.83 \mathrm{SAME}$ & PERLND & 115 & & EXTNL & PETINP \\
\hline$\star \star \star$ & Met Seg BIG & SAND, P I : GATMP & 3, PI:PETII & $\mathrm{NP}=0.83$ & & & & \\
\hline WDM & 511 PREC & ENGLZERO & SAME & PERLND & 125 & & EXTNL & PREC \\
\hline WDM & 503 ATEM & ENGL & $0.83 \mathrm{SAME}$ & PERLND & 125 & & EXTNL & GATMP \\
\hline WDM & 506 PEVT & ENGL & $0.83 \mathrm{SAME}$ & PERLND & 125 & & EXTNL & PETINP \\
\hline$\star \star \star$ & Met Seg BIG & SAND , P I : GATMP & 3, PI:PETII & $\mathrm{NP}=0.83$ & & & & \\
\hline WDM & 511 PREC & ENGLZERO & SAME & PERLND & 205 & & EXTNL & PREC \\
\hline WDM & 503 ATEM & ENGL & $0.83 \mathrm{SAME}$ & PERLND & 205 & & EXTNL & GATMP \\
\hline WDM & 506 PEVT & ENGL & 0.83 SAME & PERLND & 205 & & EXTNL & PETINP \\
\hline$\star \star \star$ & Met Seg BIG & SAND , P I : GATMP & 3, PI : PETII & $\mathrm{NP}=0.83$ & & & & \\
\hline WDM & 511 PREC & ENGLZERO & SAME & PERLND & 305 & & EXTNL & PREC \\
\hline WDM & 503 ATEM & ENGL & 0.83 SAME & PERLND & 305 & & EXTNL & GATMP \\
\hline WDM & $506 \mathrm{PEVT}$ & ENGL & $0.83 \mathrm{SAME}$ & PERLND & 305 & & EXTNL & PETINP \\
\hline$\star \star \star$ & Met Seg BIG & SAND, P I : GATMP & 3, PI : PETII & $\mathrm{NP}=0.83$ & & & & \\
\hline WDM & 511 PREC & ENGLZERO & SAME & PERLND & 405 & & EXTNL & PREC \\
\hline WDM & 503 ATEM & ENGL & $0.83 \mathrm{SAME}$ & PERLND & 405 & & EXTNL & GATMP \\
\hline WDM & 506 PEVT & ENGL & $0.83 \mathrm{SAME}$ & PERLND & 405 & & EXTNL & PETINP \\
\hline$\star \star \star$ & Met Seg BIG & SAND, P I : GATMP & 3, PI:PETII & $\mathrm{NP}=0.83$ & & & & \\
\hline WDM & 511 PREC & ENGLZERO & SAME & PERLND & 605 & & EXTNL & PREC \\
\hline WDM & 503 ATEM & ENGL & 0.83 SAME & PERLND & 605 & & EXTNL & GATMP \\
\hline WDM & $506 \mathrm{PEVT}$ & ENGL & $0.83 \mathrm{SAME}$ & PERLND & 605 & & EXTNL & PETINP \\
\hline$\star \star \star$ & Met Seg BIG & SAND, P I : GATMP & , PI:PETII & $\mathrm{NP}=0.83$ & & & & \\
\hline WDM & 511 PREC & ENGLZERO & SAME & PERLND & 705 & & EXTNL & PREC \\
\hline WDM & 503 ATEM & ENGL & $0.83 \mathrm{SAME}$ & PERLND & 705 & & EXTNL & GATMP \\
\hline WDM & 506 PEVT & ENGL & $0.83 \mathrm{SAME}$ & PERLND & 705 & & EXTNL & PETINP \\
\hline$\star \star \star \star$ & Met Seg BIG & SAND, P I : GATMP & 3,PI:PETII & $\mathrm{NP}=0.83$ & & & & \\
\hline WDM & 511 PREC & ENGLZERO & SAME & PERLND & 805 & & EXTNL & PREC \\
\hline WDM & 503 ATEM & ENGL & $0.83 \mathrm{SAME}$ & PERLND & 805 & & EXTNL & GATMP \\
\hline WDM & 506 PEVT & ENGL & $0.83 \mathrm{SAME}$ & PERLND & 805 & & EXTNL & PETINP \\
\hline$\star \star \star$ & Met Seg BIG & SAND, P I : GATMP & 3, PI:PETII & $\mathrm{NP}=0.83$ & & & & \\
\hline WDM & 511 PREC & ENGLZERO & SAME & PERLND & 905 & & EXTNL & PREC \\
\hline WDM & 503 ATEM & ENGL & $0.83 \mathrm{SAME}$ & PERLND & 905 & & EXTNL & GATMP \\
\hline WDM & 506 PEVT & ENGL & $0.83 \mathrm{SAME}$ & PERLND & 905 & & EXTNL & PETINP \\
\hline$\star \star \star$ & Met Seg TWEL & ¿EPO & & & & & & \\
\hline WDM & 91 PREC & ENGLZERO & SAME & RCHRES & 1 & 3 & EXTNL & PREC \\
\hline WDM & 103 ATEM & ENGL & SAME & RCHRES & 1 & 3 & EXTNL & GATMP \\
\hline$\star \star \star$ & Met Seg BUFF & & & & & & & \\
\hline WDM & 211 PREC & ENGLZERO & SAME & RCHRES & 4 & 8 & EXTNL & PREC \\
\hline WDM & 203 ATEM & ENGL & SAME & RCHRES & 4 & 8 & EXTNL & GATMP \\
\hline & Met Seg TV E & LKIN & & & & & & \\
\hline WDM & 311 PREC & ENGLZERO & SAME & RCHRES & 9 & 15 & EXTNL & PREC \\
\hline WDM & 303 ATEM & ENGL & SAME & RCHRES & 9 & 15 & EXTNL & GATMP \\
\hline$\star \star \star$ & Met Seg CLEA & $\mathrm{R} \quad \mathrm{FO}$ & & & & & & \\
\hline WDM & 411 PREC & ENGLZERO & SAME & RCHRES & 16 & 20 & EXTNL & PREC \\
\hline WDM & 403 ATEM & ENGL & SAME & RCHRES & 16 & 20 & EXTNL & GATMP \\
\hline & Seg BIG & AND, $P I: G$ & PET & 83 & & & & \\
\hline WDM & 511 PREC & ENGLZERO & SAME & RCHRES & 21 & 27 & EXTNL & PREC \\
\hline
\end{tabular}




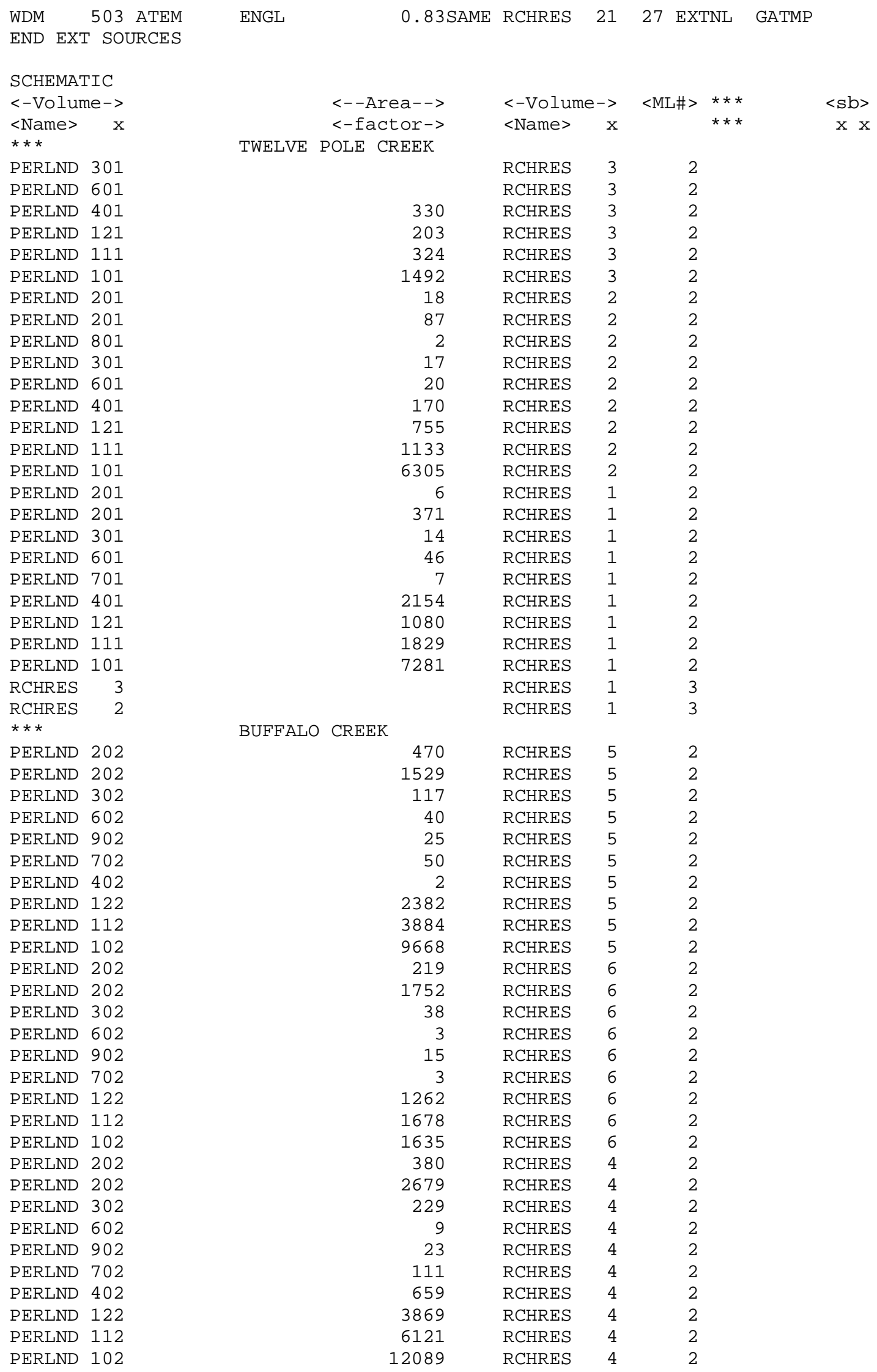


PERLND 202

PERLND 202

PERLND 302

PERLND 602

PERLND 902

PERLND 702

PERLND 402

PERLND 122

PERLND 112

PERLND 102

RCHRES 5

RCHRES 4

PERLND 202

PERLND 202

PERLND 302

PERLND 602

PERLND 702

PERLND 402

PERLND 122

PERLND 112

PERLND 102

RCHRES 6

RCHRES 7

***

PERLND 203

PERLND 803

PERLND 303

PERLND 603

PERLND 903

PERLND 703

PERLND 403

PERLND 123

PERLND 113

PERLND 103

PERLND 203

PERLND 203

PERLND 103

PERLND 303

PERLND 603

PERLND 903

PERLND 703

PERLND 123

PERLND 113

PERLND 103

PERLND 203

PERLND 203

PERLND 103

PERLND 303

PERLND 603

PERLND 903

PERLND 703

PERLND 123

PERLND 113

PERLND 103

PERLND 203

PERLND 203

PERLND 103

PERLND 303

PERLND 603

PERLND 903

PERLND 703

PERLND 403

$\begin{array}{rlll}507 & \text { RCHRES } & 7 & 2 \\ 3640 & \text { RCHRES } & 7 & 2 \\ 802 & \text { RCHRES } & 7 & 2 \\ 79 & \text { RCHRES } & 7 & 2 \\ 14 & \text { RCHRES } & 7 & 2 \\ 18 & \text { RCHRES } & 7 & 2 \\ 197 & \text { RCHRES } & 7 & 2 \\ 2725 & \text { RCHRES } & 7 & 2 \\ 3658 & \text { RCHRES } & 7 & 2 \\ 6036 & \text { RCHRES } & 7 & 2 \\ & \text { RCHRES } & 7 & 3 \\ & \text { RCHRES } & 7 & 3 \\ 54 & \text { RCHRES } & 8 & 2 \\ 872 & \text { RCHRES } & 8 & 2 \\ 102 & \text { RCHRES } & 8 & 2 \\ 2 & \text { RCHRES } & 8 & 2 \\ & \text { RCHRES } & 8 & 2 \\ 26 & \text { RCHRES } & 8 & 2 \\ 752 & \text { RCHRES } & 8 & 2 \\ 939 & \text { RCHRES } & 8 & 2 \\ 892 & \text { RCHRES } & 8 & 2 \\ & \text { RCHRES } & 8 & 3 \\ & \text { RCHRES } & 8 & 3\end{array}$

TV ELK

$\begin{array}{rlll}37 & \text { RCHRES } & 11 & 2 \\ 2749 & \text { RCHRES } & 11 & 2 \\ 21 & \text { RCHRES } & 11 & 2 \\ 410 & \text { RCHRES } & 11 & 2 \\ 179 & \text { RCHRES } & 11 & 2 \\ 44 & \text { RCHRES } & 11 & 2 \\ 34 & \text { RCHRES } & 11 & 2 \\ 301 & \text { RCHRES } & 11 & 2 \\ 1462 & \text { RCHRES } & 11 & 2 \\ 2125 & \text { RCHRES } & 11 & 2 \\ 6487 & \text { RCHRES } & 11 & 2 \\ 13 & \text { RCHRES } & 13 & 2 \\ 1944 & \text { RCHRES } & 13 & 2 \\ 3 & \text { RCHRES } & 13 & 2 \\ 62 & \text { RCHRES } & 13 & 2 \\ 33 & \text { RCHRES } & 13 & 2 \\ 31 & \text { RCHRES } & 13 & 2 \\ 30 & \text { RCHRES } & 13 & 2 \\ 1636 & \text { RCHRES } & 13 & 2 \\ 2630 & \text { RCHRES } & 13 & 2 \\ 7710 & \text { RCHRES } & 13 & 2 \\ 61 & \text { RCHRES } & 14 & 2 \\ 792 & \text { RCHRES } & 14 & 2 \\ 80 & \text { RCHRES } & 14 & 2 \\ 159 & \text { RCHRES } & 14 & 2 \\ 4 & \text { RCHRES } & 14 & 2 \\ 42 & \text { RCHRES } & 14 & 2 \\ 12 & \text { RCHRES } & 14 & 2 \\ 3138 & \text { RCHRES } & 14 & 2 \\ 3467 & \text { RCHRES } & 14 & 2 \\ 6482 & \text { RCHRES } & 14 & 2 \\ 1093 & \text { RCHRES } & 15 & 2 \\ 9669 & \text { RCHRES } & 15 & 2 \\ 126 & \text { RCHRES } & 15 & 2 \\ 313 & \text { RCHRES } & 15 & 2 \\ 74 & \text { RCHRES } & 15 & 2 \\ 328 & \text { RCHRES } & 15 & 2 \\ 531 & \text { RCHRES } & 15 & 2 \\ 73 & \text { RCHRES } & 15 & 2\end{array}$




\begin{tabular}{|c|c|c|c|c|c|}
\hline PERLND & 123 & & 10516 & RCHRES & 15 \\
\hline PERLND & 113 & & 13916 & RCHRES & 15 \\
\hline PERLND & 103 & & 44497 & RCHRES & 15 \\
\hline PERLND & 203 & & 225 & RCHRES & 12 \\
\hline PERLND & 203 & & 7159 & RCHRES & 12 \\
\hline PERLND & 103 & & 66 & RCHRES & 12 \\
\hline PERLND & 303 & & 232 & RCHRES & 12 \\
\hline PERLND & 603 & & 159 & RCHRES & 12 \\
\hline PERLND & 903 & & 231 & RCHRES & 12 \\
\hline PERLND & 703 & & 337 & RCHRES & 12 \\
\hline PERLND & 123 & & 3282 & RCHRES & 12 \\
\hline PERLND & 113 & & 4162 & RCHRES & 12 \\
\hline PERLND & 103 & & 12140 & RCHRES & 12 \\
\hline RCHRES & 14 & & & RCHRES & 12 \\
\hline RCHRES & 15 & & & RCHRES & 12 \\
\hline PERLND & 203 & & 77 & RCHRES & 10 \\
\hline PERLND & 203 & & 3130 & RCHRES & 10 \\
\hline PERLND & 103 & & 54 & RCHRES & 10 \\
\hline PERLND & 303 & & 371 & RCHRES & 10 \\
\hline PERLND & 603 & & 97 & RCHRES & 10 \\
\hline PERLND & 903 & & 378 & RCHRES & 10 \\
\hline PERLND & 703 & & 169 & RCHRES & 10 \\
\hline PERLND & 123 & & 1596 & RCHRES & 10 \\
\hline PERLND & 113 & & 1939 & RCHRES & 10 \\
\hline PERLND & 103 & & 7240 & RCHRES & 10 \\
\hline RCHRES & 13 & & & RCHRES & 10 \\
\hline RCHRES & 12 & & & RCHRES & 10 \\
\hline PERLND & 203 & & 53 & RCHRES & 9 \\
\hline PERLND & 203 & & 1396 & RCHRES & 9 \\
\hline PERLND & 103 & & 5 & RCHRES & 9 \\
\hline PERLND & 303 & & 1103 & RCHRES & 9 \\
\hline PERLND & 603 & & 80 & RCHRES & 9 \\
\hline PERLND & 903 & & 127 & RCHRES & 9 \\
\hline PERLND & 703 & & 193 & RCHRES & 9 \\
\hline PERLND & 403 & & 136 & RCHRES & 9 \\
\hline PERLND & 123 & & 724 & RCHRES & 9 \\
\hline PERLND & 113 & & 717 & RCHRES & 9 \\
\hline PERLND & 103 & & 1750 & RCHRES & 9 \\
\hline RCHRES & 11 & & & RCHRES & 9 \\
\hline RCHRES & 10 & & & RCHRES & 9 \\
\hline$\star \star \star$ & & CLEAR FORK & & & \\
\hline PERLND & 204 & & 199 & RCHRES & 16 \\
\hline PERLND & 204 & & 25 & RCHRES & 16 \\
\hline PERLND & 804 & & 7 & RCHRES & 16 \\
\hline PERLND & 304 & & 46 & RCHRES & 16 \\
\hline PERLND & 604 & & 40 & RCHRES & 16 \\
\hline PERLND & 704 & & 3 & RCHRES & 16 \\
\hline PERLND & 404 & & 136 & RCHRES & 16 \\
\hline PERLND & 124 & & 170 & RCHRES & 16 \\
\hline PERLND & 114 & & 279 & RCHRES & 16 \\
\hline PERLND & 104 & & 4642 & RCHRES & 16 \\
\hline PERLND & 204 & & 109 & RCHRES & 17 \\
\hline PERLND & 204 & & 57 & RCHRES & 17 \\
\hline PERLND & 804 & & 22 & RCHRES & 17 \\
\hline PERLND & 304 & & 12 & RCHRES & 17 \\
\hline PERLND & 604 & & 47 & RCHRES & 17 \\
\hline PERLND & 904 & & 3 & RCHRES & 17 \\
\hline PERLND & 704 & & 218 & RCHRES & 17 \\
\hline PERLND & 404 & & 543 & RCHRES & 17 \\
\hline PERLND & 124 & & 664 & RCHRES & 17 \\
\hline PERLND & 114 & & 1128 & RCHRES & 17 \\
\hline PERLND & 104 & & 12525 & RCHRES & 17 \\
\hline PERLND & 204 & & 35 & RCHRES & 18 \\
\hline
\end{tabular}




$$
\begin{array}{lr}
\text { PERLND } & 204 \\
\text { PERLND } & 304 \\
\text { PERLND } & 604 \\
\text { PERLND } & 704 \\
\text { PERLND } & 404 \\
\text { PERLND } & 124 \\
\text { PERLND } & 114 \\
\text { PERLND } & 104 \\
\text { RCHRES } & 16 \\
\text { RCHRES } & 17 \\
\text { PERLND } & 204 \\
\text { PERLND } & 204 \\
\text { PERLND } & 804 \\
\text { PERLND } & 304 \\
\text { PERLND } & 604 \\
\text { PERLND } & 904 \\
\text { PERLND } & 704 \\
\text { PERLND } & 404 \\
\text { PERLND } & 124 \\
\text { PERLND } & 114 \\
\text { PERLND } & 104 \\
\text { PERLND } & 204 \\
\text { PERLND } & 204 \\
\text { PERLND } & 304 \\
\text { PERLND } & 604 \\
\text { PERLND } & 904 \\
\text { PERLND } & 704 \\
\text { PERLND } & 404 \\
\text { PERLND } & 124 \\
\text { PERLND } & 114 \\
\text { PERLND } & 104 \\
\text { RCHRES } & 18 \\
\text { RCHRES } & 19 \\
\text { A** } & \\
\text { PERLND } & 205 \\
\text { PERLND } & 805 \\
\text { PERLND } & 305 \\
\text { PERLND } & 605 \\
\text { PERLND } & 905 \\
\text { PERLND } & 705 \\
\text { PERLND } & 405 \\
\text { PERLND } & 125 \\
\text { PERLND } & 115 \\
\text { PERLND } & 105 \\
\text { PERLND } & 205 \\
\text { PERLND } & 805 \\
\text { PERLND } & 305 \\
\text { PERLND } & 605 \\
\text { PERLND } & 905 \\
\text { PERLND } & 705 \\
\text { PERLND } & 405 \\
\text { PERLND } & 125 \\
\text { PERLND } & 115 \\
\text { PERLND } & 105 \\
\text { PERLND } & 205 \\
\text { PERLND } & 805 \\
\text { PERLND } & 305 \\
\text { PERLND } & 905 \\
\text { PERLND } & 405 \\
\text { PERLND } & 125 \\
\text { PERLND } & 115 \\
\text { PERLND } & 105
\end{array}
$$

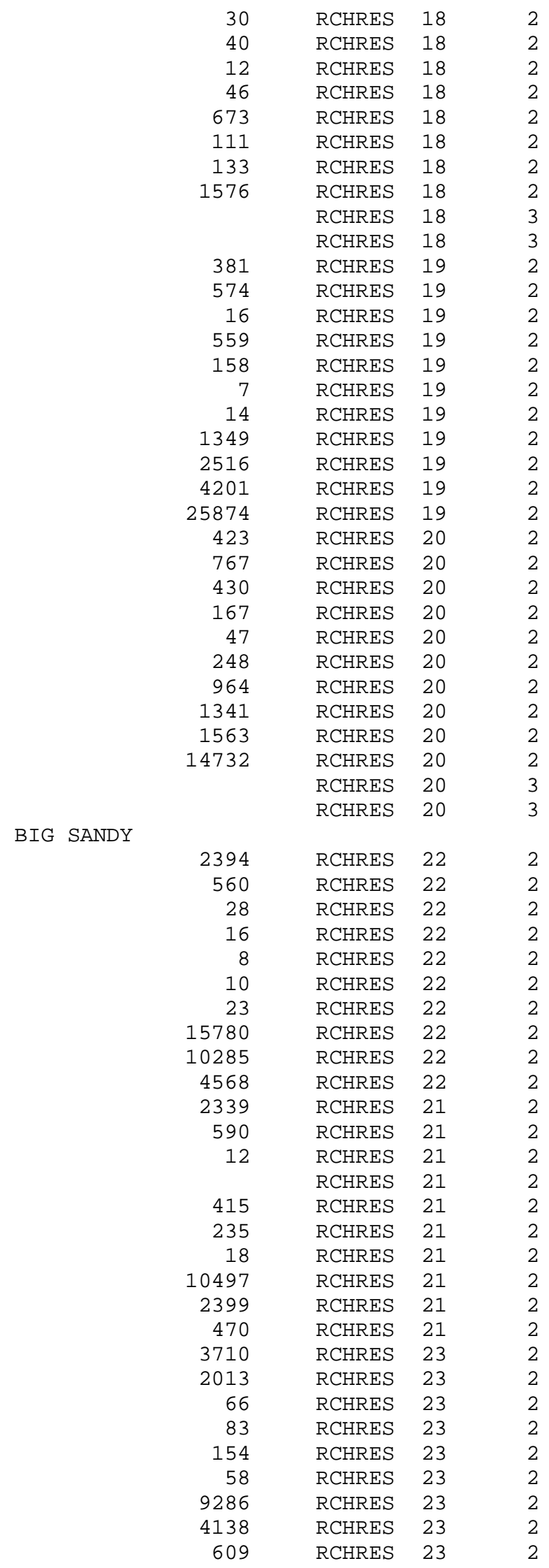




$$
\begin{array}{lr}
\text { RCHRES } & 22 \\
\text { RCHRES } & 21 \\
\text { PERLND } & 205 \\
\text { PERLND } & 805 \\
\text { PERLND } & 305 \\
\text { PERLND } & 905 \\
\text { PERLND } & 705 \\
\text { PERLND } & 405 \\
\text { PERLND } & 125 \\
\text { PERLND } & 115 \\
\text { PERLND } & 105 \\
\text { PERLND } & 205 \\
\text { PERLND } & 805 \\
\text { PERLND } & 305 \\
\text { PERLND } & 905 \\
\text { PERLND } & 705 \\
\text { PERLND } & 405 \\
\text { PERLND } & 125 \\
\text { PERLND } & 115 \\
\text { PERLND } & 105 \\
\text { PERLND } & 705 \\
\text { PERLND } & 125 \\
\text { PERLND } & 115 \\
\text { PERLND } & 105 \\
\text { RCHRES } & 23 \\
\text { RCHRES } & 24 \\
\text { PERLND } & 205 \\
\text { PERLND } & 805 \\
\text { PERLND } & 305 \\
\text { PERLND } & 905 \\
\text { PERLND } & 705 \\
\text { PERLND } & 405 \\
\text { PERLND } & 125 \\
\text { PERLND } & 115 \\
\text { PERLND } & 105 \\
\text { RCHRES } & 25 \\
\text { RCHRES } & 26 \\
\text { PERLND } & 201 \\
\text { PERLND } & 201 \\
\text { PERLND } & 301 \\
\text { PERLND } & 601 \\
\text { PERLND } & 701 \\
\text { PERLND } & 401 \\
\text { PERLND } & 121 \\
\text { PERLND } & 111 \\
\text { PERLND } & 101 \\
\text { PERLND } & 801 \\
\text { PERLND } & 202 \\
\text { PERLND } & 202 \\
\text { PERLND } & 302 \\
\text { PERLND } & 602 \\
\text { PERLRLND } & 702 \\
\text { PERLND } & 402 \\
\text { PERLND } & 102 \\
\text { PERLND } & 203 \\
\text { PERLND } & 103 \\
\text { PERLND } & 303 \\
\text { PERLND } & 603 \\
\text { PERLND } & 903
\end{array}
$$

\begin{tabular}{|c|c|c|c|}
\hline & RCHRES & 23 & 3 \\
\hline & RCHRES & 23 & 3 \\
\hline 671 & RCHRES & 25 & 2 \\
\hline 389 & RCHRES & 25 & 2 \\
\hline 17 & RCHRES & 25 & 2 \\
\hline 29 & RCHRES & 25 & 2 \\
\hline 96 & RCHRES & 25 & 2 \\
\hline 17 & RCHRES & 25 & 2 \\
\hline 5641 & RCHRES & 25 & 2 \\
\hline 4874 & RCHRES & 25 & 2 \\
\hline 2379 & RCHRES & 25 & 2 \\
\hline 6728 & RCHRES & 24 & 2 \\
\hline 3399 & RCHRES & 24 & 2 \\
\hline 90 & RCHRES & 24 & 2 \\
\hline 231 & RCHRES & 24 & 2 \\
\hline 33 & RCHRES & 24 & 2 \\
\hline 186 & RCHRES & 24 & 2 \\
\hline 15322 & RCHRES & 24 & 2 \\
\hline 5163 & RCHRES & 24 & 2 \\
\hline 1080 & RCHRES & 24 & 2 \\
\hline 19 & RCHRES & 26 & 2 \\
\hline 55 & RCHRES & 26 & 2 \\
\hline 53 & RCHRES & 26 & 2 \\
\hline \multirow[t]{3}{*}{105} & RCHRES & 26 & 2 \\
\hline & RCHRES & 26 & 3 \\
\hline & RCHRES & 26 & 3 \\
\hline 935 & RCHRES & 27 & 2 \\
\hline 649 & RCHRES & 27 & 2 \\
\hline 3 & RCHRES & 27 & 2 \\
\hline 16 & RCHRES & 27 & 2 \\
\hline 36 & RCHRES & 27 & 2 \\
\hline 38 & RCHRES & 27 & 2 \\
\hline 2030 & RCHRES & 27 & 2 \\
\hline 1454 & RCHRES & 27 & 2 \\
\hline \multirow[t]{3}{*}{525} & RCHRES & 27 & 2 \\
\hline & RCHRES & 27 & 3 \\
\hline & RCHRES & 27 & 3 \\
\hline 24 & COPY & 1 & 90 \\
\hline 458 & COPY & 1 & 90 \\
\hline 32 & COPY & 1 & 90 \\
\hline 67 & COPY & 1 & 90 \\
\hline 7 & COPY & 1 & 90 \\
\hline 2654 & COPY & 1 & 90 \\
\hline 2038 & COPY & 1 & 90 \\
\hline 3286 & COPY & 1 & 90 \\
\hline 15078 & COPY & 1 & 90 \\
\hline 2 & COPY & 1 & 90 \\
\hline 1630 & COPY & 2 & 90 \\
\hline 10472 & COPY & 2 & 90 \\
\hline 1288 & COPY & 2 & 90 \\
\hline 133 & $\mathrm{COPY}$ & 2 & 90 \\
\hline 183 & COPY & 2 & 90 \\
\hline 884 & COPY & 2 & 90 \\
\hline 10990 & $\mathrm{COPY}$ & 2 & 90 \\
\hline 16280 & COPY & 2 & 90 \\
\hline 30320 & COPY & 2 & 90 \\
\hline 77 & COPY & 2 & 90 \\
\hline 1559 & COPY & 3 & 90 \\
\hline 26839 & COPY & 3 & 90 \\
\hline 86640 & COPY & 3 & 90 \\
\hline 2650 & COPY & 3 & 90 \\
\hline 626 & COPY & 3 & 90 \\
\hline 1181 & COPY & 3 & 90 \\
\hline
\end{tabular}




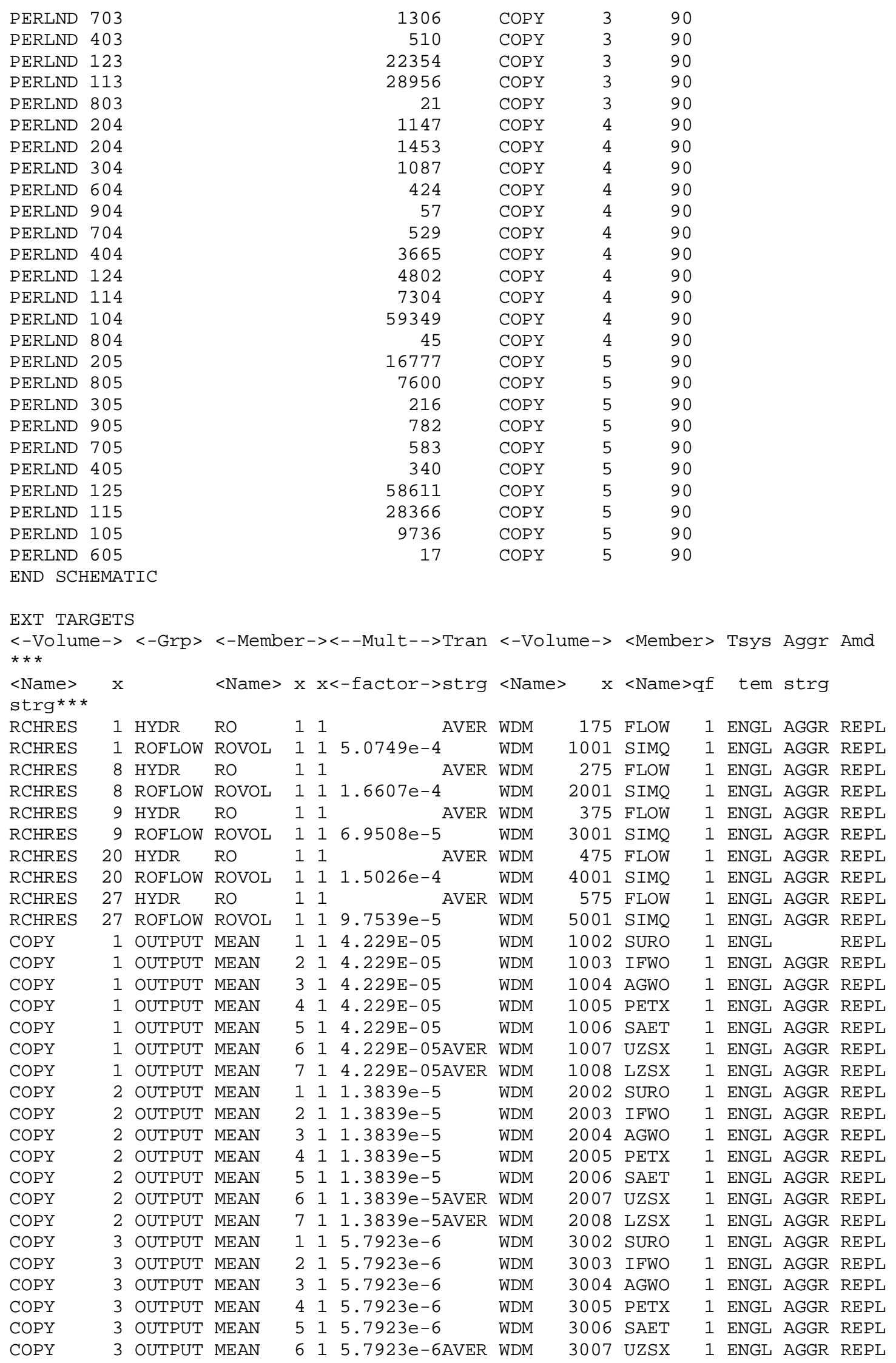




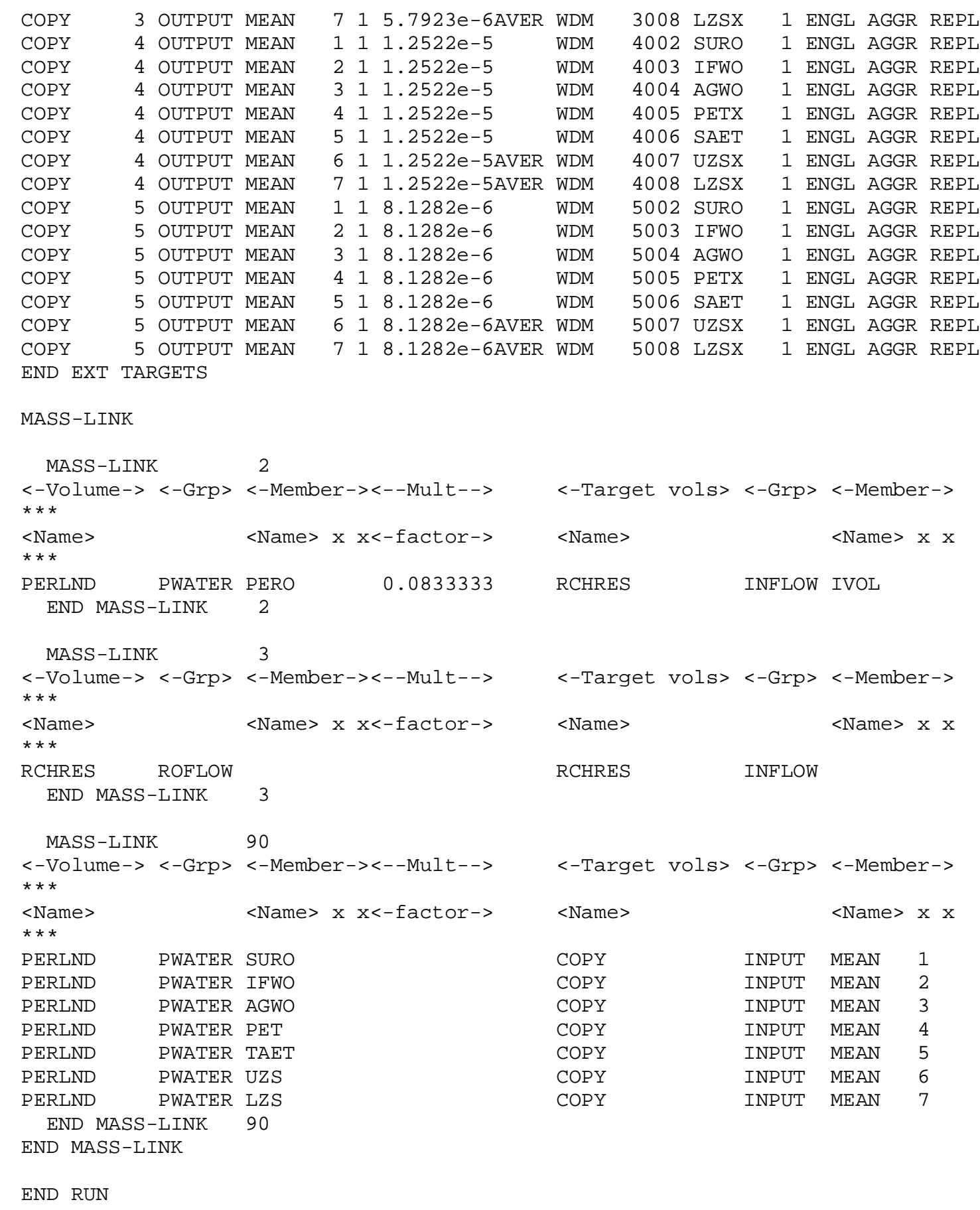




\section{Appendix C. Cyclic and Asymptotic Methods User's Control Input File (UCI)}

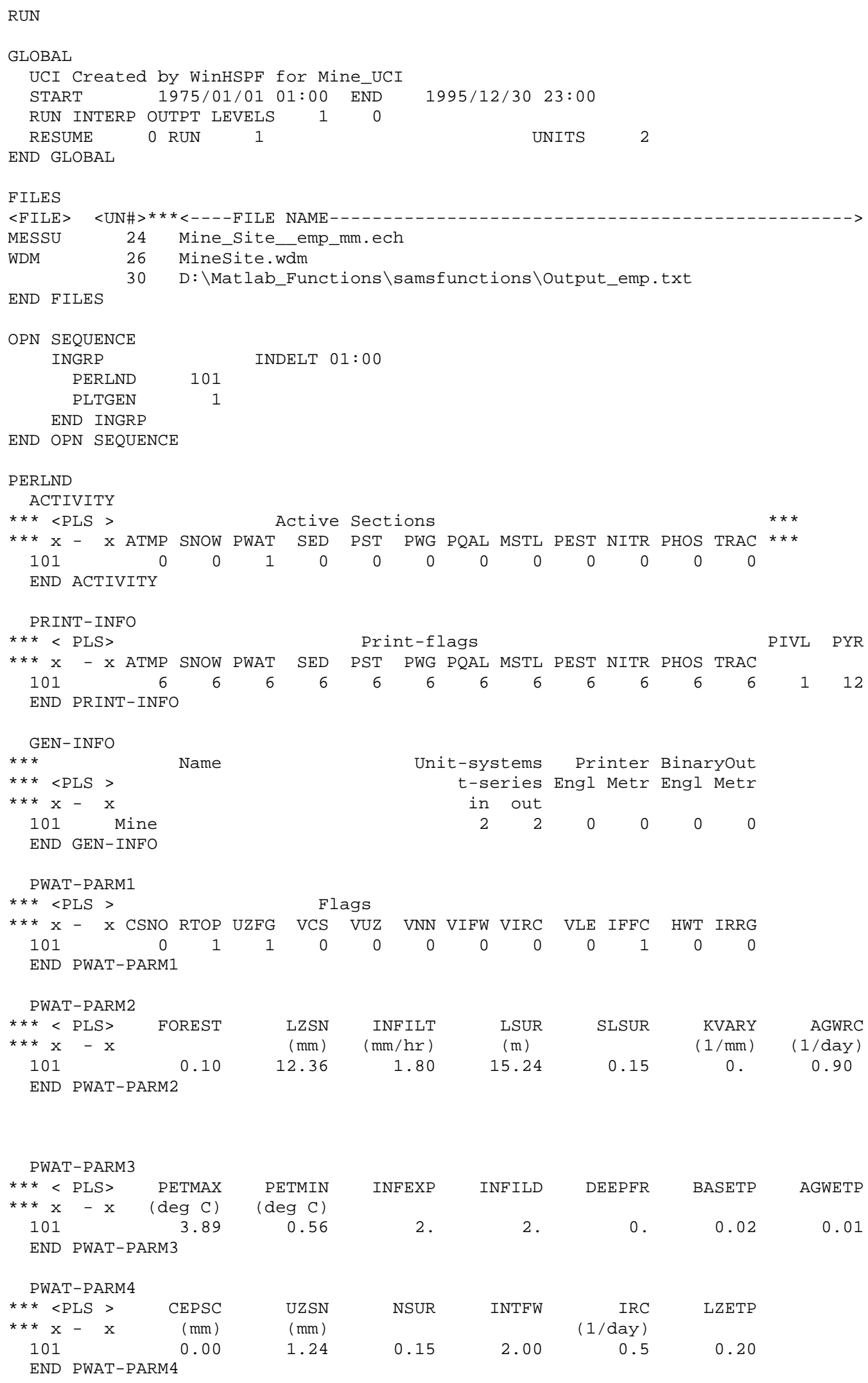




\begin{tabular}{|c|c|c|c|c|c|c|c|c|}
\hline \multicolumn{9}{|c|}{ PWAT-STATE1 } \\
\hline$\star \star * \star<<$ & PLS> & PWATER $s$ & varial & (mm) & & & & \\
\hline$\star \star \star x \mathrm{x}$ & $-x$ & CEPS & SURS & UZS & IFWS & LZS & AGWS & GWVS \\
\hline 101 & & 0 . & 12.94 & 1.27 & 0.279 & 12.95 & 25.4 & 0.000 \\
\hline
\end{tabular}

END PERLND

PLTGEN

PLOTINFO

Plot-opn $\star * \star *$

\# - \# FILE NPT NMN LABL PYR PIVL TYPE $* \star *$

30

$\begin{array}{lll}0 & 16 & 0\end{array}$

END PLOTINFO

SCALING

Plot-opn ***

$\#$ \# - YMIN YMAX IVLIN THRESH $* * *$

END SCALING

500.48 .

END PLTGEN

EXT SOURCES

$<-$ Volume-> $<$ Member $>$ SsysSgap<--Mult-->Tran $<-$ Target vols $><-$ Grp $><-$ Member-> $* \star \star$

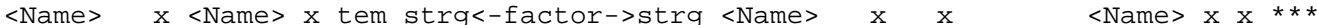

WDM 25 PREC METRZERO SAME PERLND 101 EXTNL PREC

WDM 125 PEVT METRZERO SAME PERLND 101 EXTNL PETINP

WDM 25 PREC METRZERO SAME PLTGEN 1 INPUT MEAN 1

WDM 125 PEVT METRZERO SAME PLTGEN 1 INPUT MEAN 2

END EXT SOURCES

SCHEMATIC

$<-$ Volume->

$<$ Name $>\quad \mathrm{x}$

$<--$ Area-->

$<-$ Volume->

PERLND 101

$<$-factor $>\quad<$ Name $>\quad \mathrm{x}$

$<$ ML\# $>\star \star \star *$

PLTGEN 1

91

END SCHEMATIC

MASS-LINK

MASS-LINK

$<-$ Volume-> <-Grp > <-Member $-><--$ Mult $-->$

$<$ Name $>$ Name $>\mathrm{x} x<-$ factor $->$

PERLND

PERLND

PERLND

PERLND

PERLND

PERLND

PERLND

PERLND

PERLND

PERLND

PERLND

PERLND

PERLND

PERLND

END MA

PWATER SURO

PWATER IFWO 1

PWATER UZS 1

PWATER LZS 1

PWATER AGWO 1

PWATER INFIL 1

PWATER PERC 1

PWATER TAET

PWATER LZI

PWATER UZI

PWATER IFWI

PWATER SURI

PWATER LZET

PWATER SURS

END MASS-LINK

END RUN

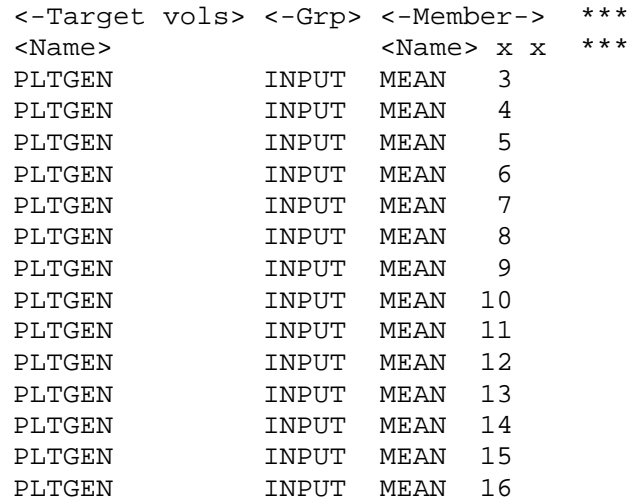

